\title{
DINÂMICA DA PAISAGEM NA REGIÃO CENTRAL DE RONDÔNIA E SEUS EFEITOS NA COMPOSIÇÃO QUÍMICA DA ÁGUA
}

\author{
SILVIO FROSINI DE BARROS FERRAZ \\ Engenheiro Florestal
}

Orientador: Prof. Dr. CARLOS ALBERTO VETTORAZZI

\begin{abstract}
Tese apresentada à Escola Superior de Agricultura
"Luiz de Queiroz", Universidade de São Paulo, para obtenção do título de Doutor em Recursos Florestais, com opção em Conservação de Ecossistemas Florestais.
\end{abstract}

\author{
PIRACICABA \\ Estado de São Paulo - Brasil \\ Novembro - 2004
}


Ferraz, Silvio Frosini de Barros. Dinâmica da paisagem na região central de Rondônia e seus efeitos na composição química da água.

\section{ERRATA}

p. 36, tabela 1 - substituir a tabela atual pela abaixo:

Tabela 1. Cenas Landsat TM e ETM+ da área de estudo utilizadas, data de aquisição e respectivas fontes

\begin{tabular}{|c|c|c|c|c|c|}
\hline Anos & $231 / 67$ & $232 / 67$ & Anos & $231 / 67$ & $232 / 67$ \\
\hline 1984 & $04 / 08 / 1984^{\varphi}$ & & 1994 & $15 / 07 / 1994^{\varphi}$ & $04 / 06 / 1994^{\varphi}$ \\
\hline 1986 & 10/08/1986* & $01 / 08 / 1986^{\varphi}$ & 1996 & 20/07/1996* & 25/06/1996* \\
\hline 1988 & $30 / 07 / 1988^{\Psi}$ & $21 / 07 / 1988^{\varphi}$ & 1998 & 06/08/1998 & $17 / 07 / 1998^{\Phi}$ \\
\hline 1990 & $08 / 05 / 1990^{\Psi}$ & $12 / 08 / 1990^{\Phi}$ & 2000 & $15 / 07 / 2000^{\Phi}$ & $06 / 07 / 2000^{\varphi}$ \\
\hline 1992 & $06 / 07 / 1992^{\Psi}$ & $22 / 06 / 1992^{*}$ & 2002 & $14 / 08 / 2002^{*}$ & 05/08/2002* \\
\hline
\end{tabular}




\section{Dados Internacionais de Catalogação na Publicação (CIP)}

DIVISÃO DE BIBLIOTECA E DOCUMENTAÇĀO - ESALQIUSP

Ferraz, Silvio Frosini de Barros

Dinâmica da paisagem na região central de Rondônia e seus efeitos na composição quimica da água / Silvio Frosini de Barros Ferraz. - - Piracicaba, 2004.

$151 \mathrm{p}$. : il

Tese (Doutorado) - - Escola Superior de Agricultura Luiz de Queiroz, 2004

Bibliografia.

1. Água - Qualidade 2.Amazônia 3. Ecologia de paisagem 4. Geoprocessamento 5. Hidrogeoquímica 6. Impacto ambiental 7. Manejo ambiental 8 . Microbacia hidrográfica 8. Proteção ambiental 9. Uso da terra !. Título

CDD 551.483

Permitoa a copta total o o parcial destedocumento, des de que ditodo a fonte 0 alto 
Aos meus pais e irmãos, pelo apoio que recebi e que me permitiu chegar onde estou

Ao meu pai, Epaminondas, pelo exemplo de homem, pai e mestre da academia e da vida

À minha mãe, Yara, por estar sempre presente apoiando e participando de minha vida

Aos meus queridos sobrinhos, André, Enzo e Laura, que representam a esperança de um futuro melhor, a inocência e a alegria e beleza da vida

À minha esposa, Katia, pelo amor, entusiasmo, apoio e incentivo para realização deste trabalho

Dedico 


\section{AGRADECIMENTOS}

Ao orientador e amigo Prof. Carlos Alberto Vettorazzi, pela orientação e apoio recebido em todos estes anos, por ter me incentivado na carreira científica desde a graduação e pelo exemplo de dedicação à carreira universitária;

Ao Prof. David M. Theobald do Laboratório de Ecologia e Recursos Naturais da Colorado State University, pela orientação, amizade durante o ano em que estive no Colorado;

Ao Instituto Nacional de Pesquisas Espacias (INPE) pelo fornecimento de imagens de satélite utilizadas, em especial ao Prof. Diógenes Alves pelo apoio e sugestões recebidas;

Aos professores José Leonardo Moraes Gonçalves, Gilberto José Garcia e Maria Victoria R. Ballester pelas importantes contribuições por ocasião do Exame de Qualificação;

À coordenação dos programas de pós-graduação da ESALQ/USP, Profa. Clarice Demétrio pela sua dedicação frente à coordenação e, empenho na resolução dos contra-tempos do último ano do meu doutorado. Ao serviço de pós-graduação da ESALQ, pela atenção e ajuda dispensada nestes anos;

À coordenação do Programa de Pós-Graduação em Recursos Florestais, especialmente aos professores Luiz Carlos Estraviz Rodriguez pelo apoio nos primeiros anos e José Leonardo Moraes Gonçalves pela amizade e grande empenho para resolução dos problemas de prazo ocorridos no último ano. $\grave{A}$ secretaria do programa, especialmente à Catarina Germuts pela sua disposição em ajudar; 
Aos professores, funcionários e colegas do Departamento de Engenharia Rural, pela convivência e ajuda dispensada, em especial à secretária Vanda Zambello, pela sua atenção;

Ao professores e colegas do Laboratório de Ecologia e Recursos Naturais da Colorado State University pelo acolhimento, amizade e auxilio técnico no período de estágio realizado no exterior, especialmente Dr. David Meritt, Dr. Jill Baron, Mark Delorey e Jonathan Straube;

Ao Prof. Jean Paul Metzger pelas discussões na área de ecologia da paisagem, e pelas valiosas sugestões que permitiram o aprimoramento do trabalho;

Ao Prof. Hilton Thadeu Z. do Couto pelo auxílio técnico e orientação na realização das análises estatísticas;

Ao professor Carlos Clemente Cerri, pelo apoio concedido na utilização das instalações equipamentos de pesquisa na fazenda Nova Vida, Rondônia;

À equipe do Laboratório de Geoprocessamento do CENA/USP, em especial à pesquisadora Dra. Maria Victoria R. Ballester, pelas importantes sugestões, disponibilização de dados e, apoio no desenvolvimento do trabalho.

Ao Prof. Reynaldo Victoria pela disponibilização de recursos e apoio recebido nestes anos;

À equipe do Laboratório de Ecologia Isotópica do CENA/USP, especialmente ao pesquisador Dr. Alex Krusche, pelos equipamentos e auxílio na coleta de amostras de água e a técnica Fabiana Fracassi, pelo auxílio na realização das análises químicas. Ao pesquisador Dr. Jorge Morais, pela convivência no trabalho de campo em Rondônia e fornecimento de dados meteorológicos;

À minha esposa Kátia pelo apoio, incentivo recebido nestes anos e pelas sugestões e imprescindível auxilio na revisão e correção do texto final;

Ao meu pai Epaminondas, pelo incentivo nesta carreira e à minha cunhada Simone pela revisão da tese; 
À FAPESP (processos 00/03740-5 e 01/14172-0), pelo suporte financeiro por meio da concessão de das bolsas de mestrado e doutorado direto;

À CAPES (processo BEX0879/02-9) pela concessão da bolsa de doutorado sanduíche, especialmente às funcionárias Stella Wolf e Aline Chanes;

À FULBRIGHT, pelo suporte no estágio de doutoramento realizado no exterior, especialmente aos funcionárias Glayna Braga da Comissão Fulbright do Brasil e Michelle Grant, coordenadora do programa para a América latina;

À IDEAWILD pela doação de equipamentos utilizados no trabalho de campo. 


\section{SUMÁRIO}

Página

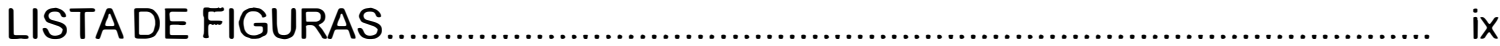

LISTA DE TABELAS .............................................................................. xiii

LISTA DE SIGLAS, ABREVIATURAS E SÍMBOLOS .................................. xV

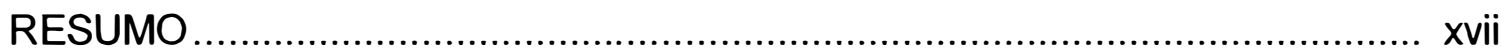

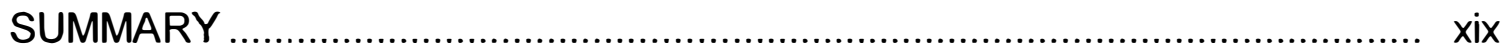

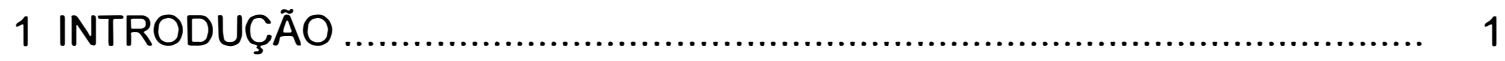

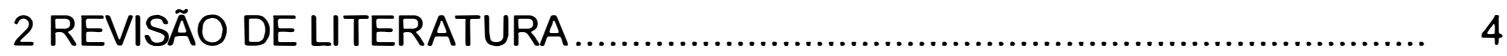

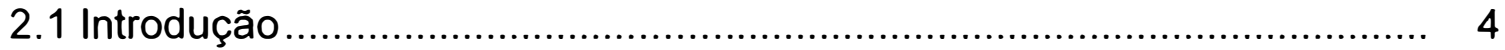

2.2 A Ecologia da Paisagem .................................................................... 5

2.3 Caracterização da paisagem........................................................... 8

2.4 Dinâmica da paisagem ................................................................... 10

2.5 A relação entre paisagem e os sistemas aquáticos ............................. 13

2.6 Considerações finais ......................................................................... 22

3 AVALIAÇÃO DA DINÂMICA DA PAISAGEM ENTRE 1984 E 2002 NA REGIÃO CENTRAL DE RONDÔNIA: TENDÊNCIAS E PERSPECTIVAS. 23

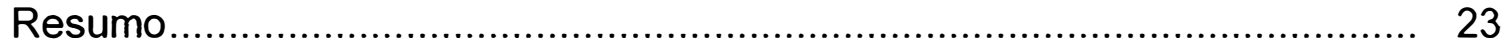

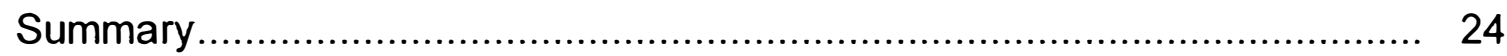

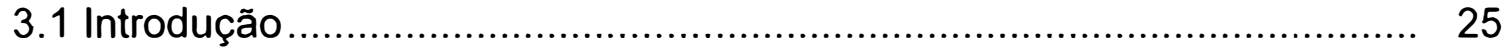

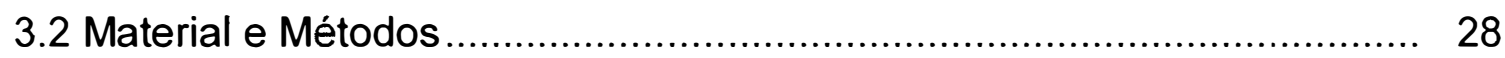




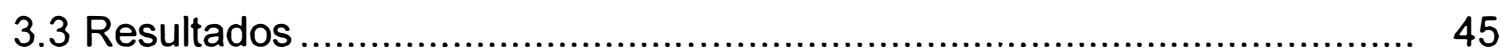

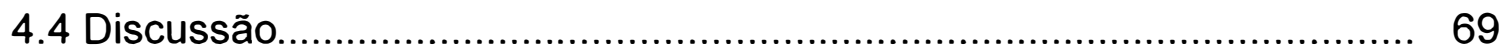

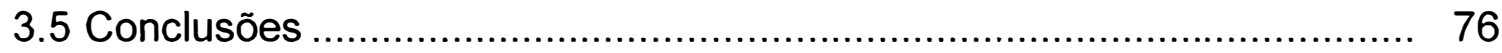

4 DINÂMICA DA PAISAGEM EM MICROBACIAS: USO DE INDICADORES E MÉTODOS DE CLASSIFICAÇÃO..................................................... 77

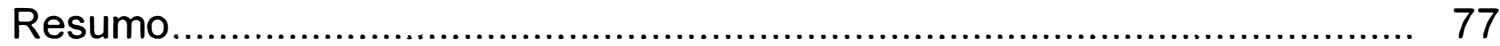

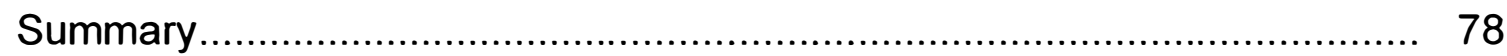

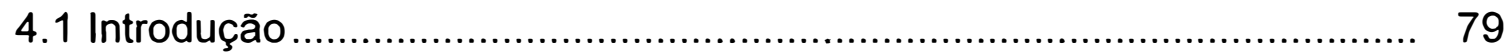

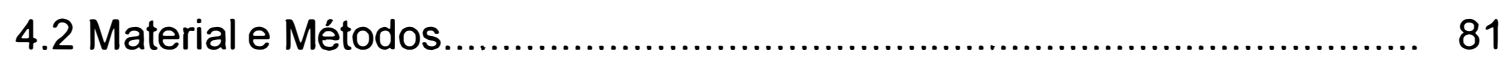

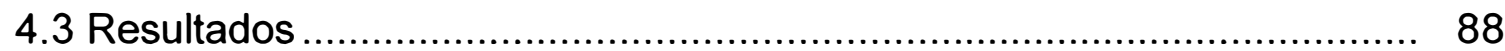

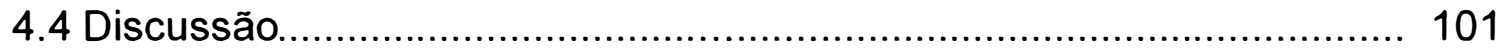

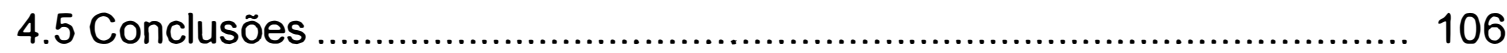

5 INFLUÊNCIA DAS CARACTERÍSTICAS FISICAS E ANTRÓPICAS DE MICROBACIAS NA COMPOSIÇÃO QUÍMICA DA ÁGUA NA REGIÃO CENTRAL DE RONDÔNIA

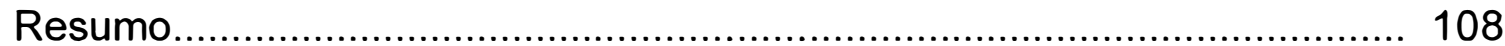

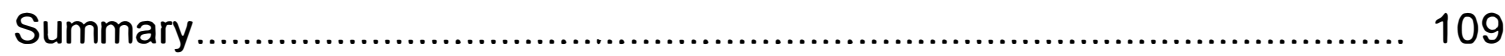

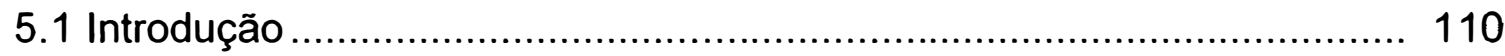

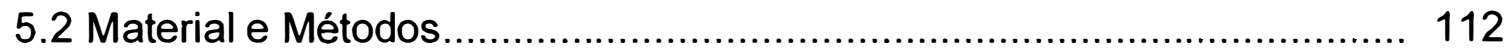

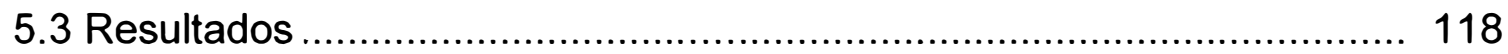

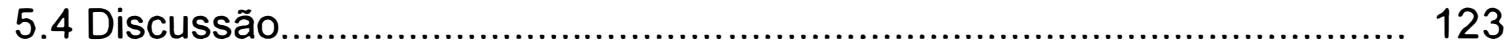

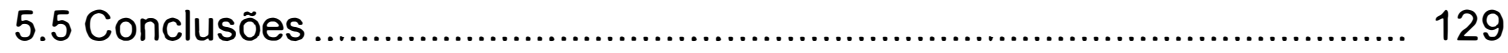

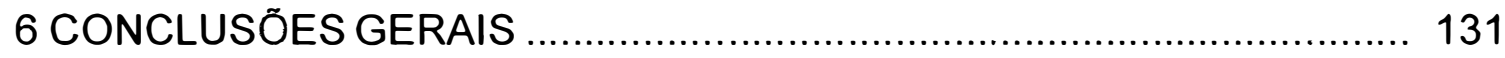

REFERÊNCIAS BIBLIOGRÁFICAS _................................................. 133 


\section{LISTA DE FIGURAS}

Página

1 Exemplo ilustrativo de diferentes configurações espaciais dos componentes da paisagem em relação à rede de drenagem em uma bacia hidrográfica

2 Exemplo ilustrativo de diferentes localizações de distúrbios (como abertura de clareiras) em relação à rede de drenagem.

3 Exemplo ilustrativo de diferentes trajetórias de uso da terra (perfis 1 a 6 ) para a região Amazônica entre $p$ anos passados e o ano presente $(n) \ldots 21$

4 Localização da bacia do rio Quatro Cachoeiras, em Rondônia. 29

5 Modelo Digital do Terreno (MDT) para a bacia do rio Quatro Cachoeiras, Rondônia.

6 Mapa de classes de solos predominantes para a bacia do rio Quatro Cachoeiras, Rondônia (Fonte: Embrapa, 1983).

7 Clima-diagrama das curvas de precipitação e temperatura médias mensais, para a bacia do rio Quatro Cachoeiras, Rondônia

8 Localização da bacia do rio Quatro Cachoeiras em relação aos grandes rios da Amazônia

9 Localização dos projetos de assentamentos rurais na bacia do rio Quatro Cachoeiras, Rondônia.

10 Evolução histórica da população do Estado de Rondônia e da área de estudo. Fonte: IBGE (2003).

11 Exemplo da classe de uso Floresta Madura (FM). 
12 Exemplo da classe de uso Floresta Secundária (FS). ......................... 38

13 Exemplo da classe de uso Pastagem introduzida (PA)........................ 39

14 Mapa de uso da terra da bacia do rio Quatro Cachoeiras em Rondônia,

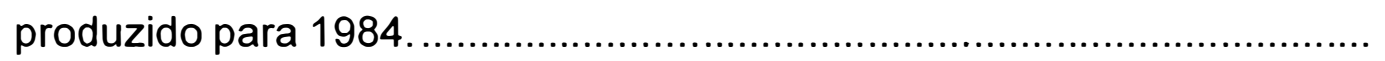

15 Mapa de uso da terra da bacia do rio Quatro Cachoeiras em Rondônia, produzido para 1986.

16 Mapa de uso da terra da bacia do rio Quatro Cachoeiras em Rondônia, produzido para 1988.

17 Mapa de uso da terra da bacia do rio Quatro Cachoeiras em Rondônia, produzido para 1990.

18 Mapa de uso da terra da bacia do rio Quatro Cachoeiras em Rondônia, produzido para 1992

19 Mapa de uso da terra da bacia do rio Quatro Cachoeiras em Rondônia, produzido para 1994

20 Mapa de uso da terra da bacia do rio Quatro Cachoeiras em Rondônia, produzido para 1996.

21 Mapa de uso da terra da bacia do rio Quatro Cachoeiras em Rondônia, produzido para 1998

22 Mapa de uso da terra da bacia do rio Quatro Cachoeiras em Rondônia, produzido para 2000 .

23 Mapa de uso da terra da bacia do rio Quatro Cachoeiras em Rondônia, produzido para 2002

24 Dinâmica do uso da terra ao longo dos anos representada pela porcentagem do uso da terra ocupada por cada classe (PLAND).

25 Taxa média anual de dinâmica entre as classes de uso da terra ao longo do período estudado. Valores no interior das caixas representam ausência de transição..

26 Distribuição da freqüência de clareiras em função do tamanho da clareira (a) em função da distribuição da área total desmatada, (b) em função do tamanho da clareira no processo de corte raso (FM $\rightarrow P A)$. 
27 Distribuição da freqüência de clareiras em função do tamanho da clareira (a) em função da distribuição da área total desmatada, (b) em função do tamanho da clareira no processo de corte seletivo $(F S \rightarrow P A) \ldots 60$

28 Área desmatada ao longo dos anos em relação à distância das estradas: a. corte raso (transição $\mathrm{FM} \rightarrow \mathrm{PA}$ ); b. corte seletivo (transição $\mathrm{FS} \rightarrow \mathrm{PA})$.

29 Área desmatada ao longo dos anos em relação à distância de pastagens antigas: a. corte raso (transição $F M \rightarrow P A$ ); b. corte seletivo (transição FS $\rightarrow$ PA)

30 Métricas da estrutura da paisagem para as três classes de uso: a. densidade de fragmentos (PD); $b$. indice do maior fragmento (LPI).

31 Métricas da estrutura da paisagem para as três classes de uso: a. distância média do vizinho mais próximo (ENN_MN); b. indice de justaposição (IJI)

32 Comportamento das métricas da paisagem em relação à proporção de uso da terra (PLAND) para Floresta Madura (FM).

33 Dinâmica do uso da terra para 1984-2002 e predição para o período 2004-2014 em três cenários simulados: 1 - taxas atuais, II intermediário e, III - conservacionista.

34 Localização das microbacias selecionadas e uso da terra para o ano de 2002, na bacia do rio Quatro Cachoeiras, Rondônia.

35 Tempo decorrido (anos) desde a ocorrência do primeiro desmatamento (1984 ou anterior) até o ano de 2002, na bacia do rio Quatro Cachoeiras, Rondônia.

36 Estabilidade média (ausência de transição) do uso da terra (em anos) para a bacia do rio Quatro Cachoeiras, Rondônia.

37 Evolução dos coeficientes dos componentes principais ao longo dos anos em relação à proporção de uso da terra (PLAND) para (a) FM e, (b) FS 
38 Coeficientes dos índices propostos e das microbacias avaliados em relação aos dois primeiros componentes de variação

39 Dendrograma de classificação das microbacias em função da dinâmica do uso da terra nos últimos 18 anos.

40 Valores da estrutura da paisagem (PLAND, PD, LPI, LSI e ENN_MN) referentes ao ano de 2002, calculados para as três classes de uso da terra das 20 microbacias (eixo $\mathrm{x}$ ).

41 Dendrograma de classificação das microbacias em função da estrutura da paisagem em 2002..

42 Relação entre os componentes de variação da dinâmica do uso da terra e estrutura da paisagem em 2002

43 Localização das microbacias e pontos de coleta de água selecionados para análise, na bacia do rio Quatro Cachoeiras, Rondônia.

44 Exemplo de dois pontos de coleta localizados em área de pastagem (a) e floresta (b).

45 Relação entre a condutividade elétrica da água (COND) e o Tempo de Introdução da Pastagem (TMIP) na microbacia.

46 Relação entre $\mathrm{pH}$ da água e a proporção de Floresta Madura (PLAND_FM) nas microbacias

47 Relação entre a densidade de fragmentos de Floresta Secundária (PD_FS) e a concentração de nitrogênio (NTOTAL) nas microbacias..... 125

48 Relação entre a estabilidade média da paisagem (ESTAB) e concentração de nitrogênio total (NTOTAL) na água das microbacias.... 126

49 Relação entre Tempo Médio de Introdução da Pastagem (TMIP) e concentração de carbono inorgânico dissolvido (CID) nas águas das microbacias.

50 Relação entre Altitude média do terreno (ALTIM) e concentração de $\mathrm{Na}^{2+}$ nas águas das microbacias. 


\section{LISTA DE TABELAS}

Página

1 Cenas Landsat TM e ETM+ da área de estudo utilizadas, data de aquisição e respectivas fontes. 36

2 Índices selecionados para a análise de estrutura da paisagem 42

3 Matriz de erros de classificação para o mapa do ano de 2002 45

4 Modelos lineares de probabilidade de transição para três cenários. y $(x)$ representa a função de probabilidade de transição $\mathrm{e} \times$ representa 0 intervalo de tempo

5 Índices selecionados para a análise de estrutura da paisagem. 83

6 Correlação entre as métricas de paisagem para as microbacias. Os números representam a frequência de correlações significativas (95\% de probabilidade) nos dez anos estudados (A_CV é uma forma abreviada de AREA_CV).

7 Análise de Componentes Principais - Coeficientes dos quatro primeiros componentes em relação à porcentagem de uso (PLAND) em cada ano e classe (FM e FS)

8 Correlação entre índices de dinâmica do uso da terra e componentes principais da dinâmica do uso da terra. Em negrito, valores significativos a $p<0,05$

9 Parâmetros da composição química da água utilizados.

10 Coeficientes de correlação de Pearson entre atributos físicos/dinâmica do uso da terra e a composição química da água nas microbacias. 
11 Coeficientes de correlação de Pearson entre a estrutura da paisagem em 2002 e composição química da água nas microbacias......

12 Regressão múltipla entre atributos físicos/dinâmica do uso da terra e composição química da água nas microbacias. Coeficientes de correlação parciais (acima) e nivel de probabilidade (entre parênteses).. 121

13 Regressão múltipla entre a estrutura da paisagem (2002) e composição química da água nas microbacias. Coeficientes de correlação (acima) e nivel de probabilidade (entre parênteses). 


\section{LISTA DE SIGLAS, ABREVIATURAS E SÍMBOLOS}

ALTIM - Altitude média do terreno

APP - Área de Preservação Permanente

AREA_CV - Coeficiente de variação do tamanho dos fragmentos

AVHRR - Advanced Very High Resolution Radiometer

COND - Condutividade elétrica da água medida em campo

CTCe - Capacidade de troca efetiva de cátions no solo

CVTFS - Coeficiente de Variação de Tamanho da Floresta Secundária

DEF2 - Porcentagem de área desmatada nos últimos 2 anos

DEF4 - Porcentagem de área desmatada nos últimos 4 anos

DECLIV - Declividade média

CID - Carbono Inorgânico Dissolvido

COD - Carbono Orgânico Dissolvido

EMBRAPA - Empresa Brasileira de Pesquisa Agropecuária

ENN_MN - Distância média do vizinho mais próximo

ESTAB - Estabilidade média do uso da terra

ETM+ - Enhanced Thematic Mapper

FM - Floresta Madura

FRAC_AM - Dimensão Fractal do fragmento ponderado pela área média FS - Floresta Secundária

IBGE - Instituto Brasileiro de Geografia e Estatística 
INPE - Instituto Nacional de Pesquisas Espaciais

IJI - Índice de Justaposição

ISA - Instituto Sócio Ambiental

LPI - Índice do maior fragmento

LSI - Índice de forma da paisagem

MDT - Modelo Digital do Terreno

NOAA - National Oceanic \& Atmospheric Administration

P.A. - Projeto de Assentamento

PA - Pastagem introduzida

PCA - Análise de Principais Componentes

PD - Densidade de fragmentos

PLAND - Proporção de uso da terra

PDBFF - Projeto Dinâmica Biológica de Fragmentos Florestais

PMFS - Proporção Média da Floresta Secundária

SAD - South America Datum

SAS - Statistical Analysis Software

SOLPRED - Classe de solos predominante

TADFM - Taxa Anual de Desmatamento da Floresta Madura

TEMP - Temperatura da água medida no campo

TM - Thematic Mapper

TMIP - Tempo Médio de Introdução da Pastagem

TRFIC - Tropical Rain Forest Information Center

UTM - Universal Transverse Mercator 


\title{
DINÂMICA DA PAISAGEM NA REGIÃO CENTRAL DE RONDÔNIA E SEUS EFEITOS NA COMPOSIÇÃO QUÍMICA DA ÁGUA.
}

\author{
Autor: SILVIO FROSINI DE BARROS FERRAZ \\ Orientador: Prof. Dr. CARLOS ALBERTO VETTORAZZI
}

\section{RESUMO}

A região central de Rondônia é uma das mais desmatadas da Amazônia brasileira, contendo áreas em diferentes estágios de fragmentação, já que o processo de desmatamento é contínuo desde a década de 1970. Este trabalho trata da avaliação das mudanças na paisagem entre 1984 e 2002 em uma bacia de drenagem localizada na região central de Rondônia e seus efeitos na composição química da água. Imagens bienais Landsat TM / ETM+ foram classificadas, resultando em uma série temporal de mapas de uso/cobertura do solo. Mudanças na paisagem foram avaliadas usando tabulação cruzada entre os anos, taxas de transição, métricas de paisagem relacionadas a tamanho, densidade, conectividade e configuração, distribuição de clareiras em relação ao seu tamanho, proximidade de estradas e pastagens antigas. Funções de probabilidade de transição foram ajustadas a fim de predizer mudanças no uso da terra para os próximos dez anos de acordo com três diferentes cenários. Utilizando-se os mapas gerados, analisou-se ainda a estrutura da paisagem em 20 microbacias selecionadas, utilizando métricas de paisagem e índices 
propostos de dinâmica do uso da terra. As microbacias foram agrupadas considerando-se sua dinâmica ao longo dos anos e situação para o ano de 2002. Testou-se a relação entre a dinâmica da paisagem nas microbacias e a composição química da água. Os resultados mostraram que as mudanças que vêm ocorrendo no uso da terra não serão sustentáveis nos próximos 15 anos. Os cenários mais sustentáveis para a região incluem a interrupção total do processo de exploração madeireira sem o devido plano de manejo, implementação da Área de Preservação Permanente ao longo dos rios e controle da dinâmica do uso da terra em niveis balanceados de transição. No estudo da dinâmica nas microbacias, os resultados mostraram também que a variabilidade na estrutura da paisagem está correlacionada à proporção de uso da terra das três classes consideradas. A dinâmica do uso da terra apresentou quatro componentes principais, sendo que três deles representaram $85 \%$ da variação e estiveram correlacionados aos índices de dinâmica propostos, os quais se mostraram bons indicadores para região por representar a variabilidade da dinâmica. A incorporação de dados históricos em conjunto a dados atuais na classificação das condições ambientais de microbacias melhorou a qualidade da classificação. Na avaliação da influência da paisagem na composição química da água, os resultados mostraram que, em relação aos atributos físicos e antrópicos, os parâmetros de composição química da água que obtiveram melhor predição $(p>0,05)$ foram a Condutividade Elétrica $\left(R^{2}=\right.$ 0,88 ) e o nitrogênio total $\left(R^{2}=0,48\right)$, enquanto que a estrutura da paisagem do ano 2002 conseguiu explicar melhor o nitrogênio total $\left(R^{2}=0,68\right)$, o oxigênio dissolvido $\left(R^{2}=0,56\right)$, o cloro $\left(R^{2}=0,51\right)$ e o fósforo $\left(R^{2}=0,46\right)$. O estudo mostrou a importância da análise integrada de fatores como histórico de uso da terra, condições físicas e estrutura da paisagem atual como indicadores para a qualidade da água na região. 


\title{
LANDSCAPE DYNAMICS AND ITS EFFECTS ON CHEMICAL COMPOSITION OF WATER IN CENTRAL RONDÔNIA
}

\author{
Author: SILVIO FROSINI DE BARROS FERRAZ \\ Adviser: Prof. Dr. CARLOS ALBERTO VETTORAZZI
}

\section{SUMMARY}

Central Rondônia is one of the most deforested regions in the brazilian Amazon and presents areas at different stages of fragmentation, creating a gradient from Primary Forest to developed areas. This paper deals with assessment of landscape changes between 1984 and 2002 in a watershed located in the central region of Rondônia State, Brazil, due to a systematic deforestation and pasture introduction since the 1970s. Landsat TM/ETM+ images (one every two years) were classified, resulting in a time series of landuse/land-cover maps. Landscape changes were evaluated using cross tabulation between years, transition rates, landscape metrics related to size, density, edge, shape, connectivity, configuration, and deforested patches distribution related to patch size and spatial proximity to roads and old pastures. Transition probability functions were fitted to the time series to predict land-use changes for the next ten years for three different scenarios. Using the land use maps, landscape structure was analyzed for 20 catchments by landscape 
metrics and proposed land use dynamics indices. Catchments were grouped by Cluster Analysis using land use dynamics data and landscape data for 2002. Current dynamics can be maintained in the region for ten years, but present-day land use changes cannot be sustained for more than 15 years. A more sustainable scenario for the region includes ceasing the deforestation process, implementing the "Permanent Preservation Area" along rivers and controlling the dynamics at balanced levels of transition. In catchment's landscape dynamics, results show that landscape structure variability is correlated to land use for the three considered classes showing the importance on considering matrix and coexistent classes' dynamics in landscape dynamics studies. Land use dynamics presented four principal components, and three of them represented $85 \%$ of variation and were correlated to proposed indices, which ones were considered good indicators for the region. The addition of historical and current data to the environmental condition classification of catchments improved the methodology. Regarding landscape influence on chemical composition of water assessment, results show that physical and human factors predict better $(p>0.05)$ the electrical conductivity $\left(R^{2}=0.88\right)$, total nitrogen $\left(R^{2}=0.48\right)$, and $\mathrm{pH}\left(\mathrm{R}^{2}=0.42\right)$, while landscape structure for 2002 could explain better total nitrogen $\left(R^{2}=0.68\right)$, dissolved oxygen $\left(R^{2}=0.56\right)$, chloride $\left(R^{2}=0.51\right)$ and phosphorus $\left(R^{2}=0.46\right)$. The study revealed the importance of an integrated analysis of factors like historical land use, physical conditions, and landscape structure as indicators of water quality in the region. 


\section{INTRODUÇÃO}

O desmatamento na Região Amazônica avança pelo chamado "Arco do Desflorestamento", principalmente pelos estados do Mato Grosso, Pará, Rondônia e Tocantins, atingindo até o ano de 2003, um total de $652.908 \mathrm{~km}^{2}$ (INPE, 2004).

As altas taxas de desmatamento têm sido uma das principais preocupações mundiais sobre o futuro da floresta Amazônica, inclusive com projeções de alterações drásticas na paisagem original nos próximos 20 anos, caso sejam mantidas as taxas atuais de desmatamento e os projetos de desenvolvimento e infra-estrutura na região, lançados pelo governo brasileiro (Laurance et al., 2001).

O processo de desmatamento vem sendo monitorado por instituições oficiais como Instituto Nacional de Pesquisas Espacias (INPE), universidades e organizações não-governamentais como o Instituto Sócio Ambiental (ISA), entre outros. Suas causas e conseqüências para a conservação da floresta vêm sendo estudadas sob os principais aspectos. Entretanto, um dos novos desafios para entender o impacto do desmatamento no processo de fragmentação tem sido a avaliação da estrutura de paisagem por meio do uso de índices que descrevem, numericamente, o padrão espacial da paisagem. Estes índices podem ser utilizados como ferramentas para diagnóstico ambiental.

A utilização de métodos de análise espacial em avaliação de processos de fragmentação é fundamental para a Amazônia pela sua extensão e diversidade (Batistella et al., 1999). Em Rondônia, a presença de áreas em 
diferentes estágios de fragmentação e a disponibilidade de dados históricos, propicia a realização de estudos de dinâmica.

Neste contexto, os objetivos deste estudo foram: $i$. avaliar a dinâmica da paisagem na bacia do rio Quatro Cachoeiras, localizada na região central de Rondônia, em função do desmatamento e implantação de pastagens ao longo dos últimos 20 anos; e, ii. avaliar possíveis impactos dessa dinâmica sobre a qualidade da água superficial.

Como objetivos específicos do estudo, pode-se listar:

- Entender a dinâmica da paisagem nos últimos 20 anos na bacia do rio Quatro Cachoeiras e avaliar cenários futuros com relação à sustentabilidade dos processos de transição de uso da terra;

- Avaliar a dinâmica da paisagem na escala de microbacias;

- Avaliar o uso de indicadores de dinâmica do uso da terra;

- Comparar a classificação das microbacias, considerando seu histórico de uso e a estrutura da paisagem atual; e,

- Avaliar a relação entre atributos físicos, histórico do uso da terra e estrutura atual da paisagem e composição química da água em córregos da bacia.

Desse modo as seguintes hipóteses foram formuladas para guiar o estudo:

1. As mudanças no uso da terra que vêm ocorrendo na bacia do rio Quatro Cachoeiras nos últimos 20 anos não são sustentáveis;

2. A dinâmica ocorrida afetou significativamente a estrutura atual da paisagem;

3. A análise do uso da terra é capaz de distinguir áreas que apresentem no momento presente, as mesmas condições de uso da terra; e,

4. A dinâmica da paisagem e a sua estrutura atual influenciam diferentemente a composição química da água nos rios da região. 
Com relação às justificativas para a realização deste estudo, alguns pontos podem ser destacados:

- O conhecimento da dinâmica do uso da terra e alterações na estrutura da paisagem, nas últimas décadas, pode fornecer subsidios para entender a dinâmica de ocupação na região e avaliar os impactos ambientais causados, principalmente quanto às alterações na dinâmica de nutrientes nos solos e rios da região;

- O diagnóstico da situação atual e a previsão de cenários para os próximos dez anos podem servir como base para o planejamento de ações relacionadas à conservação e ao manejo ambiental;

- A avaliação de indicadores e métodos para classificação de microbacias, em função da dinâmica da paisagem, poderá contribuir para o diagnóstico ambiental da Amazônia; e,

- O estudo da relação entre os fatores físicos e antrópicos e a composição química da água para a região, poderá ser útil para entender os impactos da ocupação humana sobre os recursos hídricos. Os resultados poderão servir de base para direcionar o processo de ocupação em outras regiões. 


\section{REVISÃO DE LITERATURA}

\subsection{Introdução}

A paisagem amazônica vem sendo modificada pela ocupação humana da região, sendo que as principais causas de desmatamento são: a pecuária, o aumento da migração interna da população para a região, a exploração madeireira, a mineração, os projetos de desenvolvimento com a construção de estradas e núcleos de colonização e o aumento de incêndios florestais causados pela atividade humana (Laurance et al., 2001; Pedlowski et al., 1997).

Como efeitos do processo de desmatamento na região pode-se citar a redução da biodiversidade (Laurance et al., 2002), alteração na composição química de solos (Longo \& Spíndola, 2000; McGrath et al., 2001; Moraes et al., 1996b; Neill et al., 1998) e na qualidade de água dos rios (Biggs et al., 2001; Richey et al., 1997), além de outros. Em Rondônia, Alves, F.S.M et al. (1999) observaram por exemplo, mudanças no microclima devido à conversão da floresta em pastagem, com redução de $10 \%$ da precipitação total e $24 \%$ da evapotranspiração real. A tendência de redução da taxa de evapotranspiração também foi verificada por Ichii et al. (2003).

O uso da terra em bacias hidrográficas normalmente controla a qualidade e quantidade das águas de seus rios. Em Rondônia, a conversão de floresta em pastagem tem causado modificações no regime hidrológico e na composição química da água (Biggs et al., 2002; Ballester et al., 2003; Thomas et al., 2004). No entanto, no estudo da influência do uso da terra, alguns tópicos precisam 
ser melhor estudados com objetivo de responder questões ainda pendentes. Por exemplo, como a estrutura da paisagem pode estar influenciando a qualidade da água? Como o posicionamento dos elementos da paisagem em relação aos rios e nascentes pode alterar seus efeitos sobre os recursos hídricos?

Em regiões de alta dinâmica como as áreas sob influência antrópica na Amazônia, outras questões precisam ainda ser melhor esclarecidas. Por exemplo, na abertura de clareiras, como a localização da clareira em relação aos rios e nascentes, influencia os seus impactos na água? Ainda, o histórico de uso de uma área pode influenciar a composição química da água? Neste capitulo, são retratados os esforços de entendimento da paisagem Amazônica e suas modificações, procurando-se ressaltar novas perspectivas com relação à influência da dinâmica da paisagem na qualidade da água dos rios da Amazônia.

\subsection{A Ecologia da Paisagem}

O termo "paisagem" pode ser definido através dos componentes naturais, fatores de intervenção humana e qualidades estéticas por elas proporcionadas. Os componentes naturais de maior importância na paisagem são a vegetação e o relevo. A atividade de manejo da vegetação é o fator humano mais amplo, enquanto os fatores estéticos estão relacionados com a reação mental produzida pelo que os olhos vêem (Lucas, 1991). Segundo Forman \& Godron (1986), a paisagem é uma extensa área onde um aglomerado de ecossistemas que interagem repetem-se de forma similar. Turner (1989) define paisagem como um mosaico espacial de limites arbitrários, contendo áreas distintas (manchas) que interagem funcionalmente. Entende-se por mancha uma unidade espacial, representando uma área contígua, espacialmente definida, que tenha características espaciais e não-espaciais distintas da sua vizinhança. 
A definição é ampla e dinâmica, e varia dependendo das escalas temporal e espacial, de acordo com o fenômeno de interesse (Wiens, 1976).

Com o avanço tecnológico, as áreas naturais foram substituídas por áreas urbanas e rurais. As alterações em áreas naturais têm sido muito drásticas desde a revolução industrial, causando problemas ecológicos e sociais (Magro, 1997). Os problemas ecológicos podem ser avaliados pelas alterações na estrutura e função da paisagem, as quais são objetos de estudo da Ecologia da Paisagem.

A Ecologia da Paisagem enfoca três características da paisagem: a estrutura, relação espacial entre os distintos ecossistemas presentes; a função, interações entre os elementos espaciais; e, a mudança, alteração na estrutura e função do mosaico ecológico ao longo do tempo (Forman \& Godron, 1986). A origem do termo "Ecologia da Paisagem" teve suas raízes na região centroleste européia, onde geógrafos começaram a ver a paisagem não somente pelo seu componente estético (como os paisagistas), mas como a entidade espacial e visual do espaço humano. A concepção de Ecologia da Paisagem nos Estados Unidos da América foi inicialmente influenciada por cientistas naturais, preocupados com a relação do padrão de distribuição de plantas e animais (biogeografia) com o meio físico e antrópico (Naveh \& Lieberman, 1993). Mais tarde, engenheiros florestais, agrônomos e arquitetos, preocupados com 0 planejamento do uso da terra, se interessaram pela Ecologia da Paisagem. $\mathrm{O}$ conceito "manejo de paisagem" surgiu da aplicação dos conceitos da Ecologia da Paisagem ao manejo de ecossistemas naturais (Viana \& Oliveira, 1997).

A paisagem pode ser descrita pela sua estrutura, a qual refere-se ao arranjo espacial relativo de seus elementos e as conexões entre eles. Ela representa tanto características espaciais (arranjo geográfico, por exemplo) e não espaciais (composição, por exemplo) de seus elementos (Turner, 1989). O entendimento da estrutura da paisagem é determinante em vários estudos, como disponibilidade de habitat (Harris, 1984), avaliação do impacto da ocupação humana, simulações de mudanças temporais (Turner, 1989) e 
principalmente na análise de processos de desmatamento e fragmentação da paisagem florestal (Collinge, 1996; Jorge \& Garcia, 1997). Com relação à fragmentação, Collinge (1996) verificou que suas conseqüências ecológicas primárias são a perda de espécies de plantas e animais nativos, a invasão de espécies exóticas, o incremento da erosão do solo e a diminuição da quantidade e qualidade da água. A magnitude e a extensão destas alterações são influenciadas pelo tamanho, conectividade, forma, contexto e heterogeneidade dos fragmentos. Metzger (1997) estudando a relação entre a estrutura da paisagem e a diversidade de espécies na região sudeste do estado de São Paulo, observou que a conectividade das áreas florestais e a complexidade da paisagem são as principais variáveis da estrutura espacial, que se relacionam à variação de riqueza e abundância de espécies arbóreas.

A fragmentação tem sido avaliada por meio de métricas (índices) da paisagem. Os índices são capazes de "medir" a paisagem de acordo com vários aspectos de seus elementos como, por exemplo: tamanho, borda, forma, vizinhança, área nuclear (McGarigal \& Marks, 1995). O estudo de Galo \& Novo (1998) ressalta a importância da utilização de índices de fragmentação e diversidade espacial para a discriminação entre ambientes naturais e aqueles submetidos às alterações antrópicas. A relação entre desmatamento e métricas da paisagem também foi avaliada por Trani \& Giles Jr. (1999). Os autores estudaram o comportamento dos índices de estrutura da paisagem expostos a diferentes padrões de fragmentação. Os resultados sugerem que os indices área central, contigüidade e convexidade estão relacionados ao processo de fragmentação em si, enquanto que os índices de tamanho do fragmento, número de fragmentos, densidade média e distância entre fragmentos estão mais ligados à perda de área florestal. Hargis et al. (1998) observaram que apesar de alguns índices serem altamente correlacionados, cada índice mostra um aspecto particular e que, na maioria das vezes, um índice complementa outro. 
Padrões distintos de fragmentação foram observados por Batistella \& Soares Filho (1999) em duas regiões de Rondônia com processos de colonização distintos: Vale do Anari, com rede viária do tipo "espinha de peixe" e Machadinho d'Oeste, projeto baseado no relevo da região. Os resultados indicaram maior heterogeneidade na região de Machadinho, bem como melhor preservação das áreas núcleos e maior continuidade dos habitats florestais nesta região. Neste caso, os diferentes padrões de ocupação poderão ter efeitos distintos sobre os recursos hídricos já que as propriedades são dispostas diferentemente em relação à rede de drenagem da região.

A discussão atual em relação aos estudos de fragmentação e seus efeitos sobre a biodiversidade tem sido centrada na distinção entre os efeitos da fragmentação per si e os efeitos da perda de habitat. Fahrig (2003) ressalta que muitos trabalhos não fazem esta distinção e consideram conjuntamente os efeitos da perda de habitat e fragmentação. Neste sentido, a fragmentação florestal parece não exercer efeitos diretos na qualidade da água, mas a perda de área florestal, um dos componentes mais importantes da fragmentação, exerce influência na qualidade da água (Biggs et al., 2002).

\subsection{Caracterização da paisagem}

Para a aplicação prática dos conceitos da Ecologia da Paisagem deve-se considerar que, como uma proposta holistica e integrada de manejar recursos, - manejo dessas paisagens envolve decisões baseadas em complexas interações de fatores bióticos e abióticos (Lachowski, 1994). As facilidades que o Sensoriamento Remoto e os Sistemas de Informações Geográficas oferecem para processamento e análise de dados espaciais tornam essas técnicas fundamentais para o diagnóstico, a análise e a modelagem da paisagem (Lachowski, 1994; Lucier, 1994; Oliver, 1992). Os avanços recentes dessas técnicas têm tornado possivel o processamento de dados para grandes áreas $\mathrm{e}$, 
por isso, elas têm sido amplamente utilizadas em estudos de paisagens florestais (Sachs et al., 1998).

A caracterização da paisagem inicia-se pela interpretação e classificação de imagens de sensores orbitais ou aerotransportados para avaliação da cobertura do solo na área estudada. Na região Amazônica, várias técnicas têm sido utilizadas no processo de classificação de imagens de satélite (Alencar et al., 1996; Almeida Filho et al., 1998, Alves et al., 1998b, Shimabukuro et al., 1999, Stone et al, 1991). Shimabukuro et al. (1999) sugerem o método de classificação baseado no modelo linear de mistura espectral, o qual estima a proporção entre os componentes solo, vegetação e sombra para cada pixel. A metodologia compreende ainda a segmentação da imagem sintética gerada e a utilização de classificação não supervisionada sobre as regiões criadas para o levantamento de áreas desmatadas.

A mesma técnica foi utilizada por Almeida Filho et al. (1998) para mapeamento do uso do solo na Amazônia. Os autores consideraram que a técnica de classificação automática é viável para mapeamento e monitoramento do uso da terra na região. Entretanto, o estudo de Almeida et al. (1996) apontou a dificuldade em distinguir a floresta secundária de plantios de cacau e seringueira, bem como de floresta primária, quando a vegetação secundária apresentava mais de 10 anos na região de Ariquemes, RO.

Stone et al. (1991), por exemplo, estudaram o desmatamento no Estado de Rondônia, utilizando imagens Landsat TM+ e NOAA AVHRR por meio de classificação supervisionada (algoritmo máxima verossimilhança). Já, Alves et al. (1998b) compararam cinco diferentes algoritmos de classificação para caracterização de áreas desmatadas em Rondônia. Apesar dos métodos testados terem apresentado resultados semelhantes (Índice Kappa > 0,8), o estudo apontou para as dificuldades encontradas em cada um deles. Segundo os autores, nos métodos de fatiamento, supervisionada por regiões e supervisionada por máxima verossimilhança, a maior dificuldade consiste na fase de aquisição de amostras, enquanto que nos métodos de classificação não 
supervisionada por regiões e supervisionada por modelo linear de mistura espectral, as etapas mais difíceis são o mapeamento dos resultados e criação das três imagens componentes, respectivamente.

\subsection{Dinâmica da paisagem}

As paisagens são dinâmicas. A estrutura da paisagem observada em um determinado momento representa somente uma situação estática, parte de um processo maior. $O$ fato das paisagens serem dinâmicas requer que as mudanças temporais sejam consideradas em trabalhos de quantificação das mesmas (Dunn et al., 1991).

A avaliação da dinâmica temporal da paisagem tem como etapa inicial a caracterização da variação no uso da terra (composição) ao longo dos anos, sendo que a maioria dos estudos utiliza dois ou três períodos distintos para comparação (Alencar et al., 1996; Andrade et al., 1998; Chen et al., 2001; Escada \& Alves, 2003; Fiorio et al., 2000). Os resultados deste tipo de estudo auxiliam a compreensão das alterações na área de cada classe de uso da terra, geralmente relacionadas a fatores sócio-econômicos.

Além das alterações na composição, alguns estudos avaliam também alterações em outros aspectos da estrutura da paisagem como conectividade, borda, forma, entre outros (Kammerbauer \& Ardon, 1999; Ochoa-Gaona, 2001; Rao \& Pant, 2001; Zheng et al., 1997). Segundo Turner et al. (1989), as mudanças temporais na estrutura da paisagem podem incluir mudanças no número e tamanho dos fragmentos, número e tipo de corredores, número e tipo de barreiras de dispersão, além da probabilidade e propagação de distúrbios.

Um amplo estudo foi realizado por Sachs et al. (1998) na região centrosul da British Columbia (Canadá), onde foram avaliadas as mudanças na estrutura da paisagem submetida a manejo florestal, ao longo de 17 anos, em diferentes regiões bio-climáticas. $O$ estudo mostrou que a região encontrava-se no estágio inicial de fragmentação causada pela exploração madeireira, mas 
que padrões semelhantes de exploração estavam sendo impostos em regiões ecológicas distintas.

O estudo de Herzog et al. (2001) mostrou a potencialidade do uso de índices de métrica da paisagem como indicadores ambientais. Os autores recomendam a realização de novas pesquisas nessa área, com a inclusão de estudos de correlação entre os índices e parâmetros físicos do ambiente e variáveis sócio-econômicas.Lausch \& Herzog (2002) avaliaram a aplicação de métricas no monitoramento de mudanças na paisagem e concluíram que os pontos mais críticos neste tipo de aplicação são: a utilização do sensoriamento remoto, a escolha de índices adequados, a escolha de uma unidade espacial que integre os processos avaliados e a padronização dos dados para comparação no espaço e no tempo.

$\mathrm{Na}$ região Amazônica, os estudos de dinâmica da paisagem têm procurado entender melhor o funcionamento do ecossistema florestal frente às alterações antrópicas. O trabalho realizado por Alencar et al. (1996) comparou o uso da terra na região de Bragantina (nordeste da Amazônia) entre os anos de 1991 e 1994. Os autores concluíram que as altas taxas de transição para vegetação secundária indicaram a regeneração da floresta na região, sendo que áreas em estágio avançado de regeneração não eram mais utilizadas.

Um amplo estudo de dinâmica do uso da terra em Rondônia foi realizado por Roberts et al. (2002), que encontraram diferentes padrões de dinâmica ao longo de três regiões: Ariquemes, Ji-Paraná e Luiza, entre 1975 e 1999. Os autores consideraram a hipótese de que as diferenças no padrão espacial podem estar atribuídas a uma combinação de fatores econômicos e fertilidade dos solos. Estudando a dinâmica de uso da terra causada pela atividade agrícola, Cardille \& Folley (2003) compararam padrões de ocupação em oito regiões da Amazônia entre 1980 e 1995. O estudo mostrou que no Pará, as áreas agrícolas vêm sendo substituídas pela pastagem, no Mato Grosso houve aumento da área plantada tanto para agricultura como pastagem, enquanto que 
em Rondônia a pastagem vem substituindo a floresta, abrindo caminho para a expansão agrícola.

Segundo Laurance et al. (2002), o Projeto Dinâmica Biológica de Fragmentos Florestais (PDBFF), realizado na Amazônia, é um dos maiores experimentos sobre fragmentação no mundo. Os resultados mais recentes do projeto sugerem que o efeito de borda tem papel fundamental na dinâmica do fragmento, alterando a composição de espécies, a estrutura trófica das comunidades e a dinâmica da floresta, sendo que a matriz influencia a conectividade e o funcionamento dos fragmentos.

Com relação à dinâmica ocasionada pela ocupação nos assentamentos rurais onde há grande dinâmica pela prática da derrubada e queima, Metzger (2003) observou na região de Bragantina (Pará), diferenças na estrutura da paisagem comparando áreas com períodos de descanso curto e outras com período longo. A redução do período está associada à existência de grandes áreas desmatadas e vegetação secundária jovem, enquanto que áreas de floresta e vegetação secundária madura são reduzidas. Na mesma região, Metzger (2002) observou que áreas com periodo de descanso curto não estão em equilíbrio. Em geral, existe uma tendência de redução dos períodos de descanso devido à intensificação de uso. O estudo mostrou ainda que seria necessário um período de 11 anos de descanso para cada ano cultivado.

$\mathrm{Na}$ tentativa de entender melhor a dinâmica na região e principalmente simular cenários futuros e seus respectivos efeitos, alguns autores apresentaram modelos computacionais de dinâmica. Dale et al. (1994), por exemplo, desenvolveram um modelo para simular efeitos da dinâmica no uso da terra em Rondônia. Com a simulação de três cenários possiveis de acordo com as perspectivas de desmatamento: "melhor", "típico" e "pior", foram simulados os efeitos da dinâmica na emissão de carbono, freqüência de abandono de lotes e taxa de desmatamento. Os resultados foram projetados para os próximos 40 anos, e os cenários "pior" e "típico" não apresentaram diferença a longo prazo. 
O modelo DINAMICA desenvolvido por Soares Filho et al. (2002), pode ser utilizado para investigação da dinâmica de áreas ocupadas por colonos e a predição da evolução do padrão de ocupação de acordo com seus diversos fatores que influenciam o processo, incluindo variáveis físicas e antrópicas. $O$ modelo foi avaliado na região norte do Mato Grosso na predição de desmatamento. Em Rondônia, Dale et al. (1996) desenvolveram um modelo de simulação para entender as causas e efeitos das mudanças no uso da terra. Segundo o modelo, as alterações que ocorrem na região são reguladas em função das seguintes variáveis: tamanho da propriedade, histórico do uso da terra, condições iniciais de solo e vegetação, atividade (plantio anual, perene ou pastagem), condições do mercado e efeitos de doenças na população sobre o trabalho.

\subsection{A relação entre paisagem e os sistemas aquáticos}

A heterogeneidade espaço-temporal dos ecossistemas influencia os processos ecológicos (Forman \& Godron, 1986). Os fluxos de nutrientes e sedimentos, por exemplo, são processos mais evidentes influenciados pela paisagem. Segundo Wiens (2000), rios e córregos expressam acima de tudo a variância local e a heterogeneidade da paisagem em que estão inseridos. $O$ conhecimento da relação da influência dos ecossistemas terrestres nos ecossistemas aquáticos é crucial no manejo dos sistemas aquáticos (Likens \& Bormann, 1974). A relação paisagem-água tem se tornado tão importante ultimamente, que autores como Wiens (2002) sugerem que a heterogeneidade presente em torno dos rios seja vista como "paisagem ribeirinha" e que os conceitos da ecologia da paisagem sejam aplicados aos ecossistemas aquáticos.

Vários estudos comprovaram a influência do uso da terra em bacias hidrográficas sobre a qualidade da água de seus rios (Allan et al., 1997; Basnyat et al., 1999; Biggs et al., 2002; Ometo et al., 2000; Wang \& Yin, 1997; 
Wear et al., 1998), tanto pela quantificação do tipo de uso da terra, suscetibilidade à erosão dos mesmos, utilização de índices de adequação e métricas da paisagem. Segundo Allan et al. (1997), a qualidade da água, o habitat e a integridade biótica são fortemente influenciados pelo uso da terra, sendo que a extensão de áreas agrícolas na sub-bacia é o melhor indicador direto da condição dos rios locais.

No entanto, a influência do uso da terra na qualidade da água varia em função da escala, tipo de vegetação ripária, relevo, geologia e habitat aquático. A entrada de matéria orgânica depende da cobertura do solo nas áreas adjacentes ao rio, enquanto que nutrientes, sedimentos e características hidrológicas e do canal dependem de condições regionais, incluindo a estrutura da paisagem (Allan et al., 1997). Basnyat et al. (1999) observaram a importância de áreas de uso passivo como florestas e campos em bacias de drenagem e zona ripária para garantir melhor qualidade da água.

Ometo et al. (2000) compararam a influência do uso da terra sobre a composição química e biológica dos rios, em duas microbacias na região de Piracicaba, SP. O estudo mostrou a existência de correlações entre a presença de cátions, ânions e a condutividade da água e o índice de utilização da terra. Wang \& Yin (1997) encontraram evidência da relação entre condutividade da água e extensão da área urbana na bacia. Seus resultados indicam que a condutividade pode não ser um indicador sensivel para fontes não-pontuais de poluição.

Biggs et al. (2002) estudaram a utilização de parâmetros químicos da água como indicadores do grau de desmatamento e da urbanização em bacias hidrográficas de Rondônia. O estudo mostrou a correlação entre a concentração de cátions, sílica e porcentagem de área desmatada, sendo que o cloro apresentou a maior correlação ao desmatamento. Em Rondônia, Ballester et al. (2003) encontraram que a proporção de pastagem e as propriedades do solo para $\mathrm{Ca}^{2+}$ e $\mathrm{Mg}^{2+}$ são os melhores preditores de cátions e ânions da água. Deve-se considerar, também, que as bacias de drenagem normalmente são 
heterogêneas, com diferentes usos da terra e tipos de solos, de acordo com sua extensão, e essas características interagem diferentemente com a água. Mais estudos que considerem a espacialidade explícita de elementos como estradas, rios e a heterogeneidade das bacias são necessários para melhorar o entendimento da interação água-paisagem (Jones, J.A. et al., 2000).

A composição do uso da terra em uma bacia tem efeitos diferenciados nos sistemas aquáticos dependendo da localização destes diferentes usos em relação à rede de drenagem (Lucas \& Medley, 2002). O desafio atual é entender os diferentes mecanismos que determinam a influência do uso da terra nos sistemas aquáticos em diferentes escalas e regiões (Gergel et al., 2002). Para ilustrar o efeito do arranjo do uso da terra em relação à rede de drenagem, na Figura 1 são exemplificadas duas bacias compostas por pastagem e floresta. Supondo que as bacias tenham as mesmas características físicas, composição e disposições distintas de seus componentes, provavelmente a influência do uso da terra nos rios será diferente nos dois casos. Enquanto que na bacia $A$, o componente floresta poderá garantir maior proteção à região das cabeceiras, na bacia $\mathrm{B}$ a maior proteção estará diretamente ligada ao canal principal. As duas bacias poderiam ainda ter estruturas de paisagem semelhantes quanto à borda, forma, conectividade e vizinhança. Ainda assim, estas características não expressariam suas diferenças em relação à rede de drenagem. Desse modo, apesar dos avanços na modelagem da influência do uso da terra nos sistemas aquáticos, alguns aspectos da paisagem e suas interações com a rede hidrológica não estão sendo avaliados pelas ferramentas disponiveis.

A avaliação da estrutura da paisagem pode fornecer novas alternativas para mensurar os efeitos humanos sobre os recursos hídricos que complementam os tradicionais métodos de avaliação da qualidade da água (Gergel et al., 2002). Os nutrientes presentes em água de rios podem ser preditos por métricas da paisagem (Basnyat et al., 1999; Jones, K.B. et al. 2000). Van Oost et al. (2000), por exemplo, mostraram que as mudanças na 
estrutura da paisagem podem influenciar as taxas médias anuais de erosão. Nutrientes provenientes de insumos agrícolas como fosfatos e nitratos puderam ser previstos pela estrutura da paisagem (Jonhson et al., 2001; Lucas \& Medley, 2002). Jones, K.B. et al. (2000), por exemplo, puderam explicar até $86 \%$ do nitrogênio, $73 \%$ do fósforo e $79 \%$ da variação nos sedimentos em suspensão na região central da costa leste da América do Norte por meio de métricas da paisagem.
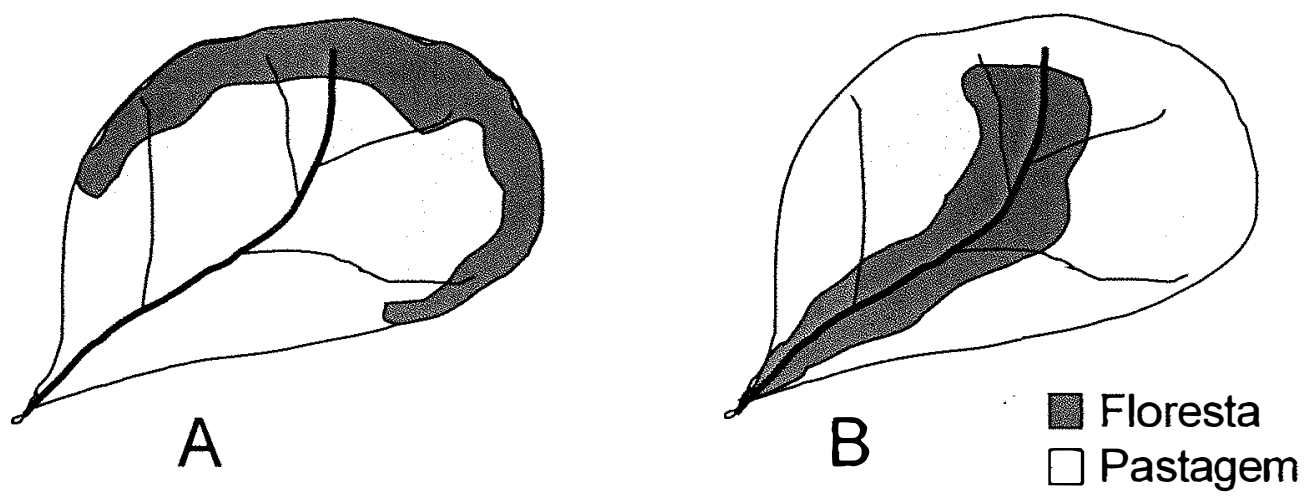

Figura 1 - Exemplo ilustrativo de diferentes configurações espaciais dos componentes da paisagem em relação à rede de drenagem em uma bacia hidrográfica

A maioria dos estudos relacionados a elementos lineares como rios e rodovias, considera sua influência utilizando zonas de influência (buffers) com diferentes tamanhos ao redor dos mesmos (Jones, J.A. et al., 2000). No caso da Figura 1, somente a análise da estrutura da paisagem em uma faixa (buffer) em torno dos corpos d'água poderia distinguir as duas bacias. Entretanto, a dificuldade ainda persistiria, por exemplo, na definição do tamanho ideal da faixa a ser considerada, pois a disposição dos elementos na região delimitada poderia ainda influenciar a qualidade da água. Alguns estudos focalizam a dinâmica do ambiente ripário e sua influência para a qualidade da água. Whiles et al. (2000), por exemplo, mostram que o uso da terra na zona ripária é a variável que melhor explica a integridade biótica de rios e córregos. Richards et 
al. (1996) obtiveram resultado semelhante, testando zonas de influência de 100 metros. Em Rondônia, Thomas et al. (2004) observaram a importância da vegetação adjacente ao canal na alteração da composição química da água de córregos. A qualidade da água depende ainda da habilidade do solo em armazenar e modificar a mesma (Hunsaker \& Levigne, 1995; O'Neill et al., 1997). Snyder et al. (2003) apontam para a hipótese de que a capacidade da zona ripária em mitigar os efeitos de mudanças na bacia é inversamente proporcional ao gradiente rio-divisor. Um bom indicador para descrever a eficiência da zona ripária na filtragem de nutrientes poderia resultar da interação entre o arranjo espacial do uso da terra e sua eficácia como sumidouro (Gergel et al., 2002).

Novos modelos estão sendo avaliados para analisar a influência do uso da terra na qualidade da água. Randhir et al. (2001), por exemplo, mostraram que o uso de zonas de influência em torno de pontos de vertedouro pode não refletir bem a interação entre a paisagem e a água. Portanto, novos estudos devem focar na avaliação da estrutura da paisagem e disposição de seus componentes em relação à rede de drenagem, a fim de melhorar os modelos que explicam a influência da paisagem na qualidade da água.

Como visto anteriormente, o uso da terra influencia a qualidade da água, mas poucos são os estudos que apontam para efeitos de sua dinâmica. $O$ desmatamento é exemplo típico de dinâmica do uso da terra com grande impacto no sistema aquático, pois a remoção da floresta, a exposição do solo e a introdução de cinzas no sistema, aumentam as perdas de solos e nutrientes pelo escoamento superficial. Cisternas et al. (2001), por exemplo, observaram que as mudanças no uso da terra influenciam o aporte de sedimentos, independentemente do tipo de transição, sendo que o fator mais importante é a mudança em si. Além disto, Elsenbeer (2001), estudando o fluxo hidrológico em solos tropicais, aponta para a hipótese de que o escoamento superficial em solos com cobertura florestal poderia contribuir diferentemente na formação da enxurrada, de acordo com o tipo de solo. 
Portanto, é possivel que a posição de um distúrbio em relação à rede de drenagem afete diferentemente a qualidade da água. Na Figura 2 são exemplificados dois casos de distúrbios no sistema florestal causados pelo desmatamento e abertura de clareira. No caso $A$, o distúrbio ocorre próximo ao curso d'água e na posição intermediária da bacia, com distância na superfície (Dt) igual a 1 (sem unidade) e distância no curso d'água em relação ao vertedouro $\mathrm{O}(\mathrm{Da})$ igual a 6 . No caso $\mathrm{B}$, o distúrbio ocorre mais distante do curso d'água e na posição superior da bacia, com Dt igual a 4 e Da igual a 10. Considerando-se condições iguais de escoamento nas duas situações e amostragem de água no vertedouro $\mathrm{O}$, é provável que os impactos na qualidade da água do distúrbio no caso $B$ sejam menores que os do caso $A$, devido à capacidade maior (maior distância percorrida) do sistema em absorver os sedimentos e nutrientes tanto no sistema terrestre, como no aquático (processamento do canal). O sistema aquático deve ser considerado como parte estrutural e funcional da paisagem, interagindo com o sistema terrestre e modificando a composição química da água ${ }^{1}$.
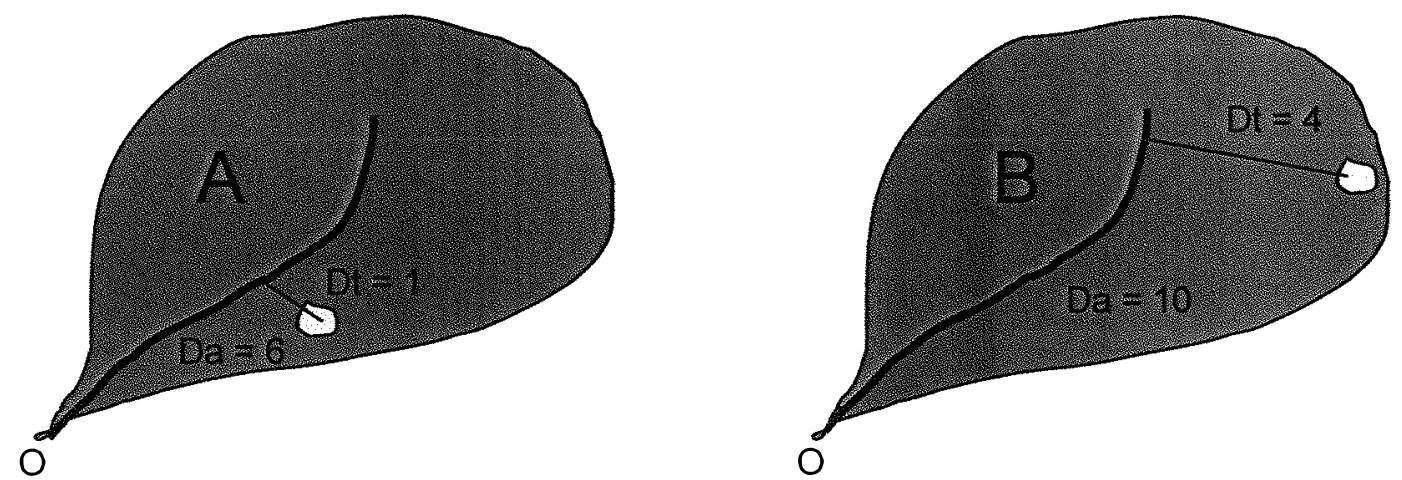

$\mathrm{Da}=$ Distância no curso d'água em relação ao ponto $\mathrm{O}$ $\mathrm{Dt}=$ Distância na superfície terrestre $\mathrm{O}=$ Vertedouro

Figura 2 - Exemplo ilustrativo de diferentes localizações de distúrbios (como abertura de clareiras) em relação à rede de drenagem

\footnotetext{
${ }^{1}$ Ballester, M.R.V. Comunicação pessoal, 2004.
} 
No exemplo acima considerou-se a distância direta (menor distância entre as posições) entre o ponto do distúrbio e o curso d'água, mas é possivel que a distância percorrida na superfície pela água (distância funcional) tenha também efeito na qualidade da água (Theobald \& Ferraz ${ }^{2}$ ). Portanto, no estudo da influência da dinâmica da paisagem na qualidade da água, os componentes composição e configuração interagem, pois a mudança na composição tem influência variável de acordo com a escala e os impactos decorrentes da alteração. Já a configuração da paisagem e sua alteração terão efeitos na capacidade de absorção dos impactos.

Outro aspecto importante é a avaliação da dinâmica da matriz, já que ela pode explicar uma porção significativa da variabilidade observada nas paisagens (Griffith et al., 2000). Em algumas regiões da Amazônia já dominadas por pastagens, por exemplo, a adubação, utilização pelo gado, conservação de solos, dentre outras técnicas de manejo, podem influenciar a qualidade da água (Biggs et al., 2001; Dias Filho, 2001; Richey et al., 1997; Thomas et al, 2004).

Um dos aspectos menos explorados no estudo de influência da dinâmica da paisagem nos recursos hídricos e também nos processos ecológicos em geral, é a avaliação de efeitos acumulativos decorrentes da trajetória de uso da terra. Estes efeitos podem ser importantes e devem ser considerados no manejo e planejamento ambiental. No entanto, a falta de dados históricos do ambiente tem limitado a avaliação dos efeitos acumulativos (MacDonald, 2000). Thompson et al. (2002) observaram que a estrutura de uma floresta (composição de espécies), por exemplo, pode ser influenciada por efeitos do histórico de uso da terra.

As paisagens apresentam não somente variabilidade espacial, mas também temporal, e a incorporação das mudanças no uso da terra ao longo do tempo adiciona uma outra camada de complexidade para o desenvolvimento de

\footnotetext{
${ }^{2}$ Theobald, D.M.; Ferraz, S.F.B.; Functional hydrologic weighted land use assessment
} within watersheds: methods and applications. (Em preparação) 
um modelo acurado de influência do uso da terra na qualidade da água (Wayland et al., 2002). Uma visão de longo prazo dos processos ocorrentes em microbacias é importante na avaliação de projetos de conservação de rios (Molnar et al., 2002) e esta perspectiva de longo prazo somente pode ser obtida pela avaliação da trajetória de uso da terra, definida como a seqüência de estados (ou usos) pelos quais uma região foi submetida em um determinado período de tempo, anterior ao momento da análise (Hietel et al., 2004).

Em regiões da Amazônia com prática comum da técnica de derrubada e queima como é o caso da região central de Rondônia, a trajetória de uso da terra da área deverá influenciar os processos ecológicos, já que normalmente ocorre a utilização da área nos primeiros anos e descanso ou abandono nos anos seguintes. Atividades desenvolvidas no passado que poderiam afetar o fluxo de água têm influência significativa na evolução de uma região (Constanza et al., 1990). O fluxo do escoamento base, por exemplo, integra a influência dos usos da terra do passado, já que existe um intervalo de tempo entre a infiltração no solo e a chegada no canal (Wayland et al., 2002).

A utilização de trajetórias do uso da terra no entendimento das condições presentes é recente; Crews-Meyer (2002), por exemplo, estudou as condições atuais de fragmentos baseando-se na trajetória da estrutura da paisagem de seu entorno. Na Figura 3, são ilustrados exemplos hipotéticos de trajetórias de uso da terra (ou perfis) para regiões sob influência antrópica na Amazônia, sendo que os impactos destes perfis nos sistemas aquáticos provavelmente serão diferentes. Áreas que apresentam a mesma condição (uso da terra) no presente poderão ter percorrido diferentes trajetórias ao longo dos anos. Áreas do perfil 1, por exemplo, foram desmatadas há muitos anos e encontram-se estabilizadas como pastagem nos últimos seis anos. Estas áreas provavelmente apresentam impactos diferenciados das áreas do perfil 4 (também área de pastagem no presente), mas com histórico de ocupação diferente, já que teve seu desmatamento ocorrido somente nos dois últimos anos. 


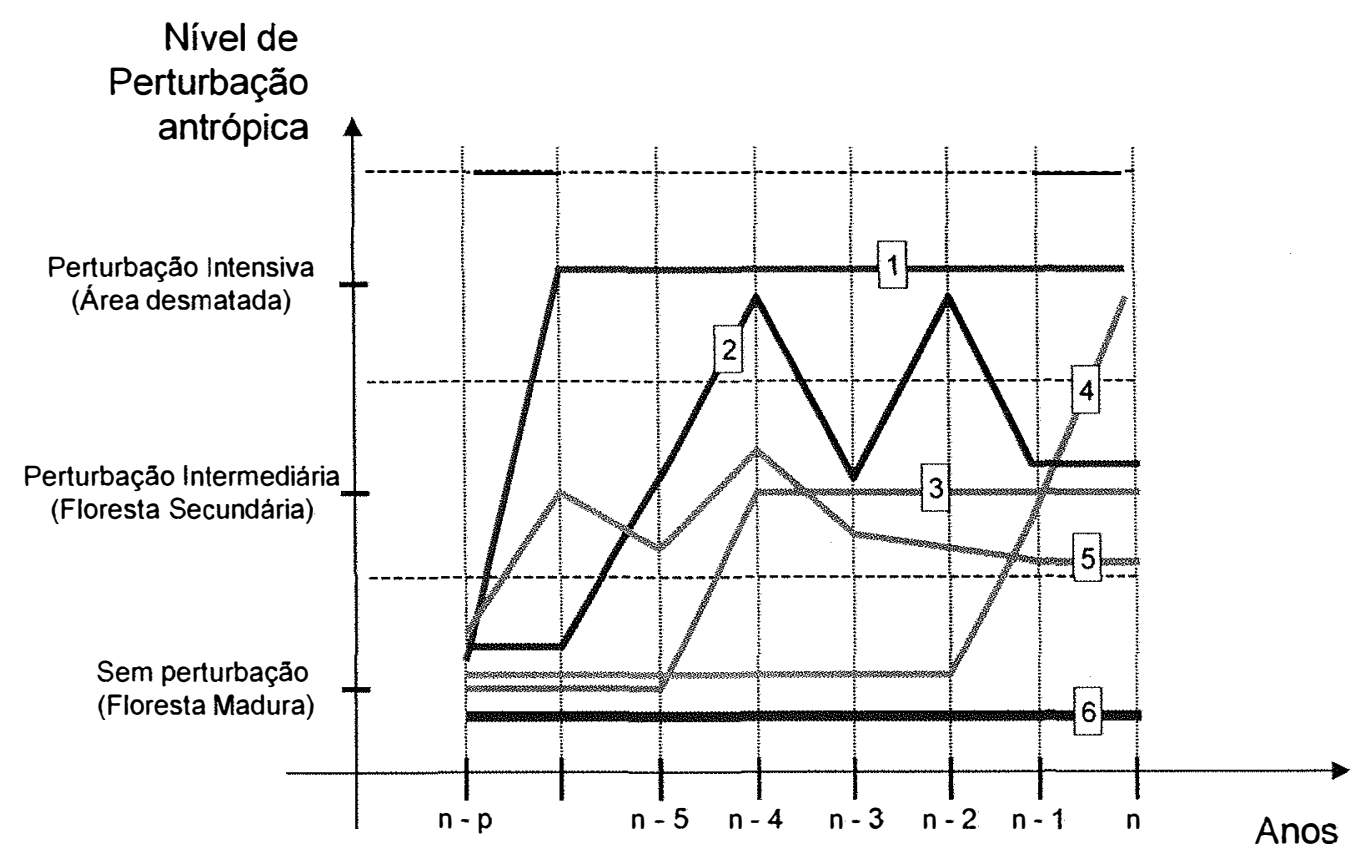

Figura 3 - Exemplo ilustrativo de diferentes trajetórias de uso da terra (perfis 1 a 6) para a região Amazônica entre os $p$ anos passados e o ano presente $(n)$

A mesma situação aplica-se às áreas com maior dinâmica, como é o caso da floresta secundária na Amazônia. As áreas dos perfis 2, 3 e 5, por exemplo, apresentam diferentes históricos que poderiam ou não ser detectados no processo de classificação, de acordo com o nível de detalhamento utilizado. Áreas do perfil 2 sofreram um processo de desmatamento no passado e, nos últimos anos, vêm alternando ciclos de regeneração e queima. Áreas do perfil 3 , foram desmatadas há quatro anos e, desde então, foram abandonadas e vêm se regenerando. Áreas do perfil 5 foram parcialmente desmatadas, e vêm se regenerando.

Dependendo do nível de detalhamento utilizado, a análise da paisagem no presente não conseguiria distinguir as áreas 1 e 4 , e 2,3 e 5 , pois seriam enquadradas na mesma classe: pastagem (1 e 4) e floresta secundária (2,3 e 5). Mesmo que a vegetação secundária fosse subdivida em várias classes de acordo com a condição da vegetação, distúrbios antigos e, mesmo o passado 
de áreas desmatadas, não seriam detectados no presente. Vieira et al. (2003) mostraram que a relação entre as propriedades espectrais e a idade da vegetação secundária depende de características específicas de cada região, como solos e histórico de uso da terra, o que dificulta o processo de classificação. Além disto, a dificuldade em obter e analisar dados multitemporais poderá dificultar a aplicação destas técnicas, o que deverá ser suprido pelo avanço na disponibilidade de dados e métodos de análises de produtos provenientes de sensores remotos. Uma outra possibilidade seria o desenvolvimento de indicadores de dinâmica do uso da terra, que representassem a trajetória de uso da terra na área e pudessem ser mensurados no presente. Estes indicadores deveriam ser especificos para cada região, já que contemplariam aspectos da dinâmica decorrentes de peculiaridades de cada área.

\subsection{Considerações finais}

O impacto da dinâmica da paisagem na qualidade da água já foi demonstrado em vários estudos. Entretanto, a influência da disposição dos elementos (usos) na qualidade da água ainda é pouco explorada. Em regiões tropicais, estudos da influência da dinâmica nos processos ecológicos são fundamentais para o entendimento de suas condições atuais. Da mesma forma, novos estudos são necessários no desenvolvimento de técnicas para avaliação de efeitos acumulativos derivados do histórico de utilização. Nestas regiões, onde grandes áreas florestais vêm sendo convertidas e existem áreas em diferentes estágios de regeneração, tais técnicas poderiam auxiliar no estabelecimento de ações para recuperação e conservação dos recursos naturais. 


\section{AVALIAÇÃO DA DINÂMICA DA PAISAGEM ENTRE 1984 E 2002 NA REGIÃO CENTRAL DE RONDÔNIA: TENDÊNCIAS E PERSPECTIVAS}

\section{Resumo}

A região central de Rondônia é uma das mais desmatadas da Amazônia brasileira, contendo áreas em diferentes estágios de degradação, já que o processo de desmatamento é contínuo desde a década de 70 . Este trabalho trata da avaliação das mudanças na paisagem entre 1984 e 2002 em uma bacia de drenagem localizada na região central de Rondônia, devido a um sistemático desmatamento e introdução de pastagens. Imagens bienais Landsat TM / ETM+ foram classificadas, resultando em uma série temporal de mapas de uso/cobertura do solo. Mudanças na paisagem foram avaliadas usando tabulação cruzada entre os anos, taxas de transição, métricas de paisagem relacionadas a tamanho, densidade, conectividade, configuração e distribuição das clareiras em relação ao seu tamanho, proximidade de estradas e pastagens antigas. Funções de probabilidade de transição foram ajustadas à série temporal a fim de predizer mudanças no uso da terra para os próximos dez anos de acordo com três diferentes cenários: mudança de uso da terra segundo taxas de transição atuais, interrupção no corte raso e seletivo de madeira, e interrupção no corte raso, seletivo e do manejo da vegetação secundária. Os resultados mostraram que as taxas atuais de conversão poderão ser mantidas na região por mais dez anos, mas as mudanças que vêm ocorrendo no uso da 
terra não são sustentáveis e segundo o ritmo atual, nos próximos 15 anos toda a área será desmatada. Os cenários mais sustentáveis para a região incluem a interrupção total do processo de exploração madeireira sem plano de manejo, implementação da Área de Preservação ao longo dos rios e controle da dinâmica do uso da terra em níveis balanceados de transição.

Palavras-chave: Amazônia, Ecologia da Paisagem, Rondônia, Uso da terra, Sensoriamento Remoto, SIG

\section{Summary}

Central Rondônia is one of the most deforested regions in the Brazilian Amazon and presents areas at different stages of degradation creating a gradient from Primary Forest to developed areas. This paper deals with assessment of landscape changes between 1984 and 2002 in a watershed located in the central region of Rondônia State, Brazil, due to a systematic deforestation and pasture introduction since the 1970s. Landsat TM/ETM+ images (one every two years) were classified, resulting in a time series of landuse/land-cover maps. Landscape changes were evaluated using cross tabulation between years, transition rates, landscape metrics related to size, density, connectivity, configuration, and deforested patches distribution related to patch size and spatial proximity to roads and old pastures. Transition probability functions were fitted to time series to predict land-use changes for the next ten years for three different scenarios: continued land use change; ceasing clear cutting and selective logging; and stopping clear cutting, selective logging, and secondary vegetation clearing. Results show that current dynamics can be maintained in the region for ten years, but present-day land use changes are not sustainable and following the current rates, the area will be completely deforested in the next 15 years. A more sustainable scenario for the region includes ceasing the deforestation process, implementing the "Permanent 
Preservation Area" along rivers and controlling the dynamics at balanced levels of transition.

Key-words: Amazon, GIS, Land use, Landscape Ecology, Remote Sensing, Rondônia

\subsection{Introdução}

A Amazônia é uma das mais importantes florestas tropicais do mundo. Entretanto, o desmatamento é uma realidade há cerca de 30 anos e vem ameaçando algumas regiões como Rondônia, Mato Grosso e sul do Pará. A área total desmatada atingiu $652.908 \mathrm{~km}^{2}$ em 2003 (INPE, 2004), ou seja, mais de $13 \%$ da extensão da floresta Amazônica em território brasileiro.

Várias instituições oficiais vêm monitorando 0 processo de desmatamento na Amazônia. As causas e conseqüências para a conservação da floresta têm sido estudadas sob vários aspectos (Alves et al., 1998a; INPE, 2004; Dale et al., 1994; Fearnside, 1996; Laurance et al., 2001; Skole \& Tucker, 1993; Stone et al., 1991; Uhl \& Kauffman, 1990; Walker \& Homma, 1996; Walker et al., 2000). Entretanto, ainda são controversas as opiniões sobre os investimentos na Amazônia, se estes irão aumentar sua destruição com suas obras de infra-estrutura (Laurance et al., 2001) ou protegê-la com o desenvolvimento econômico da região (Carvalho et al., 2001).

O desmatamento geralmente ocorre numa faixa de $100 \mathrm{~km}$ ao longo das rodovias principais, onde áreas desmatadas maiores que 50 ha representam $75 \%$ do desmatamento total (Alves, 2002). Em Rondônia, por exemplo, o desmatamento está claramente ligado à proximidade de rodovias (Alves et al., 1998a) e o processo de colonização já desmatou cerca de $67.884 \mathrm{~km}^{2}$ até 2003 (INPE, 2004), correspondendo a 10\% do total da área desmatada na Amazônia. A principais causas do desmatamento têm sido a agricultura de subsistência por 
pequenos agricultores, grandes fazendas de criação de gado, mineração e atividades madeireiras (Pedlowski et al., 1997).

Até 1996, a área derrubada para pastagem era nove vezes maior que a área para culturas (IBGE, 1998; Cardille \& Foley, 2003; Woods, 2002). Em Rondônia, mudanças no uso da terra para introdução de pastagem e exploração madeireira por fazendeiros e madeireiros têm causado um padrão de paisagem complexo, composto por fragmentos florestais em diferentes estágios e condições. Exploração madeireira, agricultura com a prática de derrubada e queima da vegetação e criação de gado, nesta ordem, são componentes da trajetória do uso da terra na região e podem ser ligados a um processo dinâmico que cria um gradiente de uso da terra, começando na floresta madura até a fronteira de exploração (Dubois, 1990; Serrão et al., 1990). Os fatores determinantes no desmatamento dependem das condições sócio-econômicas, capacidade de trabalho do proprietário, preços de mercado e de valores do colono (Browder, 1996).

$\mathrm{Na}$ Amazônia, o desmatamento vem causando não somente perda florestal, mas também fragmentação do habitat florestal (Skole \& Tucker, 1993). O padrão típico dos projetos de assentamento na Amazônia resulta normalmente no arranjo espacial dos lotes ao longo das margens de rodovias e, freqüentemente, o desmatamento se espalha a partir das estradas.

As conseqüências primárias do desmatamento são a perda de espécies vegetais e animais, invasão de espécies exóticas, aumento do processo erosivo e diminuição da qualidade da água. A extensão e magnitude destes impactos são influenciadas pelo tamanho, conectividade, contexto e heterogeneidade dos fragmentos remanescentes (Collinge, 1996). O arranjo espacial dos fragmentos e a conexão entre eles é o foco principal da estrutura da paisagem, o qual representa características espaciais e não espaciais dos elementos da paisagem (Turner, 1989). Métricas da paisagem são usadas para descrever mudanças na paisagem e podem ser utilizadas como ferramentas para diagnóstico ambiental (Herzog et al., 2001; McGarigal \& Marks, 1995). 
A estrutura da paisagem é determinante em vários estudos relacionados a habitat (Harris, 1984; Theobald et al., 2000), avaliação do impacto humano (Tinker et al., 1998) e simulação de mudanças temporais. Contudo, a estrutura da paisagem em um determinado momento representa somente uma situação estática particular, a qual é parte de um processo contínuo. Devido ao fato das mudanças na paisagem serem componentes de um processo dinâmico, estudos de Ecologia da Paisagem requerem o uso de dados temporais (Dunn et al., 1991). As mudanças temporais incluem variação no número e tamanho dos fragmentos, corredores, barreiras de dispersão e na probabilidade de propagação dos distúrbios (Turner, 1989).

As mudanças temporais na estrutura da paisagem causadas por atividades humanas têm sido avaliadas por diversos autores em diferentes aspectos (Cushman \& Wallin, 2000; Coppedge et al., 2001; Reed et al., 1996; Zheng et al., 1997; Kammerbauer \& Ardon, 1999; Chen et al., 2000; Rao \& Pant, 2001, Roberts et al, 2002; Skanes \& Bunce, 1997, Turner et al., 1996). Métricas da paisagem têm sido úteis na avaliação da dinâmica da paisagem (Sachs et al., 1998; Baskent \& Jordan, 1995) e sua relação com outras variáveis ambientais (Fuller, 2001).

Metodologias baseadas na avaliação da paisagem são essenciais para entender os processo de fragmentação em grandes regiões, especialmente aquelas importantes para a conservação da biodiversidade como a Amazônia (Batistella \& Soares Filho, 1999).

Assim, algumas questões relativas à dinâmica da paisagem na região central de Rondônia guiaram a realização deste estudo como, por exemplo, como é a dinâmica da estrutura da paisagem devido ao processo de desmatamento? Como a estrutura da paisagem se comporta frente à perda sistemática de área florestal?

Ainda em relação aos focos de desmatamento é interessante conhecer a distribuição espacial dos mesmos em relação aos pontos de acesso como 
estradas e áreas já desmatadas; e também verificar se os padrões observados são diferentes em relação ao corte raso e corte seletivo de madeira.

Com relação à dinâmica causada pelas atividades desenvolvidas na região, como é a sustentabilidade destas atividades? $\mathrm{E}$, por quanto tempo as taxas atuais de conversão ainda serão possíveis? Na tentativa de compreender melhor estas questões, neste estudo, avaliou-se a dinâmica da paisagem na região central de Rondônia, em decorrência do desmatamento e introdução de pastagens entre 1984 e 2002. Baseado nestas observações, foram realizadas avaliações sobre a sustentabilidade a médio prazo destas mudanças no uso da terra utilizando-se três cenários futuros.

\subsection{Material e Métodos}

Área de estudo - área de estudo localiza-se na região sudoeste da Amazônia brasileira, entre os municipios de Ariquemes, Cacaulândia e Jarú, na região central do Estado de Rondônia (Figura 4), entre os paralelos $10^{\circ} \mathrm{S} \mathrm{e}$ $10^{\circ} 30^{\prime} \mathrm{S}$ e dos meridianos $62^{\circ} 30^{\prime} \mathrm{W}$ e $63^{\circ} \mathrm{W}$. A área foi escolhida por estar situada em uma das regiões mais desmatadas na Amazônia. Além disto, a região tem sido objeto de estudo de diversas pesquisas relacionadas a desmatamento, fluxo de carbono, qualidade da água e condições sócioeconômicas. Estas condições e a existência de uma coleção de imagens de satélite permitiram o estudo do desmatamento ao longo do tempo. A área é delimitada pela bacia do rio Quatro Cachoeiras, com área aproximada de 950 $\mathrm{km}^{2}$ e o uso da terra é caracterizado principalmente pelo desmatamento e introdução de pastagens para criação de gado para corte e leite. 

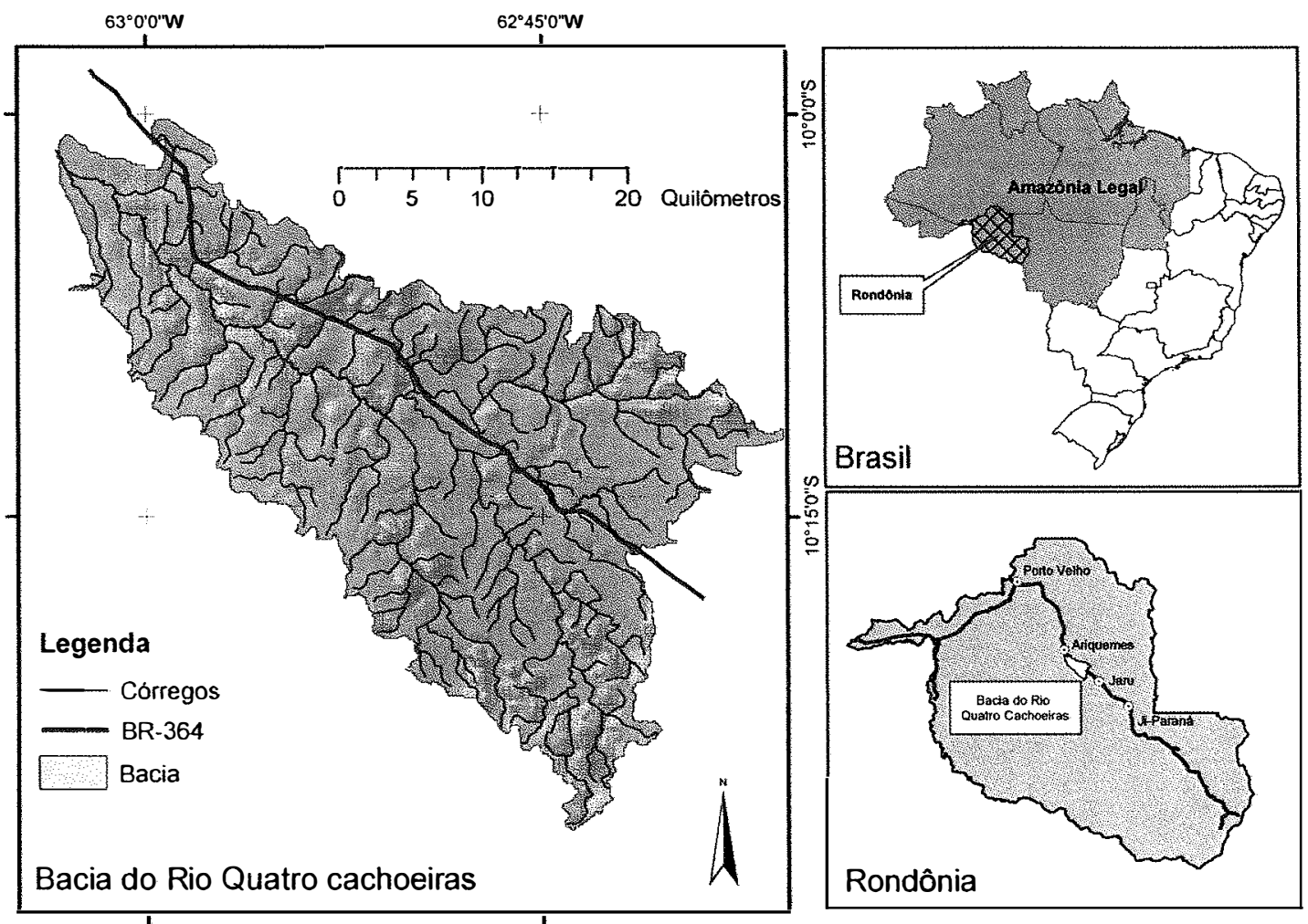

Figura 4 - Localização da bacia do rio Quatro Cachoeiras, em Rondônia

O relevo da região é caracterizado por áreas de embasamento dissecadas em colinas, suavemente onduladas (Brasil, 1978). A área é predominantemente plana, com altitudes variando entre $100 \mathrm{~m}$ a $200 \mathrm{~m}$ acima do nivel do mar (Figura 5), mas apresenta algumas áreas com altitudes até 327 metros, localizadas principalmente na parte sul da bacia. 


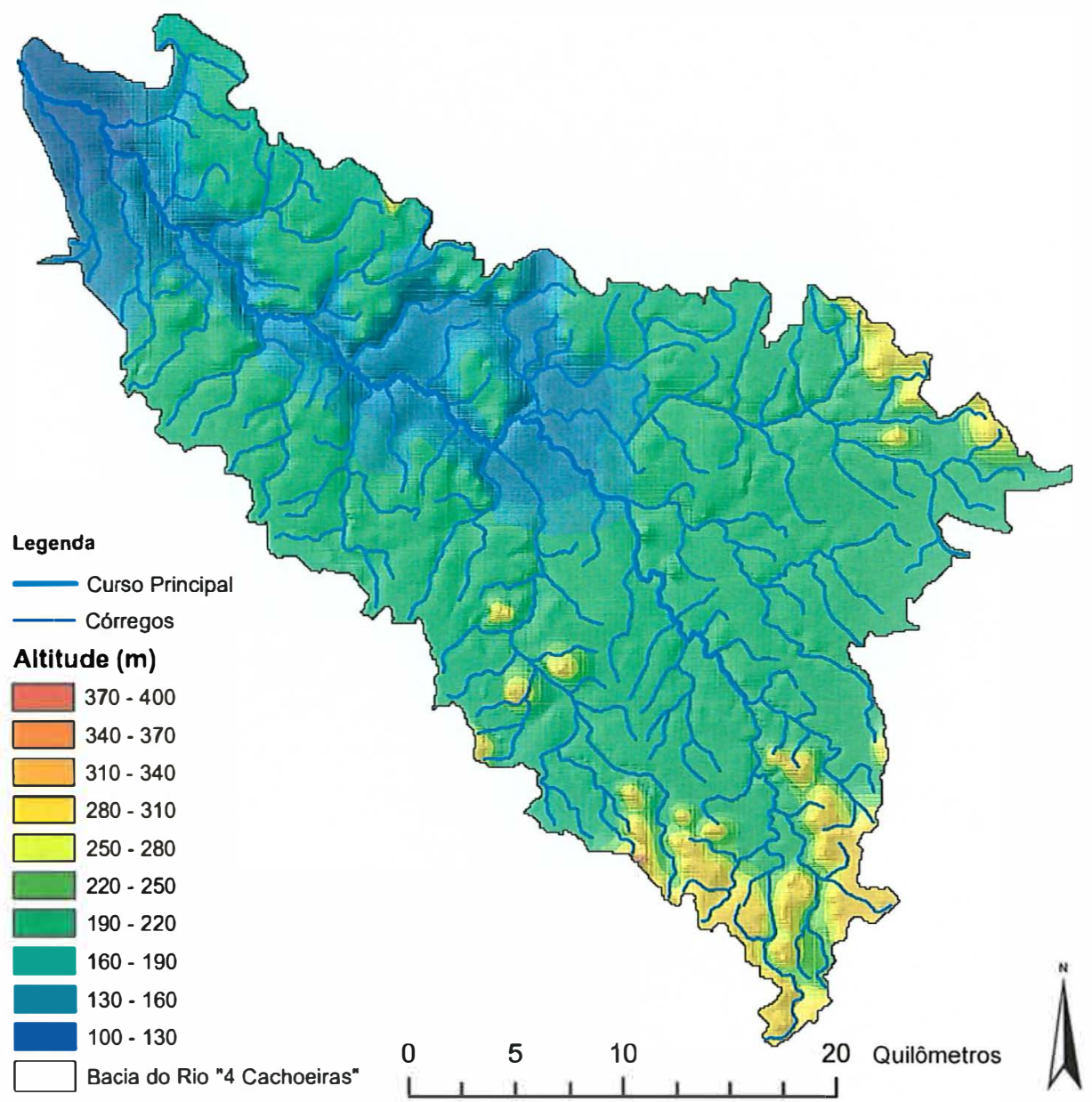

Figura 5 - Modelo Digital do Terreno (MDT) para a bacia do rio Quatro Cachoeiras, Rondônia

$\mathrm{Na}$ Figura 6 pode-se observar o mapa de classes de solos predominantes para a bacia de estudo (Embrapa, 1983), apresentados no sistema de classificação brasileiro (Embrapa, 1999). Observa-se a predominância de Latossolos e Neossolos, ambos distróficos. 


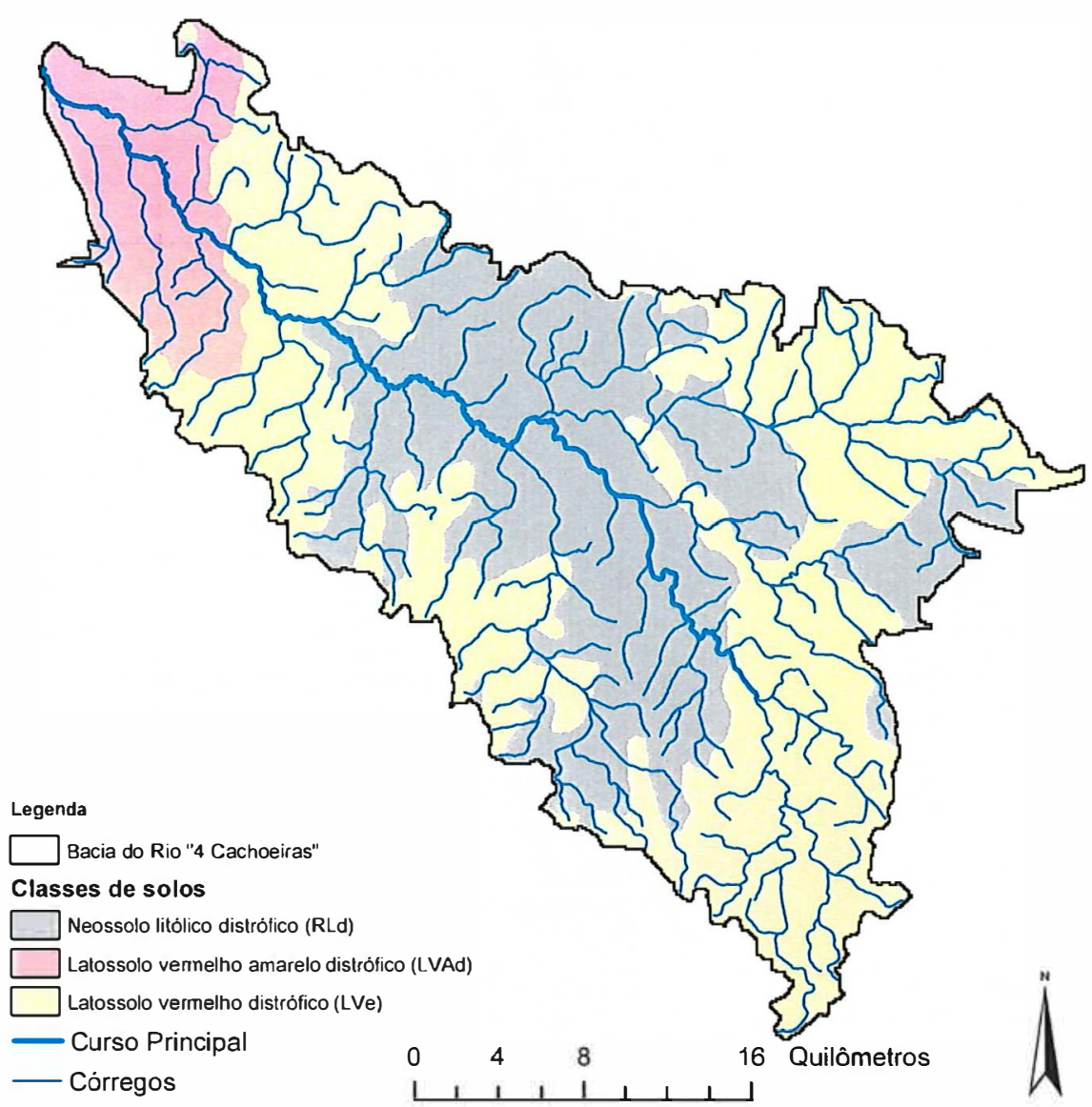

Figura 6 - Mapa de classes de solos predominantes para a bacia do rio Quatro Cachoeiras, Rondônia (Fonte: Embrapa, 1983)

O clima na região é tropical úmido, Awi na classificação de Köppen, com temperatura média anual de $25,6^{\circ} \mathrm{C}$. A precipitação anual é de $2.200 \mathrm{~mm}$, incluindo uma estação seca com duração de quatro a cinco meses, de maio a setembro. (Alencastro Graça et al., 1999). As temperaturas médias anuais máxima e mínima na região variam de $24,4^{\circ} \mathrm{C}$ a $25,6^{\circ} \mathrm{C}$ e $18,8^{\circ} \mathrm{C}$ a $20,3^{\circ} \mathrm{C}$, respectivamente (Moraes et al., 1996b). Na Figura 7 pode-se observar um diagrama de precipitação e temperatura para a região, utilizando-se médias dos últimos 10 anos para precipitação, e dados de temperatura do ano de 2003 coletados na região de Cacaulândia, RO. Nota-se, a concentração das chuvas 
entre outubro e março e um período curto de seca entre maio e julho. A temperatura média mantém-se constante durante o ano na faixa de $25^{\circ} \mathrm{C}$.

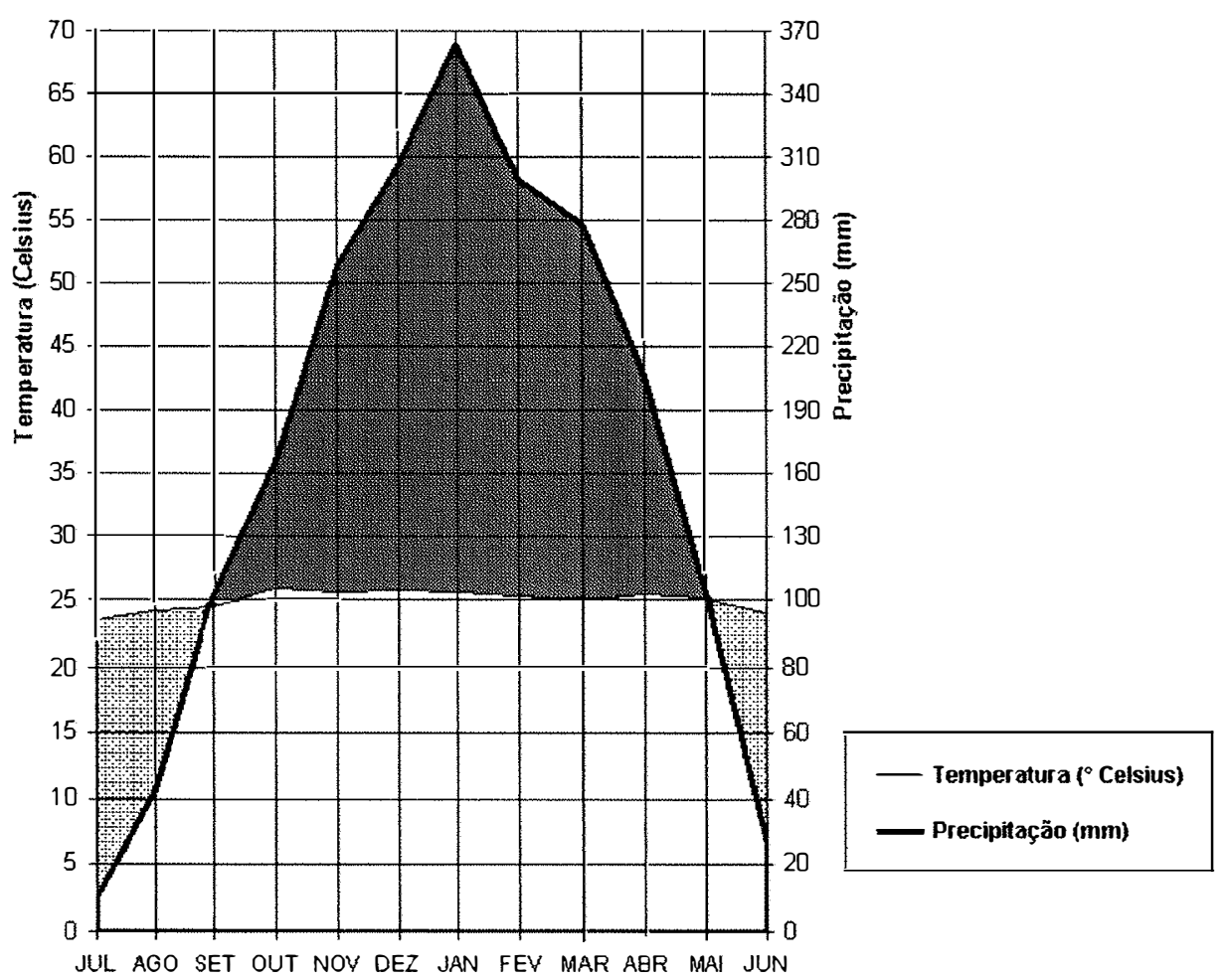

Figura 7 - Clima-diagrama das curvas de precipitação e temperatura médias mensais, para a bacia do rio Quatro Cachoeiras, Rondônia

A vegetação predominante na região é classificada como floresta tropical aberta, com um grande número de palmeiras, destacando-se babaçu (Orbignya martiana), patauá (Oenocarpus bataua) e inajá (Maximiliana regia) como espécies mais comuns. A região apresenta ainda algumas manchas de floresta tropical densa (Brasil, 1978). Nas áreas de pastagem introduzidas, a predominância é das espécies Brachiaria brizantha e Panicum maximum (Moraes et al.,1996a).

Com relação à importância da área de estudo para os recursos hídricos da região, o rio Quatro Cachoeiras é um afluente importante do rio Jamari, formador do rio Madeira (Figura 8). Apesar da baixa incidência de poluentes 
derivados de esgoto doméstico nos rios de Rondônia, devido principalmente à baixa densidade populacional e grande volume de seus rios, o rio Quatro Cachoeiras é uma fonte poluidora importante, pois localiza-se em uma das regiões de maior exploração (desmatamento) do estado, com vários núcleos de assentamentos. Além disso, a extensão da bacia apresenta condições ideais para estudo de impactos de dinâmica do uso da terra nos recursos hídricos.

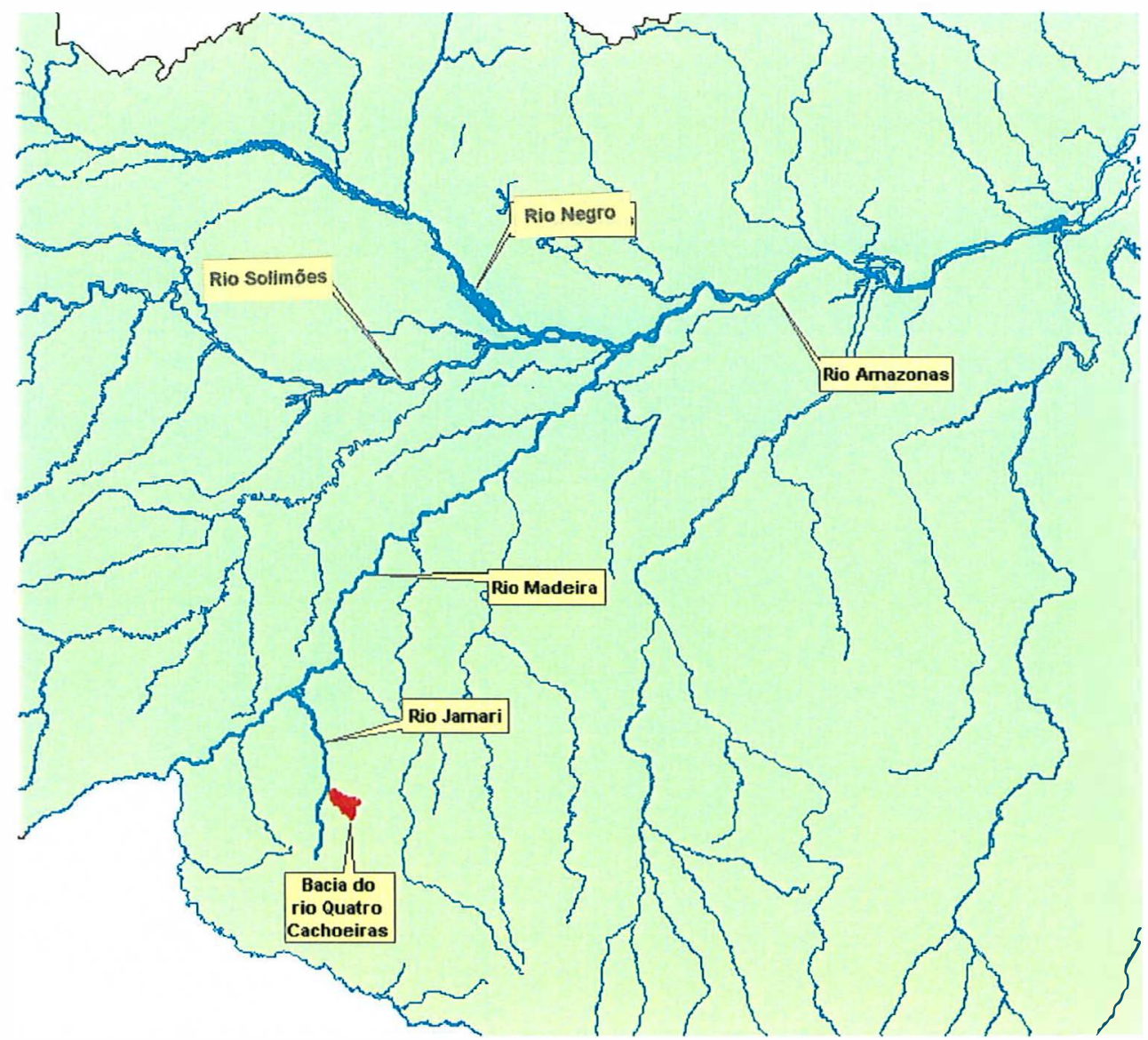

Figura 8 - Localização da bacia do rio Quatro Cachoeiras em relação aos grandes rios da Amazônia

A região vem sendo explorada desde o início dos anos $70 \mathrm{com}$ a introdução de projetos de assentamentos rurais pelo governo brasileiro (Figura 9), sendo que o desmatamento aumentou rapidamente após a construção da rodovia BR-364 entre 1960 e 1970, a qual corta a região de estudo, bem como o Estado de Rondônia (Alves et al., 1998a). 


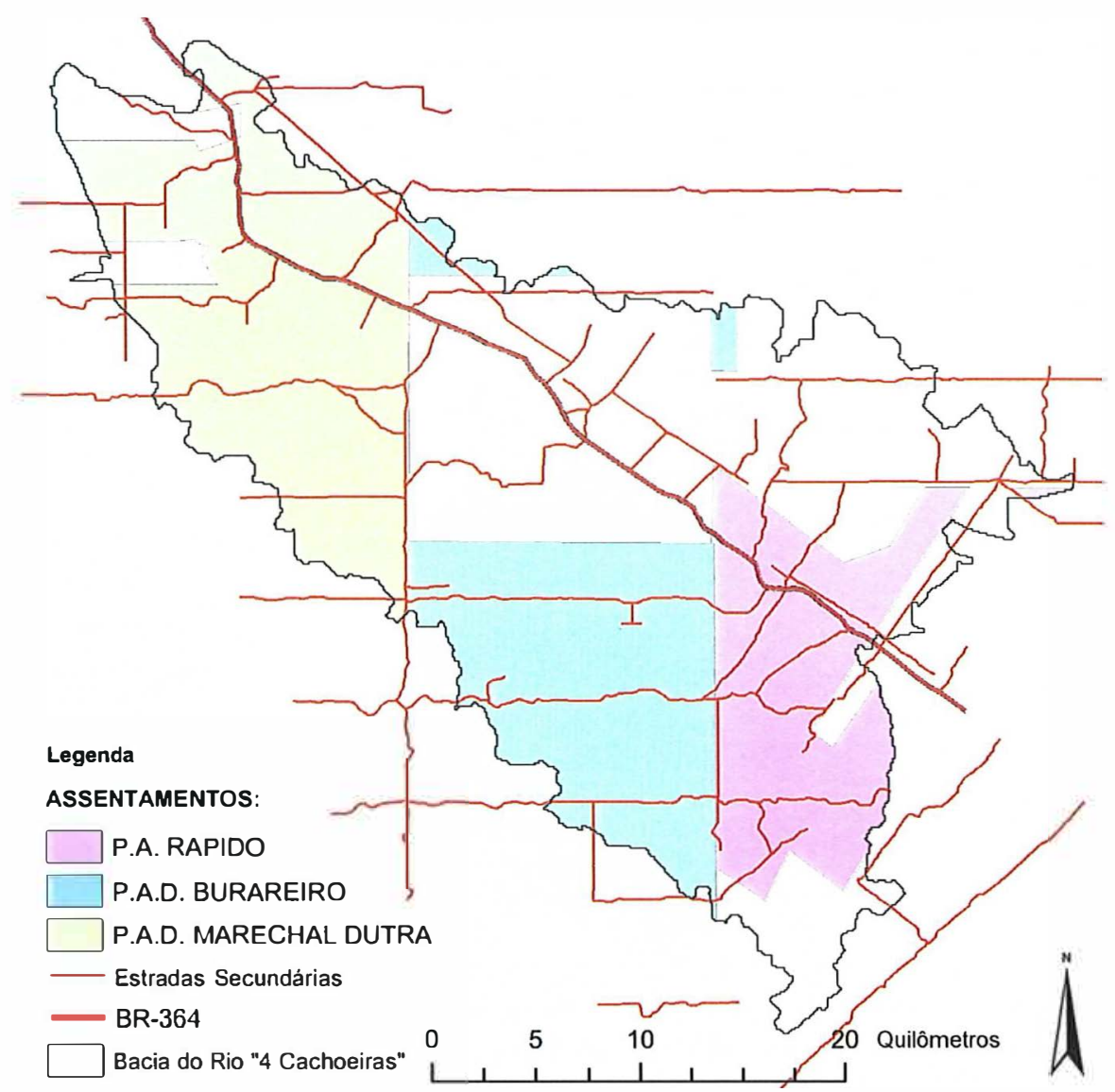

Figura 9 - Localização dos projetos de assentamentos rurais na bacia do rio Quatro Cachoeiras, Rondônia

Entre os anos de 1980 e 1988, um total de $37200 \mathrm{~km}^{2}$ foi desmatado em todo o Estado de Rondônia, principalmente para a exploração madeireira e conversão em pastagens (Stone et al., 1991). O trabalho realizado por Alves et al. (1998a) mostra que na região central de Rondônia, o desmatamento médio dos municípios é de cerca de $35 \%$ de sua área total, sendo que cerca de $80 \%$ do desmatamento ocorre ao longo de uma faixa de $12 \mathrm{~km}$ de cada lado da rodovia BR-364 que corta o estado. Pedlowski et al. (1997) observaram que as principais atividades responsáveis pelo desmatamento no estado são os pequenos agricultores praticando a agricultura de subsistência e produção de leite, as grandes fazendas de criação de gado de corte, a mineração e a exploração madeireira. Entretanto, Cardille \& Foley (2003) observaram que a 
agricultura no Estado é insipiente e o plantio de pastagem foi o principal responsável pelo desmatamento entre 1980 e 1995.

Entre 1973 e 1996, Rondônia ampliou suas estradas de $110 \mathrm{~km}$ para $4.660 \mathrm{~km}$, valores que acompanham as taxas de desmatamento de $230 \mathrm{~km}^{2}$ (em 1980) para $3.390 \mathrm{~km}^{2}$ em 1986 (Stone et al., 1991). Em 1950, a população do estado era de 37.000 habitantes e, após a pavimentação da BR-364 ligando Cuiabá a Porto Velho e o início do processo de migração para os projetos de assentamento (Perz, 2002) houve um expressivo aumento populacional de 100.000 habitantes em 1970 para 1,1 milhão de habitantes em 1990 (Stone et al., 1991). Desde o ano 2000, a população vem se mantendo em torno de 1,4 milhão de habitantes (IBGE, 2003). Na Figura 10, a curva de crescimento da população mostra que a partir de 1990, a população rural começa a declinar, com a concentração nas cidades. A população da área de estudo* nos últimos 13 anos segue a mesma tendência de crescimento da população do estado.

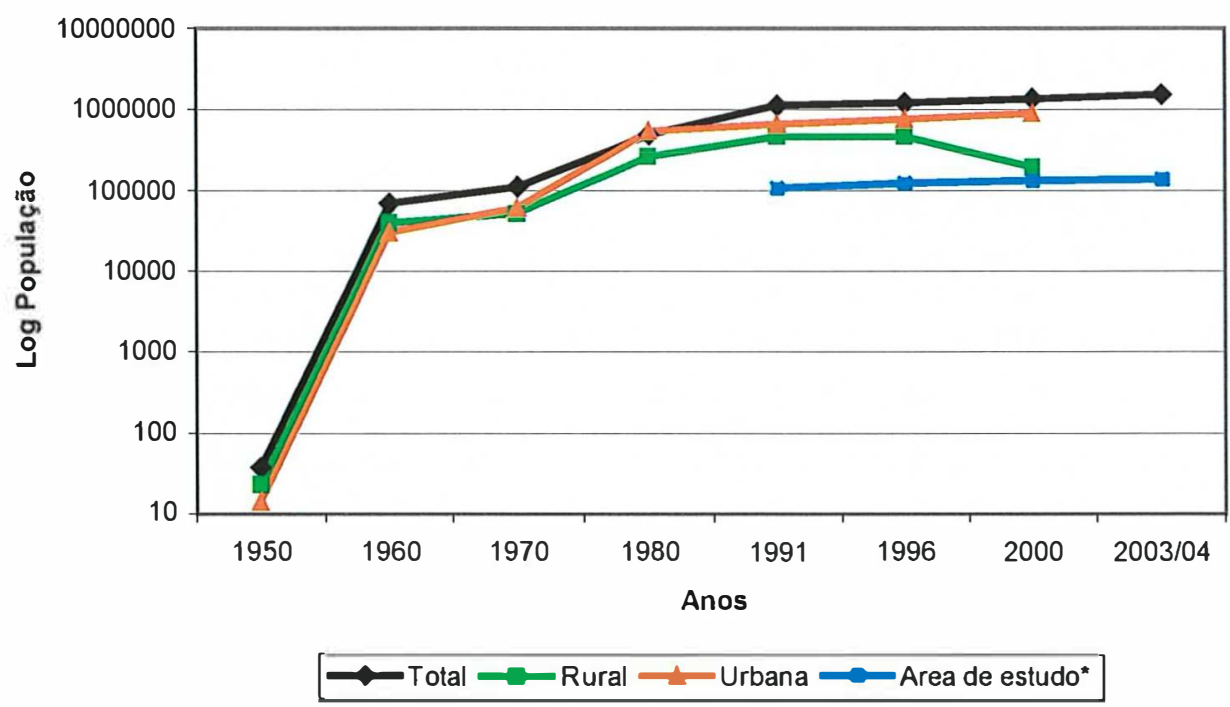

Figura 10 - Evolução histórica da população do Estado de Rondônia e da área de estudo*. Fonte: IBGE (2003)

\footnotetext{
"População considerada nos município de Ariquemes, Jarú e Cacaulândia (Rondônia).
} 
Base de dados - mapas da rede de drenagem, rodovias, e relevo (por meio de Modelo Digital do Terreno) foram derivados de mapas na escala 1:100.000 produzidos pelo Instituto Brasileiro de Geografia e Estatística (IBGE, 1982) obtidos junto ao banco de dados do projeto temático FAPESP ${ }^{1}$ (99/01159-4). Estes mapas foram projetados para UTM, fuso 20 Sul (South America Datum - SAD 69) e manipulados no ArcGIS 8.3 (ESRI, 2002). Os limites da bacia do rio Quatro Cachoeiras foram determinados utilizando-se o software Soil \& Water Assessment Tool - SWAT2000 (Di Luzio et al., 2002) e modelo digital do terreno com resolução de $50 \mathrm{~m}$ (Ballester et al., 2003). A classificação do uso da terra foi realizada com imagens Landsat TM e ETM+ (resolução de $30 \mathrm{~m}$ ), cenas 231/67 e 232/67, obtidas junto ao Instituto Nacional de Pesquisas Espaciais (INPE) - projeto "Dinâmica do Uso da Terra" (Alves, 2003a) e Tropical Rain Forest Information Center (TRFIC/MSU) para os últimos 18 anos (Tabela 1), a cada dois anos, de 1984 a 2002.

Tabela 1. Cenas Landsat TM e ETM+ da área de estudo utilizadas, data de aquisição e respectivas fontes

\begin{tabular}{cccccc}
\hline Anos & $231 / 67$ & $232 / 67$ & Anos & $231 / 67$ & $232 / 67$ \\
\hline 1984 & $08 / 04 / 1984^{\varphi}$ & & 1994 & $07 / 15 / 1994^{\varphi}$ & $06 / 04 / 1994^{\varphi}$ \\
1986 & $08 / 10 / 1986^{*}$ & $08 / 01 / 1986^{\varphi}$ & 1996 & $07 / 20 / 1996^{*}$ & $06 / 25 / 1996^{*}$ \\
1988 & $07 / 30 / 1988^{\Psi}$ & $07 / 21 / 1988^{\varphi}$ & 1998 & $08 / 06 / 1998^{\varphi}$ & $07 / 17 / 1998^{\varphi}$ \\
1990 & $05 / 08 / 1990^{\Psi}$ & $08 / 12 / 1990^{\varphi}$ & 2000 & $07 / 15 / 2000^{\varphi}$ & $07 / 06 / 2000^{\varphi}$ \\
1992 & $07 / 06 / 1992^{\Psi}$ & $06 / 22 / 1992^{*}$ & 2002 & $08 / 14 / 2002^{*}$ & $08 / 05 / 2002^{*}$
\end{tabular}

Fonte: ${ }^{*}$ TRFIC,${ }^{\varphi}$ INPE, ${ }^{\Psi}$ Alves (2003a)

As imagens do ano 2000 foram georreferenciadas utilizando-se pontos de controle facilmente identificáveis obtidos em mapas digitais, como rodovias e rios. As demais imagens foram registradas utilizando as imagens de 2000 como

\footnotetext{
${ }^{1}$ Biogeoquímica de rios da bacia do rio Ji-Paraná. Projeto LBA (http::Iljuruti.cena.usp.br).
} 
referência. Foram utilizadas as bandas 3,4 e 5 para classificação supervisionada (pelo método da máxima verossimilhança), utilizando-se o Erdas Imagine 8.6. Um mosaico final com o mapa do uso da terra foi obtido pela junção das duas imagens classificadas para cada ano. Devido à complexidade de estágios sucessionais presentes em regiões com influência antrópica na Amazônia e a dificuldade na classificação da vegetação secundária que varia de acordo com características edáficas e o histórico de uso da terra (Vieira et al., 2003), optou-se por considerar três classes de uso da terra neste estudo:

- Floresta Madura (FM): As áreas de Floresta Madura (FM), ilustradas na Figura 11 apresentam as seguintes características observadas:

- dossel superior com altura aproximada de $30 \mathrm{~m}$ a $40 \mathrm{~m}$;

- presença de vários estratos arbóreos e arbustivos intermediários;

- ausência de evidências de extração madeira ou perturbações; e,

o sub-bosque aberto.

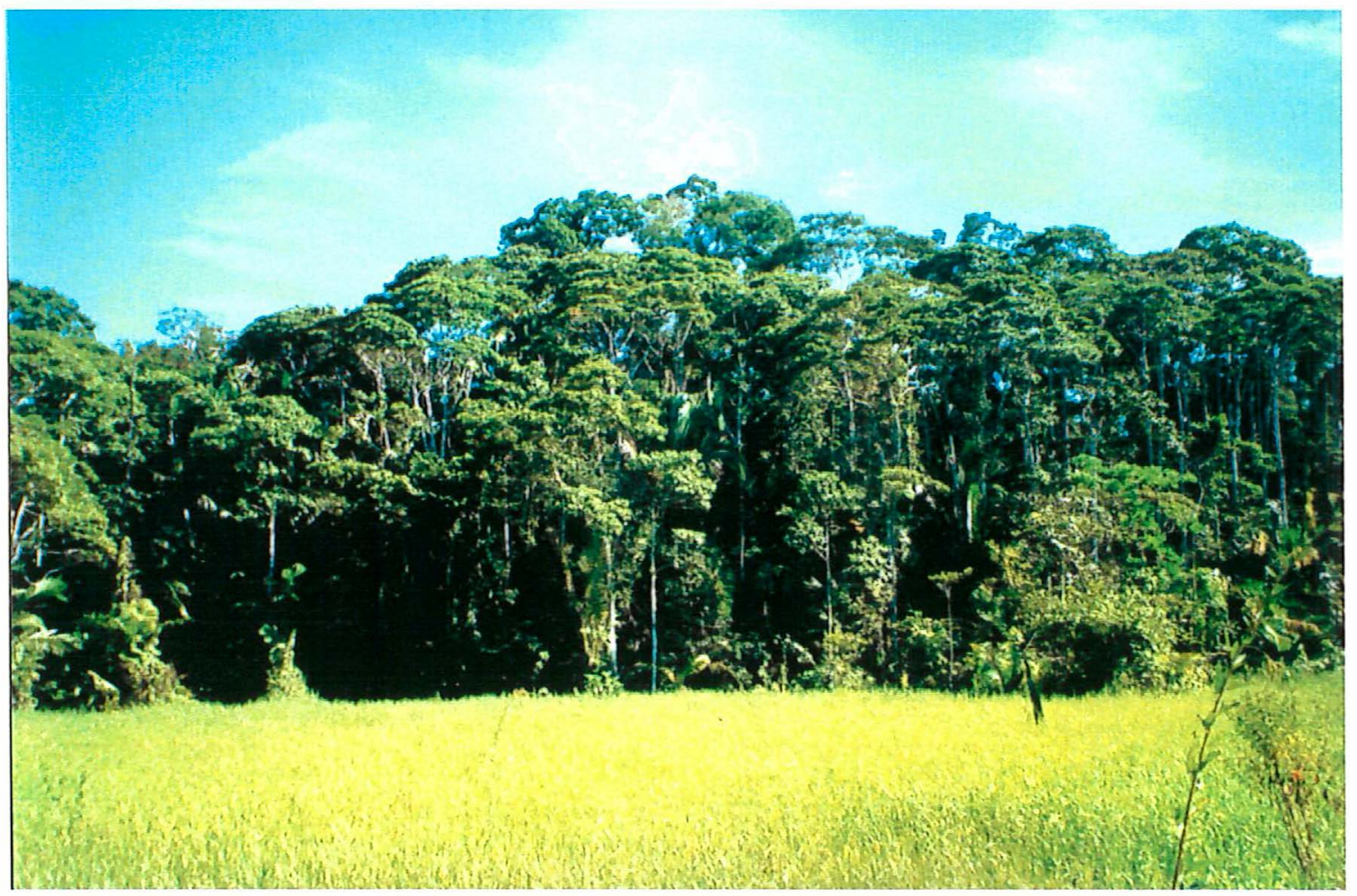

Figura 11 - Exemplo da classe de uso Floresta Madura (FM) 
- Floresta Secundária (FS): As áreas de floresta em regeneração em diversos estágios, ilustradas na Figura 12, apresentam as seguintes características observadas no campo:

- dossel superior com altura aproximada entre $5 \mathrm{~m}$ e $20 \mathrm{~m}$, em alguns casos contendo árvores remanescentes com altura superior;

- presença de vários estratos arbóreos e arbustivos intermediários com sub-bosque fechado; e,

- áreas com desmatamento prévio parcial ou total abandonadas, culturas perenes ou florestas com perturbação de qualquer natureza.

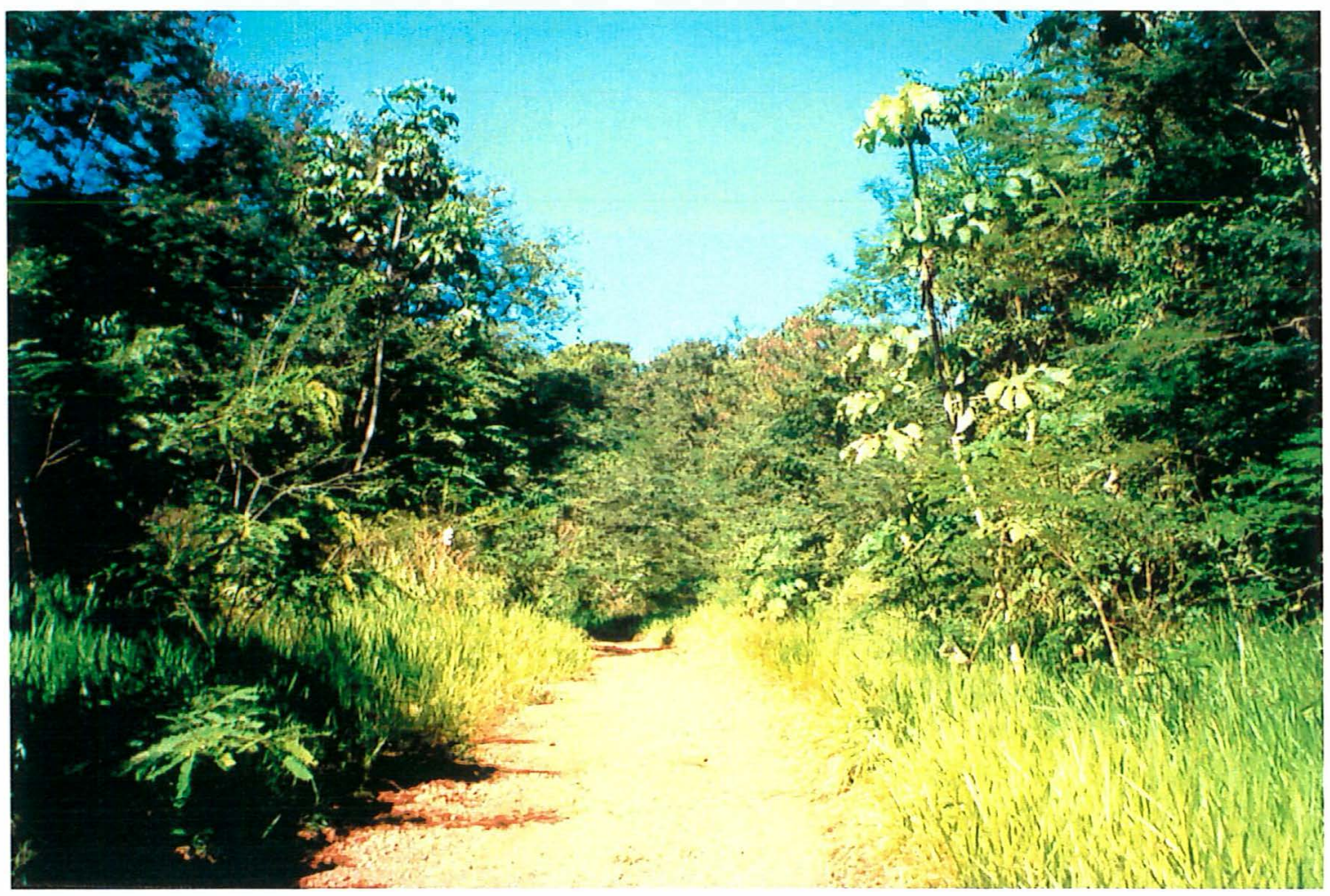

Figura 12 - Exemplo da classe de uso Floresta Secundária (FS) 
- Pastagem (PA): as áreas de pastagem ilustradas na Figura 13, apresentam as seguintes características observadas no campo:

- áreas desmatadas para introdução de pastagens a partir de 1972;

- vegetação predominantemente herbácea, com presença de palmeiras em regeneração em algumas áreas e árvores remanescentes; e,

- duas espécies de pastagens predominantes: Brachiaria brizantha, Panicum maximum.

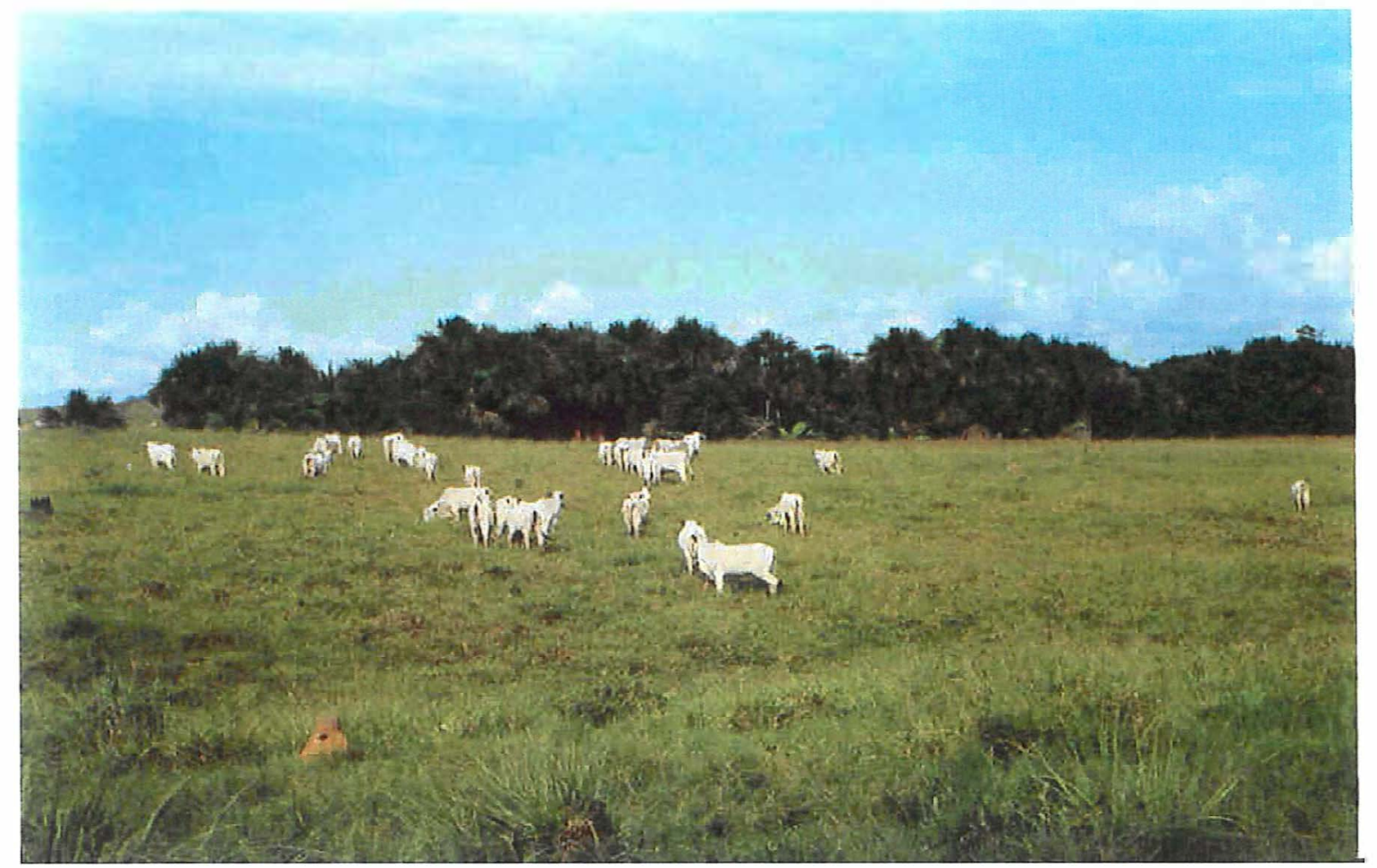

Figura 13 - Exemplo da classe de uso Pastagem (PA)

Uma avaliação da acurácia da classificação foi realizada para o ano de 2002, baseada em 100 pontos de controle para o cálculo da matriz de erros de classificação. Os pontos foram coletados em campo em outubro de 2001 e 
novembro de 2002. Alguns erros de classificação foram eliminados (pósprocessamento) utilizando filtros baseados em regras condicionais para as transições no uso da terra. Por exemplo, transições de Pastagem para Floresta Madura $(\mathrm{PA} \rightarrow \mathrm{FM})$ e de Floresta Secundária para Floresta Madura $(\mathrm{FS} \rightarrow \mathrm{FM}$ ) foram consideradas inconsistentes de ocorrerem em um intervalo de dois anos, sendo que estes pixels foram então corrigidos utilizando-se a classificação prévia (ano inicial). Os pontos classificados e os de verdade terrestres foram comparados para o cálculo do relatório de acurácia no Erdas Imagine 8.6 (Erdas, 1999).

Avaliação da dinâmica do uso da terra - As transições no uso da terra foram computadas utilizando-se o ArcGIS 8.3 (ESRI, 2002). A área total e porcentagem de uso da terra ao longo dos anos, taxas anuais de variação no uso da terra e a matriz de transição entre cada ano estudado foram calculadas a partir dos mapas de uso da terra. Essas métricas forneceram informações sobre dinâmica do uso da terra, permitindo comparações entre as classes de uso e taxas de transição em outras regiões em processo de desmatamento.

A fim de entender melhor o processo de desmatamento, especialmente a localização dos focos de ocorrência, áreas de transição de FM para PA (corte raso) e de FM para FS (corte seletivo) foram analisadas em relação a dois aspectos: distribuição e freqüência de ocorrência de novos focos de desmatamento (clareiras). Esses aspectos são importantes para entender como as atividades de pequenos e grandes fazendeiros estão mudando ao longo do tempo, uma vez que estas estão fortemente relacionadas ao tamanho da área desmatada. Na tentativa de entender a influência da localização na ocorrência dos focos de desmatamento (clareiras), foram analisadas freqüências das transições $\mathrm{FM}$ para $\mathrm{PA}$ e FM para FS em relação à distância de estradas e à distância de pastagens antigas (estabelecidas anteriormente a 1984). Nessa análise, estradas e áreas de pastagem de 1984 foram utilizadas como 
condições iniciais, permitindo-se entender a influência acumulada das mesmas no processo de desmatamento.

Dinâmica da estrutura da paisagem - baseando-se em mapas de uso da terra, foram calculadas métricas da paisagem para cada classe de uso da terra e ano estudado, resultando em uma série temporal de índices. Cinco índices foram selecionados (Tabela 2) a partir de um estudo inicial que testou mais de 20 indices (Ferraz et al., 2002) e outros estudos de dinâmica do uso da terra (Coppedge et al., 2001; Sachs et al., 1998; Tinker et al., 1998; Cushman \& Wallin, 2000; Reed et al., 1996; Ritters et al., 1995). De acordo com o observado por diversos autores, alguns índices são altamente correlacionados, mas neste estudo os índices foram escolhidos para abranger os principais aspectos da estrutura da paisagem como composição, tamanho e conectividade. A utilização das métricas para avaliação do processo de fragmentação teve também como objetivo obter respostas para algumas questões como: como é a dinâmica da fragmentação e quais as tendências futuras da estrutura da paisagem? Em que momento houve a transição da matriz floresta para pastagem? Considerando-se o processo de fragmentação, qual proporção de Floresta Madura representa um limiar crítico para a estrutura da paisagem (Green, 1994)? Quais os efeitos na estrutura da paisagem com a implantação das Áreas de Preservação Permanente (APP) de acordo com o Código Florestal (Brasil, 1965)?

Outro aspecto importante foi a escolha de índices normalmente utilizados em outros estudos de paisagem, o que permite a comparação de resultados. Esses indices fornecem um diagnóstico da estrutura da paisagem para um determinado momento, o qual será útil para comparação entre anos e também para comparação com outros estudos. Os índices foram calculados para a escala de classe com o Fragstats 3.3 (McGarigal et al., 2002), utilizando-se a bacia do rio Quatro Cachoeiras como máscara e regra de vizinhança para as oito células vizinhas na análise de paisagem. 
Tabela 2. Índices selecionados para a análise de estrutura da paisagem

\begin{tabular}{|c|c|c|}
\hline ÍNDICE & Descrição & Unidade \\
\hline PLAND & $\begin{array}{l}\text { Porcentagem do uso da terra-porcentagem de cada } \\
\text { uso da terra presente na bacia, o qual representa } \\
\text { composição da paisagem. }\end{array}$ & $\%$ \\
\hline PD & $\begin{array}{l}\text { Densidade de fragmentos - densidade de fragmentos } \\
\text { em cada classe de uso, representando um aspecto da } \\
\text { fragmentação: número de fragmentos por área. }\end{array}$ & $\begin{array}{l}\text { N / } 100 \\
\text { ha }\end{array}$ \\
\hline LPI & $\begin{array}{l}\text { Índice do maior fragmento - porcentagem da paisagem } \\
\text { ocupada pelo maior fragmento em cada classe de uso } \\
\text { da terra, representando outro aspecto da } \\
\text { fragmentação: dominância na paisagem. }\end{array}$ & $\%$ \\
\hline ENN_MN & $\begin{array}{l}\text { Distância média do vizinho mais próximo - distância } \\
\text { média entre fragmentos, representando conectividade. }\end{array}$ & $\mathrm{m}$ \\
\hline$|J|$ & $\begin{array}{l}\text { Índice de justaposição - uma medida da adjacência } \\
\text { entre as classes de uso, representando a configuração } \\
\text { da paisagem. }\end{array}$ & $\%$ \\
\hline
\end{tabular}

Simulação de uso da terra - visando entender as possiveis mudanças na paisagem nos próximos dez anos, probabilidades de transição de uso da terra baseadas na Cadeia de Markov, foram calculadas para cada transição possivel (Bell, 1974; Muller \& Middetlon, 1994, Acevedo \& Urban, 1995). Este método permite o cálculo das áreas de cada classe de uso para um ano futuro, baseado na área presente e na probabilidade de transição observada nas mudanças de uso da terra ocorridas no passado. Todas possiveis transições foram consideradas, exceto a transição PA para FM, a qual foi considerada improvável de ocorrer num período de dois anos. As probabilidades de transição foram calculadas utilizando-se a equação (1):

$$
x_{t+1}=x_{t} P
$$

onde: $x_{t}=$ vetor com as proporções de cada uso da terra no ano $t$; $P=$ matriz de transição com probabilidades; $\mathrm{e}$, $x_{t+1}=$ vetor com as predições de uso da terra para o ano $t+1$. 
Utilizando as probabilidades de transição entre os anos 1984-1986, 1986-1988, 1988-1990, 1990-1992, 1992-1994, 1994-1996, 1996-1998, 1998-2000, 2000-2002, modelos lineares foram ajustados a estas probabilidades a fim de se calcular novas probabilidades para os próximos dez anos segundo a tendência observada nos anos passados. Baseando-se nas probabilidades calculadas e efetuando operações entre as mesmas, três cenários futuros foram calculados (Kinnaird et al., 2003). Os modelos lineares foram ajustados utilizando-se regressão linear $^{2}$ entre as probabilidades de transição e intervalo de tempo, onde a primeira transição (1984-1986) foi considerada como primeiro intervalo e a última (2000-2002) intervalo nove.

Os três cenários foram criados com o objetivo de refletir três possibilidades futuras para a região, de acordo com o nivel de práticas conservacionistas aplicadas, que também refletem a expectativa quanto à redução do desmatamento e desenvolvimento de atividades mais sustentáveis. De acordo com esta expectativa, os cenários podem então ser classificados como: típico (I), intermediário (II) e otimista (III).

O cenário $I$ foi totalmente baseado nas probabilidades de transições ajustadas e reflete a premissa que a tendência atual de dinâmica da paisagem continuará no futuro. Portanto, o cenário é mais realista. Ou seja, segundo este cenário não haverá ações de controle do desmatamento, nem da exploração madeireira; e as taxas atuais de dinâmica do uso da terra irão se propagar para os anos seguintes. O cenário II exclui o processo de corte raso (sem transições para pastagem como $\mathrm{FM} \rightarrow \mathrm{PA}$ e $\mathrm{FS} \rightarrow \mathrm{PA}$ ), mas mantém as transições relativas a exploração seletiva. Neste cenário, haveria uma interrupção na expansão das áreas de pastagem; sendo assim, não haveria mais corte raso na região. Este cenário é também plausivel, já que as maiores reservas de floresta encontramse em grandes propriedades atualmente na região, as quais já exploraram as

2 a ajuste linear foi utilizado, considerando-se um intervalo restrito de probabilidade para facilitar o cálculo, já que o modelo linear não deve ser aplicado em funções de probabilidade. 
madeiras de valor comercial em suas florestas e estão mais suscetiveis à ação fiscalizadora do governo.

O cenário III é o mais conservativo, mantendo toda a floresta madura (FM) e excluindo as transições de desmatamento $F M \rightarrow F S, F M \rightarrow P A$ e $F S \rightarrow P A$. Neste cenário, também são excluídas as atividades de corte seletivo e toda a Floresta Secundária seria abandonada para regeneração. Esta alternativa representaria uma situação hipotética em que seriam realizadas todas as ações possíveis para recuperação dos remanescentes florestais. O objetivo deste cenário é estabelecer um limite real máximo de recuperação, que poderia ser atingido por meio de ações conservacionistas. Na construção dos modelos, quando houve eliminação de uma transição, a função de probabilidade foi somada àquela correspondente a manutenção da condição inicial. Por exemplo, na eliminação da probabilidade de transição $F M \rightarrow P A$, a probabilidade de ocorrência dessa transição foi somada à probabilidade da transição $F M \rightarrow F M$.

Utilizando os modelos de probabilidade, novas áreas de uso da terra foram calculadas para os próximos dez anos, considerando os três cenários futuros. Um diferente cenário chamado (APP) foi também calculado, baseado no uso da terra para o ano de 2002 e simulando alterações na paisagem pela implantação da Área de Preservação Permanente (APP) segunda a legislação vigente (Brasil, 1965), a qual determina que a uma faixa de 30 metros em torno de rios de pequeno porte (com menos de $30 \mathrm{~m}$ de largura) seja mantida com vegetação natural. Para o cenário APP, mudanças na estrutura da paisagem foram analisadas com as mesmas métricas da paisagem descritas acima, mas para os cenários futuros I, II e III, mudanças na estrutura da paisagem não foram avaliadas devido à falta de informação sobre a localização espacial das mudanças previstas, o que afeta consideravelmente a estrutura da paisagem. 


\subsection{Resultados}

Dinâmica do uso da terra - a classificação das imagens obteve Índice Geral Kappa de 0,85 para o ano de 2002. A seguir (Tabela 3), é apresentada a matriz de erros obtida para a classificação da imagem do ano de 2002. Os maiores erros foram na classificação da Floresta Secundária como comissão $(0,13)$ e omissão $(0,20)$.

Tabela 3. Matriz de erros de classificação para o mapa do ano de 2002

\begin{tabular}{|c|c|c|c|c|c|c|}
\hline & & \multicolumn{4}{|c|}{ Verdade terrestre } & \multirow[b]{2}{*}{$\begin{array}{l}\text { Erro de } \\
\text { Comissão }\end{array}$} \\
\hline & & FM & FS & PA & Total & \\
\hline \multirow{5}{*}{ 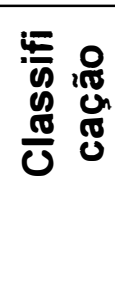 } & FM & 14 & 1 & 0 & 15 & 0,0667 \\
\hline & FS & 1 & 19 & 2 & 22 & 0.1364 \\
\hline & PA & 0 & 4 & 59 & 63 & 0,0635 \\
\hline & Total & 15 & 24 & 61 & 100 & \\
\hline & $\begin{array}{l}\text { Erro de } \\
\text { Omissão }\end{array}$ & 0,0667 & 0,2083 & 0,0328 & & 0,0800 \\
\hline
\end{tabular}

Ao todo foram gerados dez mapas de uso da terra, de 1984 a 2002 (Figuras 14 a 23). O desmatamento na área de estudo segue o padrão observado na maioria das regiões do Estado de Rondônia. Este padrão é caracterizado pela exploração a partir das margens das estradas, construindo faixas de floresta remanescente entre estradas (Alves et al., 2003b; Roberts et al., 2002). Observando-se os mapas de uso da terra para o período, pode-se notar que a região segue o padrão descrito acima, exceto na parte central da bacia do Quatro Cachoeiras, onde houve um grande corte raso por volta de 1990 para introdução de pastagens em uma grande propriedade (Figura 17). 


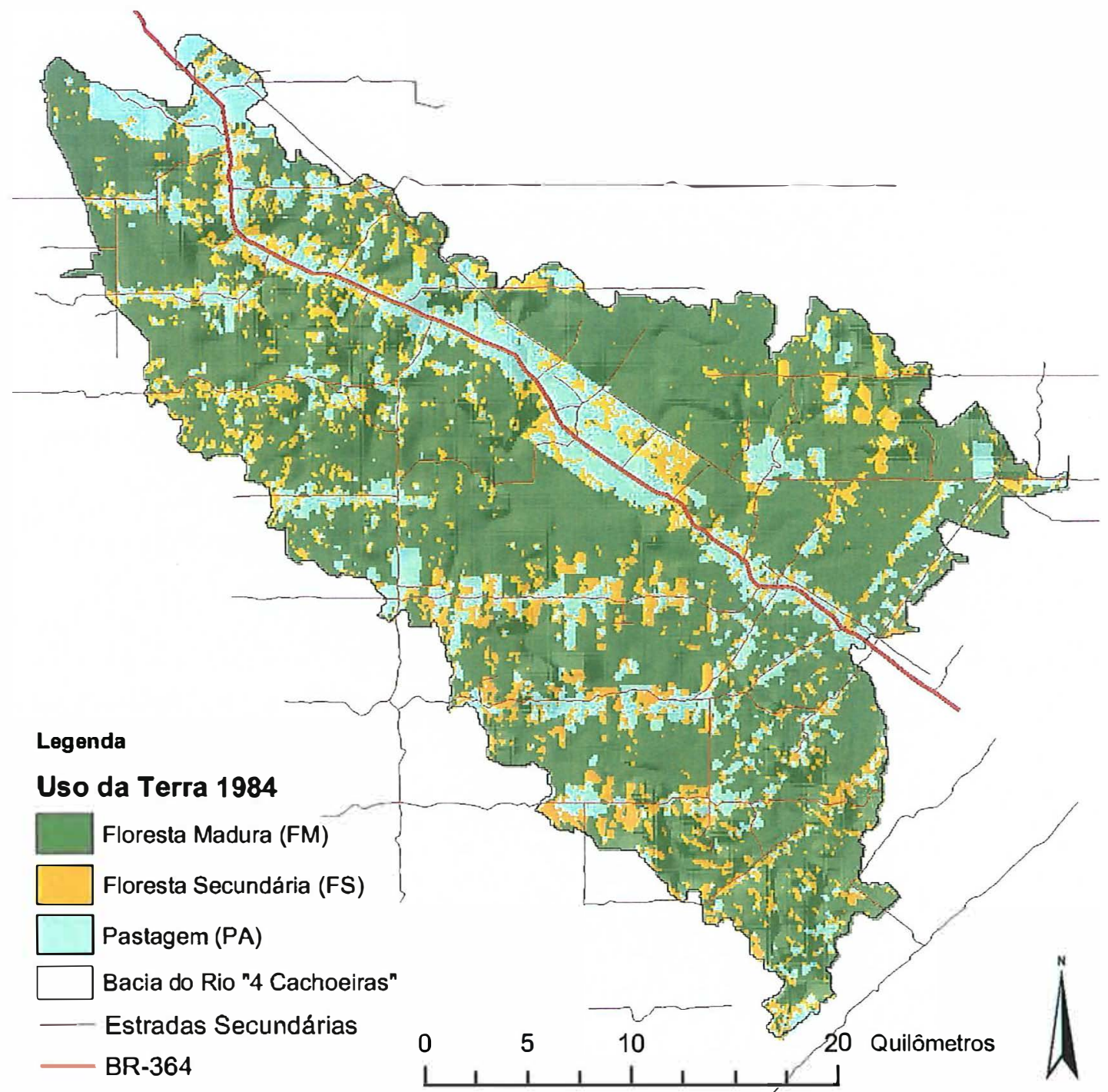

Figura 14 - Mapa de uso da terra da bacia do rio Quatro Cachoeiras em Rondônia, produzido para o ano de 1984 


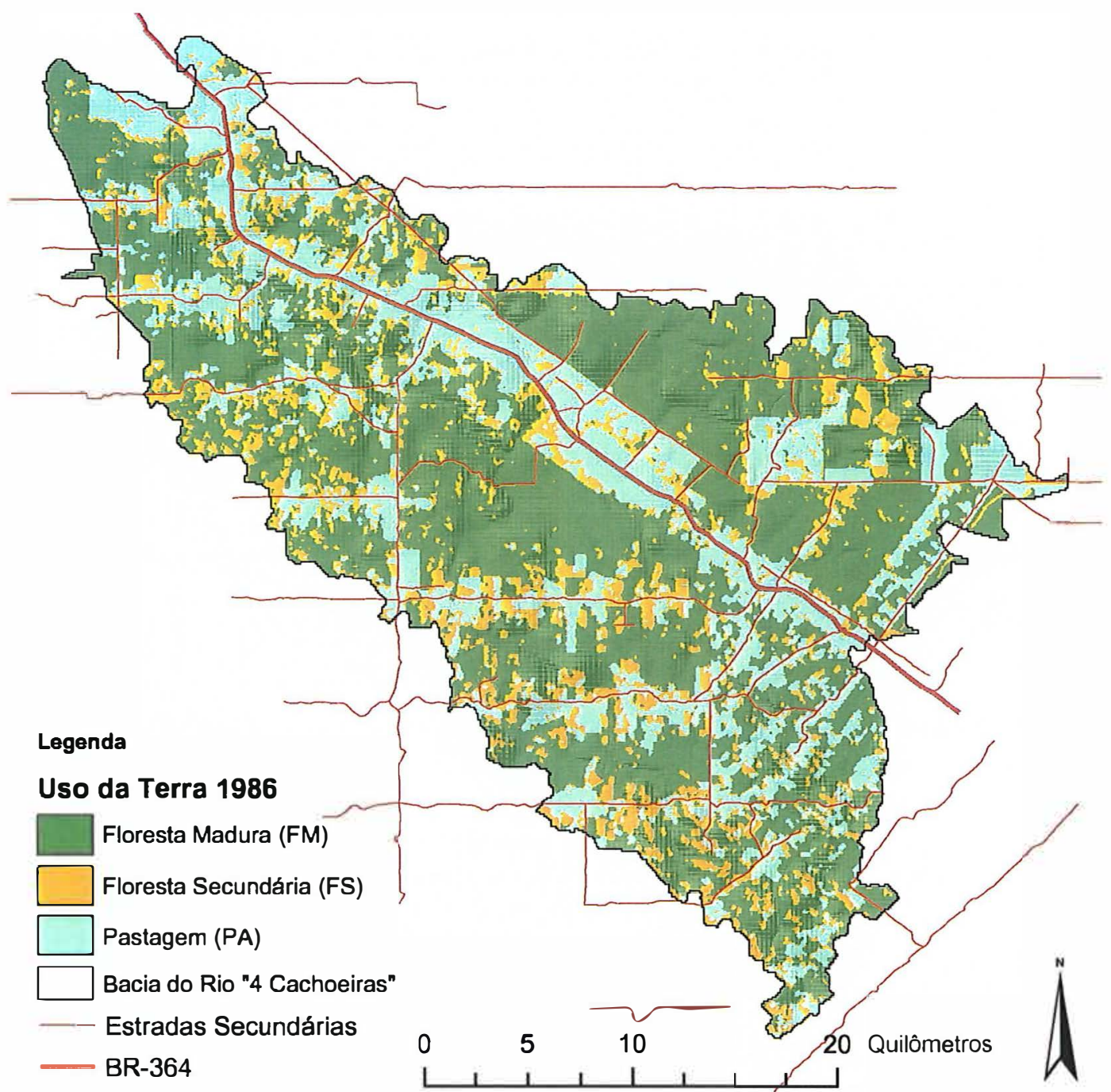

Figura 15 - Mapa de uso da terra da bacia do rio Quatro Cachoeiras em Rondônia, produzido para o ano de 1986 


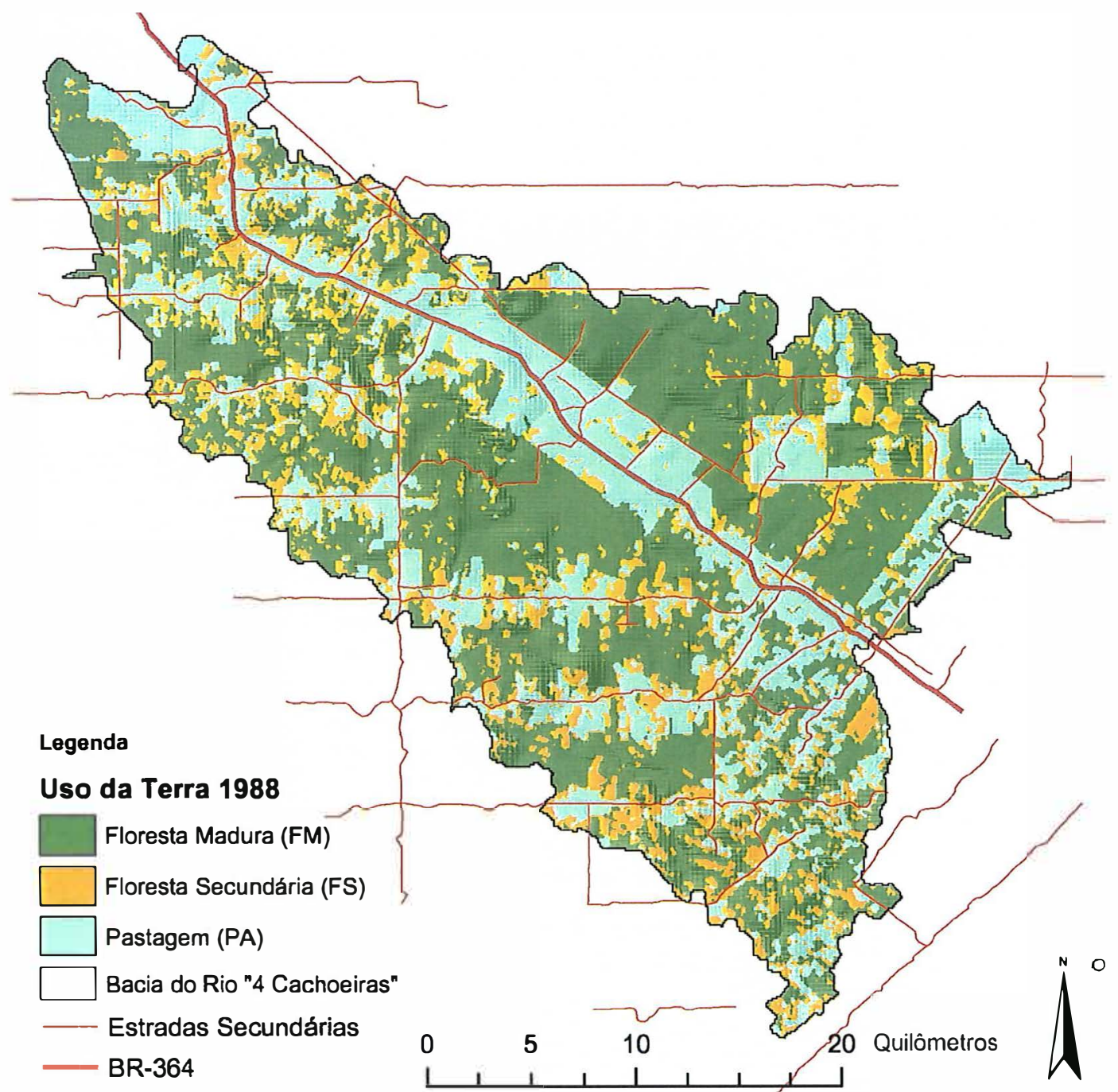

Figura 16 - Mapa de uso da terra da bacia do rio Quatro Cachoeiras em Rondônia, produzido para o ano de 1988 


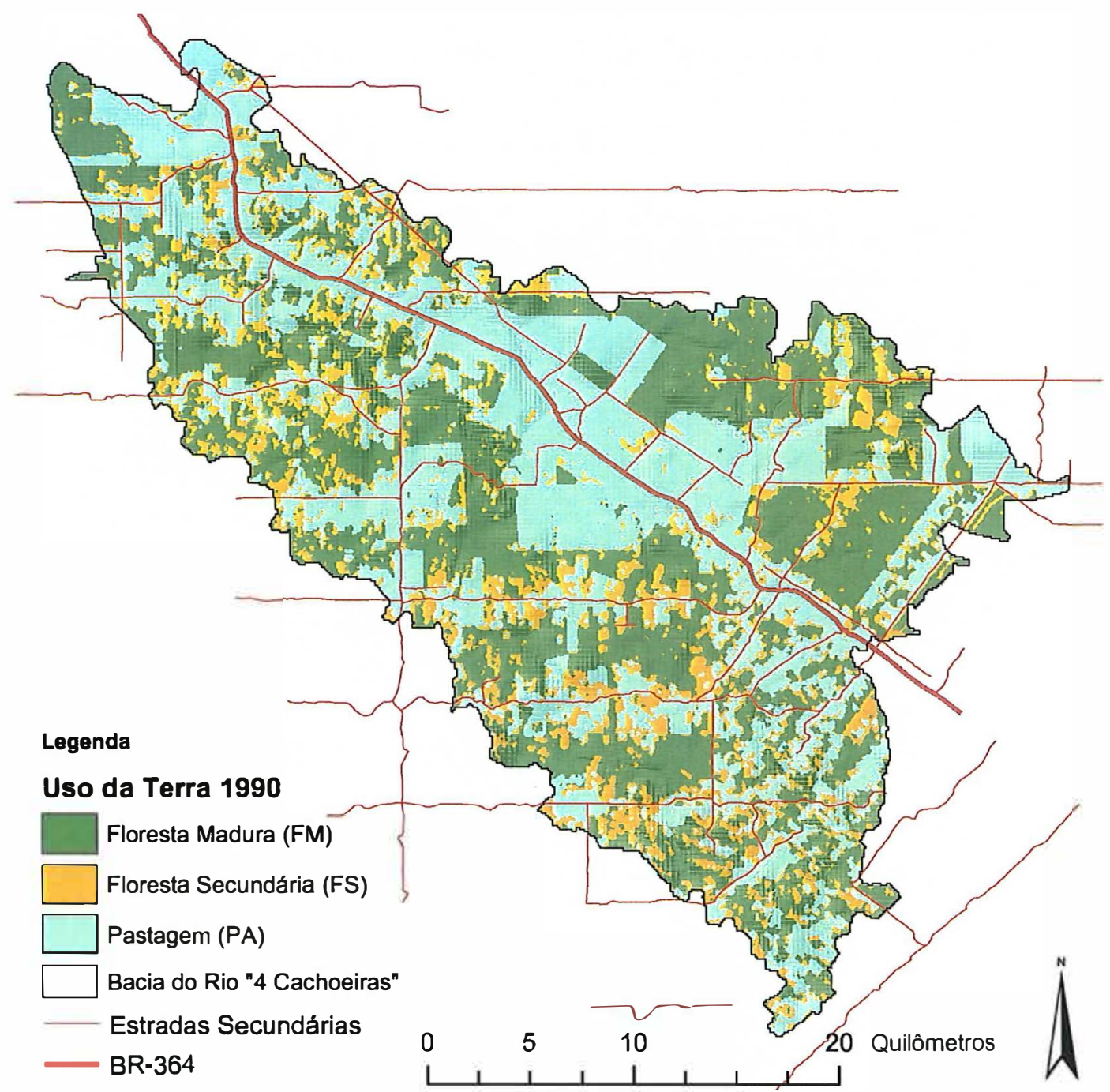

Figura 17 - Mapa de uso da terra da bacia do rio Quatro Cachoeiras em Rondônia, produzido para o ano de 1990 


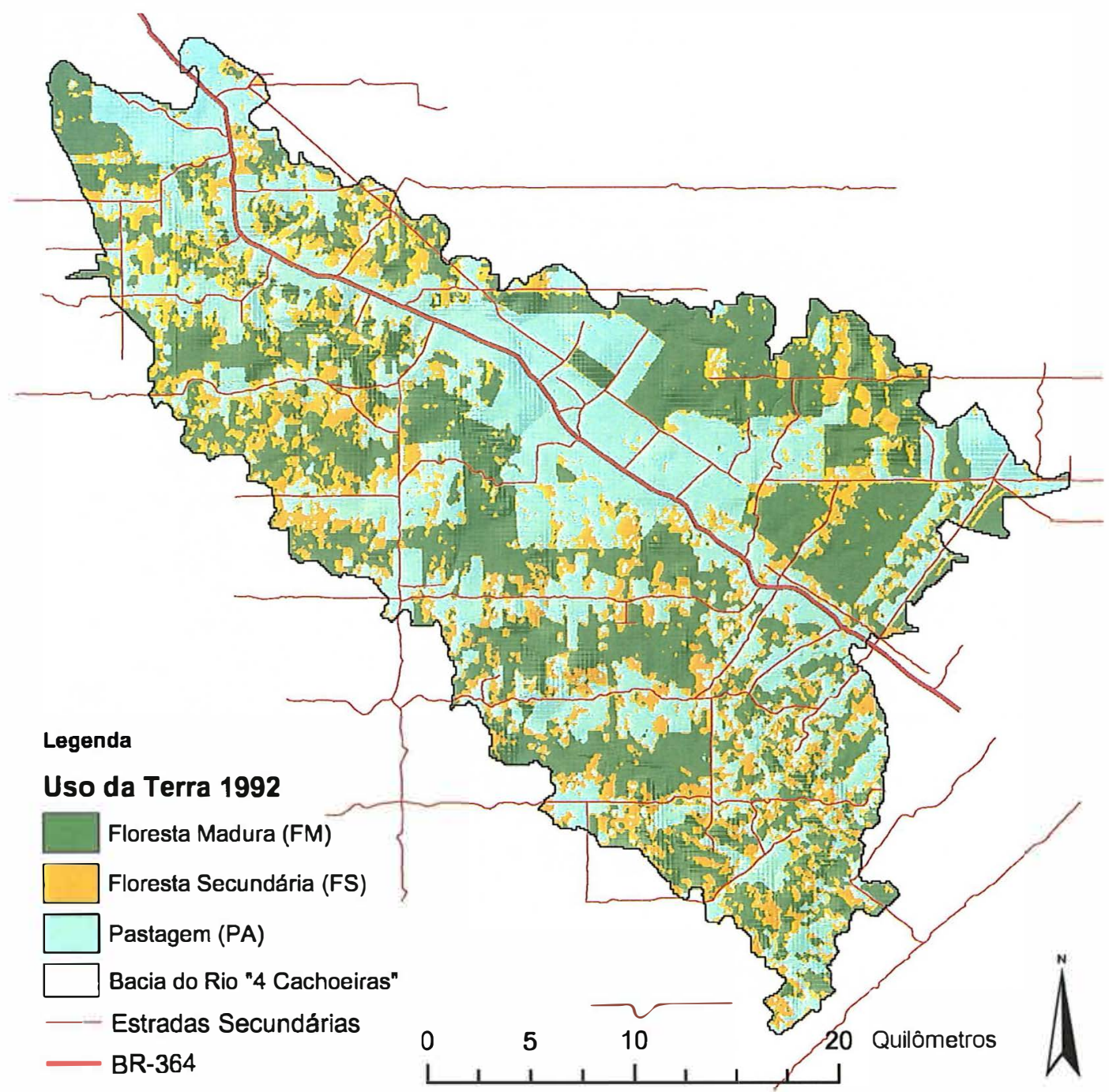

Figura 18 - Mapa de uso da terra da bacia do rio Quatro Cachoeiras em Rondônia, produzido para o ano de 1992 


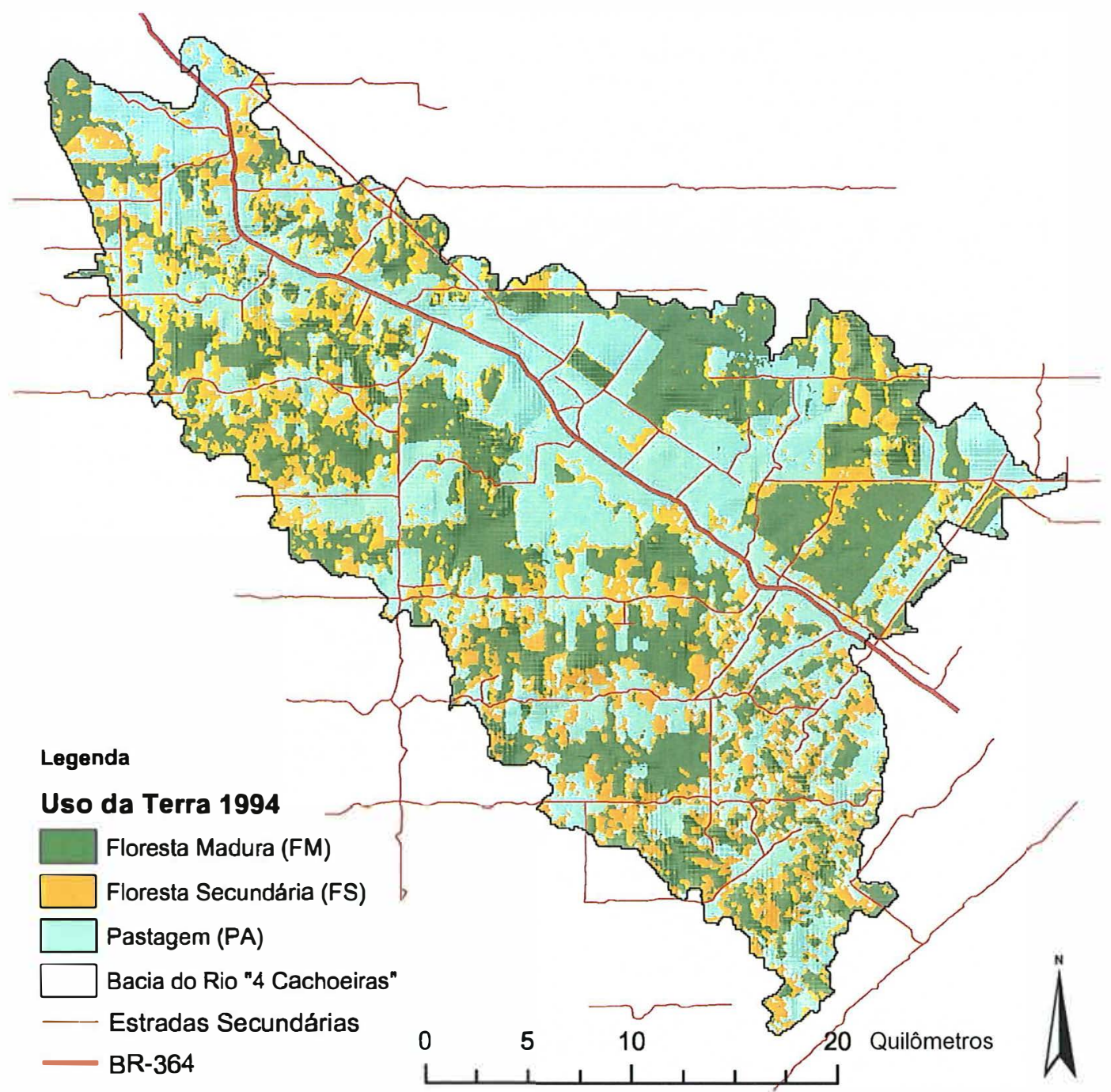

Figura 19 - Mapa de uso da terra da bacia do rio Quatro Cachoeiras em Rondônia, produzido para o ano de 1994 


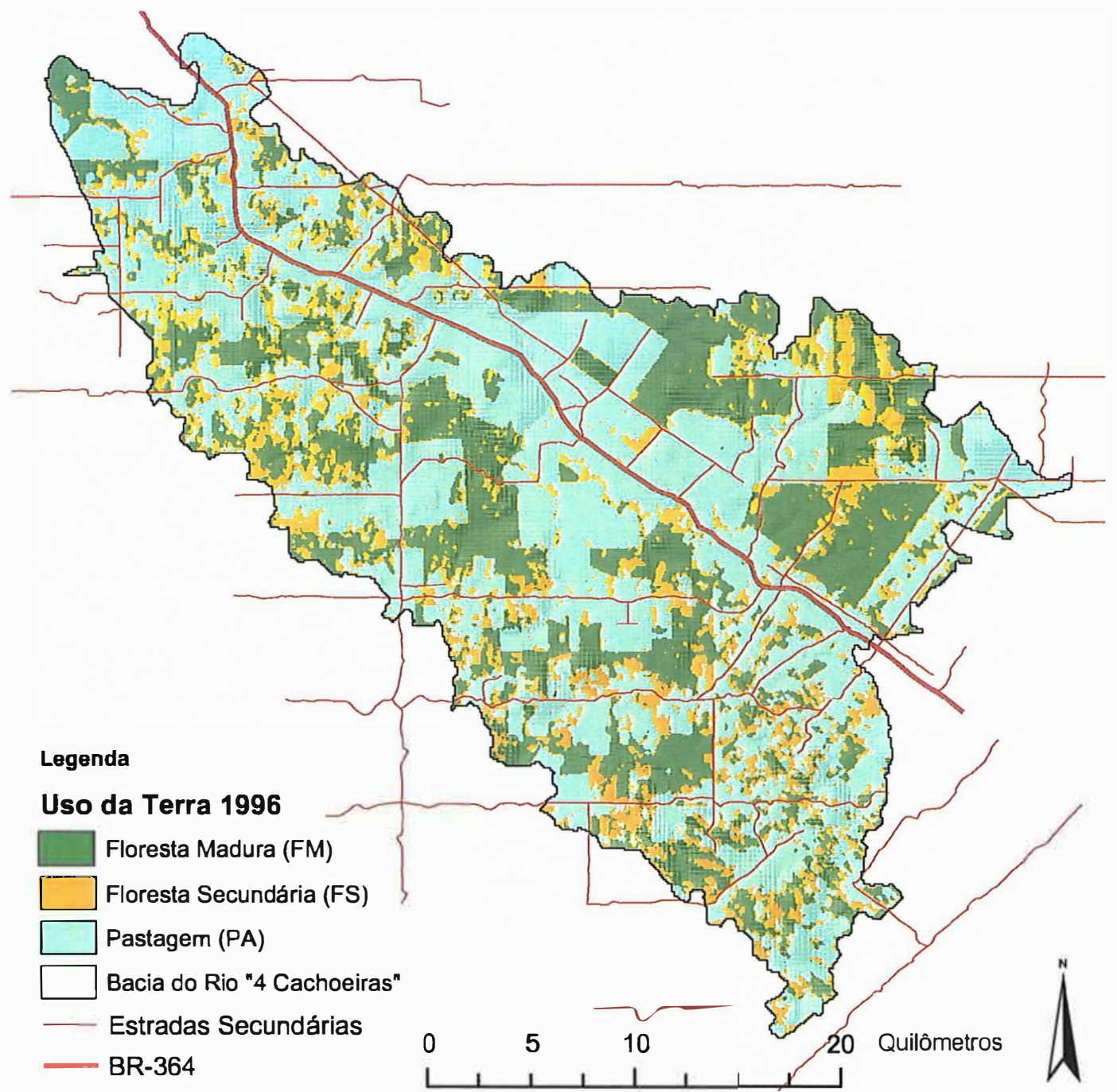

Figura 20 - Mapa de uso da terra da bacia do rio Quatro Cachoeiras em Rondônia, produzido para o ano de 1996 


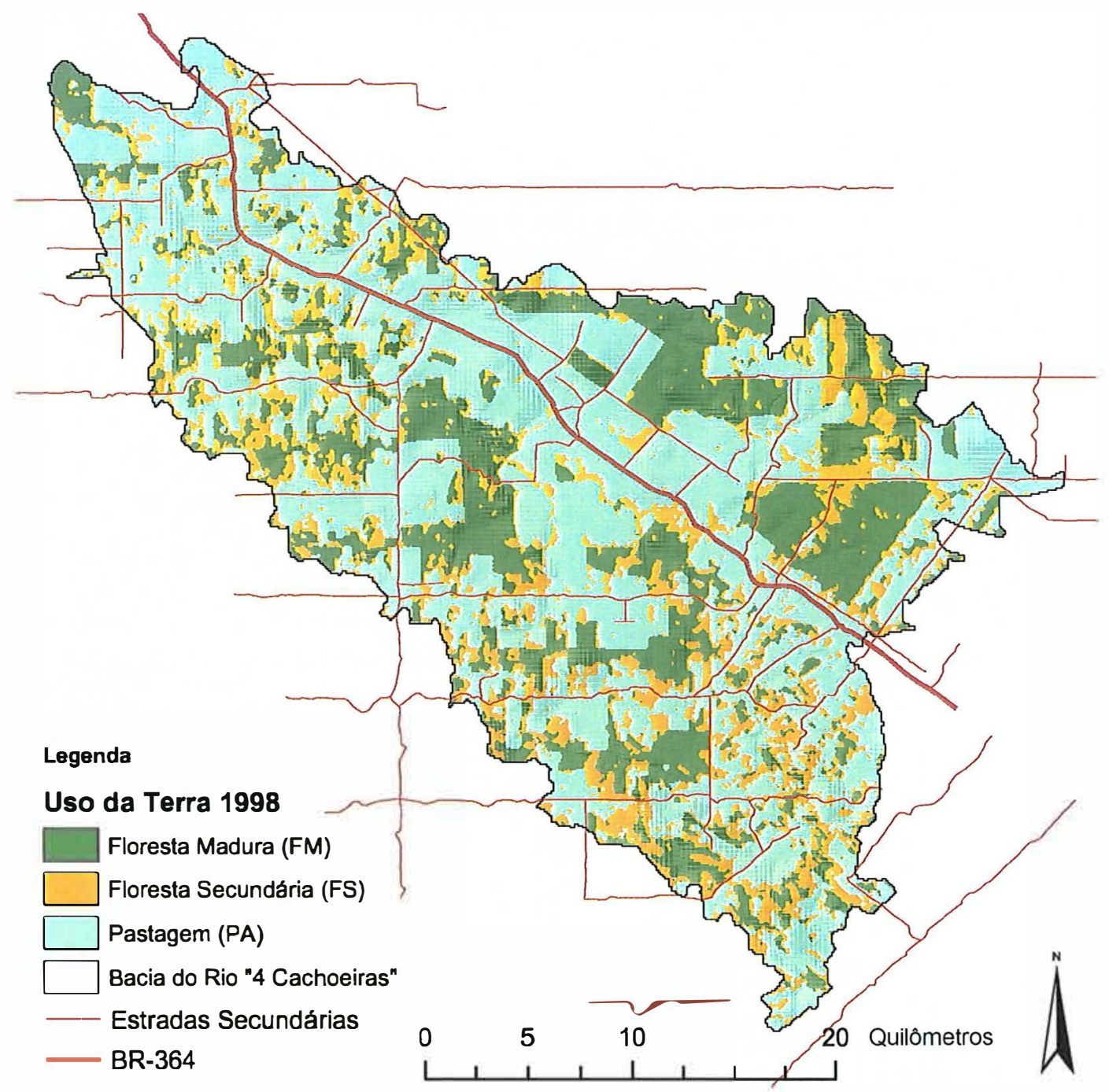

Figura 21 - Mapa de uso da terra da bacia do rio Quatro Cachoeiras em Rondônia, produzido para o ano de 1998 


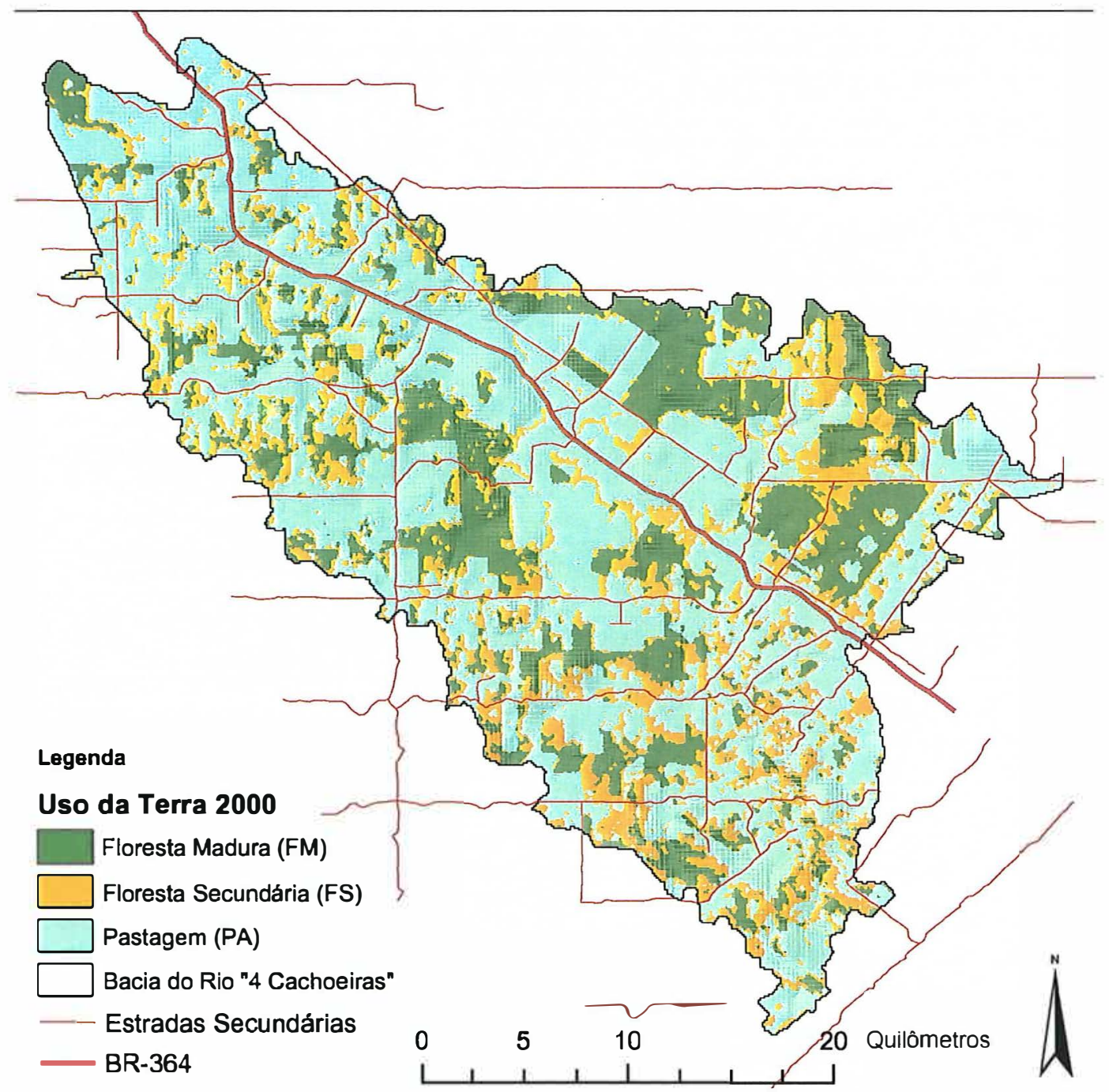

Figura 22 - Mapa de uso da terra da bacia do rio Quatro Cachoeiras em Rondônia, produzido para o ano de 2000 


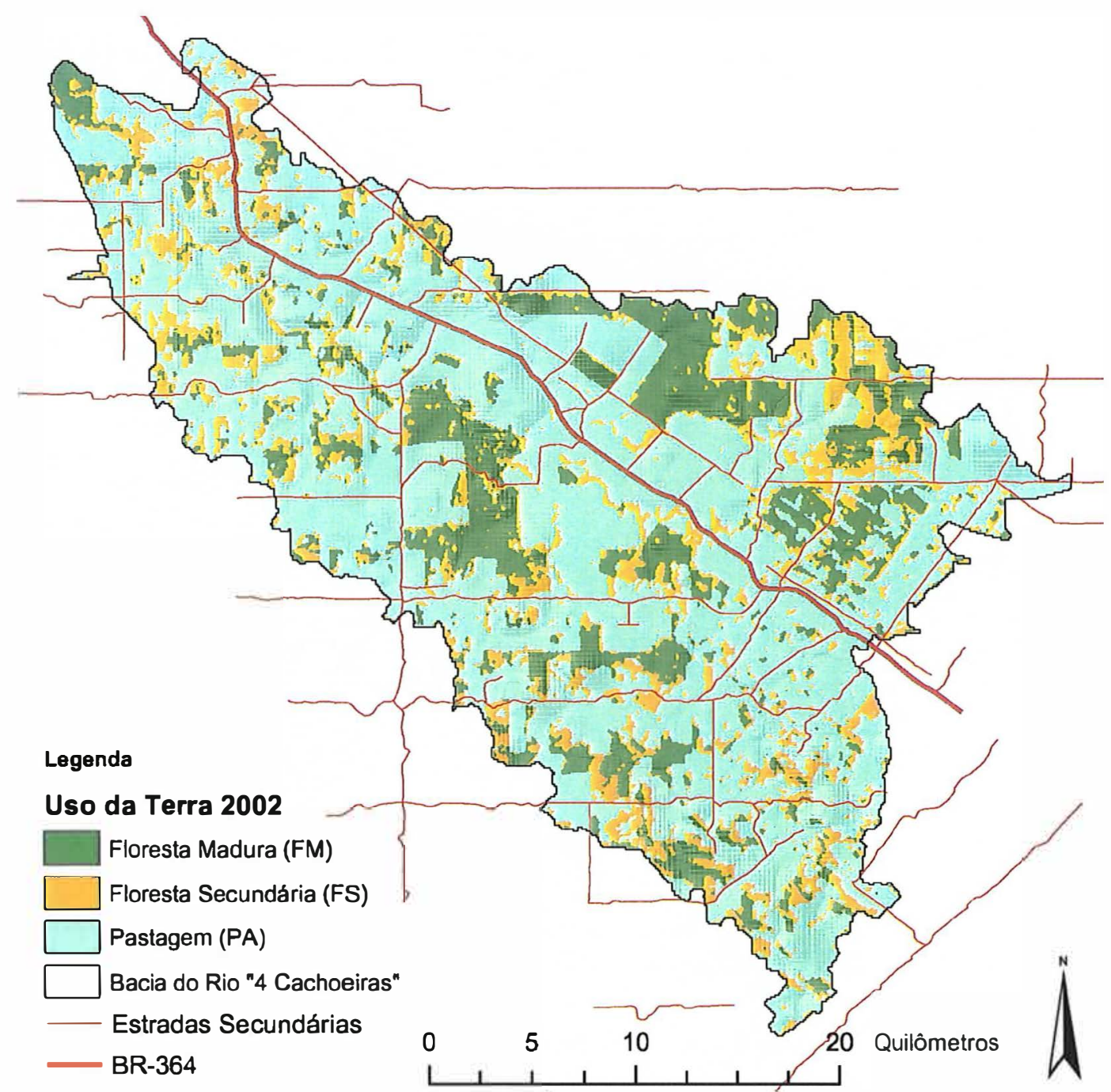

Figura 23 - Mapa de uso da terra da bacia do rio Quatro Cachoeiras em Rondônia, produzido para o ano de 2002

As curvas de porcentagem do uso da terra (PLAND) ao longo dos anos mostram uma sistemática conversão de Floresta Madura (FM) para Pastagem (PA), com FM sendo reduzida de 58.564 ha (66\%) para 22.022 ha $(24 \%)$ e Pastagem expandindo-se de 16.867 ha (19\%) para 60.004 ha $(66 \%)$. A Pastagem iniciou o domínio da paisagem a partir de 1993, ocupando maior porcentagem de terra que a FM. A FS manteve-se estável ao longo dos anos, ocupando cerca de $13 \%$ da área, na condição de vegetação de transição entre 
pastagem e floresta (Figura 24). No período, as taxas de desmatamento variaram de 2000 ha.ano ${ }^{-1}$ a 3000 ha.ano ${ }^{-1}$, sendo que os períodos de 19861988; 1990-1992 e 1998-2000 apresentaram taxas mais baixas.

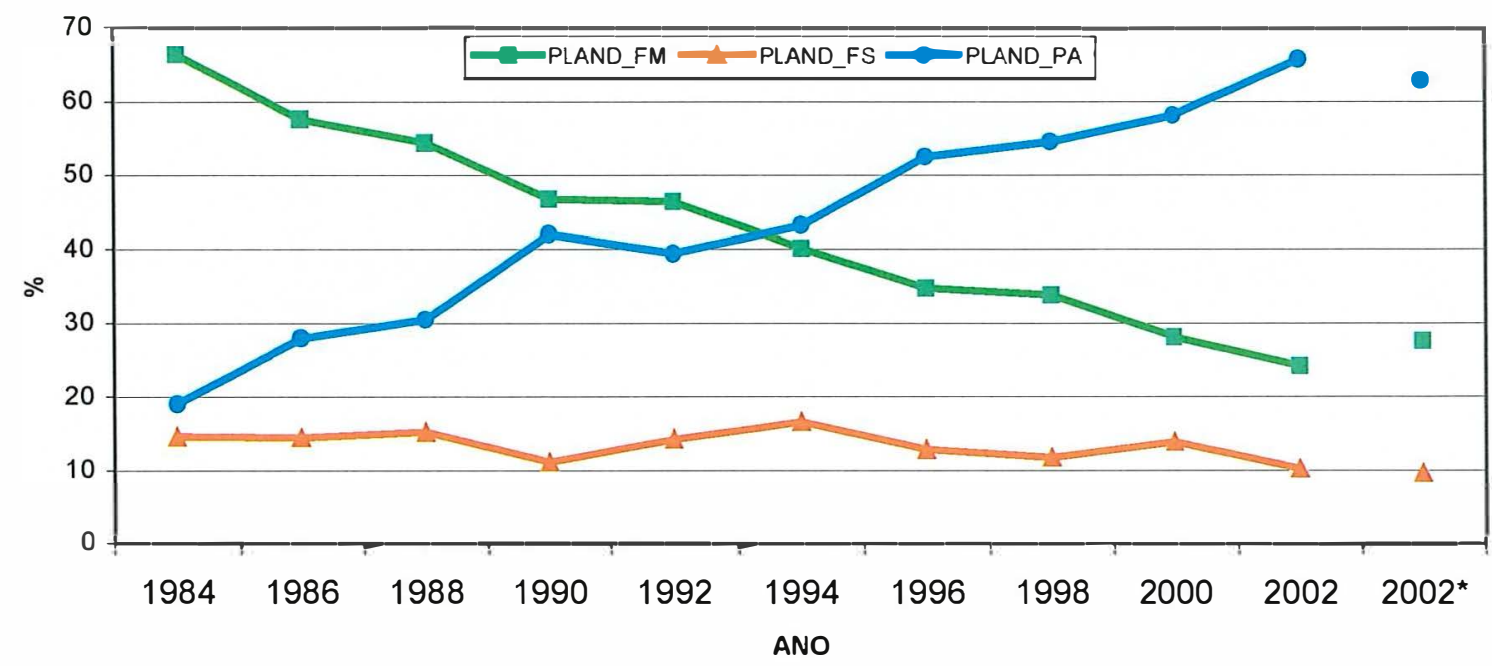

Figura 24 - Dinâmica do uso da terra ao longo dos anos representada pela porcentagem do uso da terra ocupada por cada classe (PLAND)

Examinando-se a dinâmica ocorrida no período de estudo ${ }^{3}$ por meio do cálculo da taxa média anual de transição entre os anos (Figura 25), pode-se observar que o desmatamento ocorreu de maneira equilibrada por meio de corte raso e seletivo ${ }^{4}$, ambos com taxa média aproximada de $2 \%$ ao ano. A taxa média de limpeza da Floresta Secundária superou um pouco a taxa de regeneração, ficando com $2,9 \%$ ao ano contra $2,6 \%$ ao ano. A maior dinâmica, portanto, foi registrada entre Floresta Secundária e Pastagem, totalizando 5,5\% ao ano, o que representa a dinâmica provocada pela prática da

* Cenário APP, baseado no uso da terra de 2002, com simulação da Área de Preservação Permanente (APP) nos rios e nascentes da bacia.

${ }^{3}$ Transição $F S \rightarrow F M$ não foi considerada.

4 Corte Seletivo: processo de extração parcial de uma floresta para retirada de árvores selecionadas previamente por plano de manejo. No caso da área de estudo, ocorreu a retirada das árvores de maior valor comercial. 
queima/derrubada. Na Figura 25 , os valores entre parênteses representam ausência de transição, sendo que a maior estabilidade foi registrada nas áreas de Floresta Madura (39,3\%), seguida pelas áreas de Pastagem $(37,9 \%)$ e Floresta Secundária (12,8\%). Os valores de estabilidade não devem ser confundidos com a porcentagem da classe de uso na paisagem; Floresta Madura, por exemplo, mesmo com ocupação menor na paisagem do que Pastagem nos últimos anos, apresentou, no entanto, maior estabilidade, pois ao contrário da Pastagem, outras classes de uso não podem ser revertidas em Floresta. Esses processos representam um modelo simplificado da dinâmica do uso da terra, mas muitos outros processos podem estar interagindo com estas transições.

\section{$2,3 \%$}

Corte raso

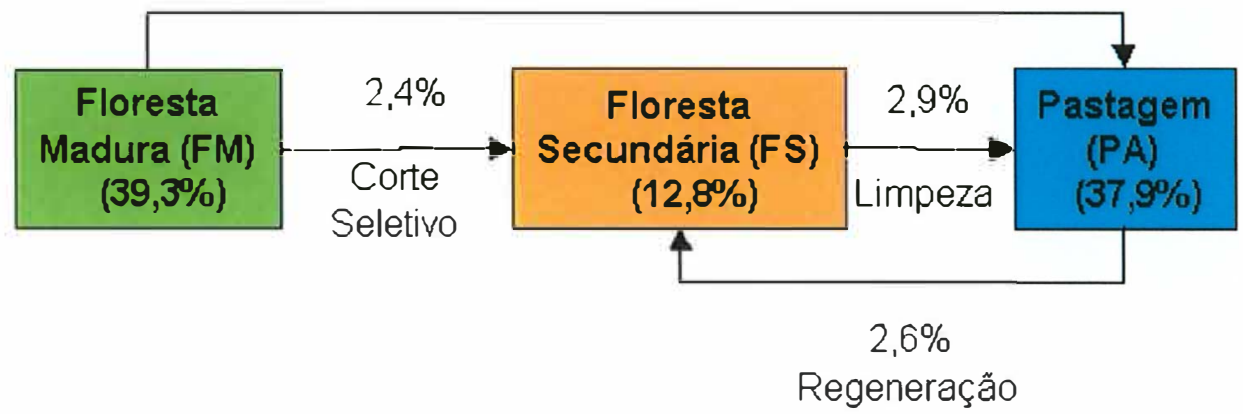

Figura 25 - Taxa média anual de dinâmica entre as classes de uso da terra ao longo do período estudado. Valores no interior das caixas representam ausência de transição

Em relação aos padrões de mudanças no uso da terra relacionadas ao desmatamento, duas transições apresentam maior interesse: FM para PA (corte raso) e FM para FS (corte seletivo). Estas transições foram analisadas em relação à freqüência e distribuição de tamanho das áreas desmatadas (clareiras). Inicialmente, na conversão FM para PA, nota-se três diferentes padrões: dominância de pequenas clareiras ( 0,5 ha) com aproximadamente 1000 clareiras por transição, freqüência intermediária de clareiras de tamanho 
médio (classes 1 ha, 5 ha, 10 ha e 50 ha) com aproximadamente 100 clareiras por transição e baixa freqüência de grandes clareiras (classes 100 ha, 500 ha, 1000 ha e 5000 ha) com menos de dez clareiras por periodo (Figura 26a).
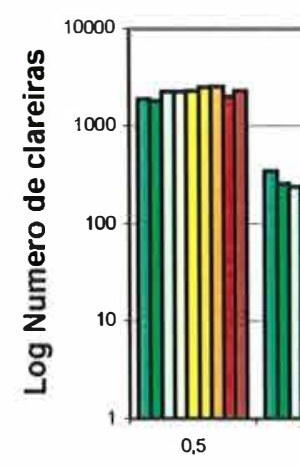

a

Limite superior de classe de tamanho (ha)

\begin{tabular}{|r|}
\hline$\square 84-86$ \\
$\square 86-88$ \\
$\square 88-90$ \\
$\square 90-92$ \\
$\square 92-94$ \\
$\square 94-96$ \\
$\square 96-98$ \\
$\square 8-00$ \\
$\square 00-02$ \\
\hline
\end{tabular}

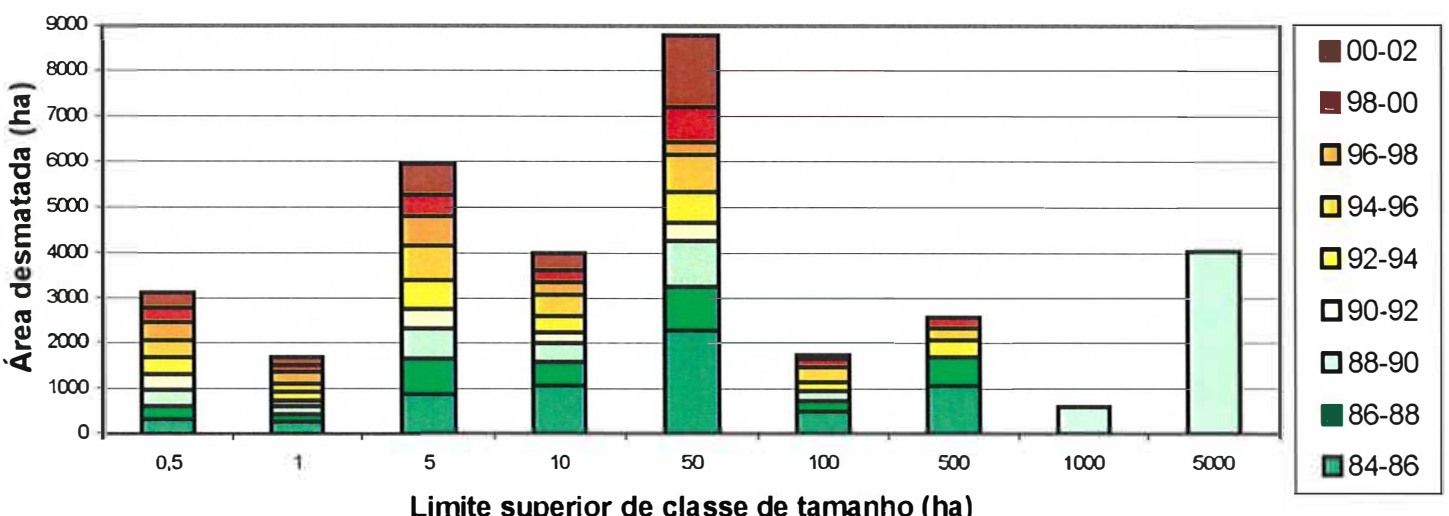

b

Limite superior de classe de tamanho (ha)

Figura 26 - Distribuição da freqüência de clareiras em função do tamanho da clareira (a) em função da distribuição da área total desmatada, (b) em função do tamanho da clareira no processo de corte raso $(\mathrm{FM} \rightarrow \mathrm{PA})$

Com relação à distribuição da área desmatada em função do tamanho das clareiras, clareiras menores que 50 ha foram responsáveis pela maior parte da área desmatada, com picos nas classes 5 ha e 50 ha. Entretanto, nota-se também um número reduzido de grandes clareiras representando importante 
participação na área total desmatada, especialmente entre 1988-1990 (Figura 26b).

Para a transição FM para FS, clareiras menores que 0,5 ha apresentam freqüências mais altas - cerca de 5000 clareiras por transição. As classes 1 ha, 5 ha, 1000 ha e 500 ha apresentaram padrão semelhante ao observado na transição $F M$ para $P A$, mas as classes 10 ha e 50 ha apresentaram freqüências dez vezes menores, com aproximadamente 15 clareiras por transição.

As classes de clareiras de 100 ha, 500 ha, 1000 ha e 5000 ha apresentaram freqüências baixas de ocorrência, mostrando que esta transição ocorre tipicamente em pequenas clareiras (Figura 27a). Esta observação pode ser confirmada pela área total desmatada por classe de tamanho de clareira, onde se nota que a área desmatada está concentrada em pequenas clareiras, com área menor que 5 ha (Figura 27b). 


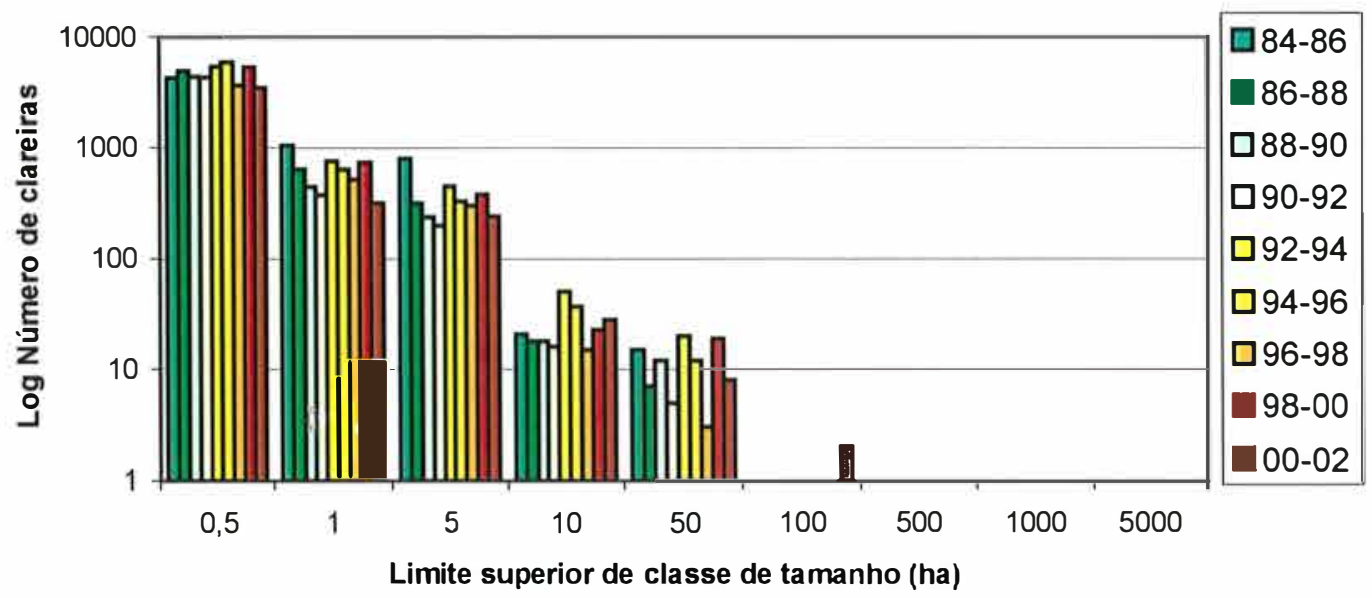

a

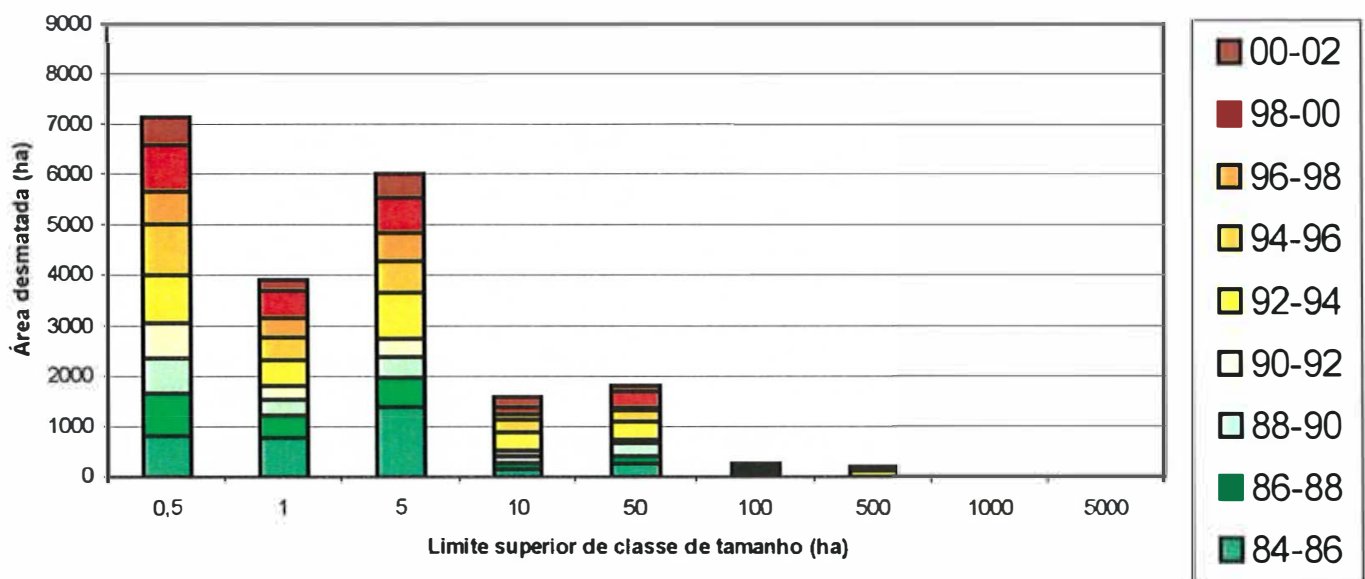

Figura 27 - Distribuição da freqüência de clareiras em função do tamanho da clareira (a) em função da distribuição da área total desmatada, (b) em função do tamanho da clareira no processo de corte seletivo $(\mathrm{FS} \rightarrow \mathrm{PA})$.

Considerando-se a freqüência de transições relacionadas ao processo de desmatamento em relação à distância de estradas e pastagens antigas, observou-se que, em relação às estradas (Figura 28), $70 \%$ do corte raso ocorreu numa faixa de até $2 \mathrm{~km}$ das estradas, enquanto que $60 \%$ do corte seletivo ocorreu na mesma faixa. Padrão similar foi observado na região por 
Alves et al. (1998a) com $80 \%$ do desmatamento ocorrendo em uma faixa de 2,5 km; e 89\% até 12,5 km em 1995 (Alves, D.S. et al., 1999). Desse modo, é possivel que a introdução de pastagens seja mais dependente de estradas que a exploração madeireira.
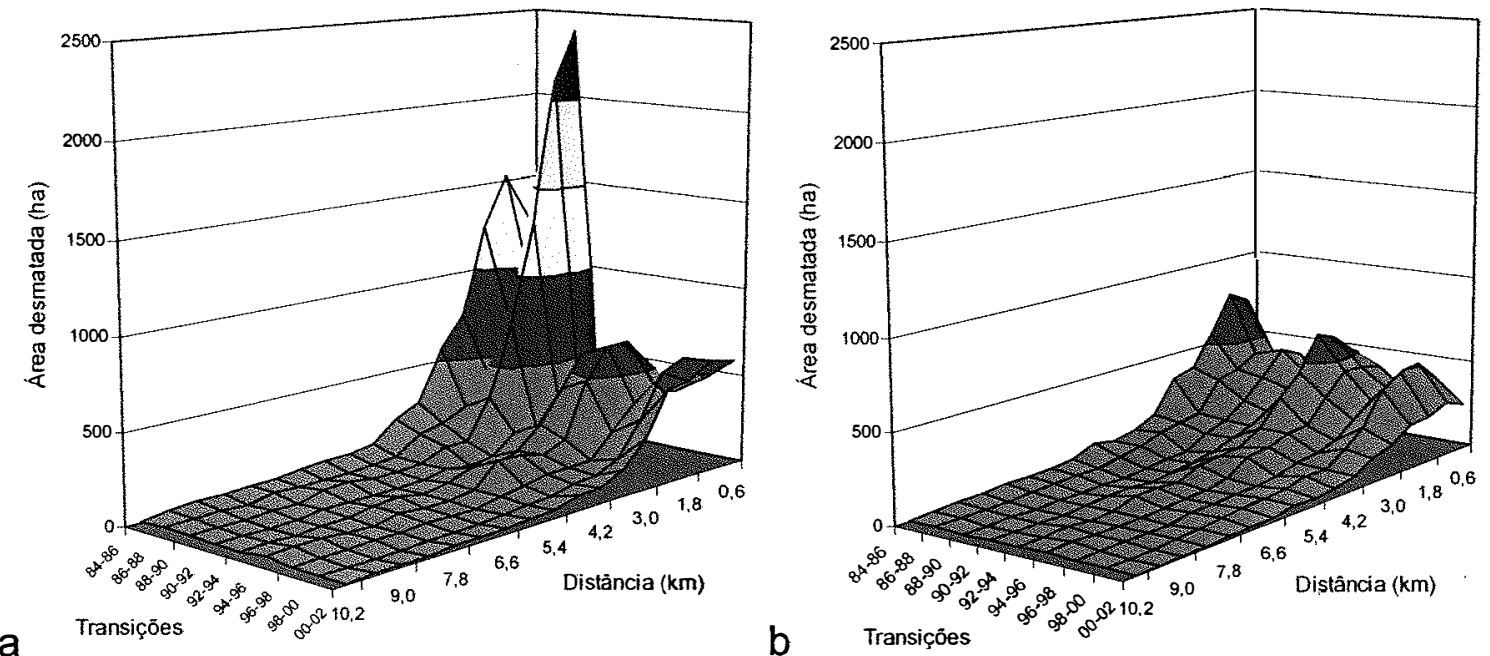

Figura 28 - Área desmatada ao longo dos anos em relação à distância das estradas: a. corte raso (transição $F M \rightarrow P A$ ), b. corte seletivo (transição FS $\rightarrow$ PA)

Em relação à distância de pastagens antigas (introduzidas antes de 1984), $80 \%$ das novas áreas desmatadas com corte raso (FM para PA) ocorreram dentro de uma faixa de $750 \mathrm{~m}$ de pastagens antigas (Figura 29), enquanto que $84 \%$ das áreas exploradas com corte seletivo (FM para FS) ocorreram nesta mesma faixa. Neste caso, não parece haver distinção na influência de pastagens antigas na ocorrência dos dois tipos de desmatamento. 
a
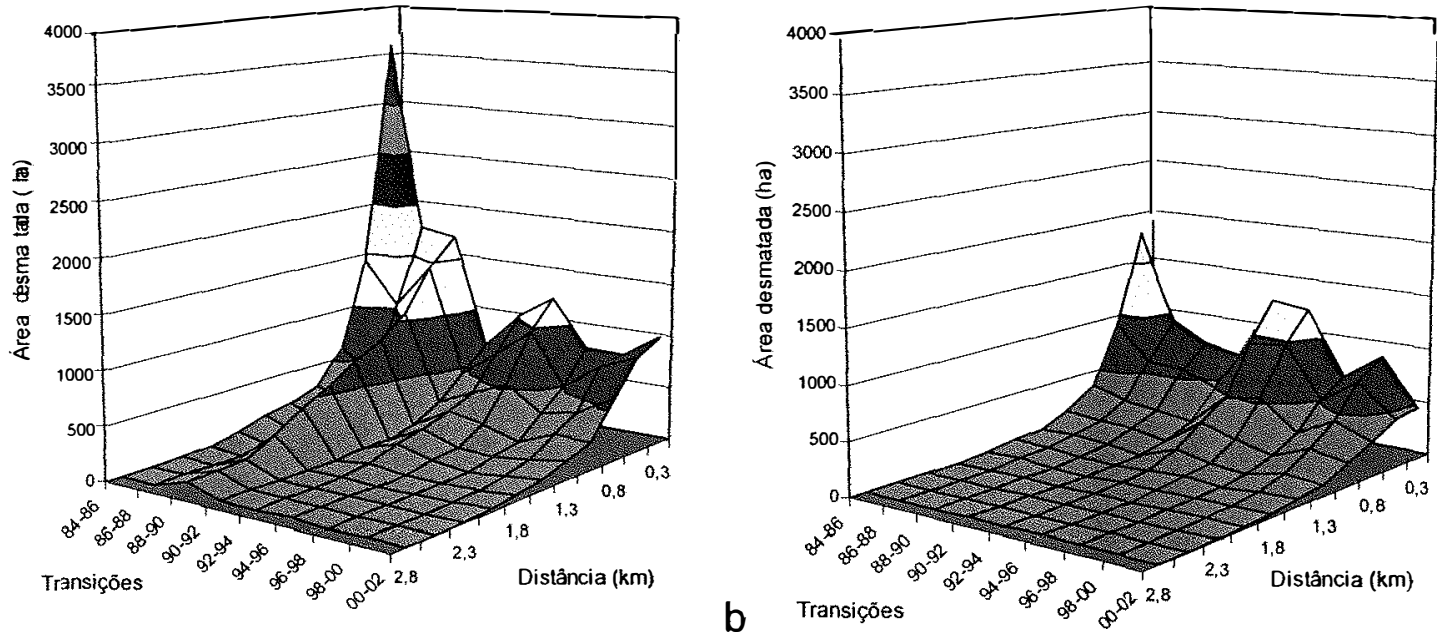

Figura 29 - Área desmatada ao longo dos anos em relação à distância de pastagens antigas: a. corte raso (transição $F M \rightarrow P A$ ); b. corte seletivo (transição FS $\rightarrow$ PA)

Comparando-se a influência de estradas e de pastagens antigas, nota-se que os processos de desmatamentos estão mais relacionados à presença de pastagens antigas, já que o maior desmatamento foi detectado em sua área de influência. Neste caso, provavelmente a presença de áreas já estabelecidas (propriedades) impulsiona o desmatamento para novas áreas ainda não exploradas.

Dinâmica da estrutura da paisagem - A densidade de fragmentos (PD) está inversamente relacionada à Porcentagem do uso da terra (PLAND) para as classes FM e PA, com o ponto de transição entre FM e PA ocorrendo por volta de 1994. A densidade de fragmentos de FM torna-se três vezes maior e o inverso ocorre com PA ao longo do periodo, sendo este comportamento esperado, visto que a diminuição de área de floresta normalmente aumenta o numero de fragmentos. Fragmentos de FS apresentam altas densidades (aproximadamente 1,8 fragmento. $100^{-1}$ ha), mas nota-se uma tendência decrescente ao longo dos anos (Figura 30a). A dominância da Pastagem (PA) 
sob a FM na paisagem foi antecipada pelo Índice do Maior Fragmento (LPI), o qual mostra a transição de dominância entre FM e PA a partir de 1988. O Índice do maior fragmento (LPI) para FM reduziu-se de 30\% (em 1984) para 10\% da área em 2002, enquanto que o LPI para PA aumentou de $10 \%$ para $60 \%$ da área no mesmo período (Figura 30b).

PD

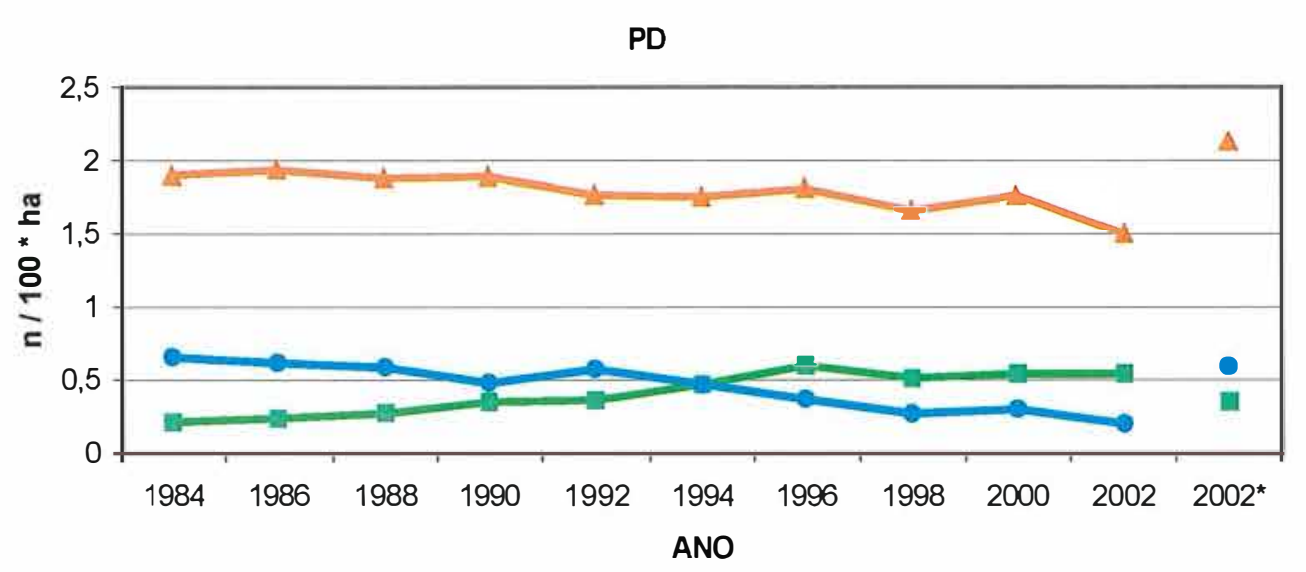

a

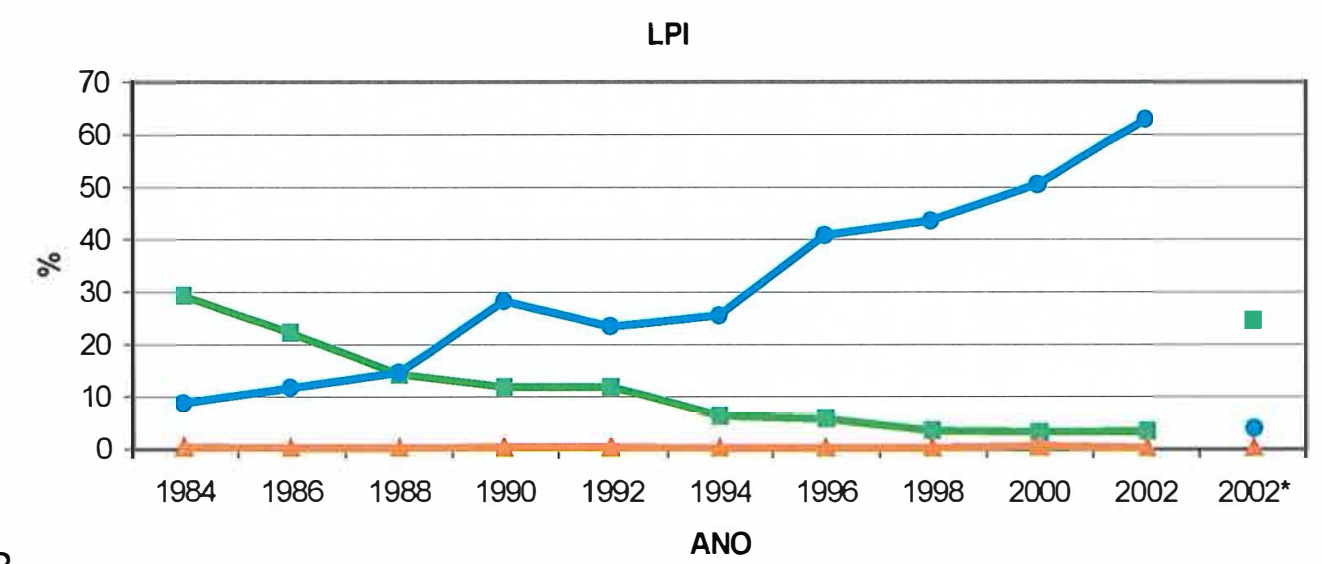

B

Figura 30 - Métricas da estrutura da paisagem para as três classes de uso: a. densidade de fragmentos (PD); $b$. índice do maior fragmento $(\mathrm{LPI})^{5}$

${ }^{5}$ Os resultados para $2002 a$ foram baseados em métricas de paisagem calculadas para a simulação do ano de 2002 com implantação da Área de Preservação Permanente (APP). 
A distância média entre os fragmentos de floresta (ENN_MN) dobrou em 2002, variando de $120 \mathrm{~m}$ a $240 \mathrm{~m}$. O inverso ocorreu com os fragmentos de pastagem (PA), com distância média reduzindo-se de $210 \mathrm{~m}$ a $160 \mathrm{~m}$. Os fragmentos de FS mantiveram uma distância estável durante o período (Figura 31a). O índice de justaposição (IJI) mostra FM e PA seguindo o mesmo padrão, com picos em períodos de desmatamento, quando as bordas de FM e PA estão em maior contato com as bordas de FS. Após a transição, ambos índices têm seus valores reduzidos. IJI para FS manteve-se estável devido a sua posição intermediária entre FM e PA (Figura 31b).

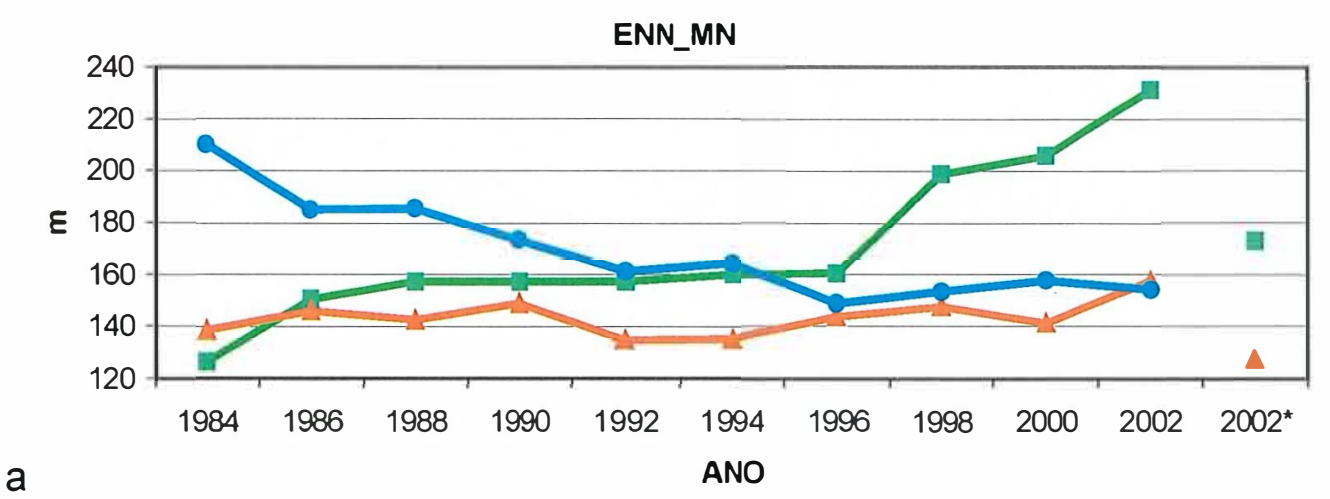

a

$|\mathrm{J}|$

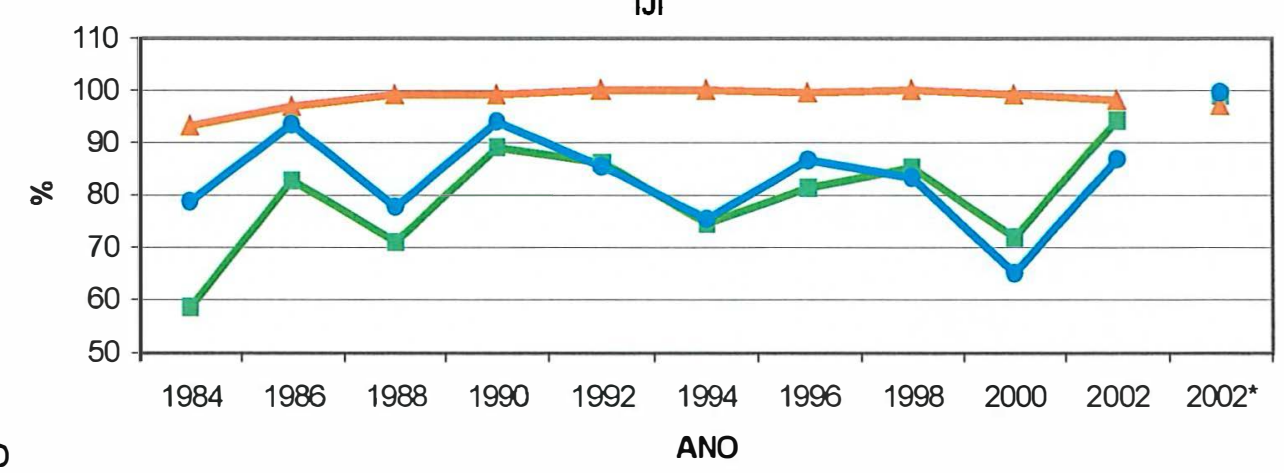

Figura 31 - Métricas da estrutura da paisagem para as três classes de uso: a. distância média do vizinho mais próximo (ENN_MN); b. índice de justaposição (IJ|) 
Considerando-se o comportamento das métricas para Floresta Madura (FM) em relação à Porcentagem Floresta Madura (PLAND_FM), observou-se ajuste ao modelo polinomial (grau três) nas métricas: densidade de fragmentos (PD), índice do maior fragmento (LPI) e distância média do vizinho mais próximo (ENN_MN). As curvas ajustadas para as métricas apresentaram ponto de inflexão em torno de $34 \%$ de Floresta Madura (PLAND_FM). O indice de justaposição não apresentou linearidade com PLAND_FM (Figura 32).

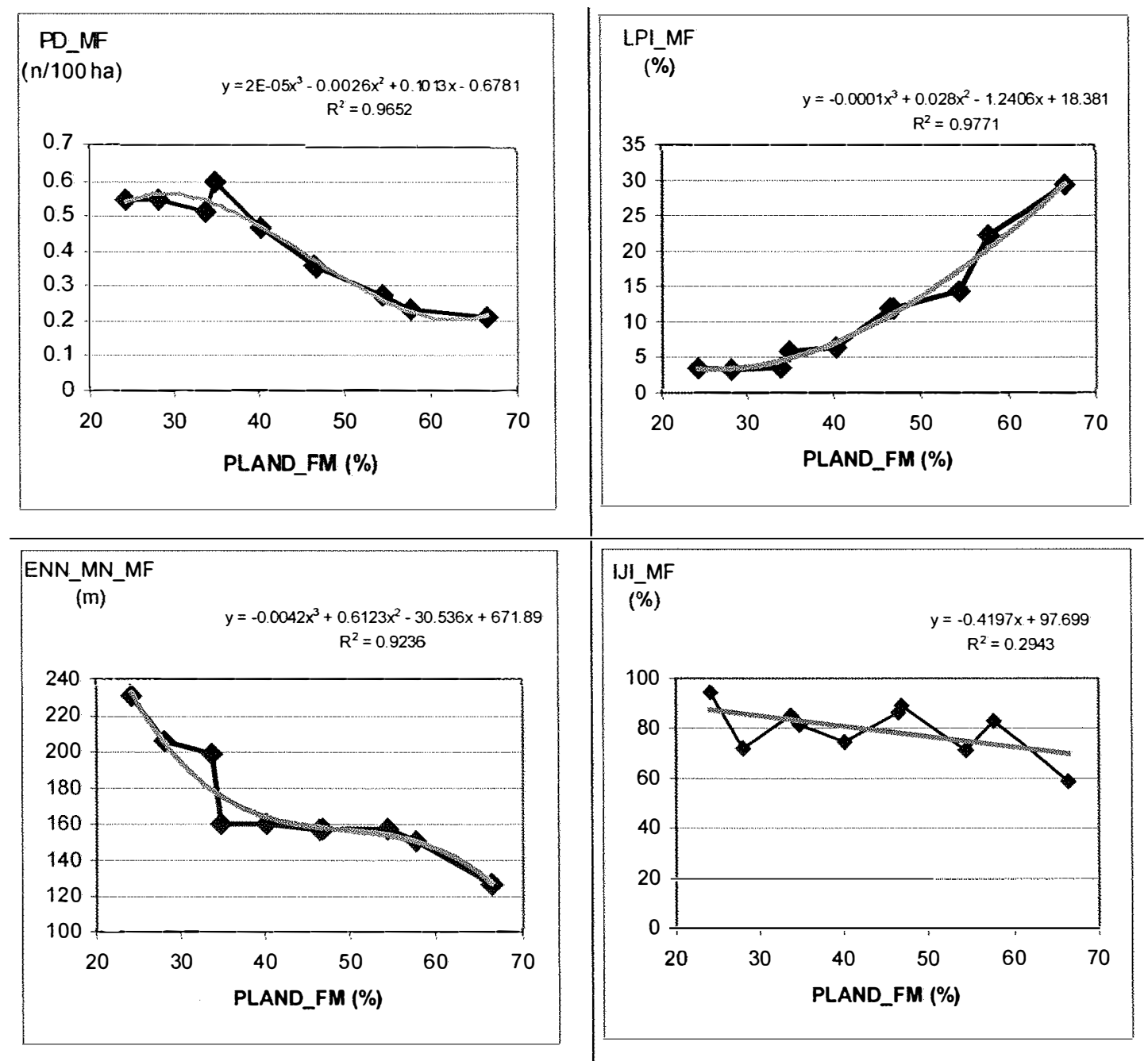

Figura 32 - Comportamento das métricas da paisagem em relação à Porcentagem de uso da terra (PLAND) para Floresta Madura (FM)

${ }^{6}$ Os resultados para $2002 a$ foram baseados em métricas de paisagem calculadas para a 
Probabilidade de mudança no uso da terra - os modelos lineares ajustados às probabilidades de transição no período são apresentados na Tabela 4. Os três cenários estimaram diferentes proporções de uso da terra para 2014, o cenário I (taxas atuais) prevê $7 \%$ de FM, 3\% de FS e $90 \%$ para PA. O cenário II (intermediário) prevê $28 \%$ de FM, $9 \%$ de FS e $63 \%$ para PA. Finalmente, o cenário III (conservacionista) prevê 37\% de FM, 0\% de FS e $63 \%$ para PA (Figura 33).

Tabela 4. Modelos lineares de probabilidade de transição para três cenários. y (x) representa a função de probabilidade de transição $\mathrm{e} x$ representa o intervalo de tempo

\begin{tabular}{lccc}
\hline Transição & $\begin{array}{c}\text { Cenário I } \\
\text { (atual) }\end{array}$ & $\begin{array}{c}\text { Cenário II } \\
\text { (Intermediário) }\end{array}$ & $\begin{array}{c}\text { Cenário III } \\
\text { (Conservacionista) }\end{array}$ \\
\hline FM $\rightarrow$ FM & $y=-0,0055 x+0,8216$ & $\begin{array}{c}y=-0,0055 x+0,8216+ \\
(2 E-05 x+0,0984)\end{array}$ & $y=1$ \\
FM $\rightarrow$ FS & $y=0,0054 x+0,0801$ & $y=0,0054 x+0,0801$ & $y=0$ \\
FM $\rightarrow$ PA & $y=2 E-05 x+0,0984$ & $y=0$ & $y=0$ \\
FS $\rightarrow$ FM & $y=-0,0202 x+0,3669$ & $y=-0,0202 x+0,3669+$ & $y=-0,0202 x+0,3669+$ \\
FS $\rightarrow$ FS & $y=0,0059 x+0,3865$ & $y=0,0059 x+0,3865$ & $y=0,0059 x+0,3865$ \\
FS $\rightarrow$ PA & $y=0,0142 x+0,2467$ & $y=0$ & $y=0$ \\
PA $\rightarrow$ FS & $y=-0,0212 x+0,2453$ & $y=-0,0212 x+0,2453$ & $y=-0,0212 x+0,2453$ \\
PA $\rightarrow$ PA & $y=0,0212 x+0,7547$ & $y=0,0212 x+0,7547$ & $y=0,0212 x+0,7547$ \\
\hline
\end{tabular}

O cenário I mostra a futura porcentagem de uso da terra para a bacia do rio Quatro Cachoeiras, baseado nas probabilidades atuais de transição, com redução da área de Floresta Madura concentrada em alguns fragmentos localizados em grandes propriedades e Floresta Secundária sendo reduzida a 
$3 \%$. A estrutura da paisagem neste cenário pode ser prevista observando-se as linhas de tendência dos gráficos de métricas da paisagem e projetando-as para o futuro (Figuras 31 e 32).

O cenário II interrompe a introdução de pastagem, mas ainda considera os processos de exploração seletiva e transições entre PA e FS. Para este cenário, a área de FM aumentaria $5 \%$ devido à regeneração de Floresta Secundária, mas o equilíbrio somente poderia ser atingido se as taxas de corte seletivo fossem balanceadas de acordo com o ciclo de recuperação da floresta, atingindo um estágio de equilíbrio da paisagem (Bormann \& Likens, 1978). A estrutura da paisagem neste cenário não pôde ser prevista devido ao fato de que a mesma depende da localização espacial onde as transições ocorreriam, o que não foi determinada pelos modelos utilizados.

O cenário III interrompe todos os processos de desmatamento, permitindo a recuperação florestal, mas ainda considera a dinâmica entre Pastagem e Vegetação Secundária como parte da prática da derrubada e queima da vegetação. A Floresta Madura poderia aumentar $10 \%$ devido à recuperação florestal, mas a Floresta Secundária seria drasticamente reduzida. A estrutura da paisagem neste cenário poderia ser prevista observando-se os valores para métricas da paisagem de 1994, quando a proporção de FM esteve por volta de $40 \%$ (porcentagem prevista para 2014). Isto seria possivel devido à alta probabilidade de aumento de FM próxima de florestas antigas em locais onde a Floresta Secundária estaria normalmente ocorrendo. 


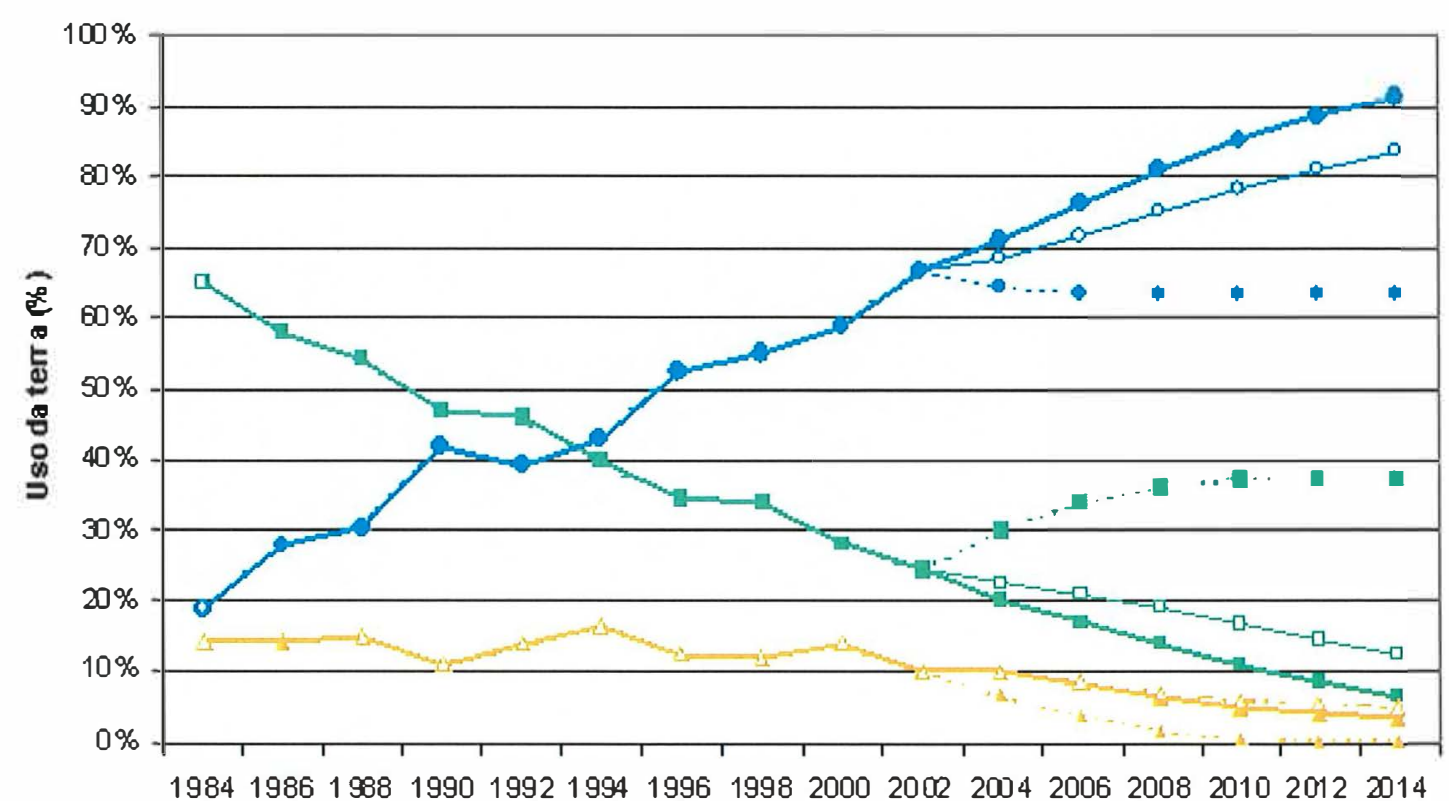

AHB

\begin{tabular}{|c|c|c|c|c|c|c|c|c|c|}
\hline $\begin{array}{l}\longrightarrow \text { FM_1 } \\
- \text { FS_2 }_{-}\end{array}$ & $\begin{array}{l}\longrightarrow \text { FS_1 } \\
\longrightarrow \text { PA_2 }\end{array}$ & $\longrightarrow$ PA_1 & ! & FM_3 & 4 & FS_3 & 中 & PA_3 & - \\
\hline
\end{tabular}

Figura 33 - Dinâmica do uso da terra para 1984-2002 e predição para o período 2004-2014 em três cenários simulados: I - taxas atuais, II intermediário e, III - conservacionista

O cenário APP (com introdução da Área de Preservação Permanente) baseado no uso da terra de 2002, não traria aumento significativo da área de floresta: aumento de 3.293 ha, ou seja, 3,5\% de aumento na área de FM na bacia (Figura 24). Mas, a vegetação ripária estaria conectando fragmentos florestais, mudando a estrutura da paisagem. Nas Figuras 30 e 31, algumas métricas da paisagem são apresentadas para este cenário $\left(2002^{\star}\right)$. Considerando FM, o novo cenário inclui redução da Densidade de Fragmentos (PD) de 0,54 para 0,34 fragmento.100 $\mathrm{ha}^{-1}$, aumento do Índice do Maior Fragmento (LPI) de $3,46 \%$ para $24,6 \%$ da bacia e redução da Distância Média do Vizinho mais Próximo (ENN_MN) de $231 \mathrm{~m}$ para $173 \mathrm{~m}$. 


\subsection{Discussão}

Observando-se as taxas de dinâmica do uso da terra, a taxa média de desmatamento esteve por volta de 2.000 ha.ano ${ }^{-1}$ ou $2,2 \% a^{-1}$, e o maior corte raso ocorreu por volta de 1990 , quando as taxas de conversão foram maiores que 5.000 ha.ano ${ }^{-1}$. Estas taxas são maiores que a média para o Estado de Rondônia, com 230.000 ha.ano $0^{-1}$ ou $0,9 \%$.ano ${ }^{-1}$ (INPE, 2004), o que caracteriza a área de estudo como uma das áreas de maior intensidade de desmatamento do estado.

Com relação à estabilidade da vegetação secundária, que apresentou pouca variação na proporção da bacia e até mesmo a tendência de redução, os resultados diferem do observado por Roberts et al. (2002), que encontraram tendência de aumento da vegetação secundária para a região de Ariquemes e Ji-Paraná, Rondônia. Desse modo, esta pode ser uma característica da bacia do rio Quatro Cachoeiras, a qual apresenta grandes áreas de pastagens manejadas, com controle sob a vegetação secundária.

Os padrões de mudanças no uso da terra mostraram dois diferentes processos de desmatamento ocorrendo na região. Primeiro, grandes áreas foram desmatadas para introdução de pastagem para criação de gado de corte. Isto ocorreu principalmente entre 1984 e 1996 com picos de desmatamento em 1986, 1990 e 1996. Grandes propriedades são responsáveis pelo desmatamento de grandes áreas (Alves, 2002) como pode ser observado entre 1994 e 1996, mas também são responsáveis por grandes remanescentes florestais, como aqueles localizados na região central da bacia no ano de 2002, os quais puderam ser confirmados por meio de mapas locais e trabalho de campo realizado.

Segundo, pequenas clareiras foram desmatadas principalmente por pequenos proprietários durante todo o período. Estes dados estão de acordo com Stone et al. (1991), que descrevem dois grupos de tamanho para os desmatamentos em Rondônia: 10-100 ha e 100-1000 ha. 
Em relação à área total desmatada $(\mathrm{FM} \rightarrow \mathrm{PA})$, pode-se observar que grandes áreas foram desmatadas principalmente entre 1988 e 1990 e que a maior parte esteve concentrada em clareiras menores que 50 ha. A alta freqüência de clareiras menores que 50 ha poderia ser explicada pelo tamanho médio do lote de pequenos proprietários, atualmente por volta de 100 ha (Browder, 1996). Este padrão pode ser uma situação particular da área de estudo, desde que, no Pará e outras regiões de Rondônia, Alves (2002) encontrou que $70 \%$ da área desmatada estava concentrada em clareiras maiores de 50 ha.

As atividades de exploração madeireira $(\mathrm{FM} \rightarrow \mathrm{FS})$ estão concentradas nas bordas da floresta, ocupadas principalmente por pequenos produtores (Serrão et al., 1996). Isto poderia explicar a alta freqüência de clareiras menores que 5 ha, desde que eles selecionam uma porção da floresta a ser explorada e então utilizam estas áreas desmatadas com solo mais fértil para agricultura por um período.

Outro importante processo é caracterizado pela alta dinâmica entre Pastagem (PA) e Floresta Secundária (FS) devido à prática da agricultura baseada na derrubada e queima, prática comum na região entre os pequenos proprietários devido ao baixo custo (Fujisaka et al., 1996; Serrão et al., 1996). Este processo representou uma taxa média anual de $5,2 \%$ no período. Roberts et al. (2002) também observaram alta dinâmica entre pastagem e vegetação secundária na região de Ariquemes, Rondônia.

As métricas da paisagem para Floresta Madura (FM) mostram um típico processo de fragmentação, com aumento na densidade de fragmentos e distância entre os mesmos, diminuição na dominância, tamanho dos fragmentos, padrão este também observado em outros estudos (Godron \& Forman, 1983; Reed et al., 1996; Roberts et al., 2002). A Pastagem segue o padrão inverso, exceto pelo índice de forma que aumentou durante o período. Os índices de Justaposição (IJI) para FM e PA apresentaram a mesma variação, provavelmente por estes dois usos estarem fortemente associados. $A$ 
variação no IJI poderia estar associada a períodos de transição, onde a Floresta Secundária (FS) esteve mais presente entre PA e FM. O mesmo padrão foi observado por Alves et al. (2003), o qual sugere que a vegetação secundária exerce um papel intermediário, reduzindo os impactos do desmatamento.

A transição da matriz Floresta para Pastagem ocorreu por volta de 1994, mas a Pastagem apresentou os maiores fragmentos a partir de 1990. Outra transição interessante pôde ser observada em 1996, considerando-se que a partir deste ponto houve um aumento linear do número de fragmentos de Floresta Madura (expressado pela Densidade de Fragmentos), o qual se torna estável posteriormente. A partir de 1996, a distância entre os fragmentos também aumenta rapidamente quando comparada aos anos anteriores a 1996, até então estável. Estas observações podem representar um limiar crítico da fragmentação, onde processos como remoção e encolhimento de fragmentos tornam-se dominantes.

A diferença entre a distância dos fragmentos florestais poderia ser explicada pela pequena redução do número de fragmentos entre 1996 e 1998, atingindo o mesmo nivel de 1994, mas em um contexto completamente diferente. Provavelmente, neste periodo (1996-1998) alguns fragmentos localizados em posições intermediárias foram removidos, aumentando a distância entre as áreas de floresta. Comparando 1994 e 1998, LPI para Floresta Madura teve uma pequena variação $(6,4 \%$ para $3,5 \%)$, mas LPI para Pastagem aumentou de $25,5 \%$ para $43,6 \%$, mostrando que vários fragmentos de floresta foram incorporados à matriz após serem desmatados, aumentando a sua dominância e reduzindo a conectividade florestal.

Neste ponto, FM representava $34 \%$ da paisagem e esta proporção poderá ser considerada um limiar crítico para a bacia que poderia ser aplicado a outras regiões de Rondônia, submetidas ao mesmo padrão de desmatamento. A idéia de limiar crítico foi proposta por Stauffer (1985) que estudou paisagens binárias e encontrou uma proporção de habitat crítica em torno de 59,28\% da paisagem, a partir da qual sua estrutura modificava-se drasticamente. Os 
limiares variam de acordo com as diferentes paisagens (Gardner, 1987), e a proporção crítica observada na região é inferior ao proposto por Stauffer, o que poderia ser explicado pelo padrão espacial da região, com rodovias localizadas em intervalos regulares. As conseqüências para paisagens sob limiares críticos são a redução da conectividade, afetando a biodiversidade e taxas de extinção, propagação de distúrbios como incêndios, doenças e espécies invasoras (Gardner, 1987). Desse modo, o limiar crítico poderia ser importante para direcionar as estratégias de conservação em projetos de assentamento.

Observando a variação da estrutura da paisagem ao longo do processo de desmatamento, pôde-se notar que as métricas de paisagem apresentaram tendências lineares em relação à Porcentagem de Floresta Madura (PLAND), apesar de se ajustarem melhor a modelos polinomiais. Este fato poderia ser explicado pelo número reduzido de amostras (anos) e a geometria original das estradas, a qual determinou o padrão espacial, já que outros autores observaram a não linearidade destas métricas (Trani \& Giles, 1999). Mesmo assim, considerando-se a linearidade no intervalo testado, somente práticas de manejo como a implementação da APP poderia mudar a estrutura da paisagem com objetivo de reduzir os efeitos da fragmentação.

Os três cenários apresentados neste estudo permitiram examinar possiveis limites futuros na porcentagem de uso da terra. Cenários I e III podem ser interpretados como extremos, mas a porcentagem futura do uso da terra certamente estará situada entre estes dois cenários. Portanto, independentemente dos cenários estarem ou não corretos, provavelmente os limites estão próximos da realidade e a configuração futura do uso da terra estará situada entre os cenários I e III.

O cenário APP mostra que a implementação da Área de Preservação Permanente não aumentaria significativamente a área florestal $(3,5 \%)$, mas sua maior importância seria a mudança na estrutura da paisagem com a redução do número de fragmentos e aumento da conectividade. Além disto, o cenário APP 
provavelmente traria benefícios para a qualidade da água e conservação do habitat aquático.

Considerando-se que o cenário III não é realista e que um cenário mais plausivel estaria situado entre os cenários I e II, alguns aspectos importantes poderiam ser esperados como:

- Em dez anos, a Floresta Madura poderia representar algo entre $7 \%$ (cenário I) e $28 \%$ (cenário II), ou seja um valor médio de 17,5\%;

- $\mathrm{O}$ crescimento secundário dos pastos abandonados e a recuperação florestal das áreas de Floresta Secundária iriam levar uma média de 25 e 12,5 anos para atingir o estágio de Floresta Madura e sua recuperação representaria um incremento na área de floresta inferior a $10 \%$;

- A Floresta Secundária tende a ser reduzida, devido à perda de Floresta Madura (menor taxa de transição entre Floresta e Pastagem), estabilização das áreas de pastagem e agregação de pequenas propriedades em grandes fazendas, que utilizam práticas de manejo diferenciadas com utilização de insumos, como descrito por Diegues (1999); e,

- A estrutura da paisagem deveria seguir as tendências presentes de fragmentação florestal, desde que a geometria da paisagem vem sendo guiada pelo traçado original das estradas, estabelecidas nos anos 70 , quando iniciaram-se os projetos de assentamento, e somente ações de manejo como a implementação da APP poderia mudar a estrutura da paisagem nas condições atuais.

Em relação à sustentabilidade da dinâmica de uso da terra atual, esperase que nos próximos 12 anos, a Floresta Madura (FM) seja reduzida a $5 \%$, de acordo com as tendências atuais, sendo que a mesma estaria presente somente em alguns pequenos e dispersos fragmentos, ou em ilhas (grandes fragmentos) isolados em grandes propriedades. A pastagem se tornaria mais dominante e a dinâmica entre vegetação secundária e pastagem persistiria 
devido ao uso da prática de derrubada e queima. Atividades de exploração madeireira não persistiriam por muito tempo, devido à diminuição de florestas de boa qualidade. Especula-se ainda que, sem florestas primárias e novas áreas para pastagem ou agricultura, pequenas propriedades provavelmente seriam aglomeradas em grandes fazendas, que teriam melhores condições econômicas para investir em equipamentos e insumos para manter a produtividade.

Os efeitos nos rios poderiam ser ainda piores devido à falta de vegetação ripária e drástica redução das áreas de floresta, afetando a qualidade da água e o balanço do regime de cheias (Allan et al., 1997; Ballester et al., 2003; Biggs et al., 2002; Thomas et al., 2004).

Um cenário positivo, posicionado entre os cenários I e III, poderia ser esperado se os remanescentes florestais atuais forem mantidos, se houver a proibição do corte raso e limitação da expansão dos pastos. Ao contrário, os processos dinâmicos entre exploração seletiva $(F M \rightarrow F S)$, regeneração $(\mathrm{PA} \rightarrow \mathrm{FS}$ e $\mathrm{FS} \rightarrow \mathrm{FM}$ ) e derrubada / queima $(\mathrm{FS} \rightarrow \mathrm{PA})$ deveriam ocorrer em taxas balanceadas, ou mais sustentáveis. Neste cenário, dois aspectos poderiam contribuir para a conservação dos fragmentos remanescentes: a implementação da APP de acordo com a legislação atual, funcionando como corredores de ligação entre os fragmentos e a manutenção de grandes fragmentos localizados em grandes propriedades como fontes de biodiversidade para a bacia.

Ainda explorando esse cenário hipotético, e considere-se como exemplo, o uso da terra de 2002 (22.000 ha de Floresta Madura), ciclo de 25 anos de manejo da exploração (Brasil, 2002), média de 12,5 anos para uma pastagem abandonada ser convertida para Floresta Secundária e média de 12,5 anos para a Floresta Secundária atingir o estágio de Floresta Madura. Para que hajam taxas balanceadas, as taxas médias de transição deveriam ser de, aproximadamente, 1.800 ha.ano ${ }^{-1}$ para cada transição: $F M \rightarrow F S, F S \rightarrow F M$, $\mathrm{FS} \rightarrow \mathrm{PA}$ e $\mathrm{PA} \rightarrow \mathrm{FS}$, representando $2 \%$ da área da bacia para cada uma das quatro possíveis transições, o que resultaria em uma dinâmica total de $8 \%$.ano ${ }^{-1}$ 
para toda a bacia. Esses números, transportados para uma pequena propriedade de 100 ha, significam que o proprietário poderia explorar em média 2 ha de floresta, derrubar e queimar 2 ha de Floresta Secundária e abandonar 2 ha de pastagem para regeneração por ano. Provavelmente essas porções de terra não são suficientes para manter a produção em pequenas propriedades e, caso não sejam, algumas questões poderiam ser levantadas para trabalhos futuros: quanto de floresta seria necessário e qual seria o momento do processo de fragmentação em que uma dinâmica balanceada funcionaria?

Um cenário otimista para região, incluiria a introdução de modelos de manejo, principalmente para os pequenos proprietários como, por exemplo, o proposto por Metzger (2001), que sugere o agrupamento das áreas de Reserva Legal na porção final dos lotes e utilização das áreas próximas à estrada para produção.

Este estudo considerou apenas aspectos como perda florestal, sustentabilidade das atividades desenvolvidas pelos proprietários e aspectos da estrutura da paisagem importantes para conservação. Outros aspectos são igualmente importantes e não foram considerados, como condições sócioeconômicas, impactos nos recursos hídricos, biodiversidade e etc. 


\subsection{Conclusões}

Os padrões observados na bacia do rio Quatro Cachoeiras representam uma amostra de outras regiões de Rondônia que tiveram trajetória semelhante, com o mesmo padrão de colonização, mas que podem estar em um estágio diferente do processo de desmatamento. Assim, os resultados deste estudo servem como exemplo para demais regiões com degradação florestal na Amazônia.

A dinâmica da paisagem na área de estudo mostrou uma conversão sistemática de floresta para pastagem, onde a floresta secundária ocupa um estágio (temporal e espacial) intermediário. Dois diferentes processos foram identificados: grandes áreas desmatadas por pecuaristas concentradas em períodos específicos e pequenos desmatamentos ocorridos durante todo o periodo por pequenos proprietários. O processo de fragmentação é influenciado pela localização espacial em relação a estradas e presença de pastagens antigas e controlado por pequenos e grandes proprietários.

Em 2002, com menos de $25 \%$ de áreas com floresta, a bacia estava no estágio final e crítico de desmatamento. $O$ atual estágio de fragmentação foi considerado crítico, observando-se que existe um limiar crítico para o desmatamento em torno de $34 \%$ de Floresta Madura, o qual poderá ser utilizado como diretriz para as decisões de manejo da região.

Com relação às hipóteses iniciais do trabalho: "1. As mudanças no uso da terra que vêm ocorrendo na bacia do rio Quatro Cachoeiras nos últimos 20 anos não são sustentáveis; 2. A dinâmica ocorrida afetou significativamente a estrutura da paisagem atual.", os resultados obtidos indicam que as duas hipóteses devem ser aceitas.

A simulação de vários cenários mostrou-se uma boa ferramenta para o planejamento, já que permite identificar possiveis limites críticos para a paisagem nos próximos dez anos, os quais poderão ser atingidos dependendo do padrão de mudanças no uso da terra nos próximos anos. 


\section{DINÂMICA DA PAISAGEM EM MICROBACIAS: USO DE INDICADORES E MÉTODOS DE CLASSIFICAÇÃO}

\section{Resumo}

No Estado de Rondônia, o processo de colonização já desmatou cerca de $68.000 \mathrm{~km}^{2}$ de florestas tropicais desde a década de 70. A qualidade da água dos rios pode ser influenciada pelos efeitos acumulativos, decorrentes do processo de desmatamento nas bacias hidrográficas da região. Imagens Landsat TM e ETM+ foram utilizadas para produzir mapas de uso da terra históricos dos últimos 18 anos, a cada dois anos de 1984 a 2002. Utilizando-se os mapas gerados, analisou-se a dinâmica da paisagem em 20 microbacias selecionadas utilizando métricas de paisagem, três indices propostos baseados na dinâmica do uso da terra entre 1984 e 2002: Taxa Anual de Desmatamento da Floresta Madura (TADFM), Proporção Média da Floresta Secundária (PMFS) e Tempo Médio de Introdução da Pastagem (TMIP), além de métricas de paisagem para o ano de 2002 (condição atual). Utilizando-se a análise de agrupamentos, as microbacias foram agrupadas utilizando-se dois critérios: sua dinâmica da paisagem e condição atual. A variabilidade na estrutura da paisagem está correlacionada à proporção de uso da terra das três classes consideradas e não somente à proporção de floresta, ressaltando a importância de se considerar a dinâmica da matriz e outras classes de uso coexistentes em estudos de dinâmica da paisagem. A dinâmica do uso da terra apresentou quatro componentes principais, representando $90 \%$ da variabilidade. Os índices de dinâmica do uso da terra propostos foram considerados bons indicadores, 
pois além de estarem correlacionados aos componentes calculados, são de fácil cálculo e entendimento. $A$ incorporação de dados históricos em conjunto a dados atuais na classificação das condições ambientais de microbacias melhorou a qualidade da classificação.

Palavras-chave: Análise de agrupamento, dinâmica da paisagem, qualidade da água, Rondônia, SIG.

\section{Summary}

In Rondônia State, colonization process has already deforested 68,000 $\mathrm{km}^{2}$ of Tropical Forests since the 1970s. Physical and anthropogenic conditions of watersheds can influence water quality in rivers of the region. Landsat TM and ETM+ images were used to produce historical land use maps of the last 18 years, each even year from 1984 to 2002. Through the maps, land use dynamics in 20 catchments were analyzed by historical landscape metrics, three proposed historical land use indices: Mean Annual Deforestation Rate (TADFM), Secondary Forest Mean Proportion (PMFS) and Mean Time of Pasture Introduction (TMIP), and landscape metrics for year 2002. Cluster Analysis was used to group catchments according to two criteria: their landscape dynamics and current condition. Landscape structure variability is correlated to land use for the three considered classes and not only forest proportion, showing the importance on considering matrix and coexistent classes' dynamics in landscape dynamics studies. Land use dynamics present four principal components representing $90 \%$ of variation. The proposed land use dynamics indices were considered good indicators, due to their correlation to components. The addition of historical and current data on environmental condition classification of catchments improved the quality of the classification.

Key words: cluster analysis, GIS, landscape dynamics, Rondônia, water quality 


\subsection{Introdução}

As condições físicas e antrópicas, decorrentes do processo de desmatamento, em que se encontram as bacias hidrográficas na região Amazônica podem influenciar a qualidade da água nos rios (Biggs et al., 2001; Richey et al., 1997; Thomas et al., 2004). A avaliação da influência antrópica nas condições ambientais das bacias hidrográficas é uma preocupação cada vez mais presente nos dias atuais e muitos estudos vêm sendo realizados com o intuito de desenvolver indicadores que auxiliem o diagnóstico e o manejo destas bacias.

Normalmente, a influência antrópica em bacias hidrográficas tem sido avaliada principalmente pela composição de uso da terra presente no momento do estudo (Ballester et al., 2003; Biggs et al., 2002; Ometo et al., 2000), ou por meio da estrutura da paisagem, também de forma estática (Jonhson et al., 2001; Lucas \& Medley, 2002). De grande importância para avaliação da influência antrópica, o histórico de utilização de uma área pode influenciar muitas das condições encontradas no presente (Wayland et al., 2002). Entretanto, a avaliação do histórico da área, envolve um grande número de variáveis que devem ser analisadas sob influência temporal, o que dificulta a análise e a obtenção de dados (MacDonald, 2000; Wayland et al., 2002). Uma alternativa para representação de histórico de uso seria a utilização de indicadores de dinâmica.

A influência do histórico da área ocorre por meio de efeitos acumulativos sob os sistemas ecológicos que devem ser considerados no manejo e planejamento ambiental. A estrutura de uma floresta, por exemplo, pode ser influenciada por efeitos do histórico do uso da terra (Thompson et al., 2002) e considerando-se os processos hidrológicos, a qualidade da água poderá ser influenciada pelo fluxo do escoamento base que integra usos da terra do passado e presente (Wayland et al., 2002). 
Em estudos de qualidade da água, a incorporação da variabilidade espacial e temporal no uso da terra pode permitir o desenvolvimento de um modelo acurado de influência do uso da terra na qualidade da água. Em regiões de alta dinâmica, com áreas de utilização da técnica de derrubada e queima para cultivo da área nos primeiros anos e descanso ou abandono nos anos seguintes, mescladas com remanescentes florestais e grandes áreas de pastagens estáveis, a análise da trajetória de uso de cada área deverá trazer novas informações para o entendimento das condições presentes (CrewsMeyer, 2002; Heitel et al., 2004).

Embora no Capítulo 3, vários aspectos da dinâmica da bacia do Rio Quatro Cachoeiras tenham sido explorados, como taxas de transição e distribuição espaço-temporal dos focos de desmatamento, neste capítulo a dinâmica do uso da terra será explorada em uma escala menor, na microbacia, visando compreender seus efeitos e, para isto, propondo metodologias de análise.

É crescente o interesse por indicadores para monitoramento das mudanças ambientais (Tiner, 2004). A dificuldade da análise da trajetória de uso e a falta de métodos para avaliação de histórico em bacias hidrográficas motivaram o desenvolvimento de uma metodologia para ser aplicada na Região Amazônica. Algumas questões que nortearam a realização deste trabalho foram: quais as principais fontes de variabilidade relacionadas à dinâmica do uso da terra? Quais indicadores de dinâmica poderiam representar sua variabilidade? Como a dinâmica de uso da terra influencia a estrutura da paisagem no presente? Na classificação da condição atual de microbacias, a incorporação do histórico de uso da terra na mesma traria benefícios para o entendimento de seus impactos nos recursos hídricos?

Desse modo, o objetivo deste estudo foi avaliar indicadores e métodos para classificação de microbacias, utilizando dados de dinâmica do uso da terra dos últimos 18 anos e da estrutura da paisagem em 2002 para a região central de Rondônia. 


\subsection{Material e Métodos}

Área de estudo - a descrição sobre a área de estudo encontra-se no Capítulo 3.

Base de dados - os métodos utilizados para preparação da base cartográfica, classificação das imagens e confecção dos mapas de uso da terra foram descritos no Capítulo 3.

A bacia do rio Quatro Cachoeiras foi dividida em microbacias com área variando entre 1.000 ha e 2.500 ha com o uso do software SWATT 2000 (Di Luzio et al., 2002), das quais foram escolhidas 20 microbacias de $2^{\mathrm{a}}$ ordem, localizadas nas proximidades do divisor de águas da bacia do rio Quatro Cachoeiras (Figura 34). As microbacias de $2^{\mathrm{a}}$ ordem foram escolhidas por apresentarem mais diretamente os efeitos da paisagem na qualidade da água na região (Thomas et al., 2004). A localização das microbacias foi escolhida em função da eliminação de efeitos indiretos e abrangência de diferentes configurações de uso da terra no ano de 2002. 


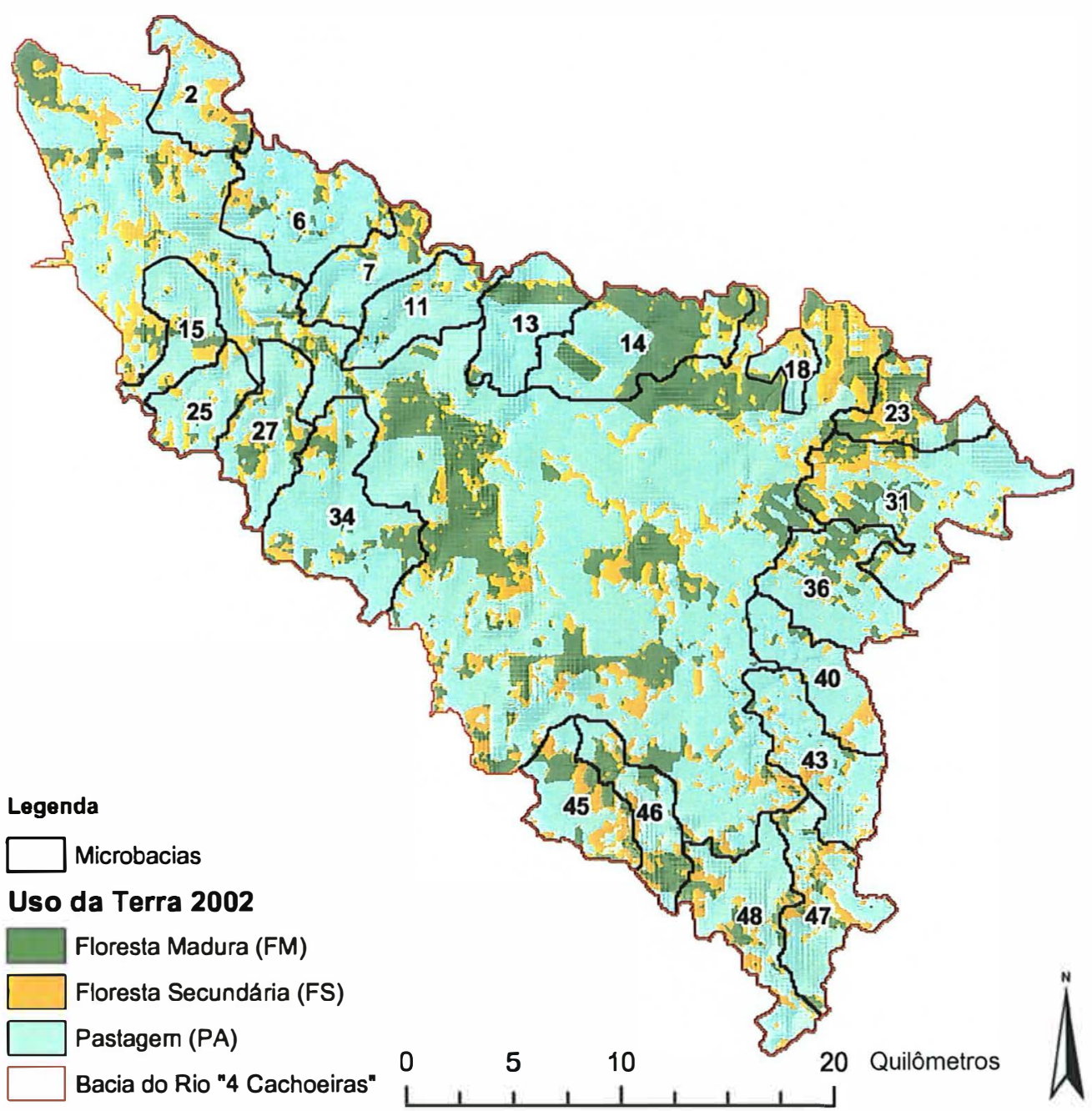

Figura 34 - Localização das microbacias selecionadas e uso da terra para o ano de 2002, na bacia do rio Quatro Cachoeiras, Rondônia

Dinâmica da estrutura da paisagem - baseando-se nos mapas de uso da terra entre 1984 e 2002, métricas da paisagem foram calculadas para cada classe de uso e ano estudado. Nove índices foram selecionados (Tabela 5) a partir de um estudo inicial (Ferraz et al., 2002) e de outros estudos de dinâmica da paisagem (Coppedge et al., 2001; Cushman \& Wallin, 2000; Reed et al., 1996; Ritters et al., 1995; Sachs et al., 1998; Tinker et al., 1998). Os índices foram calculados para as classes de uso da terra com o software Fragstats 3.3 
(McGarigal et al., 2002), utilizando-se cada microbacia selecionada como unidade de análise (paisagem) e regra de vizinhança para as oito células vizinhas.

Tabela 5. Índices selecionados para a análise de estrutura da paisagem

\begin{tabular}{clc}
\hline ÍNDICE & \multicolumn{1}{c}{ Descrição } & Unidade \\
\hline PLAND & Proporção de uso da terra & $\%$ \\
PD & Densidade de fragmentos & $\mathrm{N} / 100$ ha \\
LPI & Índice do maior fragmento & $\%$ \\
AREA_CV & Coeficiente de variação do tamanho do fragmento & $\%$ \\
ED & Densidade de borda & $\mathrm{m} / \mathrm{ha}$ \\
LSI & Índice de forma da paisagem & - \\
FRAC_AM & Dimensão fractal do fragmento ponderado pela área & - \\
ENN_MN & Dédia & $\mathrm{m}$ \\
IJI & Índice de justaposição & $\%$ \\
\hline
\end{tabular}

Para facilitar a visualização da dinâmica do uso da terra nas microbacias, dois novos mapas foram gerados por meio da combinação dos mapas históricos de uso da terra no ArcGIS 8.3 (ESRI, 2002), mantendo o histórico de uso da terra para cada pixel em um banco de dados acoplado. Os mapas derivados foram obtidos pela reclassificação dos pixels com base no banco de dados de histórico de uso, em função de dois aspectos:

a) Idade do desmatamento - mostrando o tempo decorrido (anos) entre a primeira ocorrência de desmatamento ( $\mathrm{FM} \rightarrow \mathrm{PA}$ ou $\mathrm{FM} \rightarrow \mathrm{FS}$ ) e o último ano da análise (2002) para cada pixel; e,

b) Estabilidade - mostrando o número de anos em que não houve alteração no uso da terra em cada pixel, iniciando-se a contagem inversa a partir de 2002. Por exemplo, uma área que não foi alterada de 1984 a 2002, recebeu estabilidade 18; uma área de floresta que foi desmatada em 1996, recebeu estabilidade 6. 
Análise de correlação das métricas da paisagem - as métricas da paisagem calculadas para as microbacias foram submetidas à Análise de Correlação de Pearson para identificar redundâncias entre os índices e reduzir o número de variáveis. A análise foi realizada para cada ano da série independentemente. Para se verificar a correlação no período, calculou-se o número total de vezes no período, em que houve correlação significativa a 95\% de probabilidade. É bem conhecido que métricas da paisagem são normalmente correlacionadas (Ritters et al., 1995), mas considerando-se que o padrão espacial da área de estudo é influenciado pelo desenho inicial das estradas, os índices foram testados com o objetivo de identificar quais seriam os mais importantes para avaliação da dinâmica da paisagem na região.

Análise de componentes principais (PCA) - a análise PCA foi realizada utilizando-se as proporções de uso da terra (PLAND) em cada ano para cada microbacia no período de 1984 a 2000, com o objetivo de reduzir o número de variáveis relativas à dinâmica do uso da terra no período estudado (Cifaldi et al., 2004). Para a análise utilizou-se o software Minitab 14.0 (Minitab, 2003) pelo método de matriz de correlação entre as variáveis (PLAND) para as 20 observações (microbacias). Na análise, utilizaram-se apenas as proporções de uso da terra (PLAND) para as classes Floresta Madura (FM) e Floresta Secundária (FS), já que a proporção da classe Pastagem (PA) apresentava alta correlação com Floresta Madura (FM) nesta área, segundo observado por Ferraz et al. (2002).

Índices de dinâmica do uso da terra - três índices baseados no uso da terra foram testados, a fim de se representar a dinâmica do uso da terra ao longo do período. Os índices foram calculados com base no tamanho das classes de uso FM, FS e PA para os diversos anos do período. O objetivo principal desta etapa foi obter indicadores que incorporassem aspectos da dinâmica considerados importantes para a qualidade da água. As três classes 
de uso foram utilizadas de maneira a captar fontes de variação diferenciadas que pudessem representar o histórico do uso da terra: taxa de desmatamento, dinâmica da vegetação secundária e tempo de permanência da pastagem:

\section{a. Taxa Anual de Desmatamento da Floresta Madura (TADFM) - este} indice teve como objetivo capturar a velocidade do desmatamento na microbacia por meio de uma taxa média normalizada. Altas taxas de desmatamento representam, ao mesmo tempo, grande atividade de desmatamento e mudanças bruscas na paisagem, ambos fatores considerados prejudiciais à qualidade da água.

O TADFM (equação 2) representa a taxa média de desmatamento observada para a classe $\mathrm{FM}$ ao longo dos anos ( $n$ ), e normalizada pelo tamanho da microbacia (CS). A unidade de TADFM é \%.ano-1 (proporção de área desmatada por ano). TADFM varia de zero (sem desmatamento) a $1 / n$ (desmatamento máximo em $n$ anos). Por exemplo, para uma área de 200 ha em cinco anos, TADFM irá variar de zero a $-0,20$ (ou $-200 / 5=-40$ ha / ano):

$$
T A D F M=\frac{\sum_{i=1}^{n-1} \frac{\left(F M_{i+1}-F M_{i}\right)}{Y_{i+1}-Y_{i}}}{(n-1)^{*} C S}
$$

Onde:

$$
\begin{aligned}
& F M_{i}=\text { tamanho da classe } F M \text { no ano } i \text { (ha) } \\
& Y i=\text { Ano } i \\
& n \quad=\text { número de anos estudados; } \mathrm{e}, \\
& C S=\text { tamanho da microbacia (ha). }
\end{aligned}
$$

b. Proporção Média da Floresta Secundária (PMFS) - este indice representa a dinâmica da vegetação secundária, considerada importante para a qualidade da água, já que o processo de derrubada e queima faz com que nutrientes do solo fiquem vulneráveis à lixiviação (Biggs et al., 2002). 
A opção de se utilizar a proporção média foi escolhida pela constatação de que áreas que apresentam maior proporção de vegetação secundária, também apresentam maior dinâmica em relação à esta classe de uso. Da mesma forma, a utilização de taxas de transição, exigiria o cálculo mais complexo, utilizando a matriz de transição, além do que pelo menos duas transições teriam que ser consideradas ( $F S \rightarrow P A$ e $F S \rightarrow F M)$.

Desse modo, o índice PMFS representa o tamanho médio da classe FS (Equação 3), ponderado pela área da bacia (CS). A unidade é \% (porcentagem) e o índice varia de zero (sem Floresta Secundária) a 1 (100\% de Floresta Secundária na microbacia).

Onde:

$$
P M F S=\frac{\sum_{i=1}^{n-1} F S_{i}}{n^{*} C S}
$$

$F S_{i}=$ tamanho da classe FS no ano $i$ (ha);

$n$ = número de anos estudados;

CS = tamanho da microbacia (ha).

c. Tempo Médio de Introdução da Pastagem (TMIP) - este índice representa a estabilidade das ações antrópicas nas microbacias, medindo o tempo decorrido desde a introdução de uma área de pastagem até o presente. A idade da pastagem é um dos maiores preditores das condições dos solos encontrados na região (Holmes et al., 2004). Considerou-se que pastagens antigas, introduzidas há muito tempo poderiam estar estabilizadas, sendo que efeitos na composição química da água seriam provenientes do tipo de manejo utilizado. Por outro lado, pastagens introduzidas recentemente estariam ainda instáveis com efeitos relacionados à lixiviação das cinzas e perda de solos (Krushe et al, 2004). 
Desse modo, este índice representa o tempo de permanência da classe PA em cada microbacia ao longo dos anos $(n)$, normalizado pelo tamanho da microbacia (CS). TMIP (Equação 4), não tem dimensão (unidade) e varia de zero (sem pastagem introduzida no período) a 1 (toda área com pastagem introduzida no primeiro ano do período). Por exemplo, para uma área de 200 ha, TMIP seria 1 (se 200 ha de pastagem fossem introduzidos no primeiro ano), 0,55 (Se 100 ha fosse introduzido no ano inicial e 100 ha no ano final), ou 0,1 (se 200 ha fossem introduzidos no último ano).

Onde:

$$
T M I P=\frac{\sum_{i=1}^{n}\left[\left(P A_{i}-P A_{i-1}\right) *\left(Y_{n}-Y_{i}\right)\right]}{(n-1) * C S}
$$

$$
\begin{aligned}
& P A i=\text { tamanho da classe PA no ano } i \text { (ha); } \\
& Y i=\text { ano } i \\
& n \quad=\text { número de anos estudados; } \mathrm{e} \\
& C S=\text { tamanho da microbacia (ha). }
\end{aligned}
$$

Avaliação dos índices de dinâmica do uso da terra - a fim de testar os índices propostos acima, realizou-se uma análise de correlação de Pearson com auxílio do software Minitab 14.0 (Minitab, 2003), entre os coeficientes dos componentes principais e os três índices. Desse modo, o objetivo desta análise foi avaliar a capacidade dos índices em representar a dinâmica do uso da terra.

Os índices também foram avaliados quanto à presença de redundâncias entre si e a capacidade de distinção das microbacias em função de suas diferentes dinâmicas. Para tal, realizou-se uma análise de componentes principais por meio de matriz de correlação e valores padronizados, representando no mesmo gráfico a variabilidade observada nas microbacias e indices (Gabriel, 1971). 
Análise de agrupamento para microbacias - a análise foi realizada com o objetivo de avaliar as condições das microbacias em função da estrutura da paisagem em 2002 e de seu histórico de uso da terra (1984 a 2000). Foram realizadas duas classificações para comparação:

a) Estrutura da paisagem 2002: utilizou-se a proporção de uso da terra (PLAND) para as classes FM e FS, excluindo-se a classe PA por estar correlacionada à classe FM. Alguns índices que não estiveram correlacionados a PLAND também foram selecionados para a análise; e,

b) Dinâmica do uso da terra entre 1984 e 2002: utilizaram-se os indices de dinâmica do uso da terra propostos anteriormente: TADFM, PMFS e TMIP.

A análise foi realizada com dados normalizados pelo método da ligação média de Pearson.

\subsection{Resultados}

Dinâmica do uso da terra - a dinâmica do uso da terra na bacia do rio Quatro Cachoeiras já foi descrita no Capitulo 3, sendo que neste capitulo será dada ênfase na avaliação do histórico do uso da terra, com foco principal nas microbacias.

A Figura 35 mostra o tempo decorrido desde o desmatamento inicial (1984 ou anteriormente) da floresta. Nota-se que o padrão de desmatamento tem início no entorno das estradas (áreas com idades entre 18 e 20 anos), seguindo na direção perpendicular das mesmas, formando um gradiente até os remanescentes florestais. A extensa área homogênea de pastagem localizada no centro da bacia, com idade aproximada de 12 anos, mostra uma grande propriedade instalada no ano de 1990. Na mesma propriedade também se localizam extensas áreas de floresta. 
As áreas com idades entre um e três anos, representam regiões de maior dinâmica nos últimos anos como, por exemplo, a extensa área triangular situada na parte centro-oeste da bacia, com áreas de floresta e áreas recém desmatadas. No referido local situava-se uma área de Floresta Madura (FM) incorporada a uma grande propriedade de criação de gado, mas que recentemente foi desapropriada para instalação de um novo assentamento de colonos. Considerando-se então o histórico da área, comparando-se o mapa de uso da terra em 2002 (Figura 34) e o mapa da Figura 35, nota-se claramente que áreas com pastagem em 2002, apresentam diferentes históricos, desde pastagens antigas até áreas recém introduzidas. A microbacia 2 por exemplo, encontra-se em área desmatada nos primeiros anos da série, a microbacia 18 foi totalmente desmatada no meio do período, enquanto que a microbacia 31 apresenta um conjunto de áreas de floresta, pastagens antigas e recentes. 


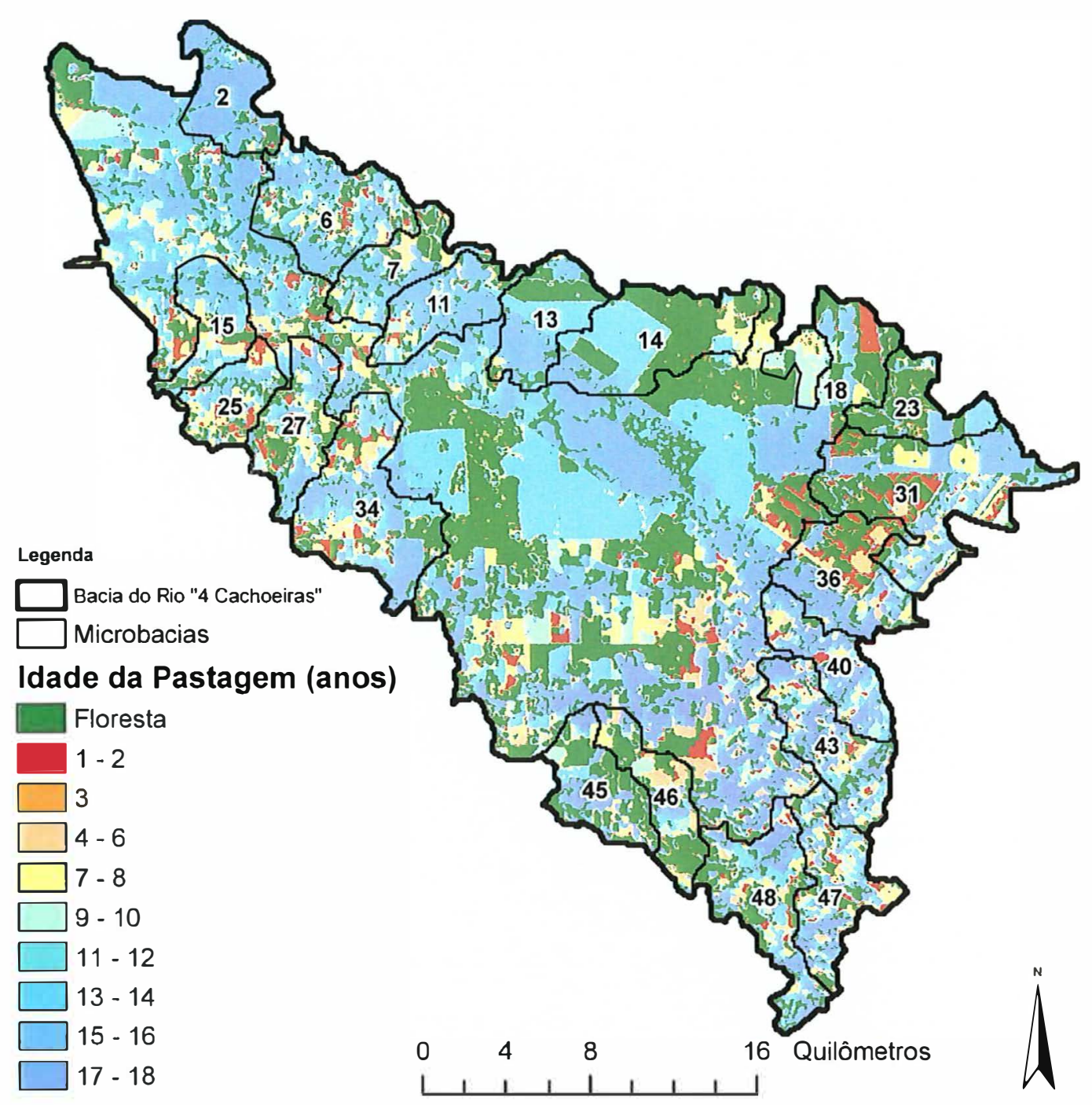

Figura 35 - Tempo decorrido (anos) desde a ocorrência do primeiro desmatamento (1984 ou anterior) até o ano de 2002, na bacia do rio Quatro Cachoeiras, Rondônia

Em relação à estabilidade do uso da terra no período (Figura 36), nota-se grande estabilidade nas regiões central e norte da bacia, seja pela existência de grandes áreas de floresta (centro) ou existência de áreas antigas de pastagem que não foram alteradas. As microbacias 13 e 14, por exemplo, aparecem com grande estabilidade, enquanto que as microbacias 25,43 e 47 mostram-se instáveis. 


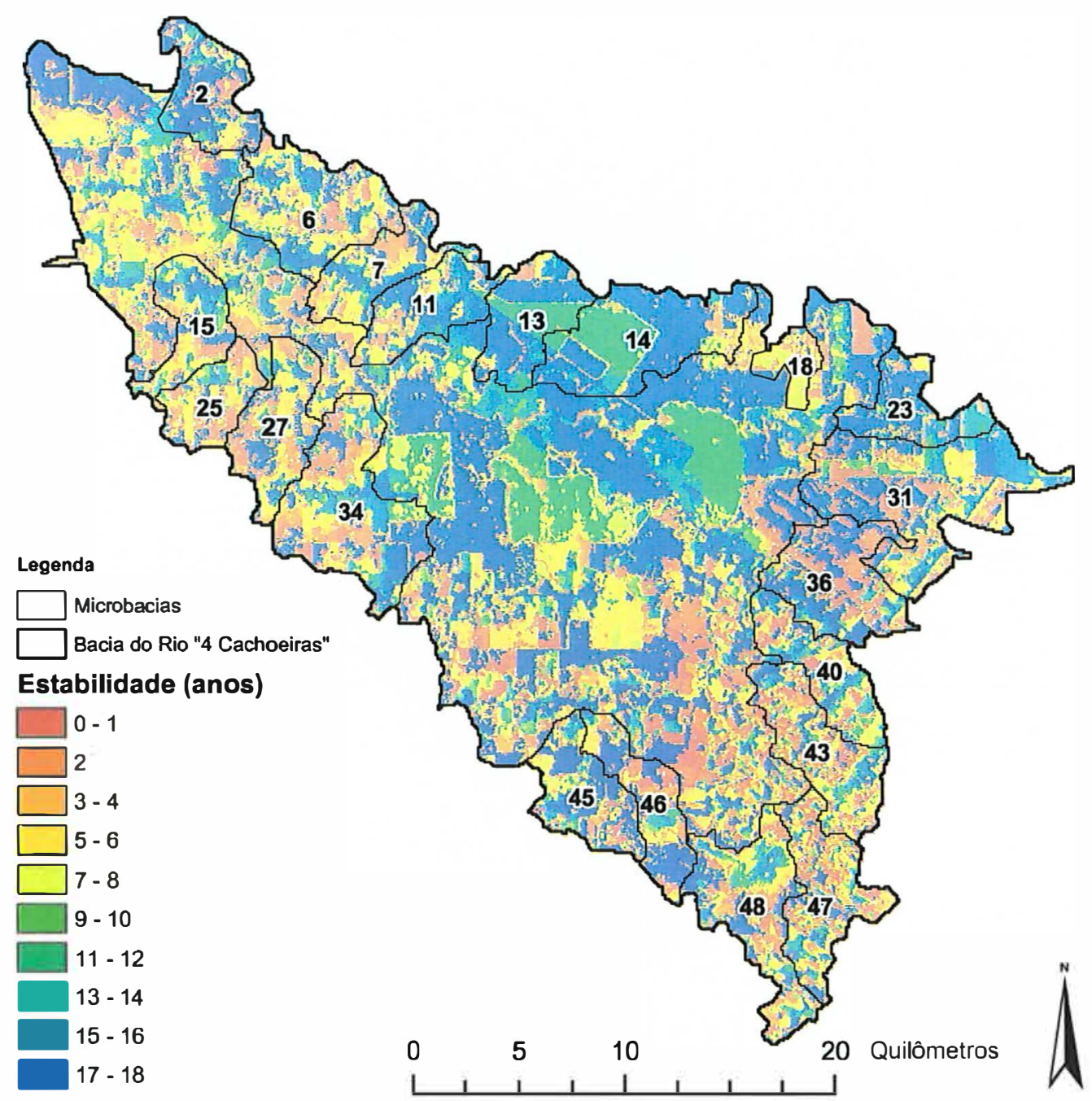

Figura 36 - Estabilidade média (ausência de transição) do uso da terra (em anos) para a bacia do rio Quatro Cachoeiras, Rondônia

Comparando-se os coeficientes de correlação entre as métricas da paisagem (Tabela 6), observa-se que a maioria dos índices avaliados está correlacionada à proporção da paisagem (PLAND). Os índices que apresentaram menor correlação com PLAND estão relacionados à forma (LSI) e coeficiente de variação de tamanho (AREA_CV). Dessa forma, optou-se pela utilização das proporções de uso da terra no estudo de dinâmica da paisagem na área de estudo. 
Tabela 6. Correlação entre as métricas de paisagem para as microbacias. Os números representam a freqüência absoluta de correlações significativas (95\% de probabilidade) nos dez anos estudados (A_CV é uma forma abreviada de AREA_CV)

\begin{tabular}{|c|c|c|c|c|c|c|c|c|c|c|c|c|c|c|c|c|c|c|c|c|c|c|c|c|c|c|}
\hline & $\begin{array}{l}\sum_{4} \\
0^{\prime} \\
2^{2} \\
\vdots \\
0\end{array}$ & 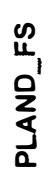 & $\begin{array}{l}a_{a} \\
\sum^{\prime} \\
\sum_{a}\end{array}$ & $\begin{array}{l}\frac{\Sigma}{10} \\
\text { o' } \\
\text { a }\end{array}$ & $\begin{array}{l}\text { 吕 } \\
\mathbf{Q}^{\prime}\end{array}$ & $\begin{array}{l}\nwarrow \\
a^{\prime} \\
a^{\prime}\end{array}$ & $\frac{\Sigma}{\Sigma_{1}}$ & $\frac{\infty}{\underline{4}}$ & $\begin{array}{l}\nwarrow \\
a_{1}^{\prime} \\
a^{\prime}\end{array}$ & 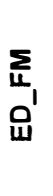 & $\begin{array}{l}\text { 足 } \\
\text { 㞻 }\end{array}$ & $\begin{array}{l}\nwarrow \\
\vdots \\
\text { ఏ }\end{array}$ & $\frac{\sum_{u}}{\bar{s}^{\prime}}$ & $\begin{array}{l}\text { జ } \\
\bar{g}\end{array}$ & & 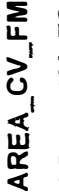 & 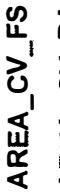 & 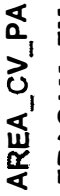 & 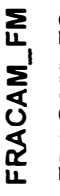 & 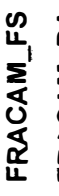 & 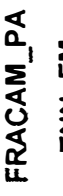 & $\begin{array}{l}\sum_{u} \\
\sum_{u}^{\prime}\end{array}$ & $\sum_{u}^{\infty}$ & & & \\
\hline \multicolumn{27}{|l|}{ PLAND_FM } \\
\hline \multicolumn{27}{|l|}{ PLAND_FS } \\
\hline PLAND_PA & 10 & & & & & & & & & & & & & & & & & & & & & & & & & \\
\hline PD_FM & 1 & 2 & & & & & & & & & & & & & & & & & & & & & & & & \\
\hline PD_FS & & 3 & & 3 & & & & & & & & & & & & & & & & & & & & & & \\
\hline PD_PA & 1 & 2 & & 3 & 10 & & & & & & & & & & & & & & & & & & & & & \\
\hline LPI_FM & 10 & & 10 & 5 & & & & & & & & & & & & & & & & & & & & & & \\
\hline LPI_FS & & 4 & & & & & & & & & & & & & & & & & & & & & & & & \\
\hline LPI_PA & 10 & & 10 & & & & 5 & & & & & & & & & & & & & & & & & & & \\
\hline ED_FM & 10 & 1 & 10 & & 6 & 1 & & & 10 & & & & & & & & & & & & & & & & & \\
\hline ED_FS & & 10 & & 2 & 10 & 4 & & 3 & & 6 & & & & & & & & & & & & & & & & \\
\hline ED_PA & 10 & 3 & 3 & 3 & 3 & 3 & 10 & 1 & 1 & & 3 & & & & & & & & & & & & & & & \\
\hline LSI_FM & & 1 & & 1 & 2 & & & & & 4 & 8 & & & & & & & & & & & & & & & \\
\hline LSI_FS & & 1 & & 1 & 2 & & & & & 1 & 8 & & 10 & & & & & & & & & & & & & \\
\hline LSI_PA & & 2 & & 3 & 3 & 2 & & & & & 3 & 3 & 10 & 10 & & & & & & & & & & & & \\
\hline A_CV_FM & 3 & & 3 & 5 & & & 3 & & 3 & & 1 & & 1 & 4 & 1 & & & & & & & & & & & \\
\hline A_CV_FS & & 3 & & & & & & 7 & & & & & & & & 1 & & & & & & & & & & \\
\hline A_CV_PA & & 1 & & 1 & 1 & 3 & 1 & & & & 1 & 3 & 3 & 3 & 3 & & & & & & & & & & & \\
\hline FRAM_FM & 3 & & 10 & 2 & 1 & & 6 & & 10 & 10 & 1 & 3 & 5 & 2 & 1 & 4 & & & & & & & & & & \\
\hline FRAM_FS & & 4 & & & & & & 3 & & & 5 & & & 2 & & 1 & 4 & & & & & & & & & \\
\hline FRAM_PA & 7 & & 3 & 1 & 2 & & 3 & & 3 & 3 & 1 & 10 & 1 & 3 & 3 & & & 8 & 2 & & & & & & & \\
\hline ENN_FM & 2 & & 4 & & 1 & 1 & 1 & & 3 & 4 & & 1 & 1 & & 1 & & & & 1 & & & & & & & \\
\hline ENN_FS & 1 & 10 & & 2 & 10 & 8 & & 1 & & 1 & 10 & & 1 & 1 & 3 & & & 1 & & & & & & & & \\
\hline ENN_PA & 3 & & & & 2 & & 3 & & & & & 3 & & & 3 & & & & & & 3 & & 2 & & & \\
\hline IJI_FM & & 3 & 8 & & & & & 3 & 2 & & & 5 & & & & & 2 & 2 & & 3 & & & & & & \\
\hline IJI_FS & 5 & & 5 & & & & 5 & & 1 & 2 & & 5 & & & & & & 6 & 1 & & 5 & 1 & & 2 & 5 & \\
\hline IJI_PA & & 3 & & & 1 & & & 3 & & 1 & & & 1 & & & & 3 & & 1 & 3 & 1 & & & 1 & 3 & 1 \\
\hline
\end{tabular}

Dessa forma a análise dos componentes principais foi realizada utilizando-se 20 variáveis de proporção de uso da terra (PLAND), para cada ano e classe ( $F M$ e $F S$ ). Os resultados da análise mostraram que os quatro primeiros componentes principais foram capazes de representar cerca de $90 \%$ da variação do uso da terra nas microbacias no período (Tabela 7). 
Tabela 7. Análise de Componentes Principais - coeficientes dos quatro primeiros componentes em relação à porcentagem de uso (PLAND) em cada ano e classe (FM e FS)

\begin{tabular}{ccccccccc}
\hline & \multicolumn{4}{c}{ PLAND_FM } & & \multicolumn{4}{c}{ PLAND_FS } \\
Anos & CP1 & CP2 & $\mathbf{C P 3}$ & $\mathbf{C P 4}$ & $\mathbf{C P 1}$ & $\mathbf{C P 2}$ & $\mathbf{C P 3}$ & $\mathbf{C P 4}$ \\
\hline $\mathbf{1 9 8 4}$ & $\mathbf{- 0 , 3 0}$ & $-0,02$ & 0,18 & $\mathbf{0 , 2 7}$ & $-0,01$ & $\mathbf{0 , 3 4}$ & $-0,16$ & $\mathbf{- 0 , 3 3}$ \\
$\mathbf{1 9 8 6}$ & $\mathbf{- 0 , 3 3}$ & $-0,07$ & 0,20 & $\mathbf{0 , 2 0}$ & 0,00 & $\mathbf{0 , 3 4}$ & $-0,19$ & $\mathbf{- 0 , 3 3}$ \\
$\mathbf{1 9 8 8}$ & $\mathbf{- 0 , 3 3}$ & $-0,06$ & 0,15 & 0,09 & 0,01 & $\mathbf{0 , 3 7}$ & $-0,01$ & $-0,17$ \\
$\mathbf{1 9 9 0}$ & $\mathbf{- 0 , 3 4}$ & $-0,05$ & 0,19 & $-0,07$ & $-0,02$ & $\mathbf{0 , 3 6}$ & $-0,12$ & 0,05 \\
$\mathbf{1 9 9 2}$ & $\mathbf{- 0 , 3 4}$ & 0,04 & 0,18 & $-0,17$ & 0,04 & $\mathbf{0 , 3 3}$ & $-0,08$ & $\mathbf{0 , 5 0}$ \\
$\mathbf{1 9 9 4}$ & $\mathbf{- 0 , 3 3}$ & 0,01 & $\mathbf{- 0 , 2 6}$ & 0,09 & 0,11 & $\mathbf{0 , 3 2}$ & $-0,18$ & $\mathbf{0 , 4 4}$ \\
$\mathbf{1 9 9 6}$ & $\mathbf{- 0 , 3 0}$ & $-0,04$ & $\mathbf{- 0 , 3 9}$ & $-0,06$ & $-0,12$ & $\mathbf{0 , 3 2}$ & 0,18 & 0,17 \\
$\mathbf{1 9 9 8}$ & $\mathbf{- 0 , 2 8}$ & $-0,07$ & $\mathbf{- 0 , 4 3}$ & 0,08 & $-0,13$ & $\mathbf{0 , 3 0}$ & 0,15 & 0,01 \\
$\mathbf{2 0 0 0}$ & $\mathbf{- 0 , 2 7}$ & $-0,10$ & $\mathbf{- 0 , 4 0}$ & $-0,09$ & $-0,20$ & $\mathbf{0 , 2 2}$ & 0,32 & $\mathbf{- 0 , 3 2}$ \\
& & & & & & & & \\
Autovalores & $\mathbf{7 , 0 4}$ & $\mathbf{6 , 0 5}$ & $\mathbf{2 , 2 7}$ & 0,93 & & & & \\
Variância (\%) & $\mathbf{0 , 3 9}$ & $\mathbf{0 , 3 3}$ & $\mathbf{0 , 1 3}$ & 0,05 & & & & \\
Var. Acumul. (\%) & $\mathbf{0 , 3 9}$ & $\mathbf{0 , 7 2}$ & $\mathbf{0 , 8 5}$ & 0,90 & & & & \\
\hline
\end{tabular}

Observando-se a variação da resposta dos componentes principais ao longo do período (Figura 37), observa-se que o componente um esteve mais relacionado ao processo de desmatamento, já que apresentou resposta negativa em relação a PLAND_FM. O componente dois, por sua vez, representou melhor a proporção de Floresta Secundária (PLAND_FS). A dominância da paisagem poderia estar representada pelo componente três, já que sua resposta apresenta correlação positiva à PLAND_FM, invertendo-se a partir do ano 1990, padrão também observado na dinâmica da paisagem para toda a bacia com predomínio da Pastagem a partir deste ano. O componente quatro parece estar relacionado à dinâmica da Floresta Secundária (FS). 


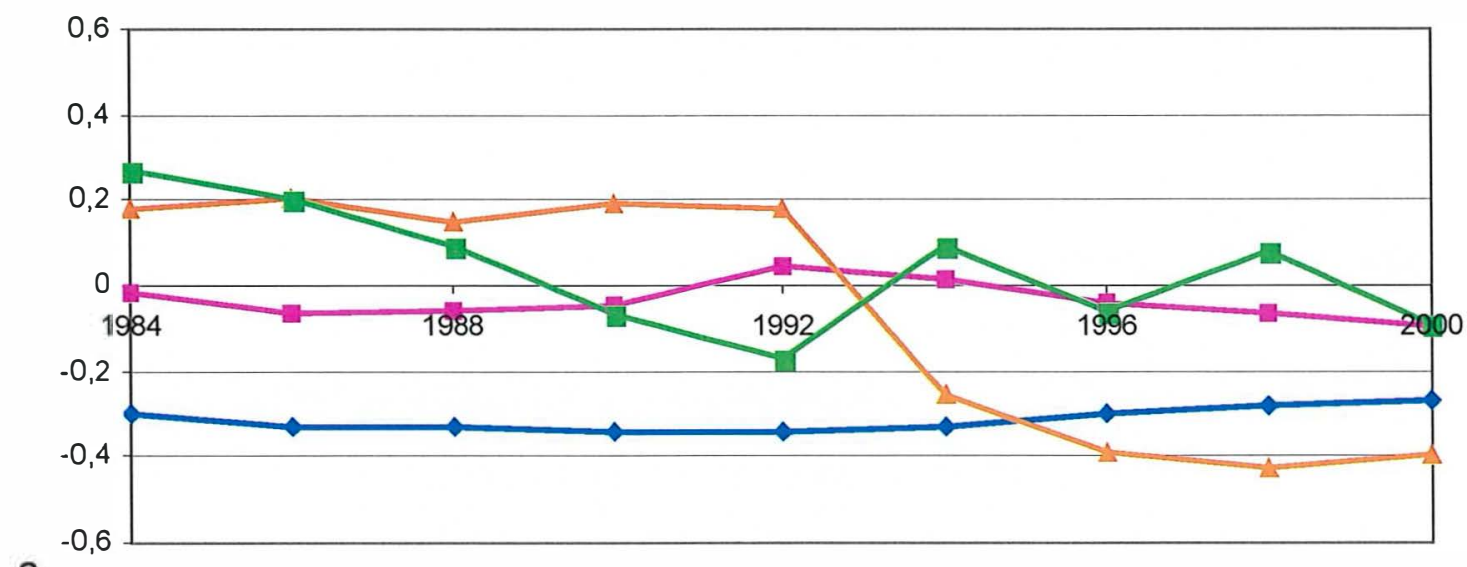

a

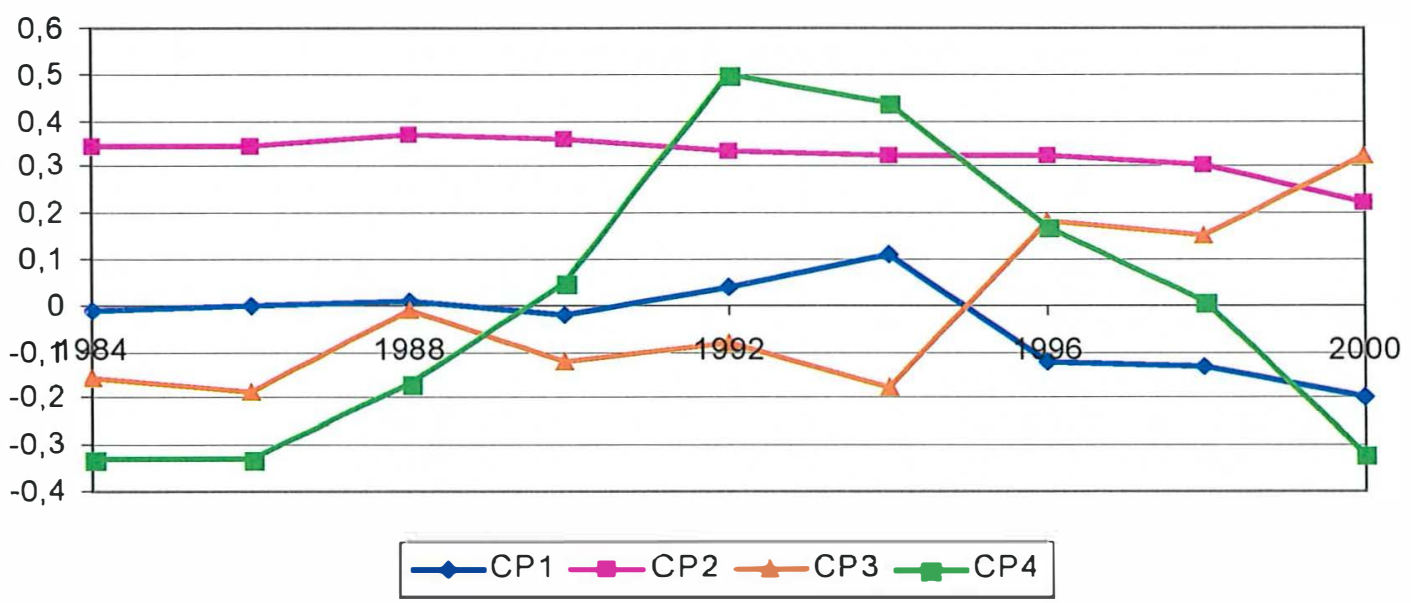

Figura 37 - Evolução dos coeficientes dos componentes principais ao longo dos anos em relação à proporção de uso da terra (PLAND) para (a) FM e, (b) FS

Com relação aos índices de dinâmica do uso da terra calculados, nota-se que TADFM apresentou valores para as microbacias entre $0,5 \%$ e $5,5 \%$, ou seja, uma variação significativa indicando que as microbacias apresentam taxas de desmatamento diferenciadas. As maiores taxas foram observadas nas microbacias $18(5,5 \%), 25(4,1 \%)$ e $40(4,1 \%)$, respectivamente, enquanto que as menores taxas ocorreram nas microbacias $2(0,5 \%), 11(1,8 \%)$ e $45(1,9 \%)$, respectivamente. 
O índice PMFS apresentou valores entre $6 \%$ e $20 \%$, sendo que as microbacias com maior proporção média de FS foram 45 (20\%) e 48 (17\%), enquanto que as microbacias de menor proporção foram 13 (6\%), 11 (9\%) e 36 (9\%). Quanto ao TMIP, as microbacias com maior tempo de pastagens introduzidas foram $2(0,79), 11(0,70)$ e $13(0,63)$, enquanto que as com menor tempo de introdução foram $23(0,26), 46(0,27)$ e $27(0,32)$. Analisando-se os coeficientes das observações (microbacias) e variáveis (índices) em relação aos dois primeiros componentes de variação por meio do gráfico Biplot (Gabriel, 1971) (Figura 38), nota-se que os índices escolhidos conseguem separar bem microbacias com dinâmica diferenciada como, por exemplo, as de número 2, 11 e 13 (alto TMIP), 14 (baixo TMIP, alta TADFM e baixa PMFS) e 45 (baixo TMIP e alto TMFS).

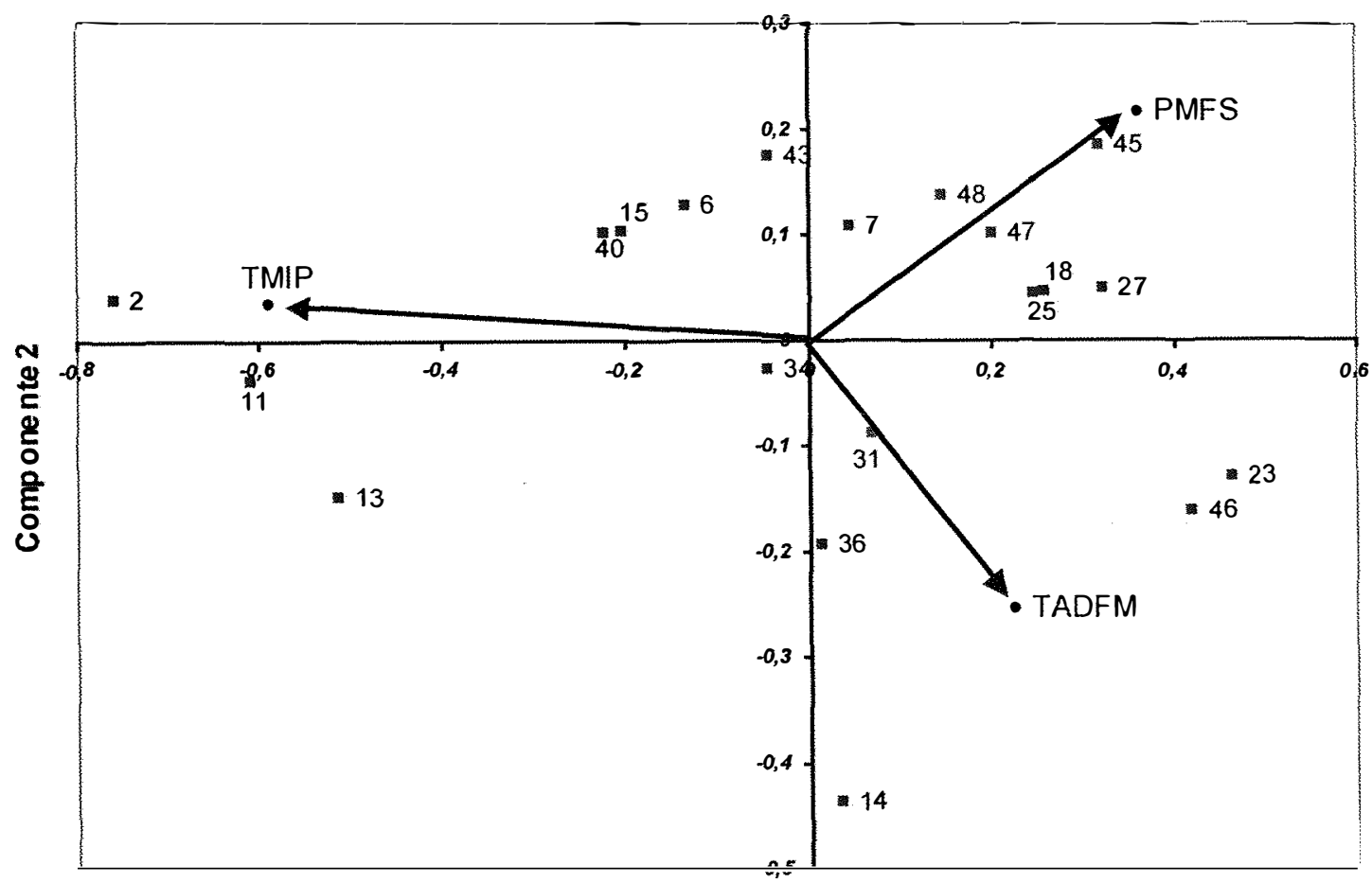

Componente 1

Figura 38 - Coeficientes dos índices propostos e das microbacias avaliados em relação aos dois primeiros componentes de variação 
A análise de correlação entre componentes e índices de dinâmica do uso da terra mostrou que os índices de dinâmica do uso da terra são capazes de representar a variação dos quatro primeiros componentes principais, com CP1 representado pelo índice TMIP, CP2 representado por PMFS, TADFM representando CP3 e CP4. Como os componentes são responsáveis por $90 \%$ da variação na dinâmica do uso da terra, os índices estão representando boa parte da variabilidade, já que estão correlacionados aos componentes principais (Tabela 8).

Tabela 8. Correlação entre índices de dinâmica do uso da terra e componentes principais da dinâmica do uso da terra. Em negrito, valores significativos a $p<0,05$

\begin{tabular}{c|cccc}
\hline Índices & CP1 & CP2 & CP3 & CP4 \\
\hline TADFM & 0,376 & $-0,158$ & $\mathbf{0 , 7 1 7}$ & $-\mathbf{0 , 4 3 9}$ \\
PMFS & $-0,103$ & $\mathbf{0 , 9 8 8}$ & 0,005 & $-0,002$ \\
TMIP & $\mathbf{0 , 9 6 3}$ & $-0,246$ & 0,090 & $-0,013$ \\
\hline
\end{tabular}

As correlações comprovam o que foi observado na resposta dos principais componentes em relação à proporção de uso da terra (PLAND), ou seja, primeiro componente ligado ao processo de desmatamento (TMIP), componente dois ligado à dinâmica da Floresta Secundária (PMFS) e componente três relacionado à dominância da paisagem (TADFM).

$\mathrm{Na}$ análise de agrupamentos que considerou a dinâmica do uso da terra por meio dos índices de dinâmica, cinco grupos foram formados conforme pode ser observado na Figura 39:

- Grupo 1 - microbacias 2, 11 e 13 - áreas com dominância de pastagens antigas, baixas taxas de desmatamento e dinâmica intermediária de Floresta Secundária (FS);

a Grupo II - microbacia 14 - área com baixa presença de FS em todo o período, provavelmente por estar situada em grande propriedade; 
- Grupo III - microbacias 23 e 46 - áreas com pastagens introduzidas recentemente, valores intermediários para taxa de desmatamento e proporção de FS;

- Grupo IV - microbacia 45 - áreas com baixa taxa de desmatamento e alta dinâmica de FS; e,

- Grupo V - demais microbacias, as quais apresentam valores intermediários para os três índices de dinâmica avaliados. No entanto, dois subgrupos poderiam ser ainda separados, pelas diferenças em relação à intensidade da dinâmica no uso da terra.

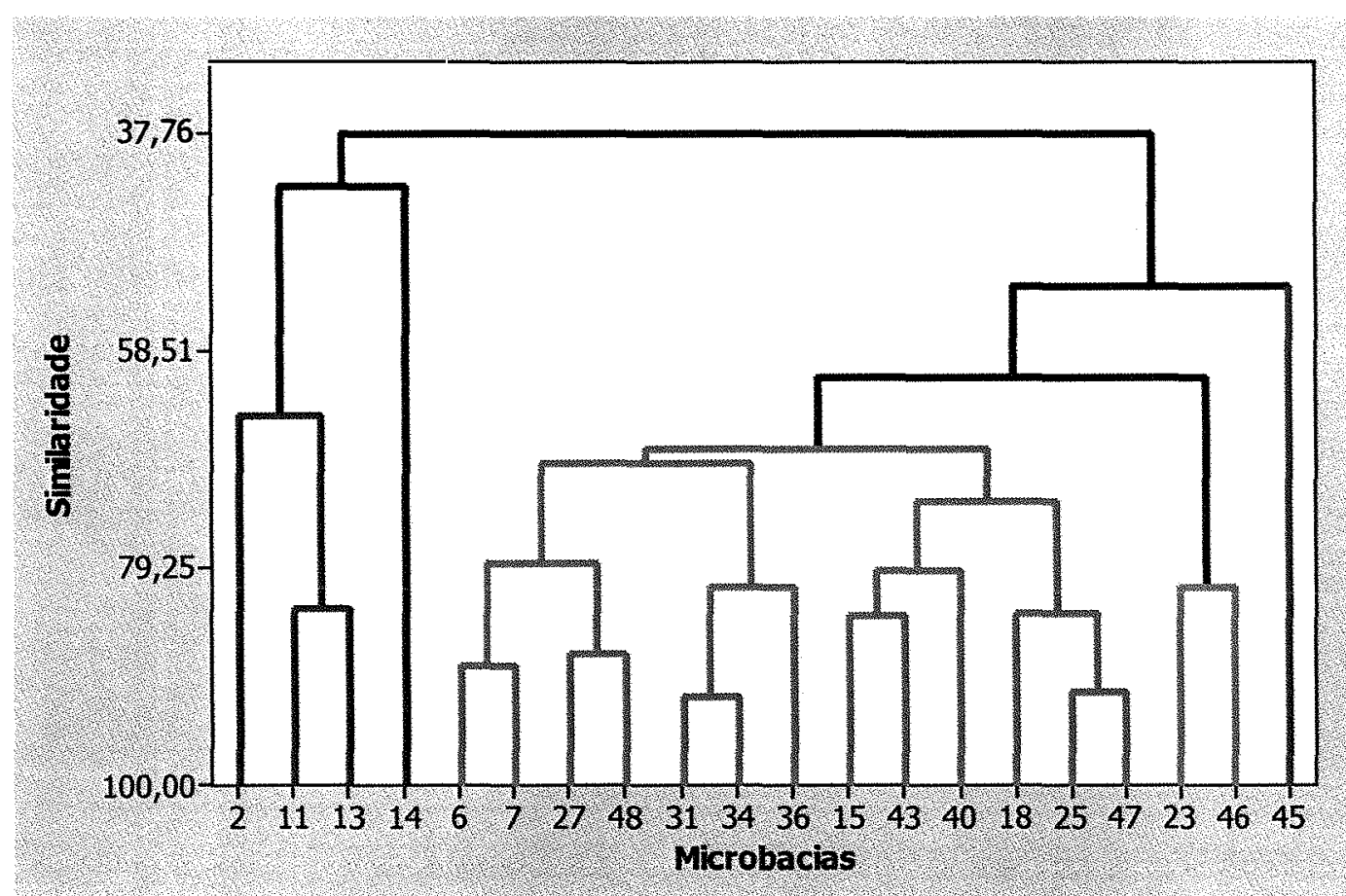

Figura 39 - Dendrograma de classificação das microbacias em função da dinâmica do uso da terra nos últimos 18 anos 
Estrutura da paisagem das microbacias em 2002 - na Figura 40, são apresentados os valores obtidos para as métricas da paisagem nas microbacias. Apesar da estrutura bastante semelhante, algumas microbacias apresentaram valores discrepantes da média. A microbacia 2, por exemplo, apresenta grande proporção de Floresta Secundária (PLAND_FS) e maior distância entre os fragmentos de Floresta Madura (ENN_FM), a microbacia 13 apresenta baixa proporção de Floresta Secundária (PLAND_FS), baixa densidade de fragmentos (PD), forma simples (expressa por LSI) e maior distância entre fragmentos de Floresta Madura (ENN_FM).

A microbacia 14 destaca-se pela grande proporção de Floresta Madura (PLAND_FM) e dominância da paisagem por esta classe de uso da terra, o qual encontra-se concentrada em grandes áreas de floresta. A maior proporção de Floresta Madura (PLAND_FM) encontra-se na microbacia 23, com maior proximidade de seus fragmentos (ENN_FM) e maior dominância da paisagem (LPI_MF). As microbacias 45 e 46 também se destacam pela grande proporção de Floresta Madura em 2002. 

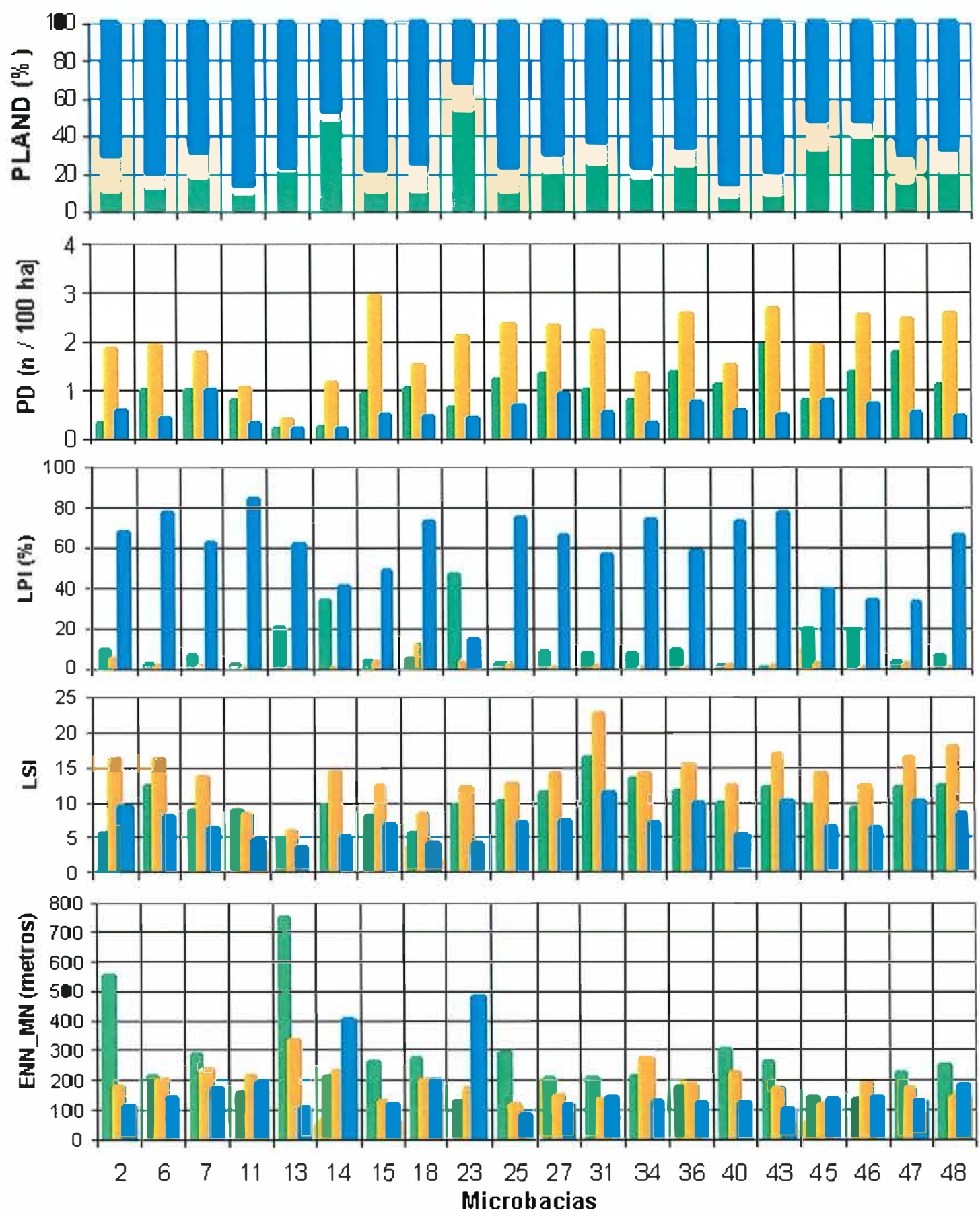

Floresta Madura (FM) Floresta Secundánia (FS) Pastagen (PA)

Figura 40 - Valores da estrutura da paisagem (PLAND, PD, LPI, LSI e ENN_MN) referentes ao ano de 2002, calculados para as três classes de uso da terra das 20 microbacias (eixo $\mathrm{x}$ ) 
$\mathrm{Na}$ análise de agrupamentos em que a estrutura da paisagem em 2002 foi considerada, seis grupos foram formados (Figura 41):

- Grupo I - microbacias 2 e 18 - áreas de FM bastante reduzidas e fragmentadas, dominância de PA e grande proporção de FS;

- Grupo II - microbacia 31 - área com maior complexidade de forma;

- Grupo III - microbacias 11 e 14 - áreas com baixa proporção de FS e poucos fragmentos, sendo que a última distingue-se pela grande proporção de FM;

- Grupo IV - microbacia 23 - área com mais de $50 \%$ cobertos por FM;

- Grupo V - microbacia 13 - bloco de FM e presença mínima de FS, pois esta microbacia está situada em uma grande propriedade; e,

- Grupo VI - demais microbacias que apresentaram valores intermediários para os indices avaliados.

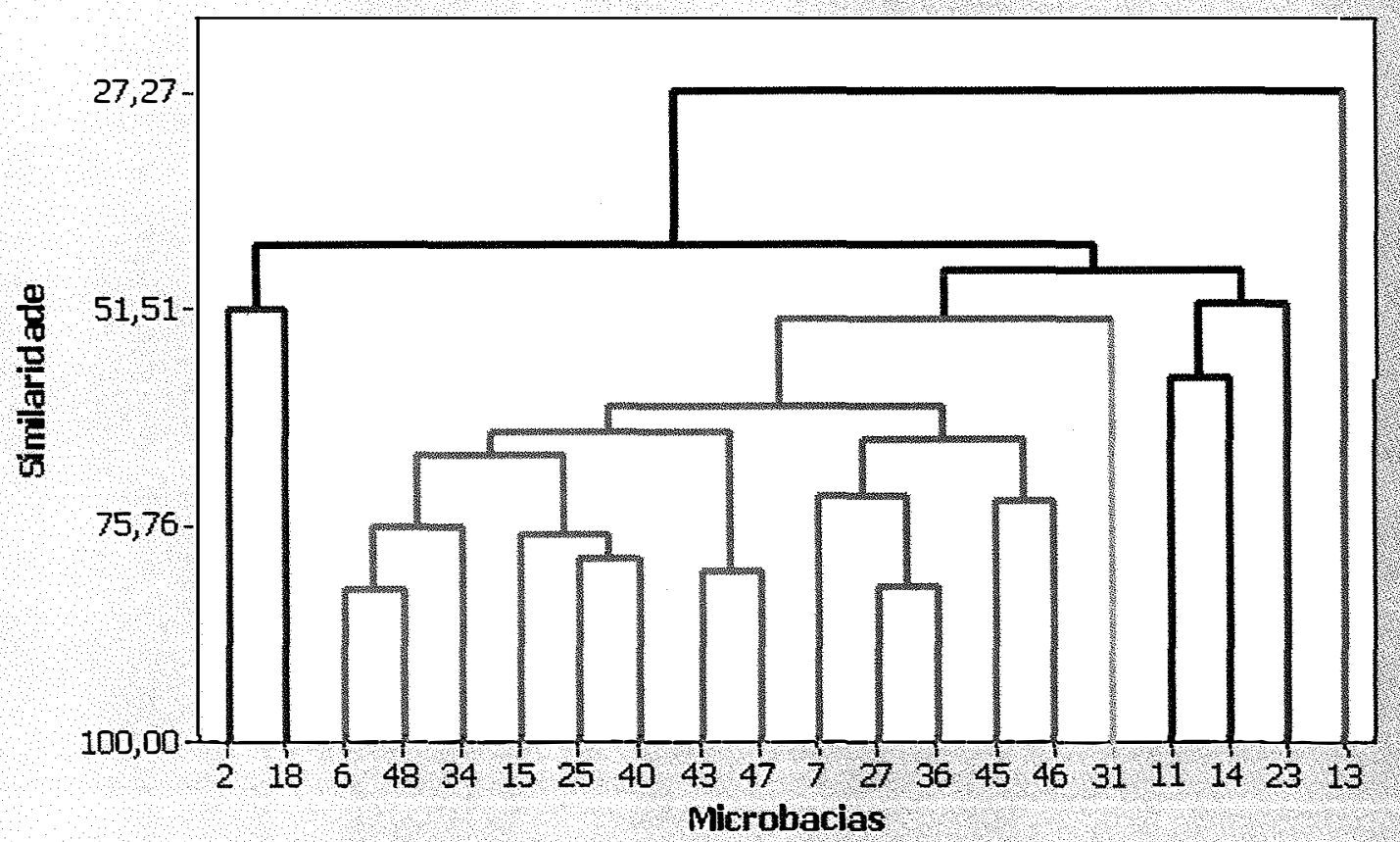

Figura 41 - Dendrograma de classificação das microbacias em função da estrutura da paisagem em 2002 


\subsection{Discussão}

As métricas da paisagem que foram consideradas mais representativas da estrutura da paisagem no período foram: proporção do uso da terra (PLAND), densidade de fragmentos (PD), indice de forma (LSI), coeficiente de variação de tamanho (AREA_CV) e, distância média do vizinho mais próximo (ENN). A correlação observada entre as métricas da paisagem já era esperada, segundo observações de diversos autores como Ritters et al. (1995) e Lausch \& Herzog (2002), que também observaram cerca de cinco componentes de variabilidade. É interessante notar as altas correlações entre PLAND e demais métricas também observadas por Cifaldi et al., (2004), mostrando que é possivel a utilização da proporção do uso da terra (PLAND) para representar grande parte da variabilidade mensurada pelas métricas da paisagem, na escala e condições estudadas. No entanto, isto somente se aplica com a utilização da proporção de uso da terra (PLAND) para as três classes estudadas e não somente para a classe floresta (ou de maior interesse), técnica bastante comum em estudos de fragmentação (Collinge, 1996; Jorge \& Garcia, 1997). Considerando-se a alta correlação observada, justifica-se a utilização da proporção de uso da terra no estudo da dinâmica da paisagem, inclusive com a utilização de índices de dinâmica.

Os indices de dinâmica avaliados apresentaram um bom desempenho quanto à representação da dinâmica do uso da terra nas microbacias. Os indices TMIP e PMFS apresentaram os melhores desempenhos, com altos coeficientes de correlação em relação aos dois primeiros componentes de variação, respectivamente. Estes índices poderão ser importantes na avaliação da influência da dinâmica do uso da terra na qualidade da água, já que a pastagem é um dos maiores preditores da composição química dos rios na região (Ballester et al, 2003) e, a vegetação secundária exerce uma grande influência na qualidade da água de córregos na região (Krushe et al, 2004). 
$O$ indice TADFM representou bem a intensidade do desmatamento, mas ele poderia ser subdividido em dois índices, calculados para diferentes períodos: início da série até a metade e deste ponto até o presente. Desse modo, poderia ser evitada a diluição de altas taxas de desmatamento ocorridas em anos recentes, o que provavelmente influenciaria mais a qualidade da água. De qualquer forma, a velocidade do desmatamento representada por TADFM, pode não apresentar grande variabilidade na região, devido às características semelhantes de ocupação encontradas. No entanto, esta variável pode ser importante considerando-se regiões distintas em Rondônia que apresentam diferentes taxas de desmatamento segundo observado por Roberts et al. (2002).

Os indices propostos, em geral representaram bem a variabilidade da dinâmica do uso da terra, trazendo para o presente informações sobre o histórico de cada microbacia, funcionando como indicadores, pois são de fácil compreensão e cálculo. Escada \& Alves (2003) propuseram três indicadores de intensificação de uso da terra para unidades de ocupação em Rondônia, baseados no cálculo da fração desmatada, taxa de desmatamento e fração de floresta cortada. Os resultados obtidos estão de acordo com observado neste estudo, pois se verificou a importância do uso de indicadores para compreender o processo de ocupação nas propriedades. A abordagem do uso de indicadores, quando comparada ao uso de trajetórias de uso da terra (Hietel et al., 2004), apresenta vantagens como facilidade de cálculo e interpretação dos resultados. No entanto, estes indicadores são específicos para regiões com alta influência antrópica na Amazônia como é o caso da região central de Rondônia e consideram apenas as classes de uso mais importantes para a região. A adaptação dos mesmos para outras regiões deverá levar em consideração as características dominantes da paisagem, principais atividades desenvolvidas e o processo ecológico envolvido para o qual interessa entender os efeitos da dinâmica já que regiões em processo de desmatamento como Pará, Mato 
Grosso e Rondônia apresentam diferentes modelos de ocupação e de atividade agrícola (Cardille \& Folley, 2003).

Conforme também observado por Lausch \& Herzog (2002), notou-se que a utilização de indicadores baseados na paisagem apresenta algumas restrições como a aplicação de sensoriamento remoto, padronização das técnicas utilizadas, seleção de indicadores e escolha da unidade espacial para integração. No entanto, neste estudo considerou-se que os indicadores e a unidade espacial utilizada (microbacia) foram adequados.

Com relação aos componentes de variação observados nos indicadores de dinâmica do uso da terra, duas dimensões poderiam ser consideradas no gráfico de componentes principais: tempo de distúrbio (eixo $x$ ) $e$ taxa/intensidade de uso (eixo y) (Figura 42). Desse modo microbacias no quadrante I poderiam ser consideradas de uso mais antigo, porém com baixa intensidade de uso (processo de desmatamento lento), principalmente áreas como a da microbacia 2, com pequenos proprietários instalados nos primeiros anos. No quadrante II, áreas de pequenos proprietários com desmatamento mais recente, alta dinâmica de FS como, por exemplo, a microbacia 18. As áreas de grandes propriedades estão localizadas nos quadrantes III e IV (microbacias 11 e 13), com maior intensidade de uso, sendo que no quadrante III, estão as áreas mais antigas com baixa presença de FS e no quadrante IV as mais recentes.

A estrutura da paisagem em 2002 também refletiu a dinâmica do uso da terra no período, já que muitas microbacias que foram separadas na análise pela dinâmica, também o foram pela análise da estrutura (por exemplo, microbacias 2, 11, 13, 14 e 23 com círculos em vermelho). Este fato, confirma as diferenças na estrutura da paisagem devido a diferentes regimes de manejo, observadas por Metzger (2003) na região Amazônica. Desse modo, a estrutura da paisagem consegue captar um pouco da dinâmica do uso da terra, pois sua condição atual reflete os efeitos acumulativos na paisagem das atividades desenvolvidas no local. Isto é interessante, pois explica algumas relações entre 
a estrutura da paisagem e qualidade da água. Por exemplo, uma relação entre Densidade Fragmentos e qualidade da água não parece ter sentido causaefeito, mas relação pode ser explicada, considerando-se que esta métrica representa a variabilidade decorrente da dinâmica do uso da terra como atividade e manejo utilizado.

A relação entre a dinâmica do uso da terra e a estrutura da paisagem em 2002 também pode ser observada na Figura 42, com duas dimensões principais em 2002: dominância da pastagem (eixo x) e área de Floresta Madura (eixo y), formando um gradiente de fragmentação partindo do quadrante IV em direção ao quadrante I. Neste gradiente, pode-se identificar alguns grupos de microbacias com estrutura da paisagem semelhante em 2002 (contornos em verde). As microbacias 18, 23 e 31 não se encaixam muito bem nesta estrutura por serem áreas de desmatamento muito recente com alta dinâmica.

A fragmentação da paisagem na região parece estar associada então, positivamente ao tempo de distúrbio, o que parece óbvio, já que áreas mais antigas provavelmente serão mais fragmentadas. No entanto, a fragmentação está negativamente associada à intensidade de uso das áreas, pois áreas mais estáveis com uso intensivo como pastagens intensivamente manejadas apresentam-se menos fragmentadas. Desse modo, a intensificação de uso com tecnologia apropriada parece ser uma alternativa para conter o processo de desmatamento e fragmentação na região. Os resultados diferem do estudo realizado por Metzger (2003), que observou em pequenas propriedades, na região Bragantina do Pará, que a fragmentação da paisagem é maior com a utilização de períodos reduzidos de pousio (maior intensificação de uso). As diferenças observadas podem estar relacionadas ao fato de que, neste estudo, foram analisadas áreas com presença de pequenas e grandes propriedades, com diferentes tipos de manejo. 


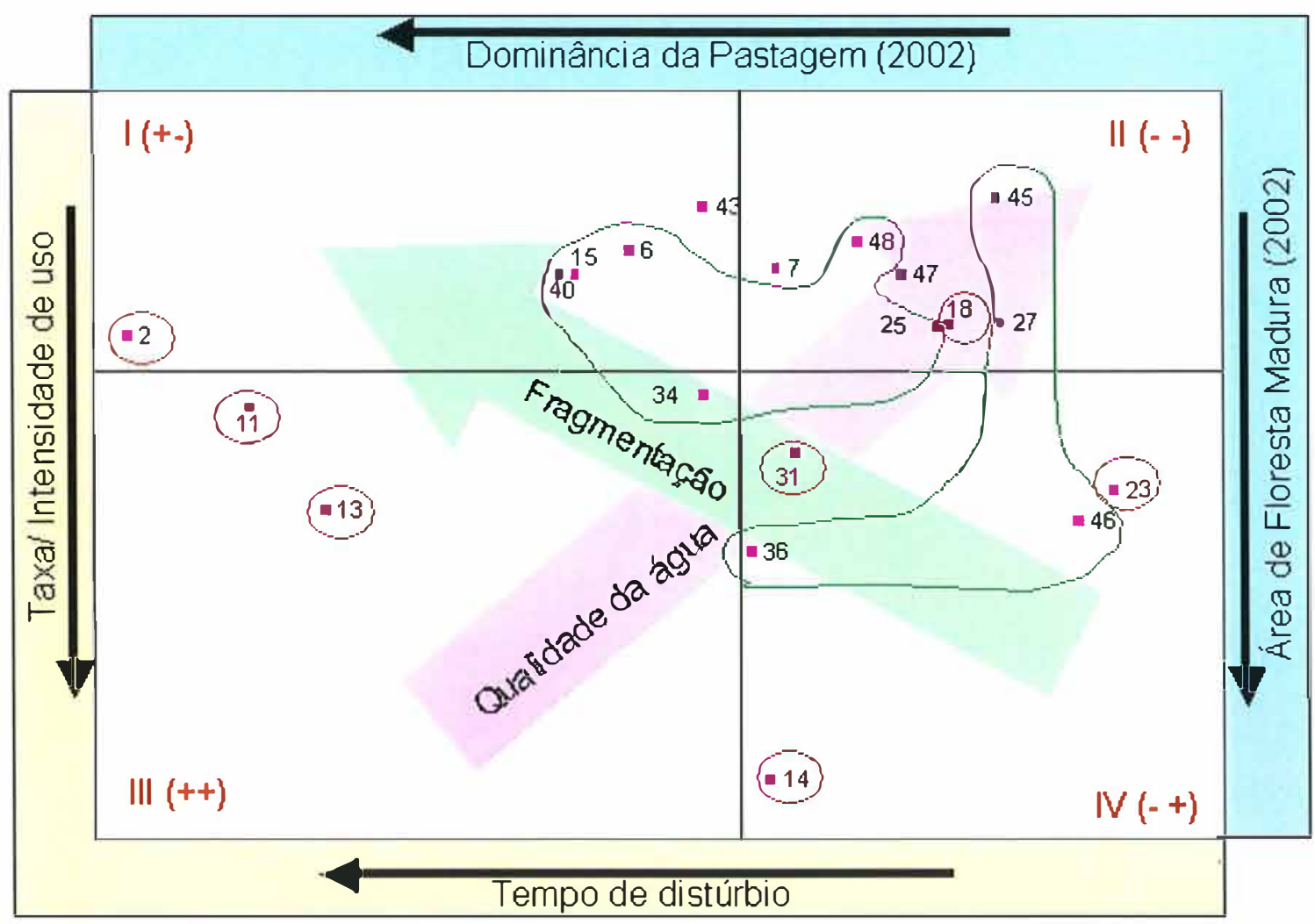

Figura 42 - Relação entre os componentes de variação da dinâmica do uso da terra e estrutura da paisagem em 2002

Em relação aos impactos da dinâmica da paisagem na qualidade da água, pressupõe-se que as microbacias com melhor qualidade de água seriam aquelas de uso não intensivo, com menor entrada de poluentes e resíduos e com menor tempo de intervenção. Segundo estes critérios, um gradiente se formaria partindo do quadrante III em relação ao quadrante II. No entanto, somente estudos futuros relacionando a dinâmica e a qualidade da água, poderão explicar melhor esta relação.

Quanto à classificação das microbacias, a análise isolada da composição em 2002 não seria capaz de distinguí-las, pois somente a proporção de uso no presente não reflete completamente o histórico de uso. Por exemplo, as microbacias 45 e 46 não apresentam diferencial às demais quando analisadas em relação à estrutura da paisagem em 2002 e somente 
puderam ser separadas considerando-se a dinâmica no período estudado. Da mesma forma, a microbacia 18 não apresenta diferencial em relação à sua dinâmica, mas pôde ser distinguida das demais pela estrutura da paisagem em 2002.

Desse modo, a informação de dinâmica expressada pelos índices complementa a análise da estrutura da paisagem, sendo que duas vantagens principais podem ser consideradas na sua utilização: em primeiro lugar, a análise permite a compreensão melhor das condições atuais, pois além de separar microbacias, o conhecimento das atividades históricas desenvolvidas no local poderá indicar a presença de outros aspectos físicos da microbacia como processos erosivos, contaminação do solo, fertilidade, dentre outros. Em segundo lugar, o cálculo de índices de dinâmica é totalmente baseado nos dados de uso da terra, de fácil cálculo e interpretação, já que utiliza parâmetros comuns como média, taxa e idade, dispensando o uso de análises estatísticas mais robustas como componentes principais ou análise da estrutura da paisagem.

A utilização de indicadores baseados em aspectos da paisagem para caracterização e classificação de microbacias mostrou-se uma boa opção para o monitoramento ambiental, confirmando a tendência observada por autores como Cifaldi (2004) e Tiner (2004).

\subsection{Conclusões}

As principais fontes de variabilidade na estrutura da paisagem estão correlacionadas à proporção de uso da terra para as três classes consideradas e não somente à proporção de floresta, ressaltando a importância de se considerar a dinâmica da matriz e outras classes de uso coexistentes em estudos de dinâmica da paisagem.

A dinâmica do uso da terra apresenta quatro componentes principais de variabilidade representando $90 \%$ da variação total, sendo que três deles 
representaram $85 \%$ da variação e estiveram correlacionados às dimensões medidas pelos indices propostos: taxa de desmatamento, dinâmica da floresta secundária e tempo decorrido desde o início da ação antrópica.

Os índices propostos: Taxa Anual de Desmatamento da Floresta Madura (TADFM), Proporção Média da Floresta Secundária (PMFS) e Tempo Médio de Introdução da Pastagem (TMIP) mostram-se bons indicadores para a região, pois além de representar a variabilidade da dinâmica, são facilmente mensuráveis. A aplicação destes indices em outras regiões com diferentes realidades deverá considerar modificações na forma de cálculo e classes de uso, de acordo com as peculiaridades da região e objetivos da análise, já que os indicadores foram elaborados visando a aspectos de conservação dos recursos hídricos e atividades desenvolvidas na região central de Rondônia.

A estrutura da paisagem em 2002 é influenciada pela dinâmica de uso da terra ocorrida no período estudado, sendo que a fragmentação da paisagem nas microbacias em 2002 apresenta dois aspectos principais: a. dominância da pastagem influenciada pelo tempo da ação antrópica; e b. proporção de FM influenciada pela taxa/intensidade de uso.

A classificação das microbacias com base somente na estrutura da paisagem atual reflete em parte a condição histórica das mesmas, mas não é capaz de captar toda a dinâmica ocorrida. A incorporação de dados históricos em conjunto a dados atuais na classificação das condições ambientais de microbacias permite melhor separação das microbacias e melhora o entendimento dos fatores envolvidos na formação dos grupos, facilitando o diagnóstico e a elaboração de um plano de ação para conservação.

Portanto, retornando à hipótese inicial do estudo: "A análise do uso da terra é capaz de distinguir áreas que apresentem no momento presente, as mesmas condições de uso da terra."; os resultados indicam que a mesma deve ser aceita. 


\section{INFLUÊNCIA DAS CARACTERÍSTICAS FÍSICAS E}

\section{ANTRÓPICAS DE MICROBACIAS NA COMPOSIÇÃO QUÍMICA DA ÁGUA NA REGIÃO CENTRAL DE RONDÔNIA}

\section{Resumo}

Mudanças no uso da terra na região central de Rondônia vêm modificando radicalmente aquele ambiente e, apesar da existência de estudos quantificando principalmente o desmatamento da região, pouco se sabe sobre seus efeitos. $O$ desafio atual consiste em entender a dinâmica histórica do uso da terra e seus impactos nos processos ecológicos, especialmente na composição química da água. Este estudo considerou parâmetros físicos (altitude, declividade e solos), antrópicos (dinâmica do uso da terra, ocupação das áreas ripárias e incidência recente de desmatamento) e da estrutura da paisagem para 2002 de 20 microbacias selecionadas na região central de Rondônia, como possíveis variáveis indicadoras da composição química da água. Foram coletadas amostras de água para a determinação de 14 parâmetros de composição química da água. Análise de Regressão Múltipla (stepwise) foi utilizada para testar a influência das variáveis indicadoras do meio físico e antrópico na composição química da água das microbacias. Os resultados mostraram que, em relação aos atributos físicos e antrópicos, os parâmetros de composição química da água que obtiveram melhor predição foram a condutividade elétrica $\left(R^{2}=0,88\right)$, nitrogênio total $\left(R^{2}=0,48\right)$, e pH $\left(R^{2}\right.$ $=0,42)$, enquanto que a estrutura da paisagem do ano 2002 conseguiu explicar melhor o nitrogênio total $\left(R^{2}=0,68\right)$, oxigênio dissolvido $\left(R^{2}=0,56\right)$, cloro $\left(R^{2}=\right.$ 
$0,51)$, fósforo $\left(R^{2}=0,46\right)$ e sulfato $\left(R^{2}=0,42\right)$. O estudo mostrou a importância da análise integrada de fatores como histórico de uso da terra, condições físicas e estrutura da paisagem atual como indicadores para a qualidade da água na região.

Palavras-chave: Ecologia da Paisagem, qualidade da água, Rondônia, SIG, uso da terra

\section{Summary}

Land use changes in central Rondônia have been changing drastically the environment, and besides studies quantifying deforestation at the region, its effects are not well understood. The current challenge is to understand the historical land use dynamics and its impacts on ecological processes, especially water chemistry in streams. This study considers physical attributes (elevation, slope and soils), anthropogenic factors (land use dynamics, riparian land use and recent deforestation) and landscape (landscape structure for year 2002) of 20 selected catchments on central Rondônia, as predictor variables of water chemistry. Water samples were collected on selected points in order to analyze 14 water chemistry variables. Multiple regression analysis (stepwise) was applied to test the influence of physical and anthropogenic indicators on catchments water chemistry. Results showed that the physical and anthropogenic influence electrical conductivity $\left(R^{2}=0.88\right)$, total nitrogen $\left(R^{2}=\right.$ $0.48)$, and $\mathrm{pH}\left(\mathrm{R}^{2}=0.42\right)$. Landscape structure for 2002 explain better total nitrogen $\left(R^{2}=0.68\right)$, dissolved oxygen $\left(R^{2}=0.56\right)$, chloride $\left(R^{2}=0.51\right)$, phosphorus $\left(R^{2}=0.46\right)$ and sulfate $\left(R^{2}=0.42\right)$. The study shows the importance of an integrated analysis of factor like land use, physical attributes and current landscape structure as indicators of water quality at region.

Key words: Landscape ecology, water chemistry, Rondônia, GIS, land use 


\subsection{Introdução}

O uso da terra em bacias hidrográficas tem grande influência na qualidade e quantidade de suas águas. Em Rondônia, a alteração do uso da terra causada pelo desmatamento, tem modificado o regime hidrológico e a composição química da água (Ballester et al., 2003; Biggs et al., 2002; Thomas et al., 2004).

No capitulo anterior observou-se que as condições atuais de microbacias na região central de Rondônia são influenciadas pelo histórico de uso da terra nas mesmas. Desse modo, em estudos de impactos do uso da terra nos recursos hídricos, torna-se importante uma visão mais abrangente das condições das bacias hidrográficas, considerando-se não apenas sua situação atual (diagnóstico presente), mas também o seu histórico de uso e dinâmica.

Os nutrientes presentes em rios podem ser preditos pelo uso da terra na bacia hidrográfica (Basnyat et al., 1999; Jones, K.B. et al., 2000). Wang \& Yin (1997) por exemplo, encontraram evidência da relação entre condutividade elétrica da água e extensão da área urbana na bacia. Seus resultados mostram que a condutividade pode não ser um indicador sensivel para fontes nãopontuais de poluição. Já Allan et al. (1997), observaram que as áreas de agricultura contribuem como fonte de nutrientes e poluição não-pontual para os recursos hídricos, portanto sua extensão na bacia pode ser um dos melhores preditores da composição química da água.

Outros aspectos da estrutura da paisagem podem influenciar a qualidade da água além da composição da bacia (uso da terra). A análise da estrutura da paisagem pode fornecer novas alternativas para mensurar os efeitos humanos sobre os recursos hidricos que complementam os tradicionais métodos de avaliação da qualidade da água (Gergel et al., 2002). Insumos agrícolas como Fósforo e Nitrogênio por exemplo, podem ser preditos pela estrutura da paisagem (Jonhson et al., 2001; Lucas \& Medley, 2002). Algumas métricas da paisagem puderam explicar até $86 \%$ do Nitrogênio, $73 \%$ do Fósforo e $79 \%$ da 
variação nos sedimentos em suspensão na região central da Costa leste americana, mas os resultados sugerem que os modelos comportam-se diferentemente de acordo com a relação rio/paisagem entre eco-regiões $\mathrm{e}$ condições físicas (Jones, K.B. et al., 2000).

Mudanças na paisagem podem afetar diretamente os processos ecológicos (Forman \& Godron, 1986) e o conhecimento das interações água / paisagem podem fornecer um dos mais importantes subsídios para o manejo racional destes recursos (Likens \& Bormann, 1974); entretanto, o estudo da interação água / dinâmica da paisagem ainda é pouco explorado.

Uma visão de longo prazo dos processos históricos de microbacias é importante para a avaliação das influências antrópicas (Molnar et al., 2002). Embora existam muitos trabalhos que estudam a relação paisagem/água, na sua maioria, a paisagem é considerada estática e, a relação dinâmica da paisagem / água não é abordada.

Em regiões de alta dinâmica como é o caso da área de estudo, conforme observado nos capitulos anteriores, algumas questões podem ser formuladas a respeito dos efeitos da ocupação nos recursos hídricos: qual a importância dos fatores físicos e antrópicos na composição química da água dos rios de Rondônia? Dentre fatores antrópicos, qual o papel do histórico de uso da terra?

O objetivo deste estudo foi avaliar a influência de características físicas e antrópicas (atuais e históricas) de microbacias na região central de Rondônia na composição química da água de seus rios. O estudo da relação entre os fatores físicos e antrópicos e a composição química da água para a região deverá ser útil para entender os impactos da ocupação humana sobre os recursos hídricos. 


\subsection{Material e Métodos}

Área de estudo - no Capítulo 3 deste trabalho, encontra-se a descrição detalhada sobre a área de estudo.

Base de dados - uma descrição completa sobre a base de dados utilizada, procedimentos para mapeamento do uso da terra e divisão da área em microbacias pode ser encontrada nos Capitulos 3 e 4 deste trabalho.

Caracterização física e antrópica das microbacias - utilizando-se as microbacias como sub-unidades de estudo, foram calculados alguns indices referentes aos aspectos físicos e antrópicos das microbacias.

- Características físicas - algumas características físicas que poderiam influenciar a composição química da água foram calculadas por meio de manipulação dos mapas no ArcGIS:

- DECLIV - declividade média da microbacia em \%;

- ALTIM - altitude média do terreno na microbacia, em metros; e,

- CTCe - capacidade de troca efetiva média de cátions do solo (cMolc. $\mathrm{Kg}^{-1}$ ).

- Uso da terra para o ano de 2002 - o uso da terra para o mesmo ano da coleta de água, foi calculado utilizando-se duas metodologias:

- PLAND - proporção do uso da terra ocupada por cada classe de uso (em \%), valores previamente calculados para análises anteriores; e,

- PLAND_100 - proporção do uso da terra ocupada por cada classe de uso (em \%) em uma faixa de 100 metros em torno dos corpos d'água. 
- Estrutura da paisagem para o ano de 2002 - a estrutura da paisagem foi representada pelas mesmas métricas utilizadas nos capítulos anteriores, calculadas para as três classes de uso da terra:

- PD - densidade de fragmentos (em $\mathrm{n} / 100 \mathrm{ha}$ );

- LPI - índice do maior fragmento (em \%);

- AREA_CV - coeficiente de variação do tamanho dos fragmentos (em \%);

- FRAC_AM - dimensão fractal do fragmento ponderado pela área média;

- LSI - índice de forma da paisagem (sem unidade);

- ENN_MN - distância média do vizinho mais próximo (em metros); e,

- $\mid \mathrm{IJ}$ - índice de justaposição (em \%).

- Dinâmica do uso da terra entre 1984 e 2002 - como indicadores da dinâmica do uso da terra, optou-se pela utilização dos índices de dinâmica desenvolvidos nas análises anteriores (ver Capítulo 4), com exceção de CVTFS que substituiu o índice PMFS devido a sua alta correlação com PLAND_SF:

- TADFM - Taxa Anual de Desmatamento da Floresta Madura (em \%);

- CVTFS - Coeficiente de Variação de Tamanho da Floresta Secundária (em \%);

- TMIP - Tempo Médio de Introdução da Pastagem na área (sem unidade); e,

- ESTAB - Estabilidade média da microbacia (em anos), ou número de anos em que não houve alteração no uso da terra, iniciando-se a contagem inversa a partir de 2002. 
- Desmatamento nos últimos quatro anos - com a finalidade de avaliar os impactos recentes do desmatamento, dois índices foram calculados:

- DEF2 - proporção de área desmatada (transição $F M \rightarrow P A)$ na microbacia nos últimos dois anos anteriores a 2002; e,

- DEF4 - proporção de área desmatada (transição $F M \rightarrow P A$ ) na microbacia nos últimos quatro anos anteriores a 2002.

Caracterização da composição química da água nas microbacias no período de 10/10/02 a 20/10/02 realizou-se o trabalho de campo na área de estudo para coleta de amostras de água nas microbacias estudadas. A coleta de água ocorreu em pontos pré-selecionados, localizados nos pontos de vertedouro de 20 microbacias de $2^{\mathrm{a}}$ ordem, com área entre 1.500 e 3.000 ha. $O$ tamanho das microbacias foi determinado pela ordem dos córregos e considerando-se o observado por Thomas et al. (2004) que verificaram maior influência do uso da terra em córregos de $1^{\text {a }}$ e $2^{\text {a }}$ ordem. Na Figura 43 podem ser observados as microbacias e os pontos de coleta selecionados. Na escolha das microbacias, procurou-se selecionar bacias em diversos estágios de desmatamento, de acordo com a disponibilidade.

Para localização dos pontos de amostragem no campo, utilizou-se um computador de mão COMPAQ IPAQ 3850, conectado a um GPS de navegação Garmin ETREX, e software ArcPad 6.0. O sistema utilizado permitiu a visualização da posição em tempo real do coletor, além de mapas de apoio à localização, como rios, estradas, pontos de coleta e imagem Landsat ETM+, o que foi fundamental para a exata localização, dos pontos de amostragem. 


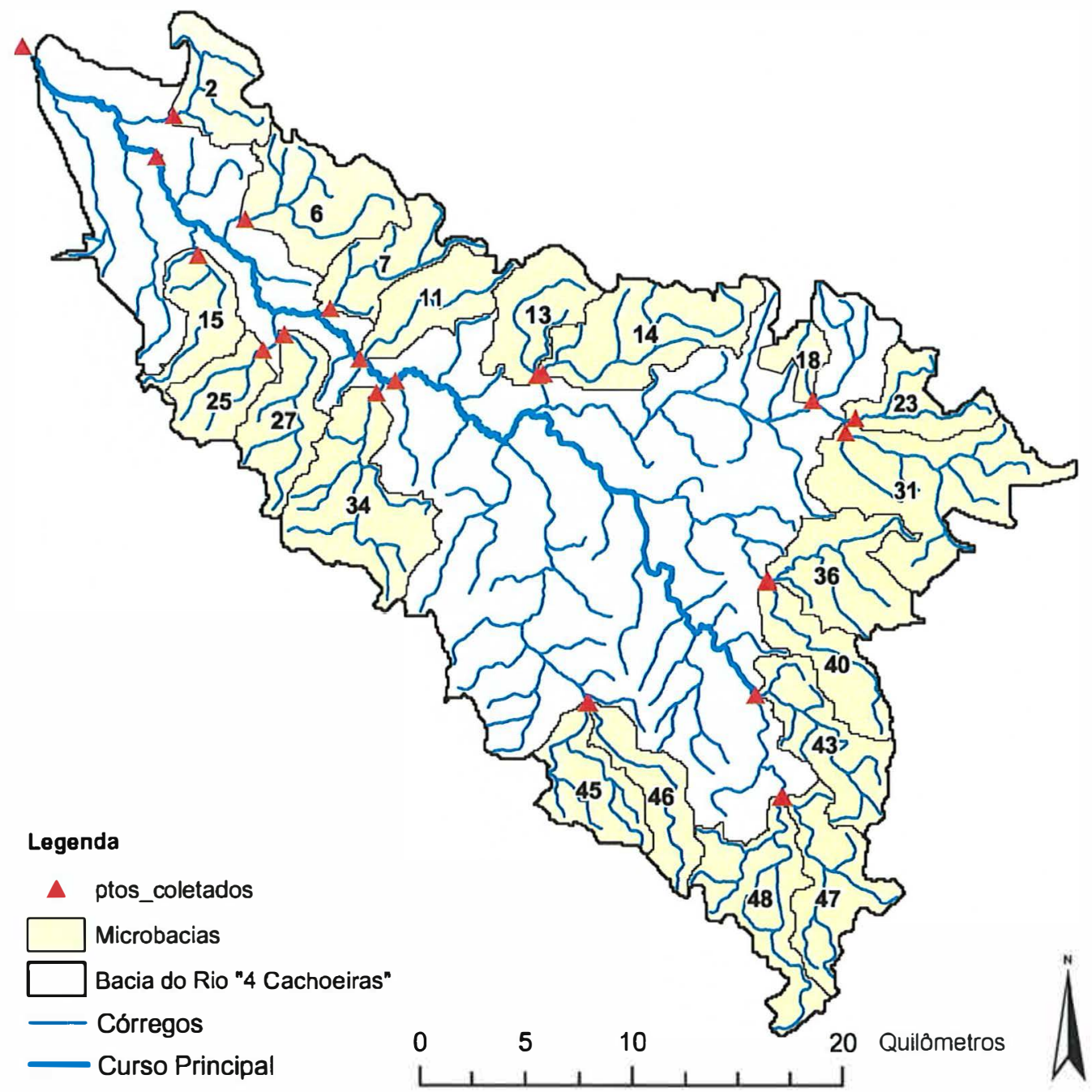

Figura 43 - Localização das microbacias e pontos de coleta de água selecionados para análise, na bacia do rio Quatro Cachoeiras, Rondônia

As amostras de água para análise química foram coletadas na superfície, no meio do canal com auxílio de uma garrafa de Niskin, conforme metodologia adotada por Ballester et al. (2003). Em campo foram determinados o pH, a condutividade elétrica, o Oxigênio dissolvido e a temperatura. Após a filtragem, as amostras foram acondicionadas em caixas térmicas para transporte até 0 
laboratório. Cerca de 14 parâmetros foram determinados para cada amostra (Tabela 9).

Tabela 9. Parâmetros da composição química da água utilizados

\begin{tabular}{clc}
\hline $\begin{array}{c}\text { Parâmetro } \\
\text { (unidade) }\end{array}$ & \multicolumn{1}{c}{ Descrição } & Variável \\
\hline Temp $\left({ }^{\circ} \mathrm{C}\right)$ & Temperatura da água & $\mathrm{TEMP}$ \\
$\mathrm{Cond}(\mu \mathrm{S} / \mathrm{cm})$ & Condutividade elétrica medida em campo & $\mathrm{COND}$ \\
$\mathrm{pH}$ & $\mathrm{pH}$ da amostra de água coletada & $\mathrm{pH}$ \\
$\mathrm{OX} 1(\mathrm{Mg} / \mathrm{L})$ & Oxigênio dissolvido medido em campo & $\mathrm{OX} 1$ \\
$\mathrm{Cl}^{-}(\mathrm{ppm})$ & Concentração de cloreto & $\mathrm{CL}$ \\
$\mathrm{SO}_{4}^{2-}(\mathrm{ppm})$ & Concentração de sulfato & $\mathrm{SO} 4$ \\
$\mathrm{PO}_{4}^{3-}(\mathrm{ppm})$ & Concentração de fosfato solúvel & $\mathrm{PO} 4$ \\
$\mathrm{Na}^{+}(\mathrm{ppm})$ & Concentração de sódio & $\mathrm{NA}$ \\
$\mathrm{K}^{+}(\mathrm{ppm})$ & Concentração de potássio & $\mathrm{K}$ \\
$\mathrm{Mg}^{2+}(\mathrm{ppm})$ & Concentração de magnésio & $\mathrm{MG}$ \\
$\mathrm{Ca}^{2+}(\mathrm{ppm})$ & Concentração de cálcio & $\mathrm{CA}$ \\
$\mathrm{N}(\mathrm{ppm})$ & Concentração de nitrogênio total & $\mathrm{NTOTAL}$ \\
$\mathrm{CID}(\mathrm{ppm})$ & Concentração de carbono inorgânico dissolvido & $\mathrm{CID}$ \\
$\mathrm{COD}(\mathrm{ppm})$ & Concentração de carbono orgânico dissolvido & $\mathrm{COD}$ \\
\hline
\end{tabular}

Para a análise de ions e CID, as amostras foram imediatamente filtradas, armazenadas em recipientes de polietileno e preservados com Thymol a $4^{\circ} \mathrm{C}$ até a chegada no laboratório. Amostras para análise de COD foram imediatamente filtradas com filtro de fibra de vidro pré-esterilizados $\left(550^{\circ} \mathrm{C}\right)$, armazenadas em frascos de vidro (vails) com vedação de Teflon e preservados em $\mathrm{HgCl}_{2}$ até a análise a $4^{\circ} \mathrm{C}$. As concentrações de CID e COD foram determinadas utilizando-se o aparelho 5000A Shimadzu TOC Analyser, enquanto que as concentrações de ions foram determinadas por cromatografia liquida com um aparelho Dionex DX500 (Ballester, 2003). A Figura 44 ilustra dois pontos de coleta localizados sob diferentes coberturas vegetais: pastagem e floresta. 


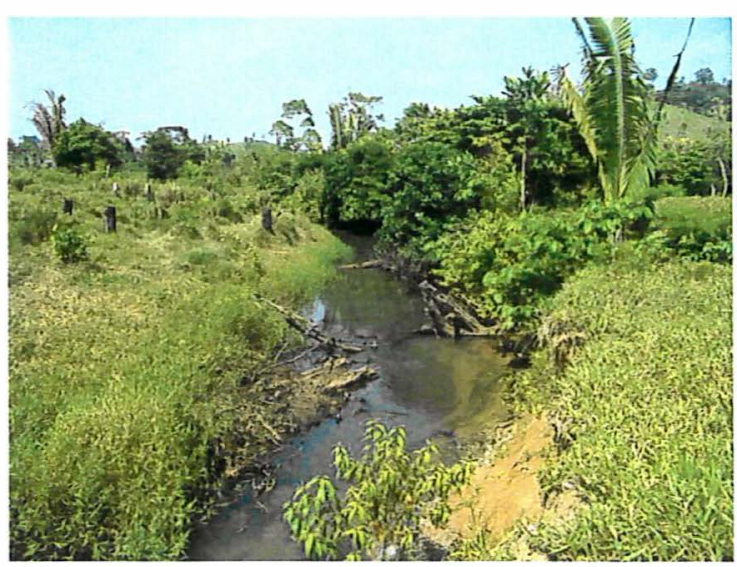

a

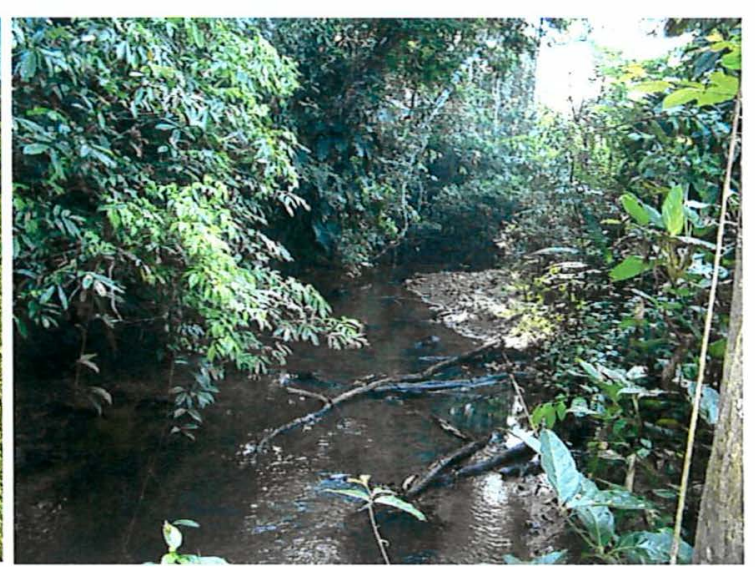

b

Figura 44 - Exemplo de dois pontos de coleta localizados em área de pastagem (a) e floresta (b)

Análise da influência das características físicas e antrópicas na composição química da água - por meio de Regressão Linear Múltipla (método Stepwise), realizou-se a análise de regressão entre as características físicas e antrópicas das microbacias (preditores) e parâmetros analisados de composição química da água (variáveis respostas). Também foi utilizada a análise de correlação (Pearson) para identificar correlações individuais entre os grupos de variáveis. As análises foram realizadas com auxílio do software SAS, considerando-se separadamente: a) dados de dinâmica de uso da terra e atributos físicos das microbacias; e, b) dados de estrutura da paisagem em 2002. O objetivo da separação das análises foi de avaliar os efeitos relativos à estrutura da paisagem isoladamente. 


\subsection{Resultados}

Os resultados da análise de correlação para atributos físicos e antrópicos e composição química da água são apresentados na Tabela 10. Com relação aos atributos físicos, nota-se que a altitude média da microbacia está correlacionada à concentração de cátions $\mathrm{Na}^{+}, \mathrm{Ca}^{2+}, \mathrm{Mg}^{2+}$, condutividade elétrica e carbono inorgânico dissolvido (CID).

A influência do uso da terra aparece principalmente no valor de $\mathrm{pH}$, com correlação negativa entre proporção de Pastagem (PLAND_PA) e pH. Quanto à dinâmica do uso da terra, observou-se correlação entre o Tempo de Introdução da Pastagem (TMIP) e, condutividade elétrica (COND) e pH. Também o coeficiente de variação de tamanho da floresta Secundária (CVTFS) se correlacionou à condutividade elétrica. A correlação mais forte em relação à dinâmica do uso da terra apareceu entre estabilidade média (ESTAB) e nitrogênio total (NTOTAL).

Tabela 10 Coeficientes de correlação de Pearson entre atributos físicos/dinâmica do uso da terra e a composição química da água nas microbacias

\begin{tabular}{|c|c|c|c|c|c|c|c|c|c|c|c|c|c|}
\hline & 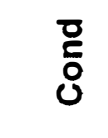 & $\frac{T}{2}$ & হ্㐅⿸ & $\overline{0}$ & 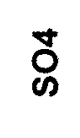 & O & $\frac{\pi}{2}$ & $x$ & $\stackrel{0}{\Sigma}$ & $\mathbb{J}$ & $\begin{array}{l}\frac{1}{5} \\
\frac{6}{2}\end{array}$ & 응 & $\frac{9}{0}$ \\
\hline PLAND_FM & 0,31 & $0,47^{*}-($ & $\overline{0,30-}$ & 0,16 & 0,21 & 0,27 & 0,06 & 0,07 & 0,06 & 0,03 & 0,380 & 0,03 & 0,33 \\
\hline PLAND_FS & 0,23 & 0,35 &, $33-$ & 0,09 - & $0,27-$ & 0,30 & 0,21 & 0,02 & 0,10 & 0,02 & $-0,43-c$ & 0,01 & 0,22 \\
\hline PLAND_PA & $-0,40-$ & $-0,55^{\star}$ &, 19 & $0,20-$ & 0,09 - & 0,14 & $-0,10-$ & 0,08 & $-0,06$ & 0,00 & $-0,15-c$ & 0,06 & $-0,41$ \\
\hline P100 FM & 0,41 & $0,42-$ &, $28-$ & 0,28 & 0,07 & 0,16 & 0,00 & 0,15 & $-0,06$ & $-0,04$ & $0,50^{*}$ & 0,06 & 0,43 \\
\hline P100 FS & 0,18 & 0,25 &, $28-$ & $0,06-$ & $0,26-$ & 0,27 & 0,20 & 0,20 & 0,08 & 0,07 & $-0,16 c$ & 0,01 & 0,19 \\
\hline P100_PA & $-0,42-$ & $-0,56^{*}$ & ),19 & $0,16-$ & $0,14-$ & 0,18 & $-0,10-$ & 0,11 & $-0,06$ & $-0,03$ & $-0,42-c$ & 0,06 & $-0,43$ \\
\hline DEF2 & 0,13 & 0,10 & 0,15 & 0,11 & $0,01-$ & 0,20 & $-0,05-($ & 0,23 & $-0,05$ & $-0,08$ & $0,05-c$ & 0,13 & 0,11 \\
\hline DEF4 & 0,38 & 0,19 &, 03 & 0,04 & 0,29 & 0,23 & $0,08-$ & 0,15 & 0,14 & 0,07 & $-0,18-c$ & 0,07 & 0,36 \\
\hline TADFM & $-0,26$ & $-0,03-$ &, 22 & $0,20-$ & 0,06 & 0,05 & $-0,27-c$ & 0,28 & $-0,24$ & $-0,21$ & 0,29 & 0,00 & $-0,26$ \\
\hline CVTFS & $-0,45^{\star}$ & $-0,09-$ & $0,17-$ & 0,09 - & $0,21-$ & 0,09 & $-0,35-c$ & 0,04 & $-0,39$ & $-0,31$ & $0,19-c$ & 0,13 & $-0,42$ \\
\hline TMIP & $-0,51^{\star}$ & $-0,46^{*}$ & 0,05 & $0,37-$ & $0,02-$ & 0,13 & $-0,28-$ & 0,28 & $-0,26$ & $-0,16$ & 0,21 & 0,06 & $-0,52^{*}$ \\
\hline ESTAB & 0,03 & $0,15-$ & 0,37 & 0,05 & 0,22 & 0,04 & $-0,23-($ & 0,21 & $-0,27$ & $-0,25$ & $0,62^{\star \star}$ & 0,11 & 0,06 \\
\hline DECLIV & $-0,04$ & 0,17 & $0,12-$ & $0,11-$ & 0,14 & 0,37 & $0,31-$ & 0,17 & 0,20 & 0,21 & $-0,02-c$ & 0,23 & $-0,11$ \\
\hline ALTIM & $-0,55^{\star}$ & $-0,41$ & 0,39 & $0,34-$ & 0,04 - & $0,03-1$ & $0,61^{* \star}-C$ & 0,32 & $0,49^{*}$ & $-0,45^{\star}$ & 0,26 & 0,07 & $-0,49^{\star}$ \\
\hline CTCe & $-0,20$ & $-0,35$ & 0,14 & 0,32 & 0,07 & 0,08 & $0,25-$ & 0,09 & 0,33 & 0,27 & $0,54^{\star}$ & 0,02 & $-0,24$ \\
\hline
\end{tabular}


Os resultados da análise de correlação para a estrutura da paisagem em 2002 e composição química da água são apresentados na Tabela 11. As principais correlações observadas foram entre a densidade de fragmentos de Floresta Madura (PD_FM) e, oxigênio dissolvido (OX1) e nitrogênio total (NTOTAL). A densidade de fragmentos de FS (PD_FS) também se correlacionou negativamente ao nitrogênio total (NTOTAL), enquanto que a distância média do vizinho mais próximo para FS (ENN_FS) se correlacionou positivamente ao mesmo elemento.

A distância média entre as áreas de Pastagem (ENN_PA) correlacionouse positivamente à concentração de cloro $\left(\mathrm{Cl}^{-}\right)$e o índice do maior fragmento de Pastagem (LPI_PA) correlacionou-se positivamente à concentração de oxigênio dissolvido (OX1). Por fim, a dimensão fractal das áreas de Pastagem (FRAC_AM_PA) correlacionou-se negativamente às concentrações de fósforo (PO4) e nitrogênio total (NTOTAL). 
Tabela 11. Coeficientes de correlação de Pearson entre a estrutura da paisagem em 2002 e composição química da água nas microbacias

\begin{tabular}{|c|c|c|c|c|c|c|c|c|c|c|c|c|c|}
\hline & 믐 & $\frac{T}{2}$ & ox & $\overline{0}$ & ষ্ঠ & O̊ & $\sum^{\infty}$ & $x$ & 일 & తే & $\begin{array}{l}\frac{1}{4} \\
\frac{5}{6} \\
\frac{5}{2}\end{array}$ & 응 & 은 \\
\hline PD_FM & 0,36 & 0,03 & $0,45^{\star}$ & $-0,25$ & $-0,04$ & $-0,01$ & 0,34 & 0,11 & 0,25 & 0,24 & $-0,45^{\star}$ & $-0,16$ & 0,30 \\
\hline PD_PA & 0,18 & $-0,09$ & 0,11 & $-0,02$ & $-0,11$ & 0,06 & 0,00 & $-0,06$ & $-0,02-$ & $-0,07$ & $-0,37$ & 0,06 & 0,16 \\
\hline PD_FS & 0,36 & 0,17 & 0,42 & $-0,06$ & 0,13 & 0,00 & 0,27 & $-0,04$ & 0,24 & 0,17 & $-0,57^{\star \star}$ & $-0,03$ & 0,31 \\
\hline LPI_FM & 0,14 & 0,36 & $-0,39$ & 0,01 & 0,17 & 0,25 & $-0,14$ & $-0,08$ & $-0,09$ & $-0,11$ & 0,32 & 0,15 & 0,16 \\
\hline LPI_PA & $-0,36$ & $-0,43$ & 0,09 & 0,13 & $-0,37$ & $-0,33$ & $-0,23$ & 0,06 & $-0,18$ & $-0,14$ & $-0,21$ & $-0,07$ & $-0,33$ \\
\hline IRLPI_FS & $-0,13$ & $-0,28$ & $-0,24$ & 0,15 & 0,11 & 0,22 & $-0,09$ & $-0,06$ & 0,00 & 0,08 & 0,39 & $-0,02$ & $-0,15$ \\
\hline AREA_CV_FM & 0,32 & 0,38 & 0,06 & $-0,01$ & 0,31 & 0,20 & $-0,02-$ & $-0,02$ & 0,10 & 0,10 & $-0,02$ & 0,15 & 0,30 \\
\hline AREA_CV_FS & 0,09 & 0,28 & 0,30 & $-0,15$ & 0,20 & $-0,18$ & $3-0,11$ & 0,04 & $-0,12$ & $-0,14$ & $-0,35$ & 0,19 & 0,12 \\
\hline AREA_CV_PA & 0,11 & $-0,14$ & 0,25 & 0,06 & $-0,10$ & $-0,30$ & $-0,17$ & 0,09 & $-0,12-$ & $-0,08$ & $-0,18$ & 0,11 & 0,12 \\
\hline LSI_FM & 0,35 & 0,14 & 0,37 & $-0,14$ & 0,18 & $-0,23$ & 0,19 & 0,24 & 0,22 & 0,25 & 0,03 & 0,00 & 0,34 \\
\hline LSI_FS & 0,36 & 0,19 & 0,38 & $-0,12$ & 0,07 & $-0,33$ & 0,14 & 0,19 & 0,09 & 0,11 & $-0,11$ & 0,10 & 0,35 \\
\hline LSI_PA & 0,32 & 0,02 & $0,44^{*}$ & $-0,02$ & 0,06 & $-0,34$ & 0,10 & 0,02 & 0,04 & 0,09 & $-0,24$ & 0,08 & 0,30 \\
\hline FRAC_AM_FM & 0,04 & 0,33 & $-0,16$ & 0,09 & 0,17 & 0,08 & $3-0,06$ & 0,00 & 0,10 & 0,04 & 0,17 & 0,06 & 0,07 \\
\hline FRAC_AM_FS & $-0,12$ & $-0,24$ & 0,05 & 0,30 & 0,30 & 0,27 & $-0,08$ & $-0,33$ & 0,10 & 0,13 & 0,16 & $-0,18$ & $-0,17$ \\
\hline FRAC_AM_PA & 0,04 & $-0,22$ & 0,35 & $-0,07$ & $-0,23$ & $-0,46^{\star}$ & 0,02 & 0,14 & $-0,02$ & 0,00 & $-0,49^{*}$ & $-0,07$ & 0,04 \\
\hline ENN_FM & 0,31 & 0,34 & 0,04 & $-0,41$ & 0,20 & 0,24 & 0,23 & 0,24 & 0,24 & 0,20 & 0,01 & $-0,13$ & 0,31 \\
\hline ENN_FS & $-0,36$ & $-0,19$ & $-0,13$ & 0,14 & 0,01 & 0,16 & $-0,27$ & 0,04 & $-0,16$ & $-0,02$ & $0,49^{*}$ & $-0,11$ & $-0,36$ \\
\hline ENN_PA & 0,01 & $-0,40$ & $-0,12$ & $0,49^{\star}$ & $-0,04$ & 0,09 & 0,13 & $-0,16$ & 0,20 & 0,19 & $-0,28$ & 0,26 & $-0,02$ \\
\hline IJI_FM & 0,02 & $-0,43$ & $-0,06$ & 0,16 & 0,16 & 0,13 & 30,05 & $-0,07$ & 0,11 & 0,14 & $-0,02$ & 0,10 & $-0,01$ \\
\hline IJI_FS & 0,17 & $-0,11$ & $-0,18$ & $-0,34$ & 0,15 & 0,16 & $-0,14$ & 0,22 & $-0,14$ & $-0,10$ & 0,07 & 0,17 & 0,19 \\
\hline IJI_PA & 0,06 & $-0,32$ & $-0,24$ & $-0,05$ & 0,19 & 0,23 & $3-0,01$ & 0,06 & 0,02 & 0,07 & 0,22 & 0,13 & 0,05 \\
\hline
\end{tabular}

Os resultados da análise de regressão múltipla para atributos físicos e antrópicos e composição química da água são apresentados na Tabela 12. Neste caso, os indicadores mais explicativos da variabilidade na composição química da água foram a proporção de Floresta Madura (PLAND_FM), proporção de Pastagem na zona ripária (P100_PA), taxa média anual de desmatamento da Floresta Madura (TADFM), tempo médio de introdução de Pastagem (TMIP), estabilidade (ESTAB) e altitude média (ALTIM). Os parâmetros que obtiveram melhor predição foram a condutividade elétrica $\left(R^{2}=\right.$ $0,88)$, nitrogênio total $\left(R^{2}=0,48\right)$ e $\mathrm{pH}\left(R^{2}=0,42\right)$. 
Tabela 12. Regressão múltipla entre atributos físicos/dinâmica do uso da terra e composição química da água nas microbacias. Coeficientes de correlação parciais (acima) e nivel de probabilidade (entre parênteses)

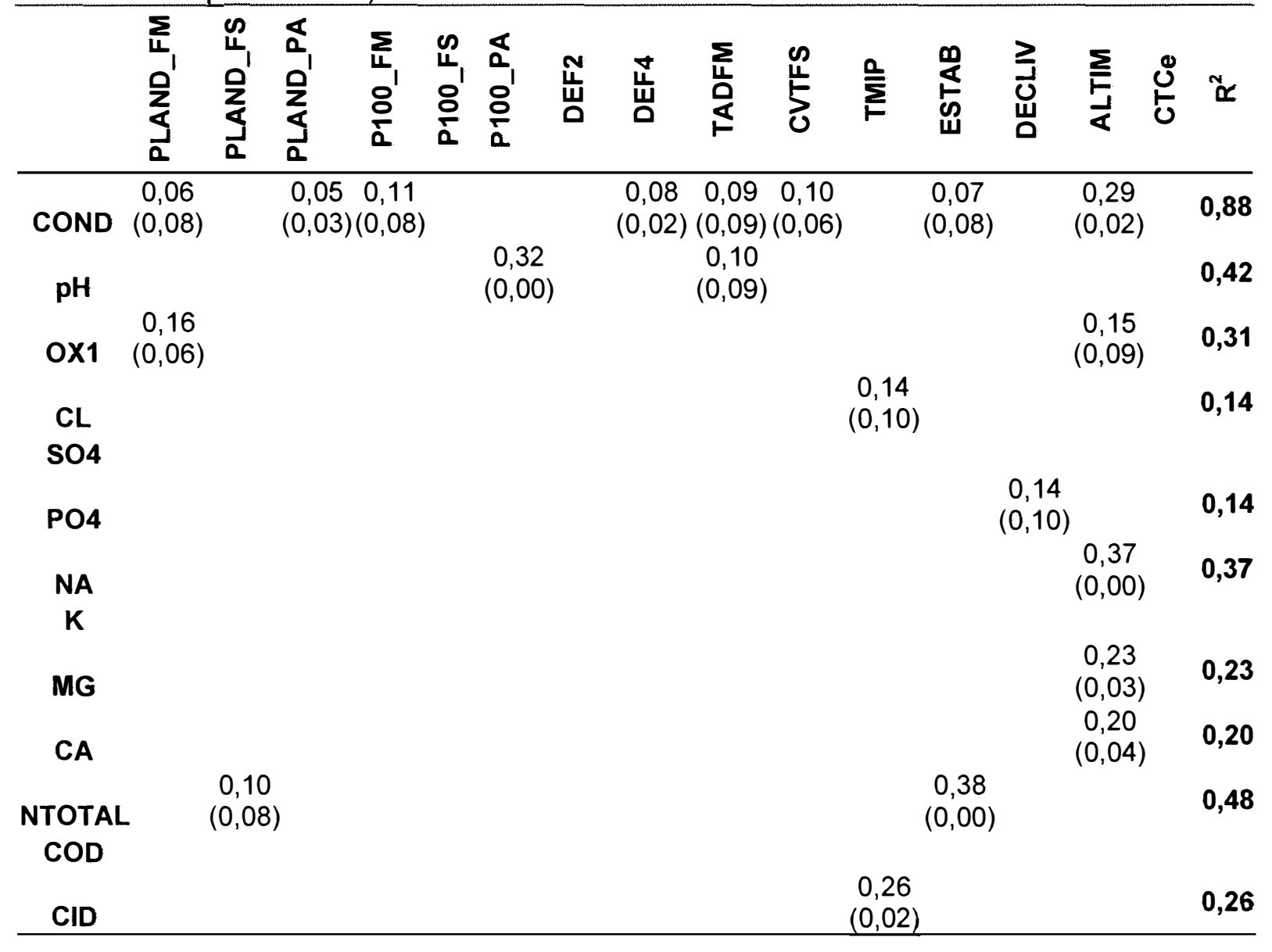

Os resultados da análise para a estrutura da paisagem em 2002 e composição química da água são apresentados na Tabela 13. Neste caso, os melhores preditores da composição química da água foram a proporção de PA (PLAND_PA), densidade de fragmentos de FM (PD_FM) e de FS (PD_FS), indice do maior fragmento de PA (LPI_PA), índice de forma da FM (LSI_FM), complexidade de PA (FRAC_AM_PA) e distância média entre PA (ENN_PA). Os parâmetros da água que obtiveram melhor predição pela estrutura da paisagem foram o nitrogênio total $\left(R^{2}=0,68\right)$, oxigênio dissolvido $\left(R^{2}=0,56\right)$, cloro $\left(R^{2}=0,51\right)$, fósforo $\left(R^{2}=0,46\right)$ e sulfato $\left(R^{2}=0,42\right)$. 
Tabela 13 Regressão múltipla entre a estrutura da paisagem (2002) e composição química da água nas microbacias. Coeficientes de correlação (acima) e nivel de probabilidade (entre parênteses)

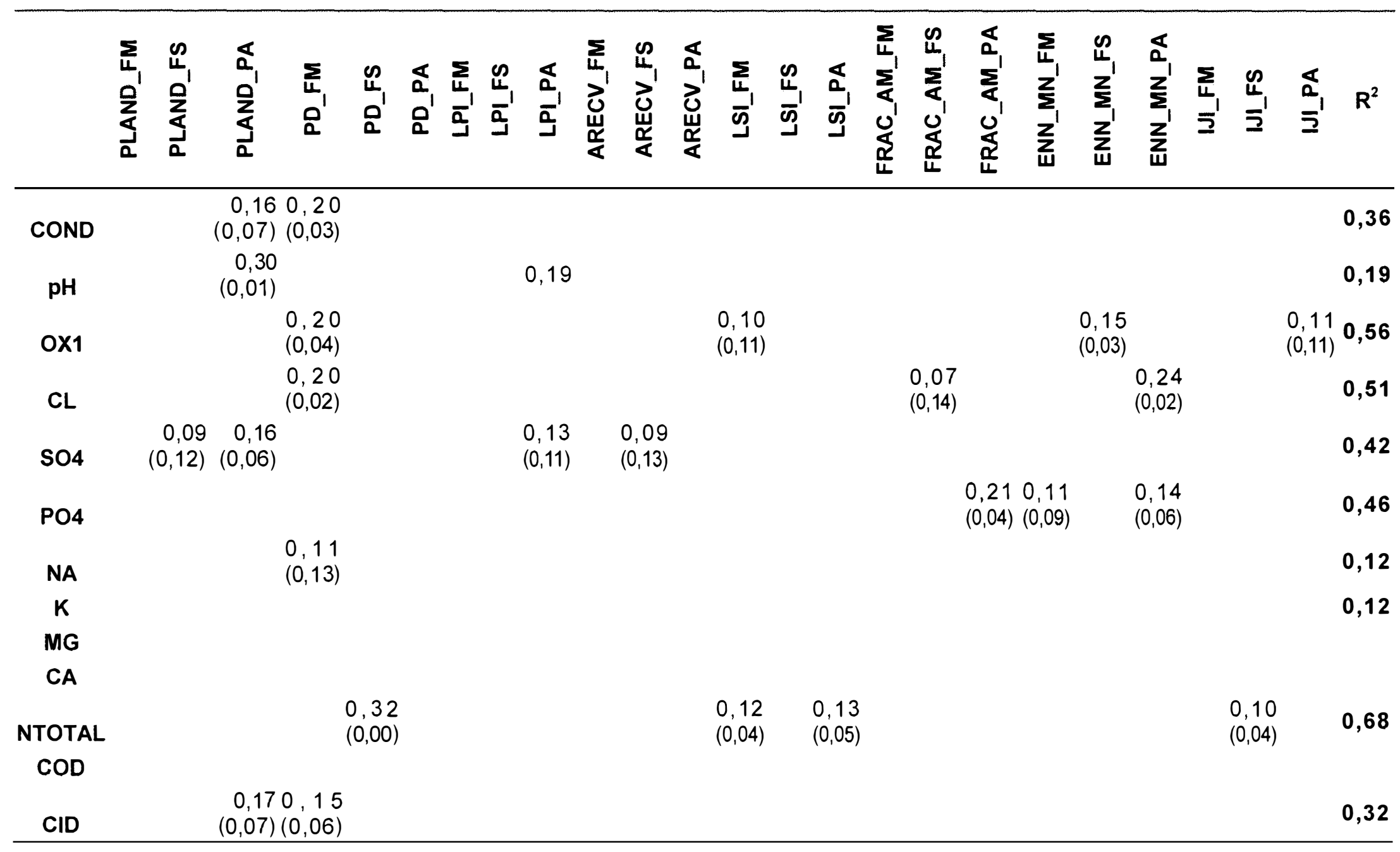




\subsection{Discussão}

A correlação negativa entre a condutividade elétrica e o Tempo de Introdução da Pastagem (TMIP) observada (Figura 45) poderia estar relacionada à estabilidade do uso da terra, já que também foi observada a mesma relação entre a condutividade elétrica e Coeficiente de Variação da Floresta Secundária (CVTFS). Desse modo, áreas mais instáveis, com pastagens mais novas estariam apresentando alta condutividade nas águas. $A$ condutividade nas águas é normalmente controlada pelo uso da terra na bacia (Levine et al., 1993). Câmara \& Lima (1999) também observaram alteração na condutividade elétrica da água em função de corte raso em plantações de eucalipto em Itatinga/SP e em Rondônia, Ballester et al. (2003) observaram que a porcentagem de pastagem foi o melhor preditor da condutividade elétrica. $A$ correlação observada poderia ser explicada pela disponibilização imediata dos nutrientes das cinzas nas áreas queimadas causando aumento da concentração em áreas recém desmatadas. Nas áreas mais antigas, o efeito da queimada seria reduzido, causando redução da concentração de nutrientes nos rios (Kauffman \& Cummings, 1995).

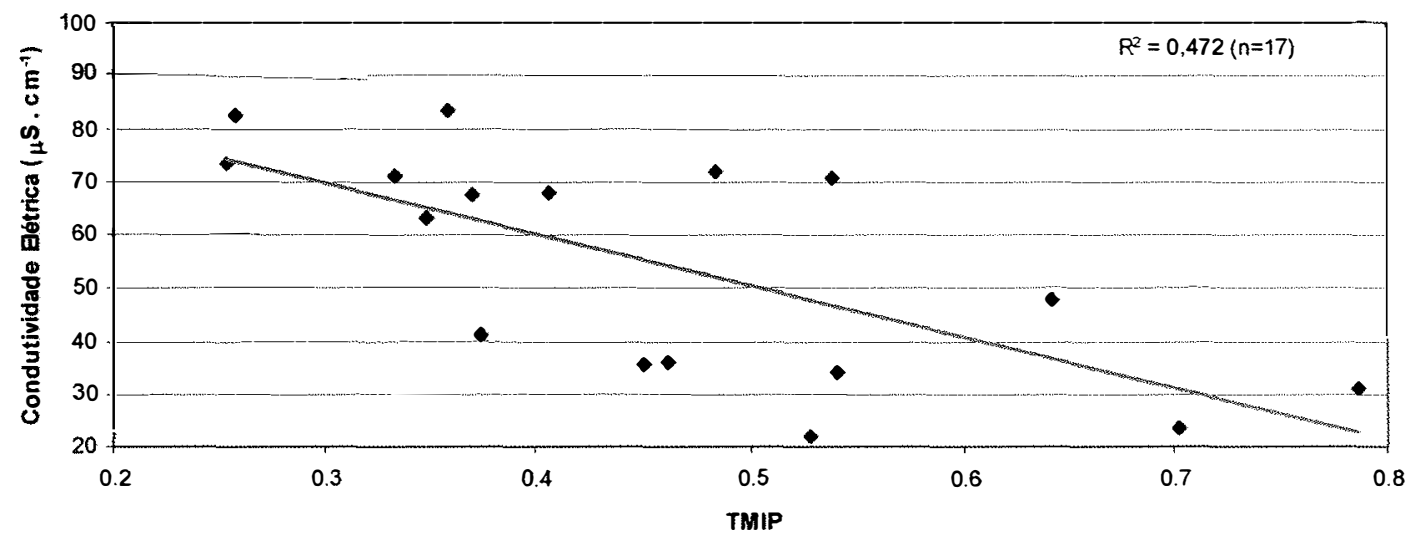

Figura 45 - Relação entre a condutividade elétrica da água (COND) e o Tempo de Introdução da Pastagem (TMIP) na microbacia 
Considerando-se a regressão múltipla realizada, a condutividade elétrica foi a variável que pôde ser melhor explicada pelas variáveis de uso da terra e atributos físicos, com cerca de $88 \%$ da variação explicada por estas variáveis. $A$ correlação positiva entre o pH e a proporção de Floresta Madura (PLAND_FM) poderia estar relacionada à entrada de cátions e ânions nas microbacias com predominância de pastagem, reduzindo o pH da água (Figura 46). No entanto, como o pH da água é muito dinâmico, variando em função de distúrbios de curto prazo na bacia e processamento no canal (Krushe et al., no prelo), somente estudos mais aprofundados poderiam comprovar a relação observada. Observando-se os números da análise de regressão, os melhores preditores para $\mathrm{pH}$ foram a porcentagem de pastagem na zona ripária (P100_PA) com $\mathrm{R}^{2}=0,32$ e Taxa Anual Média de Desmatamento (TADFM) com $\mathrm{R}^{2}=0,10$. Este resultado pode ser um indicativo de que a conversão da floresta em pastagem na microbacia, com maior entrada de nutrientes, esteja reduzindo o $\mathrm{pH}$ da água.

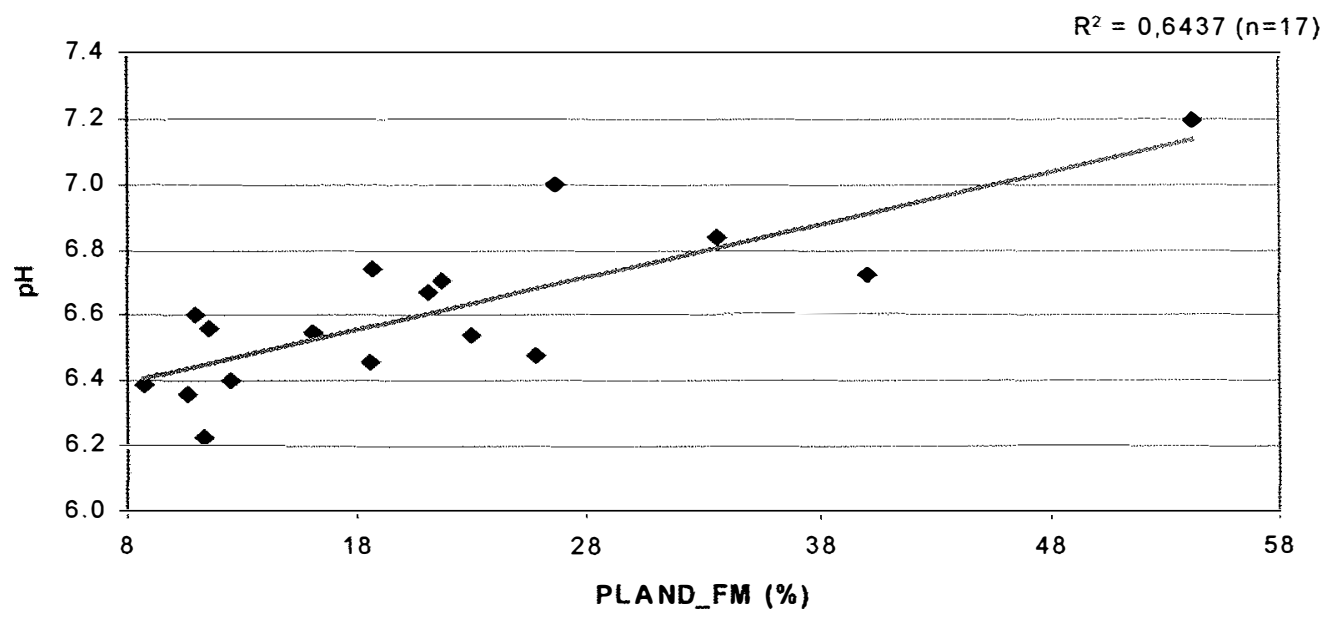

Figura 46 - Relação entre pH da água e a Proporção de Floresta Madura (PLAND_FM) nas microbacias

Uma das relações mais fortes observadas ocorreu entre a densidade de fragmentos de FS (PD_FS) e a concentração de nitrogênio. Neste caso, as áreas com baixa densidade de FS apresentaram alta concentração de nitrogênio (Figura 47), o que poderia ser explicado pela presença de pastagem 
manejada afetando a concentração de nitrogênio (Neill et al., 1999). As microbacias 13, 14 e 40, por exemplo, apresentam áreas de pastagem intensivamente manejadas, localizadas em grandes propriedades com baixa presença de FS e maior concentração de nitrogênio.

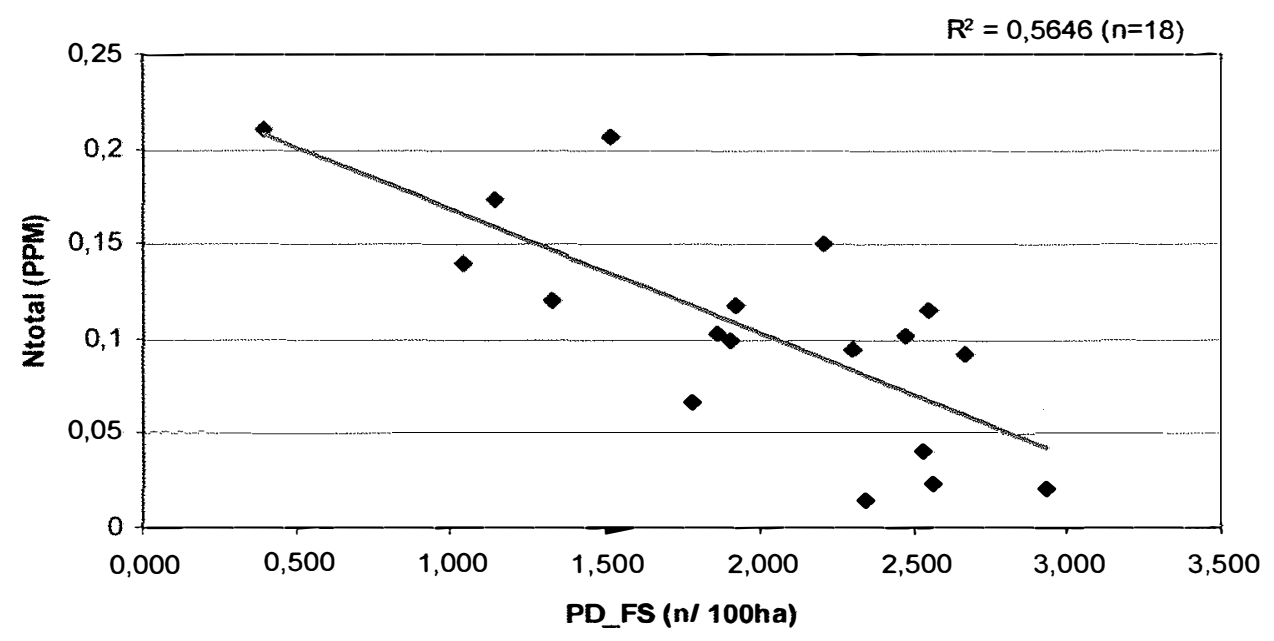

Figura 47 - Relação entre a densidade de fragmentos de Floresta Secundária (PD_FS) e a concentração de nitrogênio (NTOTAL) nas microbacias

A estrutura da paisagem em 2002 foi capaz de explicar $68 \%$ da variação na concentração de nitrogênio, enquanto que a dinâmica do uso da terra explicou $48 \%$. O fato da estrutura da paisagem estar mais relacionada com a concentração de nitrogênio poderia ser explicado pela atividade desenvolvida na microbacia, a qual é refletida na estrutura da paisagem. Este resultado está de acordo com o trabalho de Jones et al. (2001), onde as métricas da paisagem foram capazes de explicar até $86 \%$ da variação na concentração de Nitrogênio. Desse modo, como o nitrogênio é bastante dinâmico e varia em função do tipo de solo, vegetação de cobertura e manejo utilizado, o fato da estrutura da paisagem explicar melhor a concentração de nitrogênio poderia estar refletindo esta complexidade de diferentes tipos de cobertura e manejo utilizado. A tendência de áreas intensivamente manejadas apresentarem maior concentração de nitrogênio também pôde ser observada pela relação entre a estabilidade do uso da terra (ESTAB) e a concentração de nitrogênio 
(NTOTAL). Neste caso, áreas mais estáveis apresentaram maior concentração de nitrogênio (Figura 48).

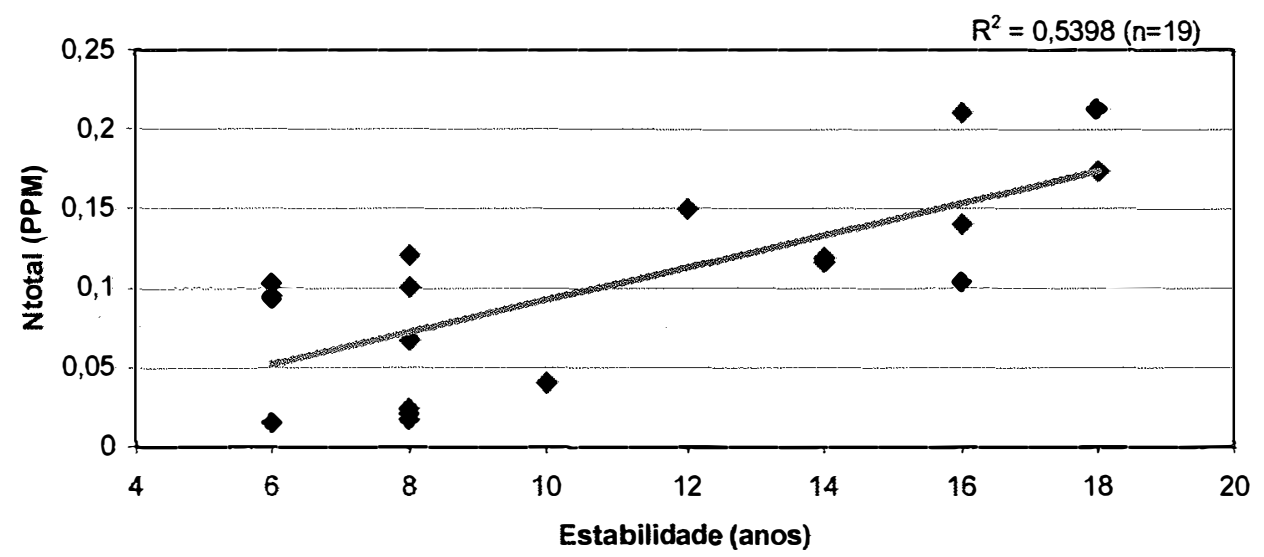

Figura 48 - Relação entre a estabilidade média da paisagem (ESTAB) e concentração de nitrogênio total (NTOTAL) na água das microbacias

Mudanças no uso da terra, como conversão de florestas tropicais em pastagens, afetam a fixação de $\mathrm{N}$, mineralização, nitrificação e denitrificação (Davidson et al, 1993). Segundo McGrath et al. (2001), a concentração de nitrogênio no solo diminui após a conversão de floresta para pastagem, ou seja, as pastagens estariam liberando mais nitrogênio para a água. Porém, em áreas mais estáveis com pastagem manejada, o declínio do nivel de nutrientes do solo em geral é mais gradual do que nos solos submetidos a uma agricultura de queima/derrubada (Moraes et al., 1996a). Na região, observando-se a influência da densidade de fragmentos de Floresta Secundária (PD_FS) e estabilidade em relação ao nitrogênio, nota-se que, não somente a proporção de uso da terra é importante na predição da composição química da água, mas também o tipo de manejo utilizado, já que as microbacias com manejo diferenciado apresentaram diferenças na composição química da água quando comparadas às demais.

Apesar da tendência observada, muitos outros fatores que não foram considerados podem estar influenciando a dinâmica do nitrogênio na área de estudo, como presença de áreas agrícolas de subsistência, diversidade de 
pastagem, presença de plantas leguminosas na pastagem ou como espécies invasoras, além do tipo de manejo utilizado. Assim, somente estudos mais detalhados que considerem estes fatores poderão obter respostas mais concretas sobre a dinâmica do nitrogênio na região.

Outra relação importante observada foi entre o Tempo Médio de Introdução da Pastagem (TMIP) e a concentração de carbono inorgânico dissolvido (CID) nas águas das microbacias (Figura 49). Neste caso, áreas com pastagens mais antigas apresentaram menores concentrações de carbono inorgânico do que áreas com desmatamento recente. Da mesma forma, como foi observado anteriormente na relação entre TMIP e condutividade elétrica, parece existir uma tendência de áreas mais dinâmicas disponibilizarem mais nutrientes. Ou seja, o desmatamento afeta a dinâmica de nutrientes no rios (Krushe et al., no prelo), devido principalmente às cinzas introduzidas pelo processo de queima e derrubada, sendo que em áreas com pastagens mais antigas as fontes de carbono inorgânico estariam reduzidas à liberação de fontes residuais de carvão, já que não é comum a prática de aplicação de calcário na região".

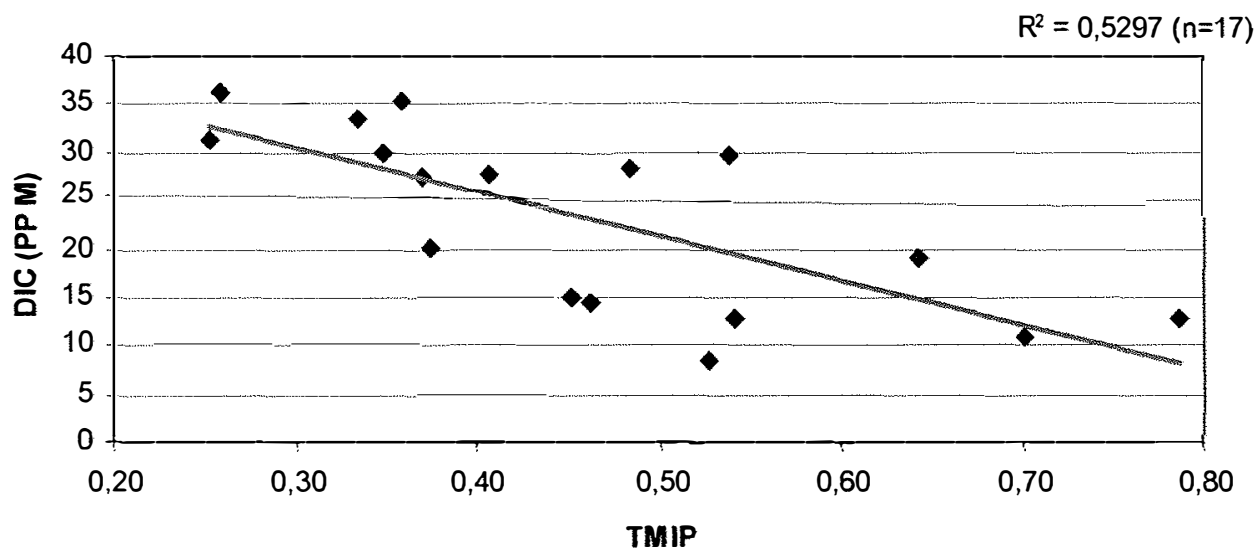

Figura 49 - Relação entre Tempo Médio de Introdução da Pastagem (TMIP) e concentração de carbono inorgânico dissolvido (CID) nas águas das microbacias

\footnotetext{
${ }^{1}$ Cerri, C.C. Comunicação pessoal, 2004.
} 
$\mathrm{Na}$ relação observada entre a altitude média do terreno (ALTIM) e a concentração de cátions $\mathrm{Na}^{+}$(Figura 50 ), um fator determinante poderia ser a formação geológica e os solos predominantes nas microbacias. No estudo realizado por Ballester et al. (2003), por exemplo, os autores observaram que a concentração de cátions como $\mathrm{Na}^{+}$esteve correlacionada com a porcentagem de pastagem, mas outros cátions como $\mathrm{Ca}^{2+}, \mathrm{Mg}^{2+}$ e $\mathrm{K}^{+}$estiveram mais relacionados à condutividade elétrica dos solos. $\mathrm{O}$ resultado obtido ressalta a importância de se considerar os aspectos físicos das microbacias como geologia e solos, conforme relatado por vários autores (Biggs et al., 2002, Ballester et al., 2003). No entanto, a bacia do rio Quatro Cachoeiras apresenta homogeneidade quanto aos solos predominantes (ver Figura 6), o que poderia minimizar a sua influência na composição química da água.

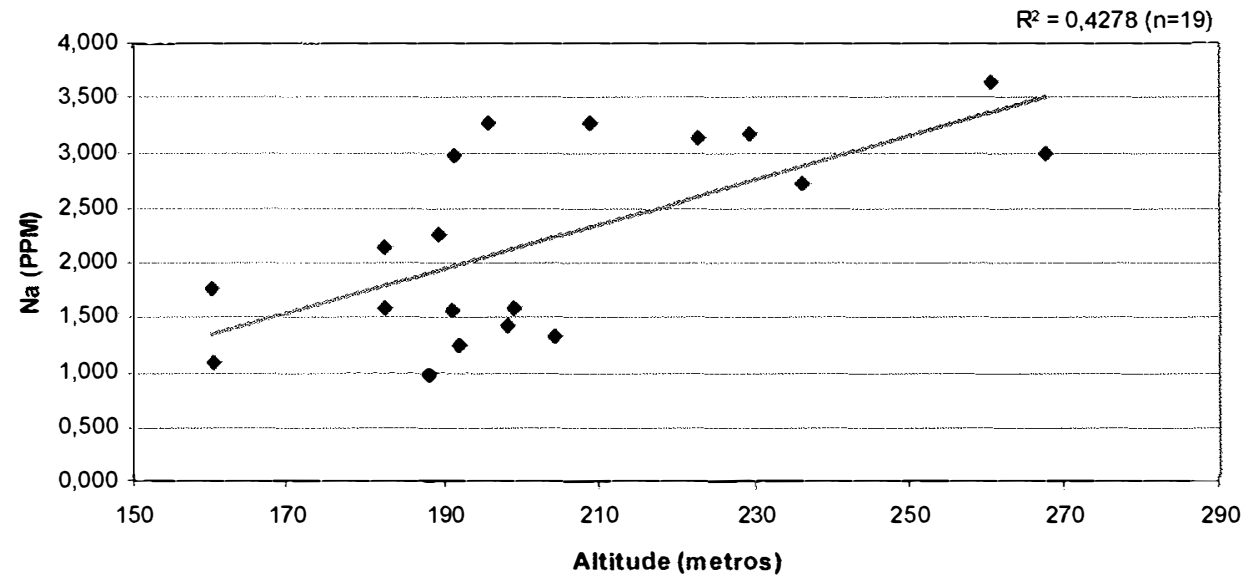

Figura 50 - Relação entre altitude média do terreno (ALTIM) e concentração de $\mathrm{Na}^{+}$nas águas das microbacias

Considerando as relações observadas entre TMIP, ESTAB, DEF4 e CVTFS e a composição química da água, fica clara a importância do histórico de uso da terra como fator determinante da composição química da água no presente. A resposta na água dos efeitos antrópicos encontrada neste estudo confirma o que foi observado por Krusche et al. (no prelo) que verificaram que 
influência das alterações antrópicas nos rios da Amazônia são mais facilmente detectadas na micro e meso escalas.

Neste estudo entretanto, não foram observadas relações entre a composição química da água e a proporção de área desmatada nos últimos dois anos (DEF2), nem em relação à taxa média anual de desmatamento (TADFM), ou seja, efeitos relativos à velocidade das mudanças e intensidade de distúrbios nos últimos anos não puderam ser detectados e somente processos de médio prazo foram observados.

Comparando-se os modelos de regressão para atributos físicos/dinâmica do uso da terra e o da estrutura da paisagem em 2002, observa-se que o uso da terra e sua dinâmica influenciaram mais a condutividade elétrica, o $\mathrm{pH}$ e $\mathrm{O}$ oxigênio na água. Por outro lado, as concentrações de cátions e ânions estiveram mais relacionadas aos aspectos físicos dos solos, representados pela altimetria. Neste caso, confirma-se o que já fora observado por outros autores, de que a composição química da água é influenciada principalmente pela pastagem e propriedades dos solos nesta região (Ballester et al., 2003; Krusche et al., no prelo).

Os resultados indicam ainda que a dinâmica do uso da terra parece ter maior influência sob as concentrações de nitrogênio total e do carbono inorgânico, do que o uso da terra no momento da coleta. A estrutura da paisagem, representando neste estudo o tipo de manejo utilizado nas áreas de pastagem e o tipo de ocupação existente, parece influenciar aspectos como presença de cloro, sulfato, fosfatos e também nitrogênio na água.

\subsection{Conclusões}

Os resultados obtidos foram capazes de identificar as principais relações envolvidas entre os parâmetros da paisagem e da água, sendo que para a região os aspectos relacionados à atividade humana mais importantes para a 
composição química da água são: o histórico de uso da terra, o uso da terra atual e o tipo de manejo utilizado.

O aspecto mais importante em relação à influência do uso da terra na composição química da água está relacionado à estabilidade da paisagem, representada pelos indicadores ESTAB, DEF4 e TMIP. Possivelmente, novos métodos para o cálculo da estabilidade poderão obter melhores resultados na predição da composição química da água.

De uma forma geral, o tipo de manejo utilizado na região foi caracterizado pela estrutura da paisagem, já que a configuração espacial da paisagem é diferente para cada tipo de manejo utilizado pelos pequenos e grandes proprietários. Desse modo, a importância de se considerar a estrutura da paisagem em estudos de qualidade da água está baseada no fato de que a estrutura da paisagem poderá influenciar não somente aspectos físicos relacionados à dinâmica da água no solo, mas também representar aspectos antrópicos, como o manejo utilizado.

As concentrações de cátions e ânions apresentaram melhor relação com as condições fisicas das microbacias, enquanto que a presença de sulfato, cloro, oxigênio dissolvido e nitrogênio relacionaram-se bem à estrutura da paisagem em 2002. A dinâmica do uso da terra influenciou mais as concentrações de carbono inorgânico e nitrogênio.

Com relação à hipótese inicial do trabalho de que "A dinâmica $d a$ paisagem e a sua estrutura atual influenciam diferentemente a composição química da água nos rios da região.", os resultados indicam que a mesma deve ser aceita.

Outros aspectos que poderiam ser melhor explorados em estudos futuros são a elaboração de um indicador de estabilidade da paisagem, a definição de uma distância ideal em torno de rios (buffer) para estudo da influência do uso da terra e avaliação de outras métricas da paisagem relacionadas à forma dos elementos da paisagem, que poderia explicar melhor a composição química da água. 


\section{CONCLUSÕES GERAIS}

A dinâmica da paisagem na área de estudo mostra uma sistemática conversão de floresta para pastagem, onde a floresta secundária ocupa um estágio (temporal e espacial) intermediário. O processo de fragmentação é influenciado pela localização espacial em relação a estradas e pastagens antigas, e controlado pelo tamanho da propriedade. Em 2002, com menos de $25 \%$ de áreas com floresta, a bacia estava no estágio final e crítico de desmatamento. As taxas atuais de dinâmica do uso da terra não são sustentáveis e, seguindo o ritmo atual, nos próximos 15 anos toda a área possivelmente será desmatada.

O atual estágio de fragmentação é considerado crítico, observando-se que existe um limiar crítico para o desmatamento em torno de $34 \%$ de Floresta Madura, no qual a estrutura da paisagem sofre grandes alterações. Nem mesmo a interrupção do desmatamento garantiria a recuperação da estrutura da paisagem e somente ações específicas de conservação, como implantação da APP, poderão fazê-la.

A dinâmica da paisagem nas microbacias segue a tendência observada na área total da bacia, mas algumas microbacias podem ser diferenciadas das demais observando-se o histórico de uso da terra nas mesmas. Para resgatar o histórico de uso da terra na região, os índices propostos Taxa Anual de Desmatamento da Floresta Madura (TADFM), Coeficiente de Variação de Tamanho da Floresta Secundária (CVTFS) e Tempo Médio de Introdução da Pastagem (TMIP) mostram-se bons indicadores, pois além de representar a variabilidade da dinâmica, são de fácil cálculo e entendimento. 
A classificação das microbacias com base somente na estrutura da paisagem atual reflete em parte a condição histórica das mesmas, mas não é capaz de descrever toda a dinâmica ocorrida. A incorporação de dados históricos, em conjunto a dados atuais, na classificação das condições ambientais de microbacias, permite melhor distinção das mesmas e melhora a compreensão dos fatores envolvidos na formação dos grupos, facilitando o diagnóstico e a elaboração de um plano de ação para conservação.

As concentrações de cátions e ânions apresentaram melhor relação com as condições físicas das microbacias, enquanto que a presença de sulfato, cloro, oxigênio dissolvido e nitrogênio relacionaram-se bem à estrutura da paisagem em 2002. A dinâmica do uso da terra influenciou mais as concentrações de carbono inorgânico e nitrogênio.

Na região, considerando-se a ação antrópica, a influência da paisagem na composição química da água pode ser caracterizada pelo histórico de uso da terra, a estrutura da paisagem atual e o tipo de manejo utilizado. $O$ aspecto mais importante em relação à influência da dinâmica do uso da terra na composição química da água está relacionado à estabilidade da paisagem, sendo que os indicadores sugeridos neste trabalho poderão ser considerados para diagnóstico ambiental. 


\section{REFERÊNCIAS BIBLIOGRÁFICAS}

ACEVEDO, M.F.; URBAN, D.L.; ABLAN, M. Transitions and GAP models of forest dynamics. Ecological Applications, v.5, n.4, p.1040-1055, 1995.

ALENCAR, A.A.C.; VIEIRA, I.C.G.; NEPSTAD, D.C.; LEFEBVRE, P. Análise multi-temporal do uso do solo e mudança da cobertura vegetal em antiga área agrícola da Amazônia oriental, (Compact disc). In: SIMPÓSIO BRASILEIRO DE SENSORIAMENTO REMOTO, 8., Salvador, 1996. Anais.

ALENCASTRO GRAÇA, P.M.L.; FEARNSIDE, P.M.; CERRI, C.C. Burning of Amazonian forest in Ariquemes, Rondônia, Brazil: biomass, charchoal formation and burning efficiency. Forest Ecology and Management, v.120, p.179-191, 1999.

ALLAN, J.D.; ERICKSON, D.L.; FAY, J. The influence of catchment land use on stream integrity across multiple spatial scales. Freshwater Biology, v.27, p.149-161, 1997.

ALMEIDA FILHO, R.; NASCIMENTO, P.S.R.; BATISTA, G.T. Avaliação de técnicas de segmentação e classificação automática de imagens LandsatTM no mapeamento de uso do solo na Amazônia. Acta Amazônica, v.28, n. 1, p.41-54, 1998. 
ALMEIDA, S.A.S.; SILVA, O.F.; MELO, E.M.K.; MOREIRA, J.C.; ORTIZ, J.O.; AMARAL, S.; SOARES, J.V.; ALVES, D. Mapeamento de Cobertura da Terra utilizando técnicas de processamento de imagens na região de Ariquemes-RO, com ênfase às florestas secundárias, (Compact disc). In: SIMPÓSIO BRASILEIRO DE SENSORIAMENTO REMOTO, 8., Salvador, 1996. Anais.

ALVES, D.S. Space-time dynamics of deforestation in Brazilian Amazônia. International Journal of Remote Sensing, v.23, n.14, p.2903-2908, 2002.

ALVES, D.S. Projeto dinâmica do uso da terra na Amazônia.

http://www.dpi.inpe.br/dalves/amazonia.html. (03 mar. 2003).

ALVES, D.S.; ESCADA, M.I.S.; PEREIRA, J.L.G.; ALBUQUERQUE LINHARES, C. Land use intensification and abandonment in Rondônia, Brazilian Amazônia. International Journal of Remote Sensing, v.24, n.4, p.899-903, 2003b.

ALVES, D.S.; PEREIRA, J.G.; SOUZA, C.L.; SOARES, J.V.; YAMAGUCHI, F. Classification of the deforested area in central Rondônia using TM imagery, (Compact disc). In: SIMPÓSIO BRASILEIRO DE SENSORIAMENTO REMOTO, 9., Santos, 1998a. Anais.

ALVES, D.S.; PEREIRA, J.L.G.; SOUZA, C. L.; SOARES, J. V.; YAMAGUCHI, F. Characterizing landscape changes in central Rondônia using Landsat TM imagery. International Journal of Remote Sensing, v.20, n.14, p.28772882, 1999.

ALVES, D.S.; PEREIRA, J.G.; SOUZA, C.L.; SOARES, J.V.; MOREIRA, J.C.; ORTIZ, J.O.; YAMAGUCHI, F.; SHIMABUKURO, Y.O. Análise comparativa de técnicas de classificação de imagens Landsat/TM para caracterização de áreas desflorestadas, (Compact disc). In: SIMPÓSIO BRASILEIRO DE SENSORIAMENTO REMOTO, 9., Santos, 1998b. Anais. 
ALVES, F.S.M.; FISCH, G.; VENDRAME, I.F. Modificações do microclima e regime hidrológico devido ao desmatamento na Amazônia: estudo de um caso em Rondônia (RO), Brasil. Acta Amazônica, v.29, n.3, p.395-409, 1999.

ANDRADE, N.S.O.; ARAÚJO, L.S.; NUMATA, I. Estudo da dinâmica da cobertura vegetal e uso da terra na região de Ji-Paraná/RO, (Compact disc). In: SIMPÓSIO BRASILEIRO DE SENSORIAMENTO REMOTO, 9., Santos, 1998. Anais.

BALLESTER, M.V.R.; VICTORIA, D. DE C.; KRUSHE, A.V.; COBURN, R.; VICTORIA, R.L.; RICHEY, J.E.; LOGSDON, M.G.; MAYORGA, E.; MATRICARDI, E. A Remote Sensing / GIS-based physical template to understand the biogeochemistry of the Ji-Paraná River Basin (Western Amazônia). Remote Sensing of Environment, v.87, p.429-445, 2003.

BASKENT, E. Z.; JORDAN, G. A. Characterizing spatial structure of forest landscapes. Canadian Journal of Forestry Research, v.25, p.1830-1849, 1995.

BASNYAT, P.; TEETER, L.; LOCKABY, B.G.; FLYNN, K.M. Relationship between landscape characteristics and nonpoint source pollution inputs to coastal estuaries. Environmental Management, v.23, n.4, p.539-549, 1999.

BATISTELLA, M.; SOARES FILHO, B.S. Ensaio comparativo de índices de fragmentação da paisagem em dois modelos de assentamento rural em Rondônia, (Compact disc). In: GIS-BRASIL., Salvador, 1999. Anais.

BELL, E.J. Markov analysis of land use change - an application of stochastic processes to remotely sensed data. Journal of Socioeconomic Planning Sciences, v.8, p. 311-316, 1974.

BIGGS, T.W.; DUNNE, T.; DOMINGUES, T.F. A stream chemistry of deforestation and urbanization in the southwestern Brazilian Amazon. Water Resources Research, v.38, n.8, p.1-16, 2002. 
BORMANN, F.H.; LIKENS, G.E. Pattern and process in a forested ecosystem: disturbance, development, and the steady state based on the Hubbard Brook ecosystem study. New York: Springer-Verlag, 1978. 253p.

BRASIL. Leis, decretos, etc. Lei $n^{\circ} 4771$ de 15 de setembro de 1965. Diário Oficial, 16 set. 1965, Dispões sobre o Código Florestal Brasileiro e dá providências.

BRASIL. Ministério das Minas e Energia. Projeto RadamBrasil: folha SC.20, Porto Velho; levantamento dos recursos naturais. Rio de Janeiro: DNPM, 1978. v.16.

BRASIL. Leis, decretos, etc. Instrução Normativa no 4 de 4 de março de 2002, Diário Oficial, 5 mar. 2002. Dispõe sobre a exploração florestal na Bacia Amazônica e dá providências.

BROWDER, J.O. Reading colonist landscapes: social interpretations of tropical forest patches in an Amazonian frontier. In: SCHELHAS, J.; GREENBERG, R. Forest patches in tropical landscapes. Washington: Island Press, 1996. p.285-299.

CÂMARA, C.D.; LIMA, W.P. Corte raso de uma plantação de Eucalyptus saligna de 50 anos: impactos sobre o balanço hídrico e a qualidade da água em uma microbacia experimental. Scientia Forestalis, v. 56, p. 41-58, 1999.

CARDILLE, J.A.; FOLEY, J.A. Agricultural land-use change in Brazilian Amazônia between 1980 and 1995: Evidence from integrated satellite and census data. Remote Sensing of Environment, v.87, p.551-562, 2003.

CARVALHO, G.; BARROS, A.C.; MOUTINHO, P. NEPSTAD, D. Sensitive development could protect Amazonia instead of destroying it. Nature, v.409, n.11, p.131, 2001.

CHEN, L.; WANG, J.; FU, B.; QIU, Y. Land-use change in a small catchment of northern Loess Plateau, China. Agriculture, Ecosystems and Environment, v.86, p.163-172, 2001. 
CIFALDI, R.; ALLAN, J.D.; DUH, J.D.; BROWN, D.G. Spatial patterns in land cover of exurbaning watersheds in southeastern Michigan. Landscape and Urban Planning, v.66, p.107-203, 2004.

CISTERNAS, M.; ARANEDA, A.; MARTÍNEZ, P.; PÉREZ, S. Effects of historical land use on sediment yield from lacustrine watershed in central Chile. Earth Surface Processes and Landforms, v.26, p.63-76, 2001.

COCHRANE, T.T.; COCHRANE, T.A. SIGTERON: Sistema de Informação Geográfica para os terrenos e solos do Estado de Rondônia, Brasil. Porto Velho: Tecnosolo, DHV Consultoria, 1998.

COLLINGE, S.K. Ecological consequences of habitat fragmentation: implications for landscape architecture and planning. Landscape and Urban Planning, v.36, p. 59-77, 1996.

CONSTANZA, R.; SKLAR, F.H.; WHITE, M.L. Modelling coastal landscape dynamics. BioScience, v.40, n.2, p.91-107, 1990.

COOPER, S.D.; DIEHL, S.; KRATZ, K.; SARNELLE, O. Implications of scale for patterns and processes in stream ecology. Australian Journal of Ecology, v.23, p.27-40, 1998.

COPPEDGE, B.R.; ENGLE, D.M.; FUHLENDORF, S.D.; MASTERS, R.E.; GREGORY, M.S. Landscape cover type and pattern dynamics in fragmented southern Great Plains grasslands, USA. Landscape Ecology, v.16, p.677690, 2001.

CREWS-MEYER, K.A., Characterizing landscape dynamism via paneled-pattern metrics. Photogrammetric Engineering \& Remote Sensing, v.68, p.10311040, 2002.

CUSHMAN, S. A.; WALLIN, D. O. Rates and patterns of landscape change in the Central Sikhote-alin Mountains, Russian Far East. Landscape Ecology, v. 15, p.643-659, 2000. 
DALE, V.H.; O'NEILL, R.V.; SOUTHWORTH, F.; PEDLOWSKI, M. Modeling effects of land managment in the Brazilian Amazonian settlement of Rondônia. Conservation Biology, v.8, n.1, p.196-206, 1994.

DALE, V.H.; O'NEILL, R.V.; PEDLOWSKI, M. SOUTHWORTH, F. Causes and Effects of Land-Use Change in Central Rondônia, Brazil. Photogrammetric Engineering \& Remote Sensing, v.59, n.6, p.997-1005, 1996.

DAVIDSON, E.A.; MATSON, P.A.; VITOUSEK, P.M.; RILEY, R. Processes regulating soil emissions of $\mathrm{NO}$ and $\mathrm{N} 20$ in a seasonally dry tropical forest. Ecology, v.74, p.130-139, 1993.

DI LUZIO, M.; SRINIVASAN, R.; ARNOLD, J.G.; NEITSCH, S.L. Soil and Water Assessment Tool (SWATT): version 2000. Texas: Texas Water Resources Institute, 2002. 346p. (GSWRL Report 02-03, BRC Report 02-07).

DIAS-FILHO, M.B.; DAVIDSON, E.A.; CARVALHO, C.J.R. Linking biogeochemical cycles to cattle pasture management and sustainability in the Amazon Basin. In. MCCLAIN, M.E.; VICTORIA, R.L.; RICHEY, J. (Ed). The biogeochemistry of the Amazon basin. New York: Oxford University Press, 2001. cap 6. p. 84-105.

DIEGUES, A.C. Desmatamento e modos de vida na Amazônia. São Paulo: NUPAUB, 1999. 146p.

DUBOIS, J.C.L. Secondary forests as a land-use resource in frontier zones of Amazonia. In: ANDERSON, A.B. Alternatives to deforestation: steps toward sustainable use of the Amazon Rain Forest. New York: Columbia University Press, 1990. cap.8, p.183-194.

DUNN, C.P.; SHARPE, D.M.; GUNTENSPERGEN, G.R.; STEARNS, F.; YANG, Z. Methods for analyzing temporal changes in landscape pattern. In: TURNER, M.G.; GARDNER, R.H. Quantitative methods in landscape ecology, New York: Springer-Verlag, 1991. p.173-198. 
ELSENBEER, H. Hydrologic flowpaths in tropical rainforest soilscapes - a review. Hydrological Processes, v.15, p.1751-1759, 2001.

EMPRESA BRASILEIRA DE PESQUISA AGROPECUÁRIA. Mapa de levantamento de reconhecimento de meia intensidade dos solos do Estado de Rondônia, Porto Velho: Comissão Estadual de Planejamento Agrícola, 1983. Escala: 1:500.000.

EMPRESA BRASILEIRA DE PESQUISA AGROPECUÁRIA. Sistema brasileiro de classificação de solos. Rio de Janeiro: Embrapa Solos, 1999. 421p.

ERDAS. Erdas field guide. Atlanta: Ed. Erdas, 1999. 671p.

ESCADA, M.I.S.; ALVES, D.S. Dinâmica da cobertura florestal como indicador para caracterização de padrões de ocupação em Rondônia. In: SIMPÓSIO BRASILEIRO DE SENSORIAMENTO REMOTO, 11., Belo Horizonte, 2003, http://iris.sid.inpe.br:1908/col/lid.inpe.br/sbsr/2002/11.17.23.19/doc/06_350.p df. (11 dez. 2003).

ESRI. ArcGIS version 8.3, Redlands: ESRI Press, 2002. 348p.

FARIG, L. Effects of habitat fragmentation on biodiversity. Annual Review of Ecology, Evolution, and Systematics, v.34, p.487-515, 2003

FEARNSIDE, P.M. Amazonian deforestation and global warming: carbon stocks in vegetation replacing Brazil's Amazon forest. Forest Ecology and Management, v.80, p.21-34, 1996.

FERRAZ, S.F.B; VETTORAZZI, C.A.; BALLESTER, M.R.V. Landscape dynamics assessment of Amazon forest deforestation in central Rondônia Brazil. In: ANNUAL SYMPOSIUM IALE-US, 17., Lincoln, 2002. Abstracts. p.65.

FIORIO, P.R.; DEMATTÊ, J.A.; SPAROVEK, G. Cronologia e impacto ambiental do uso da terra na microbacia hidrográfica do Ceveiro, em Piracicaba, SP. Pesquisa Agropecuária Brasileira, v.35, n.4, p.671-679, 2000. 
FORMAN, R.T.T ; GODRON, M. Landscape ecology. New York: John Wiley, 1986. 619p.

FUJISAKA, S., BELL, W., THOMAS, N., HURTADO, L.; CRAWFORD, E.. Slash-and-burn agriculture, conversion to pasture, and deforestation in two Brazilian Amazon colonies. Agriculture Ecosystems \& Environment, v.59, p.115-130, 1996.

FULLER, D.O. Forest fragmentation in Loudoun County, Virginia, USA evaluated with multitemporal Landsat imagery. Landscape Ecology, v.16, p.627-642, 2001.

GABRIEL, K. R. The Biplot graphic display of matrices with applications to principal component analysis. Biometrika, v.58, n.3, p.453-467, 1971.

GALO, M.L.B.T; NOVO, E.M.L.M. Índices de paisagem aplicados à análise do Parque Estadual Morro do Diabo e entorno, (Compact disc). In: SIMPÓSIO BRASILEIRO DE SENSORIAMENTO REMOTO, 9., Santos, 1998. Anais.

GARDNER, R.H.; MILNE, B.T.; TURNER, M.G.; O'NEILL, R.V., Neutral models for the analysis of broad-scale landscape pattern. Landscape Ecology, v.1, p.19-28, 1987.

GERGEL, S.E.; TURNER, M.G.; MILLER, J.R.; MELACK, J.M.; STANLEY, E.H. Landscape indicators of human impacts to riverine systems. Aquatic Sciences, v. 64, p.118-128, 2002.

GODRON, M.; FORMAN, R.T.T. Landscape modification and changing ecological characteristics. In: MOONEY, H.A.; GODRON, M. (Ed.). Disturbance and ecosystems: components of response, New York: Springer-Verlag, 1983. p.12-28.

GREEN, D.G. Connectivity and complexity in ecological systems. Pacific Conservation Biology, v.1, n.3, p.194-200, 1994. 
GRIFFITH, J.A. Geographic techniques and recent applications of remote sensing to landscape-water quality studies. Water, Air, and Soil Pollution, v.138, p.181-197, 2002.

HARGIS, C.D.; BISSONETTE, J.A.; DAVID, J.L. The behavior of landscape metrics commonly used in the study of habitat fragmentation. Landscape Ecology, v.13, p.167-186, 1998.

HARRIS, L.D. The fragmented forest. Chicago: The University of Chicago Press, 1984. 211p.

HERZOG, F.; LAUSCH, A. MULLER, E.; THULKE, H.H.; LEHMANN, S. Landscape metrics for assessment of landscape destruction and rehabilitation. Environmental Management, n. 1, p.91-107, 2001.

HIETEL, E.; WALDHARDT, R.; OTTE, A. Analysing land-cover changes in relation to enviromental variables in Hesse, Germany. Landscape Ecology, v.19, p.473-489, 2004.

HOLMES, K.W.; ROBERTS, D.A.; SWEENEY, S.; NUMATA, I.; MATRICARDI, E.; BIGGS, T.W.; BATISTA, G.; CHADWICK, O.A. Soil databases and the problem of establishing regional biogeochemical trends. Global Change Biology, v.10, p.796-814, 2004.

HUNSAKER, C.; LEVIGNE, D. Hierarchical approaches to the study of water quality in rivers. Bioscience, v.45, n.3, p.193-203, 1995.

ICHII, K.; MARUYAMA, M; YAMAGUCHI, Y. Multi-temporal analysis of deforestation in Rondônia state in Brazil using Landsat MSS, TM, ETM+ and NOAA AVHRR imagery and its relationship to changes in the local hydrological environment. International Journal of Remote Sensing, v. 24, n.22, p.4467-4479, 2003.

INSTITUTO BRASILEIRO DE GEOGRAFIA E ESTATístICA. Mapa do Estado de Rondônia, Rio de Janeiro, 1982. Escala 1:100,000. 
INSTITUTO BRASILEIRO DE GEOGRAFIA E ESTATÍSTICA. Censo agropecuário 1995/96. Rio de Janeiro: IBGE, 1998.

INSTITUTO BRASILEIRO DE GEOGRAFIA E ESTAtístiCA. Censo demográfico da População. Rio de Janeiro: IBGE, 2003.

INSTITUTO NACIONAL DE PESQUISAS ESPACIAIS, O monitoramento da Amazônia brasileira por satélite - projeto PRODES. INPE. http://www.obt.inpe.br/prodes. (18 maio 2004).

JONES J.A.; SWANSON, F.J.; WEMPLE, B.C.; SNYDER, K.U.; Effects of roads on hydrology, geomorphology, and disturbance patches in stream networks. Conservation Biology, v.14, n.1, p.76-84, 2000.

JONES, K.B.; NEALE, A.C.; NASH, M.S.; VAN REMORTEL, R.D.; WICKMAN, J.D.; RIITTERS, K.H.; O'NEILL, R.V. Predicting nutrient and sediment loadings to stream from landscape metrics: a multiple watershed study from the United States Mid-Atlantic Region. Landscape Ecology, v.16, p.301312, 2001.

JONES, K.B; HEGGEM, D.T.; WADE, T.G.; NEALE, A.C.; EBERT, D.W.; NASH, M.S.; MEHAFFEY, M.H.; HERMANN, K.A.; SELLE,A.R.; AUGUSTINE,S.; GOODMAN, I.A.; PEDERSEN, J.; BOLGRIEN, D.; VIGER,J.M.; CHIANG, D.; LIN,C.J.; ZHONG,Y.; BAKER,J.; VAN REMORTEL, R.D. Assessing landscape condition relative to water resources in the western United States: a strategic approach. Environmental Monitoring and Assessment, v.64, p.227-245, 2000.

JONHSON, G.D.; MYERS, W.L.; PATIL, G.P. Predictability of surface water pollution loading in Pennsylvania using watershed-based landscape measurements. Journal of the American Water Resources Association, v.37, n.4, p.821-835, 2001. 
JORGE, L.A.B.; GARCIA, G.J. A study of habitat fragmentation in southeastern Brazil using remote sensing and geographic information systems (GIS). Forest Ecology and Management, v. 98. p.35-47, 1997.

KAMMERBAUER, J.; ARDON, C. Land use dynamics and landscape change pattern in a typical watershed in the hillside region of central Honduras. Agriculture, Ecosystems and Environment, v.75, p.93-100, 1999.

KAUFFMAN, J.B.; CUMMINGS, D.L.; WARD, D.E.; BABITT, R. Fire in the Brazilian Amazon: biomass, nutrient pools, and losses in slashed primary forests. Oecologia, v.104, p.397-408, 1995.

KINNAIRD, M.F.; SANDERSON, E.W.; O'BRIEN, T.G.; WIBISONO, H.T.; WOOLMER, G. Deforestation trends in a tropical landscape and implications for endangered large mammals. Conservation Biology, v.17, n.1, p.245$257,2003$.

KRUSHE, A.V.; BALLESTER, M.V.R.; VICTORIA, R.L.; BERNARDES, M.C.; LEITE, N.K.; HANADA, L.; MARCONDES, R.; VICTORIA, D.C.; TOLEDO, A.M.; OMETTO, J.P.; MOREIRA, M.Z.; GOMES, B.M.; BOLSON, M.A.; GOUVEIA NETO, S.; BONELLI, N.; LINDA, D.; NEILL, C.; SUZANNE, T.; AUFDENKAMPE, A.; RICHEY, J.E. As mudanças no uso da terra e a biogeoquímica dos corpos d'água na Amazônia. Acta Amazonica, 2004. INo prelol.

LACHOWSKI, H. M.; WIRTH, T.; MAUS, P.; AVERS, P. Remote Sensing and GIS: their role in ecosystem management. Journal of Forestry, v.92, n.8, p.39-40, 1994.

LAURANCE, W.F.; COCHRANE, M. A.; BERGEN, S.; FEARNSIDE, P.M.; DELAMÔNICA, P.; BARBER, C.; D'ANGELO, S.; FERNANDES, T. The Future of the Brazilian Amazon. Science, v.19, n.291, p.438-439, 2001. 
LAURANCE, W.F.; LOVEJOY, T.E.; VASCONCELOS, H.L.; BRUNA, E.M.; DIDHAM, R.K; STOUFFER, P.C.; GASCON, C.; BIERREGAARD, R.O.; LAURANCE, S. G.; SAMPAIO, E. Ecosystem decay of Amazonian forest fragments: a 22-year investigation. Conservation Biology, v.16, n.3, p.605618, 2002.

LAUSCH, A.; HERZOG, F. Applicability of landscape metrics for the monitoring of landscape change: issues of scale, resolution and interpretability. Ecological Indicators, v.2, p.3-15, 2002.

LIKENS, G.H.; BORMANN, H. Linkages between Terrestrial and Aquatic Ecosystems. Bioscience, v.24, n.8, p.447-455, 1974.

LONGO, R.M.; ESPINDOLA, C.R. Alterações em características químicas de solos da região Amazônica pela introdução de pastagens. Acta Amazônica, v.30, n.1, p.71-80, 2000.

LUCAS, M.; MEDLEY, K.E. Landscape structure and nutrient budgets in an agricultural watershed, Southwest Ohio. Ohio Journal of Science, v.102, n.2, p. 15-23, 2002.

LUCAS, O.W.R. The design of forest landscapes. New York: Oxford University Press, 1991. 391p.

LUCIER, A.A. Criteria for success in managing: forest landscapes. Journal of Forestry, v.92, n.7, p.20-24,1994.

MACDONALD, L.H. Evaluating and managing cumulative effects: process and constraints. Environmental Managment, v.26, n.3, p.299-315, 2000.

MAGRO, T. C. Manejo de paisagens em áreas florestadas, Silvicultura, v.69, p.38-45, 1997.

MCGARIGAL, K.; MARKS, B.J. Fragstats: spatial analysis program for quantifying landscape structure. Portland: USDA, Forest Service, Pacific Northwest Research Station.1995. 122p. (Gen. Tech. Rep. PNW-GTR-351). 
MCGARIGAL, K., CUSHMAN, S. A., NEEL, M. C.; ENE, E., FRAGSTATS: Spatial Pattern Analysis Program for Categorical Maps, Amherst: University of Massachusetts, http:Ilwww.umass.edu/landeco/research/fragstats/fragstat. (25 maio 2002).

MCGRATH, D.A.; SMITH, C.K. GHOLZ, H.L.; OLIVEIRA, F.A. Effects of landuse change on soil nutrient dynamics in Amazônia. Ecosystems, v.4, p.625645, 2001.

METZGER, J. P. Relationships between landscape structure and tree species diversity in tropical forests of South-East Brazil. Landscape and Urban Planning, v.37, p.29-35, 1997.

METZGER, J.P. Effects of deforestation pattern and private nature reserves on the forest conservation in setllement areas of the Brazilian Amazon. Biota Neotropica, v.6, n.1/2,

http://www.biotaneotropica.org.br/v1n12/pt/fullpaper?bn00101122001+en. (12 dez. 2001).

METZGER, J.P. Landscape dynamics and equilibrium in areas of slash-andburn agriculture with short and long fallow period (Bragantina region, NE Brazilian Amazon). Landscape Ecology, v.17, p.419-431, 2002.

METZGER, J.P. Effects of slash-and-burn fallow periods on landscape structure. Environmental Conservation, v.30, n.4, p.325-333, 2003.

MINITAB., MINITAB Statistical Software: release 14 for windows. State College, 2003.

MOLNAR, P.; BURLANDO, P.; RUF, W. Integrated catchment assessment of riverine landscape dynamics. Aquatic Science, v.64, p.121-140, 2002.

MORAES, J.F.L.; SEYLER, F.; CERRI, C.C; VOLKOFF, B. Land cover mapping and carbon pools estimates in Rondônia, Brazil, (Compact disc). In: SIMPÓSIO BRASILEIRO DE SENSORIAMENTO REMOTO, 8., Salvador, 1996a. Anais. 
MORAES, J.F.L.; VOLKOFF, B.; CERRI, C.C.; BERNOUX, M. Soil properties under Amazon forest and changes due to pasture installation in Rondônia, Brazil. Geoderma, v.70, p. 63-81, 1996 b.

MULLER, M.R.; MIDDLETON, J. A. Markov model of land-use change dynamics in the Niagara Region, Ontario, Canada. Landscape Ecology, v. 9, n.2, p.151-157, 1994.

NAVEH, Z.; LIEBERMAN, A.S. Landscape ecology, theory and application, New York: Springer Verlag, 1993. 360p.

NEILL, C.; PICOLO, M.C.; MELILO, J.M.; STEUDLER, P.A.; CERRI, C.C. Nitrogen dynamics in Amazon forest and pasture soils measured by ${ }^{15} \mathrm{~N}$ pool dilution. Soil Biology and Biochemistry, v.31, p.567-572, 1999.

OCHOA-GAONA, S. Traditional land-use systems and patterns of forest fragmentation in the highlands of Chiapas, Mexico. Environmental Management v.27, n.4, p.571-586, 2001.

O'NEILL, R.V.; HUNSAKER, C.T. Monitoring environmental quality at landscape scale. Bioscience, v.47, n.8, p.513-520, 1997.

OLIVER, C.D. A landscape approach: achieving and maintaining biodiversity and economic productivity. Journal of Forestry, v.90, n.9, p.20-25, 1992.

OMETO, J.P.H.B; MARTINELLI, L.A.; BALLESTER, M.V.; GESSNER, A.; KRUSCHE, A.V.; VICTORIA, R.L. WILLIAMS, M. Effects of land use on water chemistry and macroinvertebrates in two streams of the Piracicaba river basin, south-east Brazil. Freshwater Biology, v.44, p.327-337, 2000.

PEDLOWSKI, M.A.; DALE, V.H.; MATRICARDI, E.A.T.; SILVA-FILHO, E.P. Patterns of deforestation in Rondônia, Brazil. Landscape and Urban Planning, v.38, p. 149-157, 1997. 
PERZ, S.G. Population growth and net migration in the Brazilian legal Amazon, 1970-1996. In: WOOD, C.H.; PORRO, R. Deforestation and Land use in the Amazon, Gainesville: University Press of Florida, 2002.p.107-129.

RANDHIR, T.O.; O'CONNOR, R.; PENNER, P.R.; GOODWIN, D.W. A watershed-based land priorization model for water supply protection. Forest Ecology and Management, v.143, p.47-56, 2001.

RAO, K.S.; PANT, R. Land use dynamics and landscape change pattern in a typical micro watershed in the mid elevation zone if central Himalaya, India. Agriculture, Ecosystems and Environment, v.86, p.113-123, 2001.

REED, R. A. JOHNSON-BARNARD, J. BAKER, W.L. Fragmentation of a forested Rocky Mountain landscape, 1950-1993. Biological Conservation, v.75, p. 267-277, 1996.

RICHARDS, C.; JOHNSON, L.B.; HOST, G.E. Landscape-scale influences on stream habitats and biota. Canadian Journal of Fishery and Aquatic Science, v.53, n.1, p.295-311, 1996.

RICHEY, J.E.; WILHELM, S.R.; MCCLAIN, M.E.; VICTORIA, R.L.; MELACK, J.M.; ARAUJO-LIMA, C. Organic matter and nutrient dynamics in river corridors of the Amazon basin and their response to anthropogenic change. Ciência e Cultura, v.49, n.1/2, p.98-110, 1997.

RITTERS, K. H.; O'NEILL, R. V.; HUNSAKER, C. T.; WICKHAM, J. D. ; YANKEE, D. H.; TIMMINS, S.P.; JONES, K.B.; JACKSON, B.L. A factor analysis of landscape pattern and structure metrics. Landscape Ecology, v.10, p.23-39, 1995.

ROBERTS, D.A.; NUMATA, I.; HOLMES, K.; BATISTA, G.; KRUG, T.; MONTEIRO, A.; POWELL, B.; CHADWICK, O.A. Large area mapping of land-cover change in Rondônia using multitemporal spectral mixture analysis and decision tree classifiers. Journal of Geophysical Research, v.107, n.D20, p.1-17, 2002. 
SACHS, D.L.; SOLLINS, P.; COHEN, W.B. Detecting landscape changes in the interior of British Columbia from 1975 to 1992 using satellite imagery. Canadian Journal of Forest Research, v.28, n.1, p.23-36,1998.

SERRÃO, E.A.S.; TOLEDO, J.M. The search for sustainability in Amazonian Pastures. In: ANDERSON, A.B. Alternatives to deforestation: steps toward sustainable use of the Amazon rain forest. New York: Columbia University Press, 1990. p.195-214.

SERRÃO, E.A.S.; NEPSTAD, D.; WALKER, R. Upland agricultural and forestry development in the Amazon: sustainability, criticality and resilience. Ecological Economics, v.18, p.3-13, 1996.

SHIMABUKURO, Y. O; DUARTE, V.; MELLO, E.M.K.; MOREIRA, J.C. Levantamento de áreas desflorestadas na Amazônia através de processamento digital de imagens orbitais. Floresta e Ambiente, v.6, n.1, p.38-44, 1999.

SKANES, H.M.; BUNCE, R.G.H. Directons of landscape change (1741-1993) in Virestad, Sweden - characterised by multivariate analysis. Landscape and Urban Planning, v.38, p.61-75, 1997.

SKOLE, D.S.; CHOMENTOWSKI, W.; SALAS, W.A.; NOBRE, A.D. Physical and human dimensions of deforestation in Amazonia. Bioscience, v.44, p.314322, 1994.

SKOLE, D.; TUCKER, C. Tropical deforestation and habitat fragmentation in the Amazon: satellite data from 1978 to 1988 . Science, v.260, n.25, p. 19051910, 1993.

SNYDER, C.D.; YOUNG, J.A.; VILLELLA, R.; LEMARIÉ, D.P. Influences of upland and riparian land use patterns on stream biotic integrity. Landscape Ecology, v.18, p.647-664, 2003. 
SOARES-FILHO, B.S.; CERQUEIRA, G.C.; PENNACHIN, C.L. Dinamica - a stochastic cellular automata model designed to simulate the landscape dynamics in an Amazonian colonization frontier. Ecological Modelling, v.154, p.217-235, 2002.

STAUFFER, D. Introduction to percolation theory. London: Taylor \& Francis, 1985. 350p.

STONE T. A.; BROWN, I. F. WOODWELL, G. M. Estimation, by remote sensing, of deforestation in central Rondônia, Brazil. Forest Ecology and Management, v.38. p.291-304, 1991.

THEOBALD, D. M.; HOBBS, N.T.; BEARLY, T.; ZACK, J.A.; SHENK, T.; RIEBSAME, W.E. Incorporating biological information in local land-use decision making: designing a system for conservation planning. Landscape Ecology, v.15, p.35-45, 2000.

THOMAS, S.M.; NEILL, C.; DEEGAN, L.A.; KRUSCHE, A.V.; BALLESTER, M.V.; VICTORIA, R.L. Influences of land use and stream size on particulate and dissolved materials in a small Amazonian stream network. Biogeochemistry, v.68, p.135-151, 2004.

THOMPSON, J.; BROKAW, N.; ZIMMERMAN, J.K.; WAIDE, R.B.; EVERHAM, E.M.; LODGE, D.J.; TAYLOR, C.M.; A-MONTIEL, D.G.; FLUET, M. Land use history, environment, and tree composition in a tropical forest. Ecological Applications, v.12, n.5, p. 1344-1363, 2002.

TINER, R.W. Remotely-sensed indicators for monitoring the general condition of "natural habitat" in watersheds: an application for Delaware's Nanticoke River watershed. Ecological Indicators, 2004. I No prelo I.

TINKER, D. B.; RESOR, C. A. C.; BEAUVAIS, G. P.; KIPFMUELLER, K. F.; FERNANDES, C. I.; BAKER, W. L. Watershed analysis of forest fragmentation by clearcuts and roads in a Wyoming forest. Landscape Ecology, v.13, p.149-165, 1998. 
TRANI, M.K.; GILES JUNIOR., R.H. An analysis of deforestation: metrics used to describe pattern change. Forest Ecology and Management, v.114, p.459-470, 1999.

TURNER, M. G. Landscape ecology: the effect of pattern on process. Annual Review of Ecology, Evolution, and Systematics, v.20, p.171-197, 1989.

TURNER, M. G.; WEAR, D. N. ; FLAMM, R. O. Land ownership and land-cover change in the southern appalachian highlands and the Olympic Peninsula. Ecological Applications, v.6, n.4, p.1150-1172, 1996.

UHL, C.; KAUFFMAN, J.B. Deforestation, fire susceptibility, and potential tree responses to fire in the eastern Amazon. Ecology, v.7, n.2. p.437-449, 1990.

VAN OOST, K.; GOVERS, G.; DESMET, P. Evaluating the effects of changes in landscape structure on soil erosion by water and tillage. Landscape Ecology, v.15, p.577-589, 2000.

VIANA, V.M; OLIVEIRA, R. E. Manejo de paisagem e a sustentabilidade de plantações florestais. In: WORKSHOP SOBRE MANEJO DE PAISAGENS EM ÁREAS FLORESTADAS, Piracicaba, 1997. Piracicaba: IPEF, 1997. $145 p$.

VIEIRA, I.C.G.; ALMEIDA, A.S.; DAVIDSON, E.A.; STONE, T.A.; CARVALHO, C.J.R.; GUERRERO, J.B. Classifying successional forests using Landsat spectral properties and ecological characteristics in eastern Amazônia. Remote Sensing of Environment, v.87, p.470-481, 2003.

WALKER, R.; HOMMA, A.K.O. Land use and land cover dynamics in the Brazilian Amazon: an overview. Ecological Economics, v.18, p.67-80, 1996.

WALKER, R.; MORAN, E. ANSELIN, L. Deforestation and cattle ranching in the

Brazilian Amazon: external capital and household processes. World Development, v.28, n.4, p.683-699, 2000. 
WANG, X.; YIN, Z.Y. Using GIS to assess the relationship between land use and water quality at watershed level. Environmental International, v.23, n.1, p.103-114, 1997.

WAYLAND, K.G.; HYNDMAN, D.W.; BOUTT, D.; PIJANOWSKI, B.C. LONG, D.T. Modelling the impact of historical land uses on surface-water quality using groundwater flow and solute-transport models. Lakes \& Reservoirs: Research and Managment, v.7, p.189-199, 2002.

WEAR, D.N.; TURNER, M.G.; NAIMAN, R.J. Land cover along an urban-rural gradient: implications for water quality. Ecological Applications, v.8, n.3, p.619-630, 1998.

WHILES, M.R.; BROCK, B.L.; FRANZEN, A.C.; DINSMORE, S.C. Stream invertebrate communities, water quality, and land-use patterns in an agricultural drainage basin of northeastern Nebraska, USA. Environmental Management, v.26, n.5, p.563-576, 2000.

WIENS, J.A. Population response to patch environments. Annual Review of Ecology, Evolution, and Systematics, v.7, p.81-129, 1976.

WIENS, J.A. Ecological heterogeneity: an ontogeny of concepts and approaches. In: HUTCHINGS, M.J.; JOHN, E.A.; STEWART, A.J.A. (Ed.). The ecological consequences of environmental heterogeneity. Oxford: Blackwell Science, 2000. p.9-31.

WIENS, J.A. Riverine landscapes: taking landscape ecology into the water. Freshwater Biology, v.47, p.501-515, 2002.

WOODS, C.H. Land use and deforestation in the Amazon. In: WOODS, C.H.; PORRO, R. Deforestation and land use in the Amazon, Gainsville: University Press of Florida, 2002. p.1-38.

ZHENG, D.; WALLIN, D. O.; HAO, Z. Rates and patterns of landscape change between 1972 and 1988 in the Changbai Mountain area of China and North Korea. Landscape Ecology. v.12, p. 241-254, 1997. 